Florida International University FIU Digital Commons

\title{
Contested Natures, Insecurities and Territorialities: The Aerial Eradication of Coca in Colombia
}

Alexander Huezo

adhuezo@gmail.com

DOI: $10.25148 /$ etd.FIDC001941

Follow this and additional works at: https://digitalcommons.fiu.edu/etd

Part of the Geographic Information Sciences Commons, Human Geography Commons, International Relations Commons, Latin American Studies Commons, and the Social and Cultural Anthropology Commons

\section{Recommended Citation}

Huezo, Alexander, "Contested Natures, Insecurities and Territorialities: The Aerial Eradication of Coca in Colombia" (2017). FIU Electronic Theses and Dissertations. 3397.

https://digitalcommons.fiu.edu/etd/3397 


\section{FLORIDA INTERNATIONAL UNIVERSITY}

Miami, Florida

CONTESTED NATURES, INSECURITIES AND TERRITORIALITIES:

THE AERIAL ERADICATION OF COCA IN COLOMBIA

A dissertation submitted in partial fulfillment of the

requirements for the degree of

DOCTOR OF PHILOSOPHY

in

GLOBAL AND SOCIOCULTURAL STUDIES

by

Alexander David Huezo

2017 
To: Dean John F. Stack, Jr.

Steven J. Green School of International and Public Affairs

This dissertation, written by Alexander David Huezo, and entitled Contested Natures, Insecurities and Territorialities: The Aerial Eradication of Coca in Colombia, having been approved in respect to style and intellectual content, is referred to you for judgment.

We have read this dissertation and recommend that it be approved.

Roderick Neumann

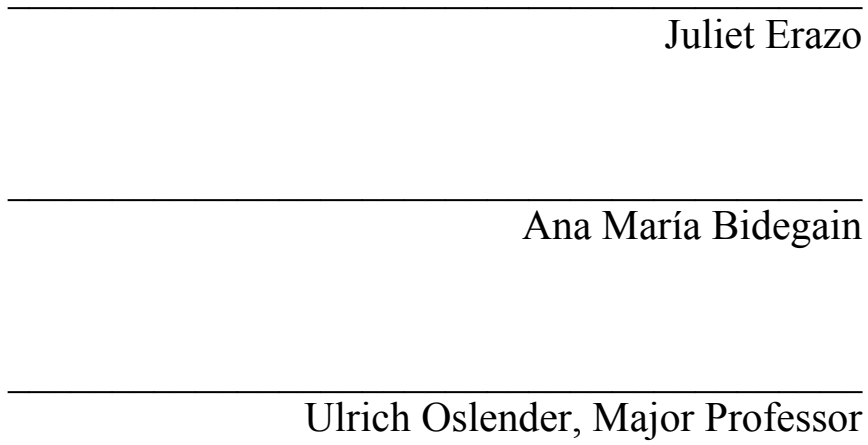

Date of Defense: June 22, 2017

The dissertation of Alexander David Huezo is approved.

Dean John F. Stack, Jr. Steven J. Green School of International and Public Affairs

Andrés G. Gil Vice President for Research and Economic Development and Dean of the University Graduate School

Florida International University, 2017 


\section{DEDICATION}

I dedicate this dissertation to my grandparents -Antonio, Maria, Francisco, Orbelina - who worked hard so that I could have this opportunity. They will not get to see me graduate but will always be with me in spirit.

I also dedicate this dissertation to my parents and am very thankful for their encouragement and support. 


\section{ACKNOWLEDGMENTS}

I wish to thank the members of my committee for their time and patience. I especially want to thank my adviser, Dr. Oslender, for his meticulous feedback and for sharing his passion for his research, which made this arduous project feel worthwhile. I would also like to thank Dr. Bidegain for making sure that I had a great start to fieldwork in Bogotá.

I would also like to give special thanks to the Process of Black Communities, especially José Santos Caicedo, Gerardo Orobio Bazán and Mario Angulo for their time and willingness to vouch for a gringo latino with an odd accent.

Funding for this project was provided by Florida International University (Broad

Fellowship, Dissertation Evidence Acquisition Fellowship, Dissertation Year Fellowship) and the Social Science Research Council's International Dissertation Year Fellowship. 


\title{
ABSTRACT OF THE DISSERTATION \\ CONTESTED NATURES, INSECURITIES AND TERRITORIALITIES: \\ THE AERIAL ERADICATION OF COCA IN COLOMBIA
}

by

\author{
Alexander David Huezo \\ Florida International University, 2017 \\ Miami, Florida \\ Professor Ulrich Oslender, Major Professor
}

Until very recently, Colombia was the only country in the world that still permitted the eradication of illicit crops - primarily coca and to a lesser extent, opium poppies - through aerial fumigation. It was a controversial practice for a number of reasons, chiefly the damage caused to plants, animals, and people living in or near fumigated areas. A favored tactic in the U.S.-supported War on Drugs, aerial eradication actually contributed to the spread of illicit crops to increasingly remote areas of Colombia, such as the collectively titled lands of both indigenous and black communities. Concerns about the practice of aerial eradication, however, appeared completely disconnected from the positive framing of the policy and guidelines governing its implementation.

Employing mixed methods, both ethnographic and cartographic, this dissertation examines how these contradictory discourses - aerial eradication explained by officials involved in its operation versus described locally by people living in or near fumigated areas - materialized in 2015, the last year the aerial eradication program was in 
operation. This study engages critical social science theory to deconstruct dominant conceptualizations of territoriality, geopolitics and environmental conservation, while at the same time proposing alternative understandings of those concepts grounded in local experiences.

This research finds that aerial eradication authorities overstated the accuracy of aerial eradication operations by: 1) downplaying the incidence of pilots spraying legal crops, 2) invalidating local reports on the effects of aerial eradication, and 3) requiring technical evidence far beyond the means of poor rural Colombian farmers. Furthermore, in the specific context of the collectively titled black communities of the Pacific region, aerial eradication authorities did not respect the right to previous consultation per Indigenous and Tribal Peoples Convention 169.

This dissertation concludes that that aerial eradication — justified by notions of security and environmental conservation that had little to do with black communities of the Pacific region - operated as a means of displacement. This displacement was literal in the sense that aerial eradication made life difficult for people to live in affected communities and figurative because local knowledge was pushed aside in favor of the external interpretations of the effects of this counternarcotics policy. 


\section{TABLE OF CONTENTS}

CHAPTER

PAGE

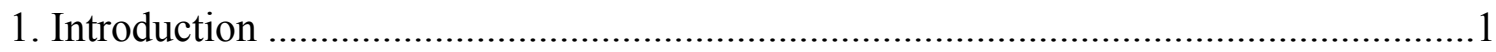

2. Conducting Fieldwork in Two Colombias...........................................................42

3. Conceptualizing Territory, Security, and Environmental Conservation through Difference.

4. Territorialities: Aerial Eradication and the Overlap between Colombian Territoriality and Black Territoriality.....

5. Insecurities: Thinking Critically about the Geopolitics of Security..........................188

6. Contested Natures: Aerial Eradication as Environmental Conservation? .225

7. Conclusion: Recognizing Technologies of Displacement and the Struggle for Black Territory .259

Bibliography .265

Vita. .290 


\section{LIST OF FIGURES}

FIGURE

PAGE

4.1 Painting inside of PCN office in Buenaventura.................................................... 144

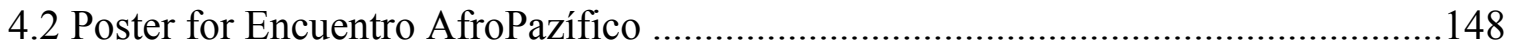

4.3 Two groups working on maps at Encuentro AfroPazífico ...................................151

4.4 Teenage group poster at Encuentro AfroPazífico............................................... 151

4.5 DIRAN PowerPoint slide explaining aerial eradication detection process...............173

4.6 DIRAN PowerPoint slide aerial eradication buffer zones ...................................176

5.1 Hacking a path through vegetation to visit a farm plot in Temuey, Guapi...............205

5.2 Plantain tree with dead leaves two weeks after aerial fumigation............................211

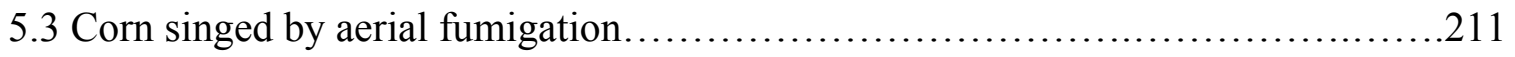

6.1 DIRAN PowerPoint slide explaining why glyphosate is not harmless.....................239

6.2 Containers to collect rainwater in Bajo Calima, Buenaventura................................241

6.3 Children bathing in Río Calima, Buenaventura...............................................241

6.4 Child with irritated skin, allegedly from aerial eradication...................................241

6.5 View from commercial flight approaching the Guapi air strip.............................247 


\section{LIST OF MAPS}

MAP

PAGE

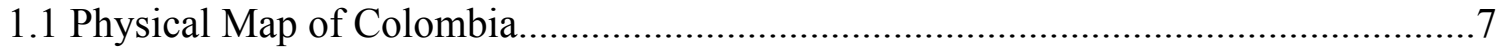

1.2. Black Territory, Roadways \& Waterways in Southwest Pacific Region..................8

4.1 Aerial Eradication, Involuntary Manual Eradication, Coca Cultivation, Alternative Development \& Ethnic Territories in Colombia

4.2 Aerial Eradication, Involuntary Manual Eradication, Coca Cultivation, Alternative Development \& Ethnic Territories in Southwest Pacific Region

4.3 Ethnic Territories, Coca Cultivation, Alternative Development \& National Parks in Southwest Pacific Region.

5.1 Stratfor: Colombia’s Cocaine Routes and Regions..............................................196

5.2 Stratfor: The Revolutionary Armed Forces of Colombia (FARC), National

Liberation Army (ELN) and Clan Usuga.

5.3 Stratfor: The Revolutionary Armed Forces of Colombia (FARC), National

Liberation Army (ELN) and Clan Golfo.

5.4 Victims of MAPS (Anti-personal Mines) and MUSE (Unexploded Munitions)

in the departments of Valle del Cauca, Cauca, Nariño

5.5 Mine Casualties, Aerial Eradication, Coca Cultivation \& Ethnic

Territories in Southwest Pacific Region. 


\section{ABBREVIATIONS AND ACRONYMS}

ACUA

AFRODES

AIDA

ANLA

ASOMANOSNEGRA

ASPROPACÍFICO

AUC

BACRIM

CIAF

CIMARRÓN

COCOCAUCA

CODHES

$\mathrm{CNE}$

DAICMA

DIRAN

ELN

FARC
Afro Cultural Activities Foundation

National Association of Displaced Afro Colombians

The Interamerican Association for Environmental Defense

The Colombian National Environmental Licensing Authority

Association Mano Negra

The Association of Producers and Commercial Entrepreneurs of the Pacific

The United Self-Defense Forces of Colombia

Newly Emergent Criminal Bands in Colombia

Center for Research and Geographic Information Development at The Colombian National Geographic Institute Agustín Codazzi

National Cimarrón Movement

The Coordination of Community Councils and Organizations Representing the Black Communities of the Cauca Pacific Coast

Colombia's nongovernmental Council for Human Rights and Displacement

The Colombian National Council on Narcotics

Directorate for Comprehensive Action Against Antipersonnel Mines of Colombia

The Colombian Anti-Narcotics Police

The National Liberation Army of Colombia

The Revolutionary Armed Forces of Colombia 
GME

IGAC

IDP

ILO

INCODER

INL

PCN

PECIG

PNCRT

SIMCI

UNDOC

UP

USAID
Mobile Manual Eradication Groups in Colombia

The Colombian National Geographic Institute Agustín Codazzi

Internally Displaced Person

The International Labour Organization

The Colombian Institute of Rural Development

The U.S. Bureau of International Narcotics and Law Enforcement Affairs

The Process of Black Communities

The Aerial Eradication Program in Colombia

The Colombian Plan for National Territorial Consolidation

The Integrated Illicit Crops Monitoring System

The United Nations Office of Drugs and Crime

The Patriotic Union Party of Colombia

The United States Agency for International Development 


\section{CHAPTER 1 \\ Introduction}

Until October 1, 2015, Colombia was the only country in the world that still used spray aircraft to eradicate illicit crops - primarily coca and to a lesser extent, opium poppies - as part of U.S.-supported War on Drugs efforts. Though conducted in Colombia since the 1980s when marijuana was the primary target, the 2000 Plan Colombia agreement — the third largest U.S. foreign aid package at the timeestablished aerial eradication as a central component of a renewed effort to reduce the production of illegal narcotics. U.S. and Colombian policymakers promoted aerial eradication as a secure, environmentally safe, and effective means of eradicating coca plants and opium poppies in difficult-to-reach areas (Veillette \& Arvelo-Velez 2003). Detractors of aerial eradication, however, contended that it was harmful to both people and the environment (O’Shaughnessy \& Branford 2005; Rincón-Ruíz \& Kallis 2013), that it failed to decrease the cultivation of coca, and that it contributed to the massive displacement of rural Colombians (Dion \& Russler 2008; Elhawary 2010), an estimated 5.7 million people since counting began in 1985 (CODHES 2013). Yet throughout the controversy, officials involved in the conduct of aerial eradication maintained that the criticism was unwarranted and that potential damages caused by this counter-narcotics strategy were grossly exaggerated.

While much has been written about the effectiveness (Moreno-Sánchez 2003; Dion \& Russler 2008; Rincón-Ruíz \& Kallis 2013), environmental and health implications (Londoño Zapata 2006; Dávalos et. al 2011; Cederstav \& Puentes 2012; Camacho \& Mejía 2015), and human rights concerns of aerial eradication in Colombia 
(Tate 2009; Landel 2010; UNDP 2011), not much attention has been paid to how the agencies that managed aerial eradication interpreted fumigation guidelines and conducted the actual spraying. While there are some interregional reports and investigations on the displacement of communities in spray zones and documentation of protests against aerial eradication (Ferro \& Uribe 2002; Walsh et. al 2008, pp.30-31; Programa Presidencial 2010; Ramírez 2011; UN Refugee Agency 2012), there is much less research on why affected communities described aerial eradication so dramatically differently than eradication authorities.

This dissertation project addresses three central research objectives: 1) it examines the reasons behind the disconnect between U.S. and Colombian authorities involved in the oversight of the aerial eradication program versus the experiences of people living in or near fumigated areas; 2) it presents how black residents of the southwestern Pacific region of Colombia conceptualized coca cultivation and illicit crop eradication efforts as the imposition of foreign logics and the violent transformation of their communities; and 3) it deconstructs two prominent discourses employed in the justification of aerial eradication -'security' and 'environmental conservation' - and explains how black communities re-imagined these discourses as part of their struggle to assert territoriality.

The rest of this introduction chapter briefly overviews: the conceptual framework of this project, what is meant by 'black communities', the transition from coca consumption in the Andes to the criminalization of cocaine production globally, the roots of the Colombian civil conflict, how the civil conflict became intertwined with the U.S. War on Drugs under Plan Colombia, why aerial eradication was a key counternarcotics 
strategy under Plan Colombia, how both coca cultivation and aerial eradication spread to the black communities of the southwestern Pacific region, and how my fieldwork coincided with the eventual termination of the aerial eradication program in Colombia.

\section{Conceptualizing Territorialities, Insecurities, and Contested Natures}

This dissertation draws on three complimentary fields — political geography, and critical geopolitics and political ecology — that correspond to the examination of three themes -territory, security and environmental conservation — that overlap throughout this study.

Political geography theorizes the boundaries, systems, processes, and movements that organize the world. 'Ethnic territory' in Colombia refers to the collectively owned lands of grupos indigenas (indigenous groups) and comunidades negras (black communities) that are guaranteed certain protections and rights per the Colombian constitution and transnational agreements (described in detail in Chapters $3 \& 4$ ). This project specifically discusses how black communities conceptualize their territory $(e l$ territorio) and territoriality (la defensa del territorio). These two concepts do not simply the connote respect for the political boundaries of black communities in the Pacific region; they more broadly refer to 'the space of life itself', which includes flora, fauna, people and their traditions (described in the next section).

Critical geopolitics, a subfield of political geography, emerged in the 1990s with a focus on deconstructing and disrupting conventional understandings of power and practices of statecraft. Recently, however, scholars have critiqued this approach as being largely restricted to the analysis of elitist discourses generated by world leaders and policymakers. This study performs critical geopolitics by contrasting the security 
arguments of authorities involved in the conduct of the aerial eradication program with the perspectives of black communities experiencing insecurities, as they are exposed to the lived implications of a transnational drug policy.

Political ecologists influenced by post-structuralism theorize socio-environmental conflicts by interrogating the assumptions that define environmental concerns. This study draws on Colombian anthropologist Arturo Escobar's 'political ecology of difference' framework (2008), which both challenges such assumptions and redefines environmental concerns in locally contingent ways. What sets Escobar's framework apart from other deconstructive and place-based approaches within political ecology is that it is developed in collaboration with people -residents and activists of the Pacific region - normally excluded from participation in academic discourses. Thus, the political ecology of difference operates both as a critique of top-down approaches to knowledge production and as a framework for the production of alternative forms of knowledge. In this dissertation I refer to discourses 'produced through the political ecology of difference', both to signal the origins of perspectives shaped by this collaborative framework and to highlight how black communities "engage in the defense of place from the perspective of the economic, ecological, and cultural difference that their landscapes, cultures, and economies embody in relation to those of more dominant sectors of society" (Escobar 2008, p.6).

I argue that aerial eradication - justified by notions of security and environmental conservation that had little to do with black communities of the Pacific region-functioned as a technology of displacement, which not only violated the socioenvironmental rights of Afro-descendants, but also compromised their territoriality. 


\section{The Titling of Black Communities}

The new Colombian constitution that took effect in 1991 included Article 7, "which recognizes and protects the ethnic and cultural diversity of the nation", (Constitución). This article, and subsequent legislation made possible by it, is especially relevant to Afro-descendants and indigenous peoples in Colombia, populations that have historically been othered, existing at the margins of a dominant Euro-Colombian imagination of national identity (Grueso et. al 2003, p.431). Black activists and their supporters pursued an indigenous model of territoriality that argued for claims to land rights on the basis of autochthony (Cárdenas 2012, p.309). This entailed an emphasis on the preservation of cultural traditions connected to land, the articulation of cultural difference tied to specific territories (ibid.).

In 1993, the establishment of Colombian Law 70 allowed for the recognition of collective titles on the basis of an Afro-descendant identity rooted in a relationship to land ${ }^{2}$."The law does this, essentially, by elaborating a 'black ethnicity,' something constituted by culture (traditional production systems), history (palenques and selfliberation), and geography (rural riverine and Pacific)" (Offen 2003, p.58). The formal titling of comunidades negras (black communities) that began in the 1990s established these new political subjects with their own representative bodies, the consejos comunitarios (community councils). The individual community titles vary greatly in terms of total area and population. Geographer Karl Offen conducted research on the

\footnotetext{
${ }^{1}$ All Spanish to English translations in this dissertation, including texts and interviews, were completed by Alexander Huezo.

${ }^{2}$ In accordance with the language conventions of the Pacific region and Colombia in general, 'Afro-descendant' and 'black' are used interchangeably in this dissertation.
} 
titling process and notes the example of a community with as little as 30 inhabitants in a single vereda (hamlet) versus another community of 30,000 people spread across 90 different veredas (2011, p.289). As of March 2015, there were 178 recognized black community titles that collectively cover 5.1 million hectares of land in the Pacific (INCODER, p.28); the titling process continues to this day (Law 70 and the titling of black communities are further discussed in Chapters $3 \& 4$ ).

\section{Disconnected Space: The Black Communities of the Pacific Region}

Colombia's Pacific region is a vast landscape of lowland tropical forests, mangroves, and waterways dotted with riverine settlements and a few major cities that comprise $7.7 \%$ of national territory (Departamento Nacional, p.40). There are approximately 1.4 million inhabitants in the Pacific region, which is $3.1 \%$ of the nation's total population (ibid., p.40). $45 \%$ of the region's inhabitants live in three major cities Quibdó, Buenaventura, and Tumaco — while 46\% live in rural areas (ibid.).

Demographically, approximately $79.5 \%$ of the Pacific region's inhabitants are ethnic minorities - either Afro-descendant (73\%) or indigenous $(6.5 \%)$ - while the remaining 20\% is either white or mestizo (Departamento Nacional, p.40). $88 \%$ of the Pacific region's 45 municipalities overlap with ethnic territories ${ }^{3}$ (ibid., p.42). The term 'Afro-Pacific' is often used in this dissertation as shorthand for the Afro-descendant population in the Pacific region. The term not meant to neglect the presence of the indigenous population in the region. Rather the intent in using this term is to avoid

\footnotetext{
${ }^{3}$ It is important to note that municipalities in Colombia (municipios) include both urban and rural spaces. In this sense the term 'municipality' is more akin to a county than a municipality in the U.S.
} 
generalizing what is said about the history and culture of black communities with the experiences of indigenous groups.

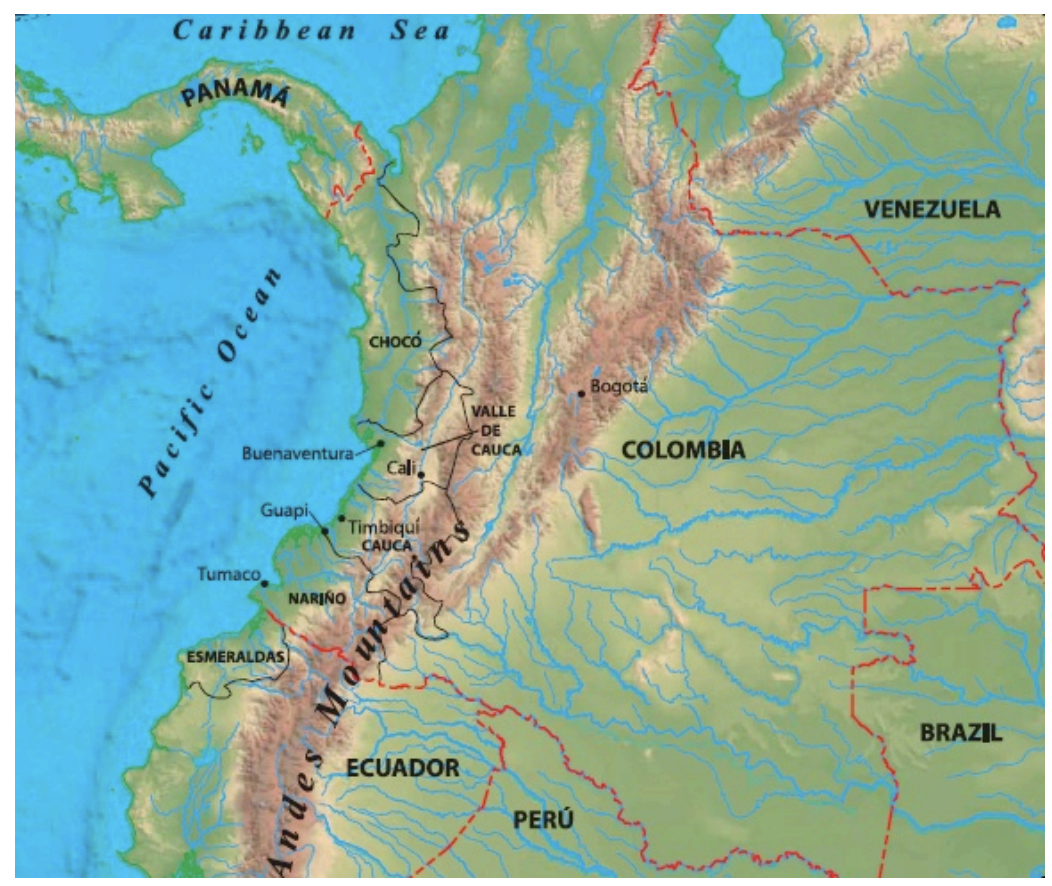

Map 1.1 - Physical Map of Colombia

(Source: liner notes of ; Arriba Suena Marimba! Smithsonian Folkways)

Topographically, the Pacific region is isolated from the rest of the country by the Andes mountain range, which can be seen in Map 1.1. The Pacific region is the green lowland region west of the Andes that extends from the Panamanian border to the Ecuadorian border. Approximately $50 \%$ of all primary forest in Colombia is located within ethnic territories (Flórez López 2012, p.287).

Map 1.2 highlights transportation routes in the Pacific region with major highways in red, other roadways in black, and rivers in blue. The map illustrates how, with the exception of the highway that connects Cali to Buenaventura and the highway that connects Pasto to Tumaco, the majority of the Pacific region is disconnected from the network of roadways that unite the central Andean highlands. Boat trips to the rural 


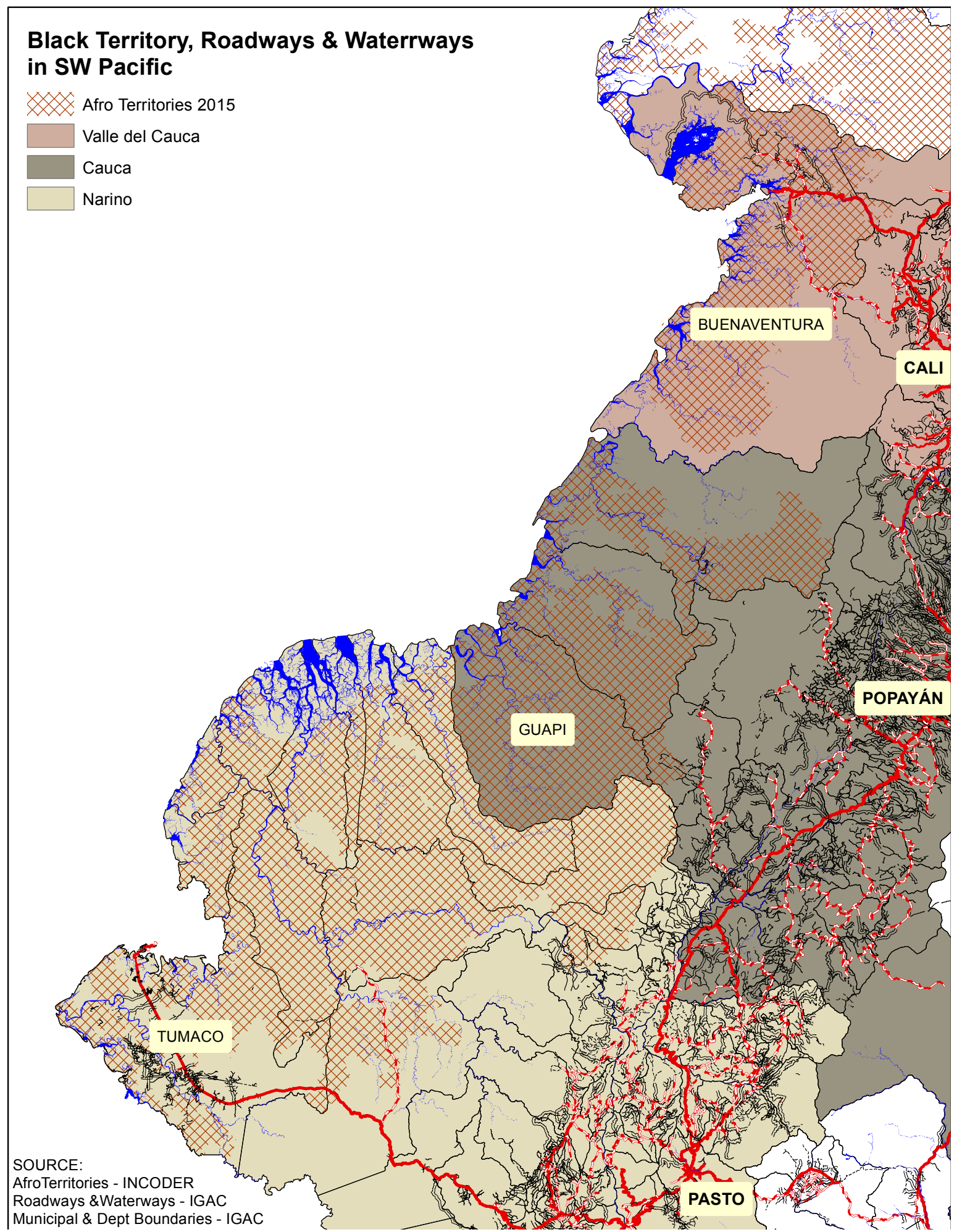

Map 1.2 - Black Territory, Roadways \& Waterways in Southwest Pacific Region (created by Alexander Huezo) 
black communities outside of major towns can range from 20 minutes to twelve hours long. Thus, transportation within the Pacific region is primarily conducted along the waterways that unify the region, both spatially and ontologically, by what Oslender (2016b) terms 'the logic of aquatic space'.

Economically, $62.5 \%$ of people living in the Pacific region do not have their basic needs met compared to the national average of $27 \%$ (Departamento Nacional, pp. 20 \& 384). Households in black communities have traditionally relied on small farm plots and fishing to guarantee their sustenance and cash crops or activities such as artisanal mining for income. In recent decades, however, these activities have been disrupted by the arrival of armed groups, oil palm plantations, industrial mining, coca cultivation, and the aerial eradication of coca.

Politically, the Pacific region is divided along departmental lines and has limited representation outside of the region. The Chocó is the only department predominately of the Pacific region (see Map 1.1). The other three departments of the region-Cauca, Nariño, Valle del Cauca - have much larger populations inland of the coast. For this reason the Pacific region has minimal representation in the national congress and other branches of government. For example Guapi is one of three Pacific region municipalities within the department of Cauca (see Map 1.2). Yet, the demographic, physical, and cultural landscape of Guapi could not be anymore different than the capital of the department, Popayán, or the rest of inland Cauca for that matter. For these reasons and a host of others, many residents of the Afro-Pacific feel disconnected from the national government, their respective departmental governments, and the rest of the country. 
The unique topography, lack of infrastructure, limited economic opportunities, and concentration of ethnic territories in forested areas in the Pacific region have contributed it to becoming one of the largest coca-growing regions in Colombia in the last two decades.

\section{Coca Consumption in the Andes}

The cultivation of coca was only recently criminalized in the grand scope of human history. Coca has been present in the Andean region of South America for thousands of years, though historians disagree as to whether coca was exclusively consumed by the Incan nobility or more widely consumed across all social classes (Thoumi 2003, pp.29-30). When the Spanish conquistadors arrived coca was consumed in a part of the Incan empire that spanned from present day Bolivia to southern Colombia as well as amongst other indigenous peoples of Colombia. During the colonial period coca consumption became a point of contention between indigenous who used coca ceremonially and believed it abated hunger and made them stronger; Catholic missionaries who perceived the ceremonial use of coca as an obstacle to converting indigenous to Christianity; and Spaniards who eventually supported indigenous coca consumption because it enabled their labor force to work long hours without food (ibid.). In spite of the missionaries' efforts, coca consumption persisted and remains an important part of Andean culture, especially in Bolivia and Peru, both countries with large indigenous populations.

Coca leaf consumption in the Andes was considered a minor domestic policy issue until the U.S. prohibition movement of the 1920s, which led to several international conventions and agreements that attempted to ban the use of psychoactive drugs (ibid. 
p.34). In the $1940 \mathrm{~s}$, Andean medical professionals launched a paternalistic anti-coca movement on the grounds that coca consumption had negative effects on the indigenous population. This movement eventually morphed into a 1980s-1990s movement that viewed coca consumption as public health issue. Coca leaf consumption, however, has never been a high priority policy issue in Latin America (ibid., p.35).

\section{Coca Leaf \& Cocaine as Western Medicine}

Coca leaf became relevant outside of the Andean region because of a growing interest in its energizing qualities. U.S. and Peruvian physicians exchanged scientific notes and samples in the 1860 s to learn more about the coca leaf's properties. "Erythroxylon coca, a mild yet complex stimulant comparable to tea or coffee, became embraced therapeutically by a range of American 'eclectic' herbal physicians and drug companies for the treatment of a broad range of ailments, real and imagined" (Gootenberg 2003, p.121). Corsican chemist, Angelo Mariani, mixed coca leaf with Bordeaux wine to create Vin Mariani, a luxurious tonic endorsed by numerous celebrities of the day, including Pope Leo XIII (Pereira 2003, pp.393-394). The North American affinity for coca leaf began when Atlanta pharmacist John Pemberton began selling Coca Cola, a syrup medicine that contained coca leaf, in 1886. By the 1890s the U.S. imported 600-1000 metric tons of coca leaf annually (Gootenberg 2003, p.121).

Cocaine, the crystallized derivative of coca leaf, was discovered around 1859 when scientists isolated alkaloid from the leaf (Pereira 2010, pp.395). It was initially lauded as a revolutionary anesthesia for painful operations and was later employed for a variety of bodily and mental ailments such as cholera, hay fever, opiate addiction, and depression (Gootenberg 2003, p.122). By the end of the $19^{\text {th }}$ century, U.S. pharmaceutical 
companies were marketing 5-6 tons of cocaine per year. Austro-Swiss medical practitioners also participated heavily in the cocaine industry (ophthalmologist Dr. Karl Köller and psycho-analyst Sigmund Freud were two famous proponents) and German mercantilists took an active role in Peruvian cocaine production. Peru —with its connections to the U.S. pharmaceutical industry, the Coca Cola Company, and German mercantilists — was the primary exporter of coca leaf in the late 1800s. By 1900 coca became Peru's fifth biggest export as the country produced two million pounds of coca and more than 10 metric tons of cocaine (ibid., p.124-126).

Coca plants, however, are not restricted to the Andean region and have been grown elsewhere in the world. Colonial powers wanting to challenge the PeruvianGerman monopoly on coca founded alternative growing sites, decimating the market for Peruvian coca from 1920 to 1940 (Gootenberg 2003, pp.127-132). The Dutch East Indies Company established large-scale coca plantations in Java (now part of Indonesia), the British experimented with coca planting in Ceylon (now Sri Lanka), and the Japanese established plantations in Formosa (now Taiwan) (Blickman 2014; Gootenberg 2003). Today the vast majority of coca is cultivated in three countries -Bolivia, Colombia and Peru — while marginal amounts are cultivated in Ecuador, Venezuela, and Brazil (Thoumi 2003, p.53). Coca could certainly be grown in other tropical areas of the world (the Congo is often rumored) if eradication efforts in the Andean region ever necessitate alternatives (Blickman 2014).

\section{The Criminalization of Coca Leaf and Cocaine}

Political economist and U.N. Narcotics Board member Francisco Thoumi describes the eventual criminalization of coca leaf and cocaine production as the product 
of a "moralistic American model" shaped by religious values and xenophobia as well as the complicated history of U.S. health professions. The moralistic model espoused a punitive approach to the popular drugs of the time (namely alcohol, cocaine, and opiates) based on the perception that these drugs were addictive and caused costly social problems (Thoumi 2003, p.18-20). By the end of the 1890s U.S. physicians were concerned about the dangerous side effects of cocaine, especially for "cocaine fiends" who were injecting and snorting the drug recreationally (Gootenberg 2003, p.122). In the early 1900s health professionals became more organized and achieved a monopoly over the practice and prescription of medicine. Two months after the $18^{\text {th }}$ Amendment was signed, however, the Supreme Court ruled against physicians' rights to prescribe psychoactive drugs for "drug addiction maintenance", which effectively criminalized the drug supply (Thoumi 2003, p.22 citing Musto 1999). From the 1910s to the 1930s, U.S. diplomats attempted to push anti-cocaine legislation in different international conventions established by the League of Nations. "The United States, as the principled, mobilized crusader for drug controls, assumed the universalist stand that all abusable manufactured drugs merited a global control" (Gootenberg 2003, p.131). These international drug agreements were largely ignored in Peru, however, which had already dropped out of the League of Nations (ibid., p.133).

After World War II the United Nations Council on Narcotic Drugs (C.N.D.) establishes a more inclusionary approach to drug control than the League of Nations, integrating countries such as Peru into the American anti-drug agenda (Gootenberg 2003, p.138). In 1961, the U.N. "Single Convention" designated both coca leaf and cocaine as Schedule 1 substances, which means that the drug has no medical use and severely high 
potential for psychological and physical dependence (U.S. DEA). Article 26 states that wild coca bushes were to be uprooted and illegally cultivated coca bushes were to be destroyed, while Article 49 stipulates that coca leaf chewing was to be abolished within a 25-year period (United States 1972). Gootenberg notes that cocaine policy was a "sideshow" of the convention as the main drug concerns in the Western Hemisphere were actually Mexican opium and marijuana (2003, p.138).

Following the 1960s — a decade marked by a renewed interest in psychoactive drugs and a weakened respect for authority— President Nixon appointed a National Commission on Marijuana and Drug Abuse in 1971 and declared a "War on Drugs" in 1972 (Thoumi 2003, p.25). U.S. cocaine consumption, however, had faded considerably since the 1940s. Ironically this hiatus in consumption may have contributed to its resurgence because, “...Americans retained no collective cultural memory of cocaine, or its perils, when it reappeared around 1970 as a prestigious and pricey sin" (Gootenberg 2003, p.138 citing Musto 1999). Middle and upper class consumers fueled the 'cocaine epidemic' of the 1970s; a trend that reversed towards the end of the decade as a result of the social disruptions associated with cocaine abuse. In the 1980s the introduction of crack created a lower class market for cocaine that was largely African-American and Latino. The 'crack cocaine epidemic' triggered the implementation of repressive drug policies and an unprecedented increase in the number of people incarcerated in the U.S. (Thoumi 2003, pp.24-25). President Reagan declared illicit drugs a national security threat in 1986 (Youngers \& Rosin 2005, p.3).

The framing of illicit drugs as a threat to U.S. national security was by no means limited to the criminalization of drug production and trafficking within U.S borders. This 
War on Drugs eventually expanded, serving as a justification for U.S. military presence abroad, especially in Latin America. However, in order to understand how U.S. drug policy became enmeshed with Colombian politics, it is first necessary to outline a brief history of the Colombian civil conflict.

\section{Conflict, Violence \& Cocaine}

Most historians signpost La Violencia (1946-1960), a period of violent disorder that began with the presidential election of 1946, as the foundation for the current Colombian civil conflict. While the Conservative Party dominated late $19^{\text {th }}$ to early $20^{\text {th }}$ century Colombian politics, the rival Liberal Party enjoyed a sixteen-year period of presidential rule (1930-1946) that coincided with the rise of populist governments elsewhere in Latin America -Mexico, Argentina, Brazil, and Peru (LaRosa \& Mejía 2012, pp.82-85). The Liberal Party pushed for labor, housing, and other reforms during this time but its reach was limited and it did little to affect the increasing consolidation of rural lands into large estates and the displacement of agrarian workers (Palacios 2003, pp.148-151). In the 1946 election the Liberal Party split its support amongst two candidates and the Conservatives reclaimed the presidency. One of these Liberal candidates, Jorge Eliécer Gaitán, embodied the marginalized working class's best hope for popular reforms in the 1950 election (Sánchez \& Meertens 2000, p.32). That is, until he was murdered campaigning in 1948, triggering a wave of urban violence that would not subside until the 1960s (Pécaut 2013, p.149). "More than anything else, the Violence symbolizes in many ways the failure of collective action in Colombia. For it resulted in...the failure, in sum, of politics as the collective construction of a democratic order and a modern state" (Uprimny Yepes 2003, p.46). In 1958 the two parties collaborated to 
create the National Front agreement, in which Liberals and Conservatives would alternate turns at the presidency every four years, as a means of defusing the political tension and diminishing the violence (Leal Buitrago 2002, p.35).

Rooted in a history of agrarian struggle, and catalyzed by the shockwaves of a Cuban Revolution felt throughout the Americas, guerilla groups emerged to declare their opposition to the Colombian state in the 1960s (LaRosa \& Mejía 2012, p.88). The Revolutionary Armed Forces of Colombia (FARC) originated from a tradition of peasant self-defense movements that preceded La Violencia (Vargas Meza 1999a, pp.42-43). The National Liberation Army (ELN) developed from a mix of university students, left-wing intellectuals, and Roman Catholic priests that espoused Marxist ideology and liberation theology (UNRIC 2016). While these movements have ideological differences, both oppose the privatization of Colombia's natural resources and advocate for the rights of the rural poor (Renwick 2016). The guerillas originally predominated in the peripheral regions of Colombia's colonization where they became de facto regional governments, asserting social control over the regulation of property and production ${ }^{4}$. Later their presence expands to cattle lands and oil regions where they extracted income through the use and threat of violence (Reyes Posada 2009, pp.56-57).

In the 1970s, emerald traders, contraband traffickers, and the first drug cartel bosses purchased massive haciendas throughout the country (Reyes Posada 2009, p.85).

\footnotetext{
${ }^{4}$ A third group, an "urban guerilla" organization known as the M-19, would later form in opposition to what it deemed a fraudulent election in 1970. The group is most famous for storming the Palace of Justice in November 1985. The Colombian military eventually drove a tank into the palace the ensuing battle resulted in the deaths of Supreme Court justices held captive by the M-19, numerous civilian workers, and the "disappearance" of survivors (LaRosa \& Mejía 2012, pp.88-89).
} 
Meanwhile FARC, still a relatively marginal armed group, was financing its insurgency through extortion, kidnappings, and threats to local authorities and civilians (Meza 1999a, pp.43-47). These new landowners were particularly vulnerable to guerilla attacks, extortion, and kidnappings. Furthermore, President Betancur's peace negotiations with the guerillas in the 1980s had handcuffed the Colombian military's capacity to wage an anti-subversive campaign and rankled military leadership. In response, the Colombian military secretly sponsored the formation of private regional peasant armies that sought to physically exterminate guerilla leaders and their political supporters (Reyes Posada 2009, pp.85-86).

Colombian scholar and government official Alejandro Reyes Posada argues that these paramilitary armies proliferated in the 1980 s as a result of cartel-military alliances predicated on mutual counter-insurgent objectives. In 1982 the cartels sponsored the creation of Death to the Kidnappers (MAS), a death squad that specifically targeted guerilla fighters and their families and later converted into a private security force contracted by large landowners. Similar paramilitary organizations appeared elsewhere in the country where the cartels conducted their business (Reyes Posada 2009, p.86). Meanwhile as part of the negotiated peace plan with the Colombian government, FARC had formed the Patriotic Union (UP), a political party consisting of demobilized soldiers. Though the party made some gains in the ensuing years it was, “...systematically eliminated by a number of webs of mysterious forces including the military, hired murderers/paramilitary forces, members of leftist organizations, and, increasingly, powerful drug cartels" (LaRosa \& Mejía 2012, p.89). Eventually this violence 
extinguished any hope for a negotiated settlement and fostered a general sense of distrust in government authority and its military backing (ibid.).

The cartels' rise to prominence in the 1980 s coincides with the national government turning a blind eye to these extrajudicial killings. As the cartels became wealthier and more violent, they transformed the State itself, as evidenced when Pablo Escobar -head of the powerful Medellín cartel— was appointed an "alternate" member of congress in 1982. The assassination of numerous government leaders, including Colombian Minister of Justice Rodrigo Lara Bonilla in 1984 and presidential candidate Luis Carlos Galán in 1989, factored into a growing resistance against the cartels (Salazar 2012).

Through a combination of internal rivalry, domestic pressure and U.S. insistence, the two major cartels -Medellin and Cali- were dismantled by the mid 1990s. The vertical drug-trafficking structure, in which the big cartels controlled the entire process from cultivation to international distribution, was replaced by a more horizontal formation in which hundreds of smaller operators specialized in different phases of drug production and distribution (Reyes Posada 2009 pp.87-88). Guerilla and paramilitary groups seized the opportunity to get involved in the trafficking business, forming alliances with Mexican and Brazilian organizations facilitating exportation (ibid., p.88). Prior to the 1990s Colombia drug traffickers mostly purchased coca paste from Bolivia and Peru. However, a combination of circumstances - the collapse of the Cali cartel (that bought paste from Peruvians), a Peruvian fungus infestation known as "El Gringo", and Peruvian President Fujimori’s increased interdiction efforts against illegal flights leaving Peru and Bolivia for Colombia - factored into Colombia becoming the 
world's largest coca cultivator by the end of the 1990s (Thoumi 2003, p.99). In 1990 Colombia cultivated $19 \%$ of all Andean coca whereas by 2000 Colombia cultivated $72 \%$ of all Andean coca (Tickner et. al 2011, p.421).

Guerilla groups -historically active in areas neglected by the Colombian government - taxed the production and distribution of illicit drugs. These taxes were initially collected from traffickers and middlemen and later collected from the campesino farmers themselves (Tate 2015, p.50). This included taxes on the following: the weight of goods cultivated or processed, the laboratories where the ingredients were processed, the airstrips where planes landed and took off, and drug shipments (Meza 1999a, pp.47-48). One study estimates that between 1991-1996, FARC and ELN generated \$2.4 billion in earnings, roughly $44 \%$ of which was derived from drug trafficking (Eltiempo.com 1998). This income allowed FARC to significantly expand its operations in Colombia, especially in what became known as the "coca belt" of southern Colombia, which contained $80 \%$ of all coca grown in the country by 1999 (Tickner et. al 2011, p.420). In 1986 FARC numbered 32 battalions and approximately 3,600 soldiers and by 1995 their forces had essentially doubled with 60 battalions and 7,000 soldiers (Vargas Meza 1999a, p.50). In the 1990s paramilitary groups began challenging guerillas' dominion over coca-producing regions and drug trafficking corridors as a means to finance the purchase of black market weapons. These groups terrorized, massacred, and forcibly displaced rural peasants throughout the country from regions controlled or thought-to-be controlled by guerilla forces. Those rural peasants that remained behind succumbed to the authority of the paramilitary group in power. In 1996, seven regional paramilitary groups formed a federation known as the United Self-Defense Forces of Colombia (AUC), which 
expanded the paramilitary offensive in regions controlled by guerillas (Reyes Posada 2009, pp.88-89). In the face of domestic and international pressure, the AUC's coalition of 37 groups was eventually demobilized by 2006 under President Uribe's administration (Human Rights Watch 2010).

The Colombian government refused to label the successor groups that followed the AUC as 'paramilitary' or 'neo-paramilitary' groups even though many of these groups have conducted the same activities as the AUC and are equally violent against the civilian population. Nevertheless, "some are more closely linked to the conflict between the Colombian security forces and FARC and ELN guerillas than others" and the government has deemed these groups "newly emergent criminal bands" or BACRIM (Human Rights Watch 2010).

\section{The Militarization of the War on Drugs in the Andes}

Prior to 1990 U.S. drug policy took a backseat to the fight against communism in Latin America. Since the end of Soviet Union, however, illegal drugs and international organized crime have largely replaced communism as threats to national security (Thoumi 2003, p.26). The National Defense Authorization Act for Fiscal Year 1989 established a new precedent, granting the Pentagon a legislative mandate for counternarcotics operations (Tate 2015, p.36). In the same year, President George H.W. Bush's administration launched the Andean Initiative to reduce the supply of drugs — mostly cocaine and heroine — by limiting drug production and seizing drug shipments from source countries, primarily in Latin America and the Caribbean (Youngers \& Rosin 2005, p.3). "The centerpiece of the Andean Initiative was to empower Latin American military and police forces to carry out counterdrug initiatives, and significant U.S. training and 
support was provided to those willing to collaborate" (ibid., pp.3-4). In the first place, U.S. policymakers believed that militarizing the War on Drugs was necessary to confront heavily armed drug traffickers and to bypass corrupt local police forces ${ }^{5}$. In the second place, this militarization provided opportunities for the U.S. military to develop relationships with Latin American military forces (Youngers 2000, pp.20-21).

Winifred Tate, author of an ethnography of U.S. policymaking in Colombia, describes how the revival of the term 'narcoguerilla' -widely used by U.S. government officials at the end of the Cold War to discursively link communist groups with criminal drug-trafficking - was instrumental to the militarization of the War on Drugs. The word 'counterinsurgency' fell out of favor in Washington D.C. after the 1993 deployment of Marines to Somalia ended in disaster. From then on, Congress took the difference between 'counterinsurgency' and 'counternarcotics' very seriously, limiting the amount of military counternarcotics aid available to combat guerilla organizations. The narcoguerilla moniker solved this dilemma by opening up a new avenue of funding to combat insurgent movements (Tate 2015, pp.46-47). Narcoguerilla discourse, “...delegitimized such movements' political claims by categorizing them as criminal organizations, and it justified the escalation of military aid to their opponents by alleging the narcoguerrillas' access to the nearly limitless resources of the drug trade" (ibid., p.47).

\footnotetext{
${ }^{5}$ Though as Youngers points out, the "Lack of accountability and transparency in the region's military forces make tackling the inevitable corruption that accompanies antidrug efforts even harder-and controlling potential human rights abuses next to impossible" $(2000$, p.20).
} 
In Bolivia, U.S. Special Forces personnel had trained Bolivian counter-narcotics paramilitary police squads since 1983 . These squads reported to the Anti-Narcotics Section of the U.S. Embassy (NAS) and the DEA. In 1990 the signing of the United States-Bolivian Anti-Narcotics Agreement signaled the official entry of the Bolivian military into the War on Drugs (Morales 1992, pp.353-354). At the time, critics questioned the effectiveness of this new partnership because "...historically, the Bolivian military has been no friend to democracy or to drug enforcement; indeed, many consider the military to be the problem rather than the solution" (ibid., p.355). In 1997 the election of former dictator General Hugo Banzer to the presidency paved the path for the further expansion Bolivian military counter-narcotics operations (Youngers 2000, p.22).

In Peru, the end of the Cold War signaled a new relationship with the Peruvian military, which formerly had ties to the Soviet Union and had been receiving payoffs from drug traffickers to thwart the Peruvian police (Krauss 1992). In fact by the early 1990s, the Peruvian military effectively replaced the Shining Path as intermediaries between local coca growers and drug traffickers (Youngers 2000, p.18). Despite this situation, in 1992 Congress approved funding for U.S. military officers to train the Peruvian military in counter-narcotics tactics ${ }^{6}$ (Krauss 1992). These efforts seemed to pay off as by the mid 1990s Peru's coca exports reduced dramatically under President Fuijimori's strong-armed approach to counter-narcotics (Gootenberg 2003, p.147).

In Colombia, U.S. policymakers worried that the rise of the cartels was jeopardizing the security of a democratically elected government closely allied with the

\footnotetext{
${ }^{6} \$ 10$ million was approved in the first stage of aid that also included aircraft and roadbuilding equipment. The U.S. Drug Enforcement Agency (DEA) and U.S. Army Special Forces had already been working with Peruvian police units at the time (Krauss 1992).
} 
United States. The Colombian military was initially resistant to participating in U.S.-led counter-narcotics operations, which were tasked to the Colombian anti-narcotics police (DIRAN), established in 1981. However, Ramírez explains, “...the Colombian police are a national body responsible to the ministry of defense, in effect an additional branch of the armed forces" and DIRAN is part of the National Police (2010, footnote \#10 p.106). More importantly, Ramírez states:

As the war on drugs took on a counterinsurgent and counterterrorist focus, U.S. policy came to mesh with the internal security discourse of the Colombian armed forces with regard to the struggle against the insurgency, now redefined as narcoterrorist and narco-guerilla. Colombian officers found this version of the war on drugs much more appealing, and the armed conflict intensified during Plan Colombia (2010, p.94).

\section{The Geopolitics of Plan Colombia}

By the end of the 1990s the U.S. State Department committed to stabilizing a Colombian government that appeared on the brink of becoming a 'failed state'. According to the 'continuum of states' established by Robert Rotburg -former president of the World Peace Foundation - 'weak states' may become 'failed states' and, ultimately, 'collapsed states' (Elden 2009, p.67). In Latin America, as is true elsewhere in the world, these designations have legitimized U.S. intervention and influence in foreign states.

In the geopolitical imagination of U.S. foreign policy analysts and military strategists, Colombia is a key ally in South America. Geographically, it is the gateway between Central and South America with access to both the Pacific and Atlantic Oceans. Currently surrounded by socialist-leaning governments leery of U.S. imperialism (Venezuela, Ecuador, Bolivia), Colombia is seen by U.S. foreign policy analysts and 
military strategists as vital to the stability of the region. 'Stability', in the geopolitical sense represents comfort with the status quo, in knowing who your allies and enemies are, and in knowing the proper way to interact with them. In his posture statement about drug trafficking in the Latin American and Caribbean region, John Kelly -Commander of U.S. Southern Command - warns Congress, “...the spread of criminal networks is having a corrosive effect on the integrity of democratic institutions and the stability of several of our partner nations" (2014, p.3, my emphasis). As Elhawary notes, “The Colombian government, with U.S. support, has in fact adopted the language of stabilisation and is implementing an 'integrated approach' as a means to defeat the guerrillas and consolidate the state's legitimate presence throughout its territory" (2010, p.388, my emphasis).

The 2000 Plan Colombia agreement established the parameters under which the U.S. would assist Colombia with this stabilization. The original purpose and history of the plan, however, are very much contested, especially in Colombia where the final version of the plan was never debated in congress, never formally introduced to the public, and never published in Spanish ${ }^{7}$. In a new round of peace negotiations with the guerillas in 1998, President Pastrana described his idea "The Plan for Peace in Colombia", which he likened to the Marshall Plan for the reconstruction of Europe after

\footnotetext{
${ }^{7}$ Author interview with Germán Ayala Osorio at La Universidad Autónoma de Occidente in Cali, Colombia on July 14, 2012. Ayala Osorio conducted a discursive analysis of how Plan Colombia was presented in mainstream Colombia print media in 2000, highlighting how the merits of the plan were lauded despite the fact that the plan had never been published in Colombia. He explained that 3-4 informal English-to-Spanish translations of Plan Colombia were circulating in Colombia after the agreement had already been implemented. The only substantive Colombian media critiques of Plan Colombia were plagiarized versions of articles originally written in The Washington Post.
} 
World War II (Ayala Osorio \& Llano Ángel 2004, p.43). Pastrana linked this new vision to the implementation of Colombia's Plan for National Development:

Plan Colombia is a collective of alternative development projects that channel the joint efforts of governments and multilateral organizations together with Colombian society. Its benchmarks for success will be the transformation of the areas where $80 \%$ of the world's coca and opium poppies are cultivated... Plan Colombia is orientated towards regional development, the strengthening of departments ${ }^{8}$ and the promotion of initiatives and energies of the most vulnerable populations... (Presidencia de la República 1999, pp.76, 78).

Realizing that the Colombian state had limited financial means to pursue these objectives, President Pastrana sought international cooperation in the form of an alliance between drug-producing nations and drug-consuming nations (Ayala Osorio \& Llano Ángel 2004, p.63).

In January of 1999, Pastrana's administration conceded FARC a demilitarized zone with the intention of advancing the latest round of peace negotiations. This zone, the size of Switzerland in southeastern Colombia, contained some of the main cocaproducing areas in the country and was pivotal to FARC expanding its participation in the drug trade (Thoumi 2003, p.90). At the behest of concerned U.S. State Department officials, Pastrana visited Washington D.C. to share his vision of the bilateral agreement. The State Department insisted that Pastrana revise his plan to take a tougher stance with FARC, by intensifying counter-insurgent military campaigns and by ramping up counternarcotics operations meant to erode FARC's finances. Therefore the version of Plan Colombia that U.S. Congress passed in 2000 -favoring military and counter-narcotics funding over investment in economic development—is dramatically different from what

8 'Departmentos' in Colombia are comparable to states or provinces. 
Pastrana had been proposing in Colombia up until that point (Ayala Osorio \& Llano Ángel 2004, pp.66-67). “Of the original \$860 million Colombia received, \$632 million was devoted to military and police assistance. The remaining \$227 million went to the general categories of economic development, displaced persons, human rights and administration of justice" (Shifter 2012).

The original plan called for U.S. financial and technical support to phase out within six years when Colombia became a highly stable democracy, capable of conducting counter-narcotics operations on its own ${ }^{9}$. Wary of entanglement in a "Vietnam-style quagmire", Congress initially limited the use of donated helicopters, other hardware, and a Colombian battalion of 3000 soldiers trained by U.S. Special Forces to counter-narcotics operations (Brodzinsky 2016). In addition, the 2000 Plan Colombia agreement limited U.S. presence in Colombia by capping the number of U.S. soldiers and restricting their primary roles to that of non-combatant advisers and trainers for the Colombian military. However, this cap did not include the network of pilots, private security types, and other contractors that work for the U.S. and Colombian governments without the accountability of government employees (O’Shaughnessy \& Bradford 2005, p.100-101). Some of the original limitations on Plan Colombia were lifted after the 9/11 attacks, when in a discursive twist; the U.S. began assisting Colombia in the struggle against "narco-terrorism"(Brodzinksy 2016). "No longer would U.S. resources have to be directly tied to the drug question. Now they could be used in combating the FARC,

\footnotetext{
${ }^{9}$ Author interview with anonymous officer that participated in Plan Colombia. Interview conducted at U.S. Southern Command in Doral, Florida on November 12, 2012.
} 
Ejército de Liberación Nacional (ELN), and AUC —all of which were considered terrorist groups by the U.S. government" (Shifter 2012).

'Plan Colombia' quickly became a lightening rod for criticism of U.S.-Colombian relations, which can partially be attributed to confusion about what 'Plan Colombia' actually means. As Tate explains, "There is this idea that it is some vast orchestrated project but Plan Colombia doesn’t exist as such" (quoted in Brodzinsky 2016). Since 2000 the original plan has been extended under successive U.S. and Colombian administrations and become something of an umbrella term for a number of different U.S. aid packages to Colombia totaling nearly $\$ 10$ billion (ibid.). What is often understated in discourse about Plan Colombia is the extent to which the Colombian government has sought out U.S. support. Within Colombia some scholars term this "the internationalization of the Colombian conflict", the process by which the U.S. was explicitly invited to participate in domestic policy, which began with President Pastrana (1998-2002) and intensified under President Uribe (2002-2010) (Tickner 2007; Borda Guzman 2010). Furthermore what is often misunderstood about Plan Colombia is the fact that the Colombian government has assumed the majority of responsibility in restoring its authority. In financial terms Colombia has invested much more than the U.S. For instance, Colombia tripled its defense expenditures between 2000-2009 to the tune of nearly $\$ 12$ billion (Shifter 2012).

Nevertheless the concern with U.S. involvement has been that, at certain junctures, the Colombian government may have lost control "over how the participation of international actors unfolds" (Borda Guzmán 2010, p.145). The principal criticisms of Plan Colombia have been that it is, "Too skewed towards trying to win the unwinnable 
war on drugs by spraying coca fields from the air, and too compromised by giving money to an army stained by human-rights abuses..." (The Economist 2016).

\section{Aerial Eradication: A Controversial Strategy}

Crop dusting has been around since there have been airplanes. It's hardly a new science. What is new of course is the involuntary nature of it when you're doing coca or opium poppy aerial eradication. - William Brownfield $^{10}$

There have been three principle strategies to limit the cultivation of illicit crops in Colombia: 1) manual eradication (voluntary and involuntary), 2) crop substitution through alternative development programs, and 3) aerial eradication. Both the INL and DIRAN have consistently lauded aerial eradication as the safest and most cost effective strategy of the three, mostly in consideration of the difficulties and dangers involved in accessing remote areas of the country (discussed in detail in Chapter 5). Between 20002013, aerial eradication totaled 1,600,000 hectares compared to 413,000 hectares manually eradicated (Mejía 2015, p.5).

The use of chemicals in the War on Drugs began in 1971 when opium poppy fields and marijuana plantations were eradicated with herbicides in Mexico. After some experimentation with different chemicals in the U.S., paraquat was chosen as the chemical to eradicate marijuana and 2.4-D, an herbicide found in Agent Orange, was chosen for the eradication of opium poppies. Following the launch of the first large-scale counter-narcotics operation in Mexico, Operation Condor in 1975, the U.S. purchased a

\footnotetext{
${ }^{10}$ William Brownfield -Assistant Secretary of the Bureau of International Narcotics and Law Enforcement Affairs (INL) and former U.S. ambassador to Colombia- responding to Alexander Huezo's question about aerial eradication at "Drugs, Security, and Latin America: The New Normal for the $21^{\text {st }}$ Century?", a talk delivered at Florida International University on September 26, 2014.
} 
fleet of spraying helicopters and reconnaissance aircraft. These spraying operations, which had expanded to Colombia in 1978, were temporarily suspended that same year as a result of "paraquat fever", the sickness and panic affecting U.S. consumers of marijuana sprayed with the poison. U.S. plans to export the Mexican model of aerial eradication operations were largely limited by the fact that other countries were not willing to do what the U.S. would not permit on its own soil ${ }^{11}$. Nevertheless in the 1980s aerial eradication operations were implemented elsewhere in the Americas -Belize, Guatemala, Jamaica, Bolivia, and Peru— as well as in Burma and South Africa (Jelmsa 2001, pp.1619).

In Colombia aerial eradication operations have been conducted in three waves beginning with marijuana in 1978, opium poppies in 1992, and coca in 1994 (Jelmsa 2001, p.4). Support for the program was funneled to the INL and the U.S. Embassy's Narcotics Affairs Section (NAS) in Bogotá. DIRAN conducted the spraying with NAS funding technical support, herbicide, fuel, and spray aircraft ${ }^{12}$. The plane pilots were U.S. citizens, Colombians, and third-country nationals contracted by the INL through DynCorp Aerospace Technologies. Armed helicopters accompanied spray aircraft

${ }^{11}$ Domestic marijuana cultivation increased six-fold in the U.S. during the 1980 s as a result of U.S. eradication efforts in Mexico and Colombia. With the exception of smallscale experimentations in various states, the aerial eradication of illicit crops was not conducted in the U.S. until the 1990s when Roundup was sprayed on marijuana fields in Hawaii (Jelmsa 2001, pp.17-18).

${ }^{12}$ Though according to INL officials, in the last few years Colombia began buying its own glyphosate. Author interview with INL staff: Jorgan Andrews (Director), Ben Embury (Environmental Program Manager) David Walter (Eradication Program Manager), Bernardo Reina (Rule of Law Program Manager), Ingrid Simón (Scientific Officer) Kate Bentley (Press Attaché), Erin Truhler (Assistant Information Officer). Interview conducted at US Embassy in Bogotá on August 4, 2015. 
because these planes were frequently the targets of ground fire (Youngers and Rosin 2005, pp.112-118).

The primary ingredients of the spray mixture used in aerial eradication were water, glyphosate, and Cosmo-Flux. In 1984 the Colombian Ministry of Agriculture sent a commission of representatives to visit drug enforcement agencies in Washington D.C. and returned to Colombia with a list of 175 herbicides that could be potentially used for the aerial eradication of illicit crops. From this list glyphosate was eventually selected and became the herbicide of choice for all aerial eradication operations in Colombia moving forward (Vargas Meza 1999b, pp.27-30). Glyphosate is the top selling herbicide in the world; the Monsanto Corporation produces variations under the name 'Roundup' (White 2009). Cosmo-Flux is a chemical additive that makes the droplets heavier to increase the likelihood of the spray hitting the intended target. Variations of the chemicals and the proportions used in the mixture changed over time in accordance with Colombian resolutions passed during the duration of the aerial eradication $\operatorname{program}^{13}$. However, to the chagrin of those wishing to independently test the mixture, the exact chemical composition of spray used in aerial eradication was never revealed at any point (Tate 2015, p.198).

The 2000 Emergency Supplemental Appropriations Act, stipulates some of the requirements for the chemical mixture used in aerial eradication in order for the aerial eradication program to be funded:

${ }^{13}$ Author interview with Leonardo Correa, Technical Coordinator of The Integrated Illicit Crops Monitoring System (SIMCI), at the United Nations Office of Drugs and Crime in Bogotá on April 28, 2015. 
Prohibits the use of funds in the bill to support the use of herbicides unless the Director of the National Center for Environmental Health at the Center for Disease Control and Prevention reports to Congress that the herbicide is safe and non-toxic to human health, and the Environmental Protection Agency reports that it does not contaminate ground or surface water (United States 2000).

The act clearly states that the herbicides used must be "safe and non-toxic to human health." The U.S. Department of State stood by its stance that the chemicals used in aerial eradication were not harmful to people, flora, and fauna despite massive mobilizations against aerial eradication in southern Colombia in the late 1990s. U.S. officials argued, "The lack of baseline studies, ongoing monitoring, and health services in the region made it impossible to definitively prove the negative effects of the fumigation or differentiate peasants' use of Roundup from fumigation" (Tate 2015, p.200)

The consequences of spraying with glyphosate continue to be debated throughout the world, but these debates were especially intense in Colombia, the last country to outlaw the aerial eradication of illicit crops. In addition to human health risks in the form of skin, respiratory and other ailments, Younger and Rosin cite Colombia's rich diversity of flora and fauna as reasons to be concerned, "About one-third of Colombia's approximately 50,000 known plant species are found nowhere else, and about one-third of all known vertebrate species live in Colombia" (2005, p.119). At the same time, aerial eradication advocates in the Colombian government discursively linked aerial fumigation to environmental sustainability and the protection of biodiversity hotspots threatened by illicit crop cultivation, arguing that spraying slows deforestation and chemical pollution caused by coca farmers (Rincón-Ruiz \& Kallis 2013, p.70). 
The Transnational Institute (TNI), a nonpartisan international group of scholars, has poked holes in Monsanto's claims that glyphosate is not dangerous for people or the environment. TNI journalist Meg White explains, "This should come as no surprise, since Monsanto has been involved in several known cases of scientific fraud regarding the same chemical, wherein the EPA found multiple instances in which labs were paid to falsify preferred results for the company. Monsanto has also been charged in multiple jurisdictions for disseminating misleading information about its Roundup products" (2009).

Models created by the Environmental Protection Agency (EPA) showed that aerial eradication spray could drift up to 600 feet from its intended target (Youngers and Rosin 2005, p.118). In May 2007, Ecuadorian President Rafael Correa invited Paul Hunt, United Nations special rapporteur on the right to the highest attainable standard of health, to investigate the impact of aerial spraying on the health of Ecuadorians living near the border. Hunt found that there existed, “...credible and trustworthy evidence that aerial fumigation with glyphosate on the border between Colombia and Ecuador is affecting the physical and mental health of the residents of Ecuador" (Walsh et. al 2008, pp.10-11). Ecuador eventually won a $\$ 15$ million court settlement for its claims that aerial drift had crossed the border and caused massive damages, resulting in the prohibition of aerial eradication within a specified range of the border ${ }^{14}$.

\footnotetext{
${ }^{14}$ The original $10 \mathrm{~km}$ strip could be narrowed to $5 \mathrm{~km}$ and later $2 \mathrm{~km}$ if Colombia followed through with certain promises according to Appendix 1 of the settlement agreement (Meléndez 2013).
} 
Apart from the allegations about the chemicals, there was considerable skepticism of the effectiveness of aerial eradication as a counternarcotics strategy. In particular, many critics cited the balloon effect:

...where production squeezed off in one locale simply forces illicit coca production into new geographic areas. The balloon-effect can be observed since Plan Colombia's commencement, with both a reversed displacement of coca to surrounding countries and a dispersion and reconstitution of coca-growing areas within rural Colombia (Dion \& Russler 2008, pp.400401).

The same study explained that coca growers have responded to the balloon effect by cultivating "greater quantities in smaller but more dispersed plots" or by cultivating lots further removed from state infrastructure (ibid., p.403 citing UNODC 2006). In 2001 the average coca lot was 1.4 hectares while in 2005 the average decreased to 1.1 hectares and by 2010 the average coca lot was all the way down to 6 hectares (SIMCI \& UNODC 2011, p.41). Thus, rather than curtail the cultivation of coca, critics have argued that aerial eradication has both spread the cultivation of coca and expanded the reach of the damaging aerial eradication chemicals intended to counteract coca (Moreno-Sánchez et al. 2003; Rincón-Ruíz \& Kallis 2013).

\section{Human Rights, Displacement \& Coca Growers}

Trepidation over the socio-environmental consequences of aerial eradication must be understood in the wider context of the Colombian conflict and the generous amount of resources being funneled toward a Colombian military force with a history of human rights violations. The Leahy amendment to the Foreign Operations Appropriations Act of

1997 was specifically written "in direct response to concerns about the possible misuse of U.S. military aid by Colombian security forces" (Tate 2015, p.66). The amendment 
"prohibits U.S. counternarcotics assistance to foreign military units facing credible allegations of human rights abuses unless the government takes effective measures to address the allegations" (ibid., p.57). María Clemencia Ramírez -who conducted an ethnography of the protests against aerial eradication in the late 1990s - observes, "The fact that the civilian population is believed to always line up with one or another of the armed groups in the conflict, and the belief that it is impossible to pry them away, is sometimes used to justify the violation of their human rights by the army and especially to justify the demand that they perform military intelligence" (2010, p.96). While supporters of the Colombian military cited a reduction in human rights violations as proof that real reforms were taking place with the implementation of the Leahy amendment, "Critics instead pointed to the evidence of collaboration between military and paramilitary forces, arguing that the military had not reformed, but had replaced direct action with collusion" (Tate 2015, p.76).

Meanwhile, caught in the middle of the territorial conflicts between the Colombian military, the guerillas, the paramilitaries, and BACRIM, the rural poor have endured the brunt of the violence. The fact that land tenure is a massive issue in Colombia, especially in rural areas where informal agreements predominate and land titles are concentrated into the hands of a few, has also contributed to the ease by which the rural poor have been displaced from their lands.

In the last 30 years nearly 6 million people have been displaced, ranking Colombia behind Syria as the country with second largest internally displaced population in the world (Blocher 2014). The two primary reasons for displacement are natural disasters and violence associated with the armed conflict. The latter group, commonly 
referred to as 'forcibly displaced,' has experienced violence in the forms of "extortion, anti-personnel mines, threats and pressure to collaborate with armed groups, forced recruitment of children by armed groups, and sexual and gender-based violence" and constitutes the vast majority of displaced persons in Colombia (IDMC 2017). Approximately $90 \%$ of the displaced population has been displaced from rural areas of the country, reflecting the struggle for territory for the production of illegal narcotics as well as the seizure of lands for other extractive commodities (UNHCR 2012). Those among the forcibly displaced that are capable and willing to provide the details of their displacement can be legally recognized as 'victims of the armed conflict', which makes them eligible to receive government assistance ${ }^{15}$.

Unfortunately, there has never been an official registry of persons displaced by aerial eradication because those "displaced as a result of coca eradication are not considered internally displaced under Law 387 of 1997 (the law defining the government's obligations to internally displaced persons) and therefore not eligible for protection” (Asher 2009, p.173). Colombia’s nongovernmental Council for Human Rights and Displacement (CODHES) estimated that from 2001 to 2002 aerial eradication caused the displacement of 75,000 people in Colombia (Youngers and Rosin 2005,

${ }^{15}$ While conducting past research on the internally displaced population in Cali, Colombia I learned that government assistance constituted a meager allowance for three months of food and rent. My interviewees typically waited six months to a year to receive such assistance. Aside from fears that their safety would be compromised by detailing the circumstances that led to their displacement, many displaced persons never seek government assistance because of pride or a lack of sufficient paperwork to identify themselves or the loss of their property. Often times, the best assistance that the displaced population can find is within the complicated web of non-governmental organizations dedicated to the cause. 
p.118). A quantitative study concerned with the effectiveness and repercussions of aerial eradication concluded, “...despite official claims to the contrary, aerial eradication does not significantly reduce coca cultivation in Colombia, and that where it does have an impact, this is both temporary and in part due to displacement associated with fumigation efforts, generating significant human and economic costs” (Dion \& Russler 2008, p.415).

Commenting on the primary regions of coca cultivation during the 1990s, Thoumi notes, "Coca plantings in Colombia have developed almost exclusively in the areas recently settled by displaced peasants. These regions are isolated and distant from the main economic centers of the country, and the state has a weak presence if any" (2003, p.86). A quantitative study conducted with data from 2001-2005 concluded, “....coca cultivation thrives in economically underdeveloped, agricultural regions where residents have the means to partake in agricultural endeavours but lack access to legal markets due to poor public infrastructure and a weak state presence" (Dion \& Russler 2008, p.419).

\section{The Spread of Coca Cultivation to the Pacific Region}

The massive aerial eradication campaigns in the Colombian Amazon region in the 1990s eventually factored into the spread of coca cultivation to other parts of the country. In the Pacific region, coca cultivation first spread to the department of Nariño, which borders both the Colombian Amazon region and Ecuador ${ }^{16}$ (Restrepo 2013, p.268). Despite the protests, aerial eradication operations were expanded to many of these new cultivation areas, including ethnic territories — indigenous and Afro-descendant-

\footnotetext{
${ }^{16}$ I created an animated map in Graphics Interchange Format (GIF) that illustrates the expansion of coca cultivation into southwestern Colombia in the 2000s $<$ https://contestednatures.com/coca-density-in-afro-territories-2000-2013/>.
} 
supposedly safeguarded by a Colombian constitution "presented as the construction of a pluriethnic and multicultural nation" (Grueso et al. 2003, p.43).

The Pacific region initially served as a trafficking corridor but has now transformed into a major coca-growing region. Colombian anthropologist Eduardo Restrepo describes how the region's unique topography facilitated the transportation of coca products:

The morphology of the southern Pacific Coast, replete with estuaries and mangroves, crossed by countless rivers and tributaries that penetrate deep into rainforests, facilitate the travel of small rapid boats with which to transport the alkaloid to Central America, and from there, to North America. At the same time, the continuous flow of cargo vessels transporting timber coming from the dozens of sawmills camouflage the drugs headed to the port of Buenaventura...(2013, p.270).

In addition to the ease of transporting illegal substances through the region, other factors that have contributed to the coca cultivation boom in the region are: the vast expanses of area disconnected from roadways (i.e., areas within easy reach of manual eradication); the predominance of ethnic territories vulnerable to intrusion by non-state armed actors involved in the regulation of coca cultivation and drug trafficking; the presence of several national forest reserves where aerial eradication is prohibited by law; easy access to the Pacific Coast through waterways for export; nearly constant cloud cover; heavy precipitation; and tropical forest canopy that make coca detection difficult. These factors and the dynamics of coca cultivation in the Afro-Pacific will be discussed in Chapters 4-

6.

\section{The Last Year of Aerial Eradication}

It is important to note that I conducted fieldwork at a truly exceptional time in the history of Colombian drug policy, with the national government engaged in peace talks 
with FARC and a lot of uncertainty about the future of illicit crop eradication in Colombia.

I arrived to Bogotá, the Colombian capital and epicenter of drug policymaking, in January of 2015 and dedicated the first four months to better understanding the perspectives of officials that participate in the oversight of the aerial eradication program, related protocols, and Colombian drug policy in general. These initial interviews revealed some of the disagreements about how aerial eradication was conducted and whether black communities should have been consulted prior to aerial eradication operations.

In May of 2015 the Colombian National Narcotics Council (CNE) suspended the use of the chemical glyphosate in the conduct of aerial eradication on the recommendation of a research unit of the UN World Health Organization (WHO), which concluded that the chemical is probably carcinogenic. The suspension of glyphosate, however, was not to be implemented until October 1, 2015. While the fate of the aerial eradication program was being deliberated the number of aerial eradication missions increased dramatically ${ }^{17}$. It was during this interim time period that I visited communities affected by aerial eradication in southwestern Colombian Pacific region, which was the most heavily fumigated region of the country (UNODC 2014).

The Process of Black Communities (PCN), an Afro-descendant organization at the forefront of the struggle to invest black communities with territorial rights in Colombia, facilitated the vast majority of my visits to the Pacific region. This organization was instrumental to the implementation of Colombian Law 70 (created in

${ }^{17}$ In 2013, aerial eradication totaled 47,000 hectares (UNODC 2014). In the month of August 2015, aerial eradication totaled 27,000 hectares (Eltiempo.com 2015). 
1993), which allowed for the recognition of collective territorial rights on the basis of an Afro-descendant identity rooted in the Pacific region's unique history, cultural traditions, and geography. While PCN is an important Afro-descendant organization nationwide, particularly in the southwest Pacific region, it is not the only organization in the defense of black territories. A combination of circumstances — my access to research contacts, PCN's willingness to assist my research, and divisive local politics — factored into my decision to primarily work with this organization. My field visits to communities affected by aerial eradication were conducted in the riverine communities surrounding Guapi, Cauca and Buenaventura, Valle del Cauca (discussed in Chapter 2).

Also during the interim period of intensified aerial eradication (between May and October of 2015), I had an opportunity to interview the staff of the Bureau of International Narcotics and Law Enforcement Affairs (INL) at the U.S. Embassy in Bogotá, the agency that oversaw U.S. support of the aerial eradication program. I asked the staff to respond to the criticisms of the program that I heard from farmers, activists, academics, and certain Colombian officials. At time of the interview (August 4, 2015) the INL staff was very concerned about what would happen if the Colombian government decided to terminate the aerial eradication program, but outwardly voiced support for whatever decision was going to be made moving forward ${ }^{18}$.

On September 30, 2015 the Colombian National Environmental Licensing Authority (ANLA) issued Resolution 1214, which officially terminated the aerial eradication program. In lieu of aerial eradication, the Comprehensive Strategy for Illicit

${ }^{18}$ Author interview with INL staff on August 4, 2015. 
Crop Substitution (Estrategia Integral de Sustitución de Cultivos Ilícitos) emphasizes crop substitution via alternative development programs, manual eradication, and the apprehension of criminals higher up in the narcotics production chain (Presidencia de la República 2015). In a complete coincidence, I had scheduled my flight to leave Colombia on the day the aerial eradication program ended.

\section{The Chapters Ahead}

Chapter 2 "Conducting Fieldwork in Two Colombias" discusses the methodology employed in this study and includes some personal reflection on my positionality as a researcher. Chapter 3 “Conceptualizing Territory, Security, and Environmental Conservation through Difference" overviews the main conceptual themes developed in this dissertation, drawing upon literature from political geography, critical geopolitics, political ecology, and critical cartography. Chapter 4 "Territorialities: Aerial Eradication and the Overlap between Colombian Territoriality and Black Territoriality" is the first empirical chapter, which analyzes how aerial eradication shaped and was shaped by the intersection of mulitple territorialities - mainly in the context of the Colombian state and black communities, but also considering non-state armed actors and transnational capital. Chapter 5 "Insecurities: Thinking Critically about the Geopolitics of Security" alternates between the perspectives of aerial eradication authorities -justifying this counternarcotics strategy for 'security' reasons — and the residents of black communities who experienced aerial eradication as various forms of 'insecurity'. This chapter builds towards an explanation of why many interviewees perceived aerial eradication as a form of intentional dispossession. Chapter 6 "Contested Natures: Aerial Eradication as Environmental Conservation?" continues the discussion set forth in Chapter 5 -aerial 
eradication as an instrument of dispossession. In it I describe how black communities rejected coca cultivation and aerial eradication as the imposition of foreign logics, in the process reconceptualizing 'biodiversity' through the political ecology of difference. Finally, Chapter 7 "Recognizing Technologies of Displacement and the Struggle for Black Territory" concludes the dissertation by explaining what has happened with illicit crop eradication since the termination of the aerial eradication program and by reflecting on the importance of acknowledging local knowledge production. 


\section{CHAPTER 2}

\section{Conducting Fieldwork in Two Colombias}

\section{Scaling back the proposal \& choosing fieldwork sites}

In the first draft of my dissertation proposal I established some unrealistic goals for the amount of ground I could safely cover during the fieldwork period. I had proposed visiting and conducting interviews in all six of the main areas in Colombia where aerial eradication was happening at the time. My dissertation committee encouraged me to scale back these plans to only focus on one region. I decided to focus on the southwestern Afro-Pacific for two reasons. The first reason was that Dr. Oslender had shared a letter from a black organization in this region, which served as the initial catalyst for the project. The letter, addressed to the international community, framed aerial eradication as an act of biochemical warfare of the Colombian state against its own people ${ }^{19}$. Having previously researched the history of the Afro-Pacific and visited the southwestern corner of the region, I was already interested in conducting fieldwork in this part of Colombia. This decision also made sense because of Dr. Oslender's experience and connections with black social movements in the very same area, a major factor in my decision to attend Florida International University to begin with. In the second place, the southwestern Pacific was the most heavily fumigated region of Colombia at the time I embarked on fieldwork.

\footnotetext{
${ }^{19}$ The letter from the Coordination of Community Councils and Organizations Representing the Black Communities of the Cauca Pacific Coast (COCOCAUCA) is dated August 21, 2012.
} 
I decided then that I would specifically focus on the black communities surrounding three important municipalities -Tumaco, Buenaventura, and Guapi ${ }^{20}$. I was most interested in visiting Tumaco, Nariño, an important port city located near the Ecuadorian border (Agier et al. 1999), because it has been the epicenter of the most recent coca boom in the Pacific region and thus the most heavily fumigated municipality in the country. Tumaco was caliente as everyone explained, which meant that it was simply too dangerous to visit. In the span of a few months, the FARC allegedly exploded bombs in the city center, which cut off electricity for days at a time and assassinated a PCN leader in one of the communities I had hoped to visit ${ }^{21}$. In September of 2015 I saw a potential opportunity to visit; a friend of mine was part of a caravan delivering food to Tumaco and requested that I accompany the group. The request was denied by the caravan leadership on the basis that it would not have been appropriate for me to ask questions at the time ${ }^{22}$. I did, however, manage to conduct interviews with people from Tumaco at PCN events hosted in other locations (Guapi and Piendamó).

${ }^{20}$ These three cities are also signaled as the main black centers of the southern Pacific Coast in contrast to Quibdó, Chocó, the capital of the only majority black department in Colombia, which has "an older and stronger link to the state and to traditional political parties than the rest of the region" (Grueso et al. 2003, footnote \#4 on p.443).

${ }^{21}$ These incidents with the FARC were by no means isolated and are part of a longer history of violence towards black communities in the Pacific region that continues to this day $<\mathrm{http}$ ://colombia2020.elespectador.com/territorio/el-perdon-de-las-farc-llegotumaco $>$.

${ }^{22}$ It should also be noted that the original caravan was delayed because some of the organizations funding this shipment in Cali, where the caravan was organized, had ties to politicians wanting to attach their names to this charitable action. The caravan organizers, wanting to steer away from such political entanglements, then raised money to ship the food on their own terms. After explaining what happened my friend involved in the caravan complained, "Even philanthropy is politicized in Colombia!" 
To compensate for the lack of access to Tumaco, I spent more time in Buenaventura and Guapi. Buenaventura, Valle del Cauca, is Colombia's largest port and a major gateway for cocaine shipments trafficked through Central America and Mexico. Buenaventura is also the city where the Process of Black Communities (PCN) established its first office (Oslender 2016b, p.3) and thus certain communities in the area are proud to have resisted the recent wave of coca cultivation, while others were fumigated quite often (discussed in Chapter 4). Lastly, Guapi, Cauca is a much smaller port city, only reachable by plane or boat. I specifically chose to visit the communities surrounding Guapi because the town itself is so isolated from the interior of the country.

In terms of the mapmaking in my proposal, I suggested that I might collaborate with local communities of the Afro-Pacific to produce alternative representations of maps produced for military and counternarcotics purposes. These aspirations were based on what I had read about PCN social cartographic forums (Offen 2003; Oslender 2007a) and the collaborative nature of the 'political ecology of difference' framework (Escobar 2008), which I discuss in Chapters $3 \& 4$. Similar to the frustrations Oslender expressed about organizing a Participatory Action Research (PAR) project 'on the ground' (2015, p.70), I quickly realized that initiating a collaborative mapping project required preparation far beyond the limited time I could dedicate to such an endeavor. I did, however, observe how mapping is integrated into PCN events, critique and construct maps, and develop future plans for collaborative research that involve maps (discussed below).

The main reason why I spent less time in the Pacific region than I originally envisioned is that I had greater access to government officials than I ever thought 
possible while writing the proposal. I believe this was an extremely fortuitous development because drug policy research is so polarizing that many researchers, whether by choice or because of limited opportunities, often only document arguments from one side of any given drug policy debate. Francisco Thoumi, a drug policy expert and Colombia's representative on the United Nations International Narcotics Control Board, explained that it is difficult to implement reforms in his line of work because there is not much common ground between drug policymakers and the academics and activists staunchly opposed to such policies ${ }^{23}$. Thus interviewing some of the policymakers and government officials that supported or facilitated the aerial eradication program provided a unique opportunity to problematize some of the assumptions that factor into the binary perception of this particular drug policy.

\section{Research Design}

This project employs a mixed methods approach to investigate how a transnational counternarcotics program -U.S.-supported aerial eradication in Colombiawas understood at national and transnational levels as well as experienced at the local level. Table 2.1 highlights how the methods are designed to fulfill the research objectives of the study:

Table 2.1 - Research Design

\begin{tabular}{|c|c|}
\hline Objectives & Methods \\
\hline $\begin{array}{l}\text { Elucidate the reasons behind the } \\
\text { disconnect between U.S. and Colombian } \\
\text { authorities involved in the oversight of the } \\
\text { aerial eradication program versus the } \\
\text { experiences of people living in or near } \\
\text { fumigated areas. }\end{array}$ & $\begin{array}{l}\text { - Semi-structured interviews with and } \\
\text { observation of U.S. \& Colombian } \\
\text { officials involved in the conduct of } \\
\text { the aerial eradication program } \\
\text { - Analysis of official discourses }\end{array}$ \\
\hline
\end{tabular}

${ }^{23}$ Author interview with Francisco Thoumi at his home in Miami, Florida on March 21, 2013. 


\begin{tabular}{|l|l|}
\hline & $\begin{array}{l}\text { including government legislation, } \\
\text { government reports, press releases, } \\
\text { and speech transcripts }\end{array}$ \\
$\begin{array}{ll}\text { Present how one particular population } \\
\text { affected by aerial eradication, residents in } \\
\text { the heavily fumigated communities of the } \\
\text { southwestern Afro-Pacific region, } \\
\text { differentiates itself from the external forces } \\
\text {-namely transnational geopolitics, armed } \\
\text { groups, and narco-culture- violently } \\
\text { transforming their territories. }\end{array}$ & $\begin{array}{l}\text { observation of people representing } \\
\text { communities affected by aerial } \\
\text { eradication in Afro-descendant }\end{array}$ \\
territories of the southwestern \\
Pacific region
\end{tabular}

I conducted interviews, gathered map data, and collected additional documents/media in Colombia from January to October of 2015. During that time I traveled between Bogotá, Cali, Popayán, Piendamó, and two municipalities in the southwestern Pacific region impacted by aerial eradication, Guapi and Buenaventura.

\section{'Official' \& 'Local' Perspectives}

The term 'official' in this dissertation refers to information gathered from those that determined and/or interpreted the parameters of aerial eradication policy and other policies affecting ethnic territories in Colombia. The term has double significance in the sense that those empowered to affect the outcomes of aerial eradication program and 
ethnic territories are also referred to as 'officials' and, interchangeably, as 'authorities' in this dissertation. I also use the term to distinguish between data furnished by government institutions versus data collected from other sources.

The term 'local' in this dissertation refers to information gathered from those most affected by the conduct of the aerial eradication program or those that champion the rights of those most affected by the conduct of the aerial eradication program. Following Escobar (2008), this dissertation emphasizes the value of local knowledge production in alternative narratives of geopolitics, ecology, and territory. In terms of scale, 'local' refers to how the aerial eradication program was and afro-descendant territorial rights are understood in the Afro-Pacific.

Furthermore, this project nuances 'official' and 'local' perspectives -that are certainly not monolithic — by documenting some of the tensions that exist among the institutions in charge of aerial eradication, among other Colombian government entities, and among residents of black communities.

\section{Preliminary Steps}

In 2009-2010, I conducted research for my Master of Arts thesis in Cali, Colombia. I interviewed people forcibly displaced by the civil conflict (internally displaced persons or IDPs) and was particularly interested in finding out how the violent transition from rural to urban life affected people's beliefs in supernatural entities. I recorded interviews in the poorest neighborhoods of Cali, where the majority of IDPs settle, and also collected literature on local mythology from archives, libraries, and bookstores. With this research I established contacts and a general sense of the dangers and difficulties of fieldwork in Colombia. I also learned that people displaced by aerial 
eradication were not granted the benefits of IDP status by the Colombian government because coca cultivation is criminalized in Colombia ${ }^{24}$ (Ceballos 2003, p.26).

In 2012, I compiled a dataset to examine the relationship between violence, the presence of armed groups, and the distribution of rural land in Colombia. This dataset included variables -such as armed group violence and forcible displacement — that I eventually included in the database I compiled for this dissertation project.

In the summer of 2012, I conducted preliminary dissertation research to get a sense of the viability and usefulness of studying U.S. drug policy in Colombia. I met with faculty of the Institute of Regional Studies (INER) at La Universidad de Antioquia (Medellín), at La Universidad Autónoma de Occidente (Cali), and in the School of Government of La Universidad de los Andes (Bogotá). I also took a guided tour of the Colombian Police Museum in Bogotá and photographed the displays in the counternarcotics section.

In 2013, I conducted interviews at U.S. Southern Command with officers involved in the implementation of Plan Colombia. That same year I also met with Colombian drug policy expert Francisco Thoumi about the feasibility of my research plans and suggested readings.

\footnotetext{
${ }^{24}$ In addition to the denial of IDP status, it was extremely difficult to estimate the number of people displaced by aerial eradication because this strategy was employed in areas already plagued by violence related to the internal conflict and coca cultivation. In its only publication, specifically focused on the subject of aerial eradication and displacement, Colombia's nongovernmental Council for Human Rights and Displacement (CODHES) estimated that 35,000 families were displaced by aerial eradication in southern Colombia from 1999-2003 (Ceballos 2003, p.26). Thus there is little research on the relationship between aerial eradication and forcible displacement, which also served as a motivation to conduct my dissertation project.
} 
In 2013 and 2014 I had an opportunity to ask questions of two prominent U.S. officials -Carmen Lomellin, U.S. Ambassador to the Organization of American States (OAS) as well as William Brownfield, Assistant Secretary of the Bureau of International Narcotics and Law Enforcement Affairs (INL) and former U.S. ambassador to Colombia - at two separate events held at Florida International University.

Prior to dissertation fieldwork, Dr. Oslender reached out to prominent Afrodescendant organizations -The Process of Black Communities (PCN), the National Association of Displaced Afro-Colombians (AFRODES), and COCOCAUCA - to introduce my project to key research contacts. Dr. Bidegain also provided me with a number of important contacts and she facilitated my invitation to become a visiting researcher in the Political Science Department of La Universidad de los Andes in Bogotá (UniAndes).

\section{Positioning of the Storyteller}

Understanding the world is about living inside stories. There's no place to be in the world outside of stories (Haraway 2000, p.107).

This dissertation attempts to understand why the stories being told about aerial eradication in Colombia were so dramatically different from one context to the next. Before outlining the methods employed to tell this particular story, however, I will first spend some time talking about the inclinations and limitations of the storyteller.

As the author of this dissertation it is my responsibility to divulge how my research is shaped by my experiences and the personal details of my being. I subscribe to the post-positivist and poststructuralist notion that there is no such thing as "objective" scientific research. Researchers have the responsibility of 'situating their knowledge' to 
avoid presenting their findings as universal truths; this is what Haraway describes as the "God Trick" because it appears as though knowledge is conjured up by some entity that sees everything but exists nowhere (1988). Situating knowledge then is about placing knowledge production in context.

I am a U.S. citizen - not a Colombian citizen, nor of Colombian descent — who conducts research in a country with a history of U.S. interventionism. Being of Latin American descent and having lived in a number of Latin American countries - Argentina, Brazil, Chile, Colombia, and Costa Rica — has made me acutely aware of both the privileges and resentments that accompany a U.S. citizen living abroad in this part of the world. For example, my Colombian friends like to tell me that Colombians are often more trusting of - and thereby more accommodating to - foreigners than fellow Colombians. Though I speak Spanish, it is not perfect. Occasionally my Colombian friends have encouraged me to exaggerate the broken-ness of my accent so that we could all reap the benefits of my foreigner status ${ }^{25}$. On the other hand, being a foreigner can also be a burden for friends and research contacts that feel responsible for my safety. Though I have traveled quite a bit and can generally pass for Colombian (until my accent is detected or someone asks for my documents), I have received ample warnings about traveling alone.

I am male, college educated, and grew up comfortably in a middle class family. If forced to pick out a racial/ethnic label I would choose mestizo (of European and indigenous descent). With regards to these descriptors, I tended to blend in with the

\footnotetext{
${ }^{25}$ This normally happens in the context of asking a stranger for help or trying to get into a crowded restaurant.
} 
mostly white-mestizo population in the Andean highlands of Colombia (discussed further in Chapter 3) and had much in common with the majority of people I interviewed about aerial eradication policy in Bogotá. In addition, my affiliation with La Universidad de los Andes, the premier private university in the country and the alma mater of most of the government officials I interviewed in the capital, was extremely helpful towards securing interviews and access to institutions.

My ability to go unnoticed in Bogotá, however, was in stark contrast to my inability to blend into the crowd in the Afro-Pacific. Jhally and Hall describe racial identification as a 'floating signifier' in which one's racial identity will change or "float" according to the situation and social history of the people described by their color (1997). My self-identification as mestizo, which situates my identity in contrast to the generic category of 'white' in the U.S., thus did not mean much in the Afro-Pacific context where I was simply perceived as a white foreigner. This was especially the case in smaller communities where I was often the unfamiliar face amongst people who knew each other.

In these different fieldwork contexts my last name served as an icebreaker of sorts, prompting me to explain my heritage and upbringing as a gringo latino ${ }^{26}$. Throughout most of Latin America, gringo is the derogatory term for a foreigner with privilege (i.e., from the Global North). This is a label often rejected by U.S. Latinos, including myself in the past, because gringos in the U.S. are normally associated with

\footnotetext{
26 "Huezo" is a fairly common surname in El Salvador and it literally means "bone" in Spanish (though spelled slightly differently, h-u-e-s-o). In Colombia people often smirk once I tell them my last name because in many Spanish-speaking Caribbean countries, the expression un hueso duro de roer (a bone that is tough to gnaw on) connotes someone that is dull or requires an inordinate amount of explanation to be convinced of something.
} 
mainstream white American culture, devoid of any connection to Latin America and often looking out of place within it. Throughout fieldwork I made it a point to refer to myself as a gringo latino or el investigador de gringolandia (the researcher from Gringoland). In the first place, I wanted to let people know that I was aware of my privilege and connection to a country responsible for initiating the War on Drugs in Colombia. This self-description would normally lead to a discussion about why I was conducting this particular line of research. I usually responded by expressing concern about the appropriateness of U.S. foreign policy, particularly with regard to the rural communities affected by aerial eradication. In the second place, my self-deprecating introduction gave the really busy people I was trying to interview something funny to remember me by.

Having studied the history of U.S. imperialism in Latin America, I am very much interested in U.S. geopolitics in Latin America. As Haraway explains, situating knowledge also entails using the vantage point of the subjugated to argue against 'unlocatable' and 'irresponsible' knowledge claims made by objective science (Haraway 2000, p.59). I have approached this project in a similar manner, willing to challenge the "scientific" knowledge claims that justified aerial eradication by arguing that perspectives subjugated by such claims, matter. I have done so in the spirit of Colombian anthropologist Arturo Escobar, who aims "to demystify theory that ignores subaltern experiences and knowledge of the local economy, environment, and culture in order to relocate their politics of place as a key to our understanding of globalization" (2008, p.15, original emphasis). This project, which draws on critical geopolitics and political ecology theory, is therefore political itself. I began this investigation precisely because I 
felt the aerial eradication program was a violation of the socio-environmental rights of already marginalized rural populations throughout Colombia. In doing so, I aspire to raise further awareness about the Afro-Pacific struggle for territorial rights and to contribute to social science theory that values the local production of ecological concerns.

At the same time, however, the intent of this project is not to simply replace one particular narrative about aerial eradication with another. Rather this project involves:

...the struggle to produce inter-subjective truths, to understand why so many versions of events are produced and recited...Therefore, stories told in the research encounter are not simply to be regarded as means of mirroring the world, but as the means through which it is constructed, understood and acted out (Crang \& Cook 2007, p.14, original emphasis).

In the context of this dissertation, the explanations gleaned from research subjects about aerial eradication are not documented as absolute facts nor dismissed as false if contradicted by other sources. The intent rather is to figure out how such explanations have factored into the conceptualizations of both ethnic and national territorialities.

\section{Gaining Access in Bogotá}

I originally anticipated only spending three months in Bogotá but spent the majority of my first five months there. Bogotá is not only the capital of Colombia but also the epicenter of drug policy work and where most organizations representing ethnic minorities are headquartered. UniAndes is one of the top universities in the country with a long list of professors and alumni advising or serving in the Colombian government. 'Visiting researcher' status gave me access to professors working on drug policy (Farid Benavides and Daniel Mejía) and international relations (Arlene Tickner and Sandra Borda Guzmán) who facilitated interviewees in other important governmental entities such as the Ministry of Justice, the Ministry of the Interior, the National Narcotics 
Council (CNE), the Counternarcotics Police (DIRAN), and the United Nations Office of Drugs \& Crime (UNODC) as well as Ricardo Vargas of the Transnational Institute (TNI), who has written a number of books and articles on aerial eradication (1994; 1999a; 1999b; 2005; 2011).

I also failed to speak with people at a few institutions that I had intended to visit. For instance, Colombia's nongovernmental Council for Human Rights and Displacement (CODHES) is located in Bogotá but I did not have any direct contacts within this institution. I sent an inquiry requesting to interview someone about displacement caused by aerial eradication through the CODHES website message portal and received an email two weeks later, referring me to their 2003 publication on the subject. I similarly requested an interview with a lawyer for the Interamerican Association for Environmental Defense (AIDA) and she responded by emailing an attachment of the petition that the organization filed against the aerial eradication program.

Three important national organizations representing Afro-descendant Colombians are headquartered in Bogotá: The National Movement for Human Rights of AfroColombian Communities (CIMARRÓN), the Association of Displaced Afro-Colombians (AFRODES), and the Process of Black Communities (PCN). I interviewed Juan de Dios Mosquera, the director of CIMARRÓN, who put me in contact with activists, leaders, journalists, and scholars in the Pacific region. At AFRODES I met with the then president of the organization, Luz Marina Becerra, and Axcan Duque, their attorney in charge of reparation cases. Axcan shared his insights on the struggle for the recognition of ethnic rights in Colombia and gave me an electronic file of court decisions and decrees that chronicle the efforts of afro-descendant and indigenous communities to receive previous 
consultation about activities and projects conducted within their respective collective territories. He also put me in contact with a scholar working on the topic of previous consultation in indigenous communities.

Of the three organizations, $\mathrm{PCN}$ provided the greatest access to interviewees representing communities affected by aerial eradication. In the first place, PCN has a significant presence in all of the communities that I had planned to visit. In the second place, PCN prides itself on a horizontal leadership structure spread throughout its network. This means that PCN leaders are constantly traveling -mostly within Colombia and sometimes internationally — to workshops, meetings, and other events. This meant that I had the opportunity to meet with people from Tumaco, Guapi and Buenaventura in Bogotá, Cali, and other cities. Finally, PCN also prides itself on its collaboration with academics and activists from all over the world, which meant that I was not only invited to many events but PCN leaders were accustomed to granting interviews and facilitating access to their members.

José Santos Caicedo was my primary contact in PCN and he generously spent many hours recommending interviewees and personally contacting them on my behalf. He introduced me to PCN leadership in the three municipalities I endeavored to visit Tumaco, Guapi, and Buenaventura - as well as the ex-Director of Previous Consultation in Colombia. José also invited me to PCN events and met with me periodically to update my contact list.

Interested in collecting map data and learning more about how maps are produced for Colombian government entities, I visited the National Geographic Institute Agustín Codazzi (IGAC). Within IGAC I was directed to the Center for Research and Geographic 
Information Development (CIAF), which is both a school and a GIS center. With a letter of support from UniAndes, I was provided office space for the semester with access to researchers and databases not available to the general public. I used this time to gather the best map data possible, learn about the different projects researchers were working on, and secure more research contacts.

Lastly, one of the most important contacts I made in Bogotá happened by accident. I was speaking English to a friend when a man overheard me and asked where I was from and what I was doing in Colombia. I briefly explained my research and it just so happened that he was the Director of Eradication, Rural Security and Demobilization for the Bureau of International Narcotics and Law Enforcement Affairs (INL) within the U.S. Embassy in Bogotá ${ }^{27}$. We spoke informally for about 30 minutes. He expressed interest in a formal interview so that he could respond to the criticisms of journalists and academics that he felt were unfairly maligning the aerial eradication program. Though Mr. Walter promised an interview in the near future, I emailed and called him for six months before it became a reality. Part of the reason for the delay was that in May of 2015 the Colombian government decided to temporarily suspend the use of glyphosate (effective October 2015), a decision that panicked the INL because aerial eradication was the primary strategy for limiting the cultivation of illicit crops.

${ }^{27}$ This was just one of several fortunate coincidences that happened while I was in the field. Oslender (2015) argues that coincidence has not been properly addressed in methodological literature. Rather it is something that researchers have sought to eliminate when "doing science" (p.72). While I agree with these assertions, I'll refrain from offering my unscientific theory as to why these coincidences kept happening. 


\section{Conducting Research in Bogotá}

I conducted all interviews, with the exception of the INL at the U.S. Embassy, in Spanish with a digital recorder and a notebook. These interviews were semi-structured as I normally would prepare 6-8 questions and would then ask follow-up questions or deviate from the scripted questions according to the flow of the conversation. Almost all interviews conducted in Bogotá were one-on-one with one major exception (described below).

The biggest challenge to conducting interviews and gathering data in Bogotá was scheduling. It is a massive city with horrendous traffic. Though it is lauded for its public transportation system, many people spend a good portion of their day commuting so are often in a rush to leave the workplace. Emails and phone calls to key people I wished to interview were not returned most of the time. Emails sent to institutional websites almost never received responses. I found that the most effective way to secure interviews was to have the person I was interviewing in the moment, directly contact future potential interviewees on my behalf.

Once I did secure an interview or meeting the next biggest challenge was the bureaucratic formalities of the institution I was visiting. Many government buildings in Bogotá have strict security protocols that require a great deal of time and patience, both for the person I was interviewing and for myself. For instance, it took 45 minutes to pass security and reach the Ex-Director of the CNE at his current office in the Fiscalía General de la Nación. Part of the process involved his administrative assistant drafting and personally delivering a letter to security that permitted me to enter with a digital recorder. To be able to work in CIAF offices required me to have a professor at UniAndes supply a 
letter to the director of CIAF. Both the professor and the director were so busy the process required three weeks of me following up with emails, phone calls, and surprise office visits. After finally securing an interview with INL staff in the U.S. Embassy, I had to pass multiple security checks, divest myself of any electronics (including my digital recorder), and then sign a waiver stating that I would only publish quotes that received direct approval from the INL press liaison ${ }^{28}$.

Not all interviews required such formalities as many were conducted outside of government offices. For instance, I had numerous interviews in cafés and restaurants throughout the city with government officials on lunch break. I was also very fortunate to learn that one of my housemates in Bogotá was married to a lawyer that represented three communities in the southwestern Pacific region seeking restitution for damages caused by aerial eradication. This was an extremely fortuitous interview because this case, which lasted several years and was ultimately not successful, provided a point of comparison for another case I would study later in the year (described below). The most informal interviews were conducted over the phone with people too busy or too difficult to reach in person. I conducted three such interviews - with a manual eradication monitor, an NGO worker, and a government analyst- via Skype conversations I digitally recorded, though I would have preferred to conduct these in person.

One of the most fruitful visits to a government entity was the morning of April 28, 2015, which I spent at the United Nations Office of Drugs and Crime (UNODC). The

\footnotetext{
${ }^{28}$ Per the waiver, I am allowed to cite this interview in my dissertation but must ask permission if I choose to cite in any publication. I am still undecided as to how willing I am to challenge this mandate in publications, especially in light of the fact that the aerial eradication program was eventually terminated.
} 
Integrated Illicit Crops Monitoring System (Project SIMCI) is the office within UNODC that annually reports on the cultivation of illicit crops through spatial analysis of satellite images. These same images are used by DIRAN for the detection of coca lots (discussed in Chapter 5). I met with Leonardo Correa, the technical coordinator of Project SIMCI, and was able to ask very specific questions about how SIMCI produces their reports. I was also able to observe one of the technicians responsible for processing satellite images of coca lots in the department of Nariño. I learned the following: how coca is detected, general patterns of coca cultivation, the limitations of using satellite imagery, and what measures SIMCI takes to verify the presence of coca. Also within the UNODC complex is an office that tracks data for Mobile Manual Eradication Groups (GME) and the alternative development programs Families for the Conservation of Forests (Familias Guardabosques) and Productive Projects (Proyectos Productivos). I briefly interviewed the director of this office, who explained the UNDOC's participation in the data collection process. The director also gifted me the UNDOC's latest publications on alternative development and the Plan for National Territorial Consolidation (PNCRT).

As stated earlier, the most difficult interview to schedule was the only interview with a U.S. agency, the INL at the U.S. Embassy ${ }^{29}$. I imagined that I would be able to speak to a couple of low-level INL staff members for a short amount of time as Mr. Walter, my contact, did not answer many of my questions about the details of the visit. I was able to sit with the entire staff (seven people total) for over two hours. In the first

\footnotetext{
${ }^{29}$ This interview took place in August of 2015, which meant that I had to fly back to Bogotá because I had already moved to Cali.
} 
thirty minutes I was lectured about misperceptions of the aerial eradication program ${ }^{30}$. Though I initially felt like this was a waste of time because I had already done so much research, the lecture highlighted what the INL was most defensive about. For the rest of the allotted time, the staff, which consisted of five Americans and two Colombians, took turns responding to my questions. By the end of the interview I realized that the INL had some of its own misgivings about how aerial eradication and other U.S.-supported strategies were implemented in Colombia.

\section{Gaining Access in the SW Pacific region}

Travel to most Afro-descendant communities of the Pacific can be expensive because of travel costs (i.e., plane flights, buses, and/or boat fuel), time-consuming because of difficulty of travel and distances, and dangerous because of the presence of various armed actors. For instance, trips to Guapi involved 1-2 flights, a motorcycle taxi ride, and a boat ride to the specific veredas I wished to visit. The flight to Guapi, always in a small commercial propeller plane, was both breathtaking for the views of the riverine landscape once the plane cleared the mountain range separating Cali from the Pacific Coast, but also frustrating at times for the long hours spent waiting for the flight to take off. On one particular occasion I woke up at 4:30am to be at the airport for a $7 \mathrm{am}$ flight that did not depart until $11 \mathrm{am}$. Halfway through the 45-minute flight, the pilot turned the plane around because the Guapi airport had closed due to weather conditions. I could actually see Guapi from my window when the plane turned around! The flight was then

\footnotetext{
${ }^{30}$ I was later informed that this was standard practice for interviews because the majority of interviewers that speak with the INL are journalists with limited knowledge of how the program works.
} 
rescheduled for 2:30pm and when I finally got into Guapi at 3:30pm, the people I had planned to interview that day were no longer available.

Because boat fuel is expensive the most economical way to travel by boat is with others headed in the same direction, which was not always a possibility. Communication can also be very challenging because most veredas have limited electricity and limited or non-existent cellphone coverage. Likewise internet access is extremely restricted and intermittent even within municipal centers. For these reasons it was very difficult to plan trips to the southwestern Pacific without leaning heavily on my contacts at PCN. As desperate as I was to visit and conduct interviews, I always had to keep in mind that I could be a tremendous burden. PCN leaders not only had to constantly facilitate interviews on my behalf but also made sure that I never traveled alone to interviews, both for lack of familiarity of my whereabouts and for safety reasons (further discussed under "Challenges \& Limitations of the Qualitative Data").

I first visited the Pacific region in March 2015 with a group of PCN leaders from Bogotá. I was extremely nervous as the only person from the U.S. and one of only two non-Afro-descendants in attendance for a meeting in Temuey, Guapi attended by over 200 people. The PCN leaders that organized the event sought two outcomes: the formal association of five communities and the launch of an alternative development program organized by PCN. Every person in the meeting hall introduced himself or herself at some point during the event. Not wanting to stick out more than I already did, I kept my introduction very brief. Later on a gentleman stood up and questioned whether an alternative development project was a good idea if it was likely going to be aerially fumigated, just as past projects had been. I found his speech so impassioned that I 
recorded a video of it and later asked to formally interview him ${ }^{31}$. I was shocked (and humored) to find out that he had spoken out because he believed I was working for the aerial eradication program.

From then I was much more careful about how I presented myself, which was key as I made a lot of contacts during that trip and conducted several interviews, which ranged from 15-45 minutes long. The most important person I met was Gerardo Orobio Bazán, a PCN leader in Guapi and the point person for visits I made later in the year. I also learned that life in the Pacific region has its own rhythm, quite a bit slower than the bustle of Bogotá or Cali. I accepted the fact that I would have to wait around a lot without knowing why and not worry too much when things did not go as planned.

In May of 2015 the Colombian government voted to suspend the use of glyphosate in the aerial eradication program. While many critics of aerial eradication celebrated this decision as a victory, the reality was that aerial eradication missions increased dramatically in the months following the decision. The May decision simply established that glyphosate was "probably carcinogenic" and that it was no longer going to be used in aerial eradication operations, effective October 2015.

That same month I moved to Cali to be closer to the Pacific region. Cali is an important city for the southwestern Pacific region because it is the only city where one can catch a flight or bus to the municipalities -Buenaventura, Tumaco, or Guapi- I endeavored to visit. Cali also boasts a large population of Afro-descendant Colombians from the Pacific and is sometimes referred to as the de facto capital of the Pacific region

\footnotetext{
${ }^{31}$ I posted the video $<$ https://contestednatures.com/guapi-cauca-ii/> on my dissertation website, which I discuss in further detail later in this chapter.
} 
(Arboleda 1998; Agier et. al 2000). Many PCN leaders regularly pass through to visit family or on their way to other destinations. In Cali I conducted multiple interviews, attended the Petronio Álvarez festival ${ }^{32}$, traveled to Buenaventura by bus three times, flew to Guapi two more times, and attended a PCN workshop in Piendamó, Cauca. I also met a lawyer working on a collective action suit against DIRAN and made several trips to Popayán, Cauca to conduct research on the case (explained below).

\section{Conducting Qualitative Research in the Pacific Region}

I followed the same protocol for conducting qualitative research in the Pacific region (semi-structured, digitally recorded interviews) as I did in Bogotá except that I had more opportunities to observe meetings and events. I also made a concerted effort to visually document my visits as often as possible. I normally request to take photos of my interviewees as a way to remember them and where I interviewed them. The vast majority of interviews in the Pacific were one-on-one. At the end of most interviews I would ask the interviewee if they had any questions or suggestions for myself. A few interviewees commented that it is important that I convey to my audience how beautiful the Pacific is and why it is such a shame that many parts of it were being damaged by

\footnotetext{
${ }^{32}$ The Petronio Álvarez festival, named after a legendary musician from an island near Buenaventura, is a weeklong celebration of Afro-Pacific culture that has grown in size every year since it began twenty years ago. In 2016, festival organizers expected an average of 60,000 attendees per day $<\mathrm{http}: / / \mathrm{www}$.elpais.com.co/elpais/cultura /noticias/festival-petronio-alvarez-cambiara-escenario $>$. There are dozens of food, liquor, and artisanal stands than line the entrance before one even makes it to the main stage where 60-100 musical groups compete every year in a number of Afro-Pacific genres. After weeks of trying to schedule an interview, I was finally able to meet PCN leader Yolanda García at the festival. I recorded our interview in front of her friend's liquor stand while a band played in the background. In between questions and shots of viche and arrechón, Yolanda introduced me to other people I could interview.
} 
aerial eradication. To this end, I have made a point of including photos and videos of my fieldwork visits in presentations and papers as well as this dissertation.

I also conducted several group interviews in the Afro-Pacific with multiple sets of farmers and a group of displaced women (described later in this chapter). Farmers often work together to cultivate their lots with the help of peones (hired farm hands) so the group interviews not only documented the oral histories of these farms but also the interpersonal dynamics of the personalities involved. In the group interview format I tried to have a conversation rather than stick to pre-written questions. Inevitably one or two people would dominate the conversation so I would interject and solicit the opinions of the more quiet participants from time to time.

On one of my trips to Río Calima, Buenaventura I brought along a friend from the U.S. who took photographs and recorded video of my interviews. Similar to what I recorded in Guapi, these videos captured the humility and the frustration of the interviewees $^{33}$. One farmer explained that his lot had never been sprayed but that, nonetheless, beetles from fumigated areas had migrated to his farm and damaged his chontaduro (peach palm) harvest ${ }^{34}$. While multiple farmers had complained about this same phenomenon, this particular farmer informed me that a local research group was about to investigate his claim ${ }^{35}$. As a continuation of this narrative I interviewed women

\footnotetext{
${ }^{33}$ I posted an interview with a community resident here: $<$ https://contestednatures $</$ bajocalima/s.

${ }^{34}$ I posted the video of this visit here: $<$ https://contestednatures.com/el-chontaduropeach-palm/>.

${ }^{35}$ I am not sure, however, whether this research was ever conducted as the aerial eradication program was terminated three months later.
} 
that sell chontaduro on the streets of Cali about recent changes in the supply and price of the fruit. From my perspective, this was just one of a number of different theories about the effects of aerial eradication -some believable, some far-fetched - that I was told while conducting fieldwork. I was more interested in finding out how such allegations originated versus assessing the validity of these claims. I was also very much interested in how these types of claims were interpreted and addressed by aerial eradication authorities. I further discuss these allegations in Chapter 6, which relate to ideas about knowledge production developed in Chapter 3.

\section{Visits to Aerially-Fumigated Farms}

I visited three lots that had been aerially fumigated in Guapi, one that had been sprayed one week prior, one that had been sprayed a month prior, and one that had been sprayed three months prior. Each visit started with a lengthy wait at the boat dock in Guapi while my guide for the day searched for a boat pilot willing to take us to the farm lots. The first trip took place late in the day at a time when most men were done with the day's work. Thus, I was invited to drink multiple shots of Aguardiente Caucano, the local brand of sugarcane-derived firewater, while I chatted with my new acquaintances hanging out at the docks. The lanchas (boats) I travelled in were narrow fishing boats, resembling large canoes, equipped with outboard motors.

The first stop on every trip was the floating gasoline station, about a quarter mile from the docks, where I would provide enough money to cover each trip. The three farm lots I visited were each within thirty minutes of Guapi, which I thought was reasonable because gas was very expensive and I was unsure how safe it was to travel much further away from the main town. After turning off the main river onto tributaries, the second 
stop on each visit was to pick up the farmers at their respective homes. The homes I visited were constructed of wooden planks with corrugated metal sheets as roofing. Whether on the shore or inland, homes usually sat a few to several feet above ground to protect each home from rising tides as well as flooding from the heavy rainfall. It was fairly common to see people bathing near their homes and chickens roaming freely, picking at the trash that collects on the shore. The farms I visited were on average 20-25 minutes away from the farmers' homes by motorboat.

Visiting each farm lot involved putting on rubber boots and trudging through muddy ground in intense heat while the farmers cleared the path with a machete. I conducted interviews while recording video with one hand and swatting insects as well as wiping my sweat with the other hand. At one point I made the mistake of stepping on soft ground and sunk into the mud all the way up to the top of my legs. I had to be pulled out of the mud by my concerned/amused farmer guides. I was exhausted after these visits and could only imagine how difficult it must be to work under those conditions.

In the case of the farm that had been sprayed three months prior, it appeared that the aerial eradication spray did not affect every plant the same way. The most striking evidence of aerial eradication spraying was the dead palm leaves of plantain trees. However, the rest of the lot was quite green with foliage growing between the dying trees. Samuel, a soft-spoken farmer with a lean physique and greying hair, explained that this lot had been sprayed several times and that he had also lost rice, papa china (white taro root), and colino (small cabbage) ${ }^{36}$. From my perspective, it was difficult to see

\footnotetext{
${ }^{36}$ Author interview with Samuel Segura at his farm in El Penitente near Guapi, Cauca on July 19, 2015.
} 
everything that had been damaged because the crops he specifically named grow underneath or at the surface of the soil. Most of the green plants in the lot were quite small, which left me with the impression that this was new foliage that had grown since the last round of fumigation. I wondered how damaged the soil was if new plants were growing so quickly but I later learned that farmers dedicated much time, money and energy to clearing out unwanted foliage.

In the case of the farm that had been sprayed one week prior to my visit, I felt a sense of despair as I surveyed the lot. Most of the vegetation was dead with the exception of the occasional tree or plant. At the same time it was difficult to gauge how the spray affected each individual crop. The farmers who cultivated this plot had hired peones (laborers) to clean out the plants that had already been ruined, which added to the stark appearance of their farm ${ }^{37}$. These gentlemen commented that they had chosen to cut their losses because the spray singed most of the crops and they simply did not trust that any remaining crops would not be contaminated ${ }^{38}$ (this visit is further discussed in Chapter 5).

The pain in the farmers' faces and voices also let me know how heartbreaking it was to lose their crops so easily without explanation. While proponents of aerial eradication might argue that the effects of the spray are minimal, I found it very telling that all of farmers I had spoken with had given up on the sprayed crops. With little hope

\footnotetext{
${ }^{37}$ I posted the video of this visits here: $<$ https://contestednatures.com/guapi-cauca/>.

${ }^{38}$ Author interview with Juan Alturo, Adolfo Sánchez, Tulio Montaño, and Teodoro Montaño on their farm in Temuey, Guapi on July 20, 2015.
} 
of receiving restitution for the damages (discussed in Chapters 4 \& 5), these gentlemen pursued this strategy rather than trying to consume or sell the sprayed crops.

\section{Researching a Court Case}

About midway through 2015 one interviewee, from a community affected by aerial eradication, repeatedly suggested that I meet a lawyer that represented his community for the damages caused by the opening of a dam many years ago. The lawyer is currently representing seven communities (roughly 40,000 people), half of which were in Afro-descendant territories (in Guapi and Timbiquí), in a class action suit against DIRAN for the unjust aerial eradication of farm lots, homes, and waterways. I initially met with the lawyer, who resides in Cali, to learn more about the case and to see if I could assist him in anyway. He was working with Earth Economics, an NGO that uses econometrics to win restitution for environmental damages caused to vulnerable populations, and had put together an academic team from La Universidad del Cauca (UniCauca) to work on the case. He was interested in meeting me because the UniCauca team lacked a geographer and he wanted to find out whether I had any insights on the case. After a few conversations with him in Cali we visited Popayán, the capital of Cauca and the location of the courthouse holding the evidence, on three separate occasions. The judge granted me access to all thirty boxes of evidence and I eventually met the rest of the academic team. I revised the evidence and offered suggestions about what additional information to request from DIRAN. I was also debriefed about what had been accomplished in the case so far and I explained how maps could be useful to the case. I met with the lawyer a few more times to discuss strategy and recorded our conversations to get a better sense of the trajectory of this case, which had already been going on for 
years. I am still in contact with him and he might call upon me to create maps for the case at some point ${ }^{39}$. I cannot share evidence from the case in any publications until six months after the court case has ended.

This was an amazing experience for a number of reasons but chiefly the personal satisfaction of putting my research to good use $\mathrm{s}^{40}$. The evidence contained correspondences between the legal team and various Colombian institutions that denied culpability for a variety of reasons. It also contained the flight logs of the aerial eradication pilots, which had spaces for signatures from various departmental and municipal authorities. There were pages and pages of residents' individual damage claims, photos of damages, as well as reports from local universities and organizations chronicling the effects of aerial eradication. Lastly, and perhaps most importantly, the lawyer's arguments for seeking restitution and process for calculating restitution were different than the earlier case I mentioned. In researching the case I also learned how communities are transformed by both the complaint and restitution processes (discussed in Chapter 4).

\section{Thinking Reflexively about Fieldwork}

Thinking reflexively about this research entails considering how my research affected and was effected by the people I interviewed and the information I collected in

\footnotetext{
${ }^{39}$ I have been receiving updates on the case every so often and have asked to participate in meetings with the UniCauca team through Skype.

${ }^{40}$ While some might consider this experience a form of activist research, it is interesting to note that the other academic researchers involved in this project did not ascribe such a description to this project. The experience thus highlighted a major difference I have noticed between academia in Latin America versus the U.S.; in Latin America applied social science is much more common than it is in the U.S.
} 
the field. In the first place, I must address how fieldwork impacted my preconceived notions about the aerial eradication program. Having conducted interviews at U.S. Southern Command in Miami, Florida, I had some very positive experiences talking with military officers despite my personal convictions about the role of the U.S. military in Latin America. I approached my interviews with Colombian and U.S. government officials, therefore, with the similar sense that I might enjoy the conversation but disagree with the politics that informed the responses. Li (2007) emphasizes the power of assuming positive intent in her own research on development projects in Southeast Asia. In her writing she substitutes the highly stigmatized term 'development' for the 'will to improve' in order to keep things "messy" and not fall into the trap of viewing the world from a binary perspective of winners versus losers, government versus subjects...etc. After several interviews with government officials I had a much deeper appreciation for the practical reasons why aerial eradication was favored over manual eradication (discussed in Chapter 5). I also appreciated the sincerity of my interviewees, many of who were in positions of power and openly questioned the effectiveness and repercussions of forced eradication strategies.

After the first time I spoke with Mr. Walter of the INL, I noticed that he continually corrected me about using the term 'aerial fumigation' and that he preferred the term 'aerial eradication'. Though I never had used the term before, I felt that 'aerial eradication' was a fairer way to describe this particular counternarcotics strategy and have used this term in my writing ever since. On the one hand, 'aerial fumigation' can be confusing because it also refers to the more common practice of fumigating crops for pest control. On the other hand, 'aerial eradication' more specifically refers to the objective 
sought by this strategy, which is the eradication of illicit crops. The conscious decision to use the term 'aerial eradication', therefore, at least assumes a measure of positive intent in the spirit of the 'will to improve' (Li 2007). I should also point out, however, that I never heard anyone say 'aerial eradication' in Spanish as people in Bogotá preferred aspersion aérea (aerial spraying) and people in the Pacific often referred to it as $l a$ fumiga (a more colloquial expression for 'fumigation').

In terms of how my presence affected my interviewees in Bogotá, I suspect that my line of questioning did not impact anyone's personal opinion of the aerial eradication program but that I did perhaps contribute to the general feeling of uneasiness about the program's future. Part of this can be attributed to the timing of my fieldwork because numerous communities and organizations, including FARC during the most recent round of peace negotiations in Havana, have actively campaigned against aerial eradication. Another part of this can be attributed to the gradual turnover of the aerial eradication program from a U.S.-financed-and-controlled operation to a 'Colombian program' (discussed in Chapter 4). Thus for Colombian officials, my questions resonated with preexisting concerns about whether aerial eradication should be conducted at all. Whereas for U.S. INL officials, I had the impression that their hesitation to speak with me stemmed from the concern that more negative press could further tilt the balance of public opinion about the program and eventually lead to its termination. This concern was certainly warranted as the aerial eradication program was terminated within two months of my interview with $\mathrm{INL}^{41}$.

\footnotetext{
${ }^{41}$ Though once again, I am not implying that my fieldwork had any impact on the decision to terminate the program.
} 
In contrast to my apprehension about the merits of the aerial eradication program, I began fieldwork with a great deal of empathy for the communities affected by this strategy. While some government officials also expressed a similar empathetic stance towards affected communities, other officials appeared more interested in refuting the complaints lodged against the aerial eradication program. During interviews with affected residents I attempted to balance my empathetic stance by first presenting some of the arguments made in favor of aerial eradication. I prefaced these conversations by expressing sympathy and explaining the limits of my own understanding. These discussions featured a mix of acceptance of certain arguments and some strong rebuttals of other arguments. In pursuing this line of engagement, I believe that, in some instances, I expanded awareness of why aerial eradication was preferred over other approaches.

Many interviewees were noticeably, and understandably, hesitant to discuss their experiences with a stranger they had just met. As time passed I began to see the same people repeatedly and rely less on PCN leaders to facilitate interviews. Eventually local residents in Guapi and Buenaventura saw me enough at PCN events that I could approach them without asking someone to vouch for me first. In these instances I had a better opportunity to explain why I was conducting research before requesting an interview. For example, one particularly fiery gentleman resisted my first four requests before wanting to speak with me for over an hour. After the interview he facilitated three more interviews on my behalf. Another interviewee barely spoke to me for the first twenty minutes of our lunchtime interview, during which time I nervously rambled on about my research. After he finished his meal (and his blood sugar level was restored to normal) he answered my questions for long stretches at a time without pause. 
In all interviews I had to be careful about the types of questions I asked, especially if the interviews were conducted in public spaces. The few interviews with farmers that cultivated coca were conducted in private spaces and I did not request to take their picture. I generally avoided questions about the presence of armed groups unless the interviewee seemed open to sharing such details. This has been true of my experiences in Colombia in general, whether talking with friends or conducting interviews, so I was particularly sensitive to the lines of questioning that can make people uncomfortable.

I struggled with the decision to post the videos of interviews and visits recorded in the field online as I was concerned that doing so might put the participants in danger. Wondering if this was the case, I asked all of the participants in the videos and the PCN leaders that facilitated these interviews how they felt about this. All responded positively about having the stories published online, especially in consideration of the pending decision about the fate of the aerial eradication program. I had an opportunity to share two of the four videos with the participants while still in the field and they were very pleased with the final cut of their respective videos. I initially posted all of the videos on Youtube and eventually posted them on my research website. On the one hand, I created the website because I selfishly felt it was important to highlight some of my research in an easy-to-digest format. On the other hand, I did so knowing that if the aerial eradication program should return some day my website could be useful ${ }^{42}$.

\footnotetext{
${ }^{42}$ This is certainly a possibility, which I will discuss in further detail in the concluding chapter of the dissertation.
} 


\section{Challenges \& Limitations of the Qualitative Data}

Table 2.2 summarizes the affiliations of the interviewees I spoke with during dissertation fieldwork:

Table 2.2 - Affiliations of Interviewees

\begin{tabular}{|c|c|}
\hline Public Institutions & Critics of Aerial Eradication \\
\hline $\begin{array}{l}\text { Colombian Government: The National } \\
\text { Council on Narcotics (CNE), The Ministry of } \\
\text { Justice, The Ministry of the Interior, La } \\
\text { Defensoría del Pueblo (The Denartment of }\end{array}$ & $\begin{array}{l}\text { Local: Residents, Farmers, Community } \\
\text { Council Members, Vendors of } \\
\text { Agricultural Products }\end{array}$ \\
\hline $\begin{array}{l}\text { Advocacy for the People), The Institute of } \\
\text { Rural Development (INCODER) }\end{array}$ & $\begin{array}{l}\text { Local Representation: Clergy, } \\
\text { Ombudsman (Personero), Lawyers }\end{array}$ \\
\hline The Counternarcotics Police (DIRAN) & \multirow{2}{*}{$\begin{array}{l}\text { Afro-descendant Organizations: The } \\
\text { Process of Black Communities (PCN), } \\
\text { National Association of Displaced Afro } \\
\text { Colombians (AFRODES), National } \\
\text { Cimarrón Movement (CIMARRÓN), } \\
\text { Association Mano Negra } \\
\text { (ASOMANONEGRA), Afro Cultural } \\
\text { Activities Foundation (ACUA) }\end{array}$} \\
\hline $\begin{array}{l}\text { United Nations Office on Drugs and Crime } \\
\text { (UNODC): The Integrated Illicit Crops } \\
\text { Monitoring System (Project SIMCI), Office } \\
\text { on Alternative Development, Manual } \\
\text { Eradication Monitor }\end{array}$ & \\
\hline $\begin{array}{l}\text { Regional Government: Corporación } \\
\text { Autónoma Regional del Cauca (CRC) }\end{array}$ & \multirow{3}{*}{$\begin{array}{l}\text { NGOs: Transnational Institute (TNI), } \\
\text { Grupo Semillas, Earth Economics, The } \\
\text { Interamerican Association for } \\
\text { Environmental Defense (AIDA), The } \\
\text { Association of Producers and } \\
\text { Commercial Entrepreneurs of the Pacific } \\
\text { (ASPROPACÍFICO) }\end{array}$} \\
\hline $\begin{array}{l}\text { Academic Institutions: La Universidad de los } \\
\text { Andes (UniAndes), La Universidad del } \\
\text { Cauca (UniCauca), The National Geographic } \\
\text { Institute Agustín Codazzi (IGAC) }\end{array}$ & \\
\hline $\begin{array}{l}\text { U.S.: Bureau of International Narcotics and } \\
\text { Law Enforcement Affairs (INL) }\end{array}$ & \\
\hline
\end{tabular}

The above list should not be read as 'those in favor of aerial eradication' versus 'those against it'. Though there was not anybody necessarily in favor of aerial eradication in the right column, there were plenty of people that questioned the merits of the strategy in the public institutions listed on the left. 
The vast majority of interviewees for this project were educated males between the ages of 18 to 65 years old. I had the opportunity to speak with women in various institutions (SIMCI, INL, UniAndes, IGAC) in the left column but, as explained above, white males that attended elite universities dominate government institutions in Colombia. While I do believe I spoke with some extremely important officials, I had limited access to people integral to the conduct of the program. This is especially true for DIRAN, the main institution involved in the conduct of aerial eradication. The one officer I was able to interview, the Director of the Detection of Illicit Crops Unit, was extremely generous with his time in our interview and subsequently answered most of my follow-up questions via email. He was also the only DIRAN officer willing to talk to me and, as I was later informed, the most relatable person to talk to from the institution ${ }^{43}$. After speaking with the former Director of the CNE, I reached out to the current director multiple times to no avail. Similarly, I interviewed the former Director of Previous Consultation but was never able to speak with the current director. I endeavored to speak with aerial eradication pilots but never successfully tracked any down ${ }^{44}$.

Another challenge I encountered in discussing the aerial eradication program is that it was difficult to differentiate current practices from past practices. Many of the changes implemented in the program never materialized in the public record. For

\footnotetext{
${ }^{43}$ Daniel Mejía, professor at UniAndes, explained that Lieutenant Colonel Tunjano was an agronomist by training and therefore considerably friendlier to academics than some of his colleagues at DIRAN.

${ }^{44}$ I am still interested in conducting interviews with former pilots and learned that many retire in Ecuador. I will attempt to conduct these interviews on my next trip to Colombia, hopefully in 2017.
} 
instance, I was very curious about the prevalence of 'dumping', when aerial eradication planes dumped their chemical cargo while under attack ${ }^{45}$, because I believed it partially explained why so many lots without coca were being sprayed. I learned that, for a variety of reasons, this was a very rare occurrence in the last five years, however, the terms of the decision to remedy this problem were classified (discussed in Chapter 6 "Insecurities").

Colombian government officials were very open when speaking to me about aerial eradication, even in circumstances when other officials would later contradict the facts I had been given. In contrast, INL officials were extremely guarded about what was said in our interview. They went so far as to request and subsequently edit the notes I had taken (without a digital recorder) to guarantee the accuracy of what I had documented. I obliged their request though I also kept a separate copy of my original notes. Most of the edits involved word choices, such as replacing 'aerial fumigation' with 'aerial eradication'.

The interviews conducted with residents of the Afro-Pacific presented one of the same limitations. In the right column of the table the vast majority of interviewees affected by aerial eradication and their representation were also male. In the Afro-Pacific males farm most agricultural products with the exception of rice. I was constantly referred to males in the course of scheduling interviews and made it a point to request interviews with women once I noticed a pattern developing. While local representation in community councils was also male-dominated, there are a few women's organizations in

45 The FARC are credited with the bulk of these attacks, as one of the few armed groups with the weaponry to shoot down aircraft from the ground. Author interview with Lieutenant Colonel Miguel Tunjano Villaraga, in charge of aerial eradication detection group, conducted at Hotel Tequendama in Bogotá on May 8, 2015. 
the Pacific that espouse an alternative politics of black social movements ${ }^{46}$. I conducted a group interview with one such organization for displaced women, the ACUA Foundation, which is led by renowned black women activist Teofila Betancourt. Unfortunately the interview was not very informative because the participants were new to the group and very shy, causing Teofila to reluctantly dominate the conversation. I was unable to schedule an interview with a group of concheras (women shellfish collectors) despite multiple attempts to do so. Feeling as though I was missing an opportunity to meet with another women's organization, I asked Yolanda García of ASOMANOSNEGRA some direct questions about how aerial eradication impacted women's lives. Yolanda's responses were extremely insightful but, moving forward, I have a better sense of which organizations to contact and how a future project in the field will provide better gender balance (discussed in the next section).

Aside from this issue, interviews conducted in the Afro-Pacific presented an entirely new set of challenges from Bogotá. Initially, I had no idea whether people were being honest about: whether they did or did not grow coca, whether the spraying occurred as they described it, whether the spraying occurred when they described it, and whether the spraying caused the problems they attributed to it. I was able to verify that many of these communities had been fumigated through interviews with other residents of the same region and/or through other sources such as the aerial eradication flight logs from

\footnotetext{
${ }^{46}$ Both Asher (2009) and Oslender (2016b) discuss some of these organizations in their respective publications. Asher specifically details how women's contributions to mainstream black organizations such as PCN and COCOCAUCA have been underappreciated and how alternative women's organizations have developed their own understandings of and goals for black social movements in the Pacific (2009, pp.130153).
} 
the court case and mapping data provided by the UNODC. In other cases, some of the claims made about aerial eradication seemed far-fetched. For instance, some residents went so far as to blame aerial eradication for the chinkunguña virus outbreak throughout the country ${ }^{47}$. Given the wide range of theories about why aerial eradication was occurring and what it was causing, I was more interested in finding out how each community dealt with the circumstances. Often times dealing with the circumstances, however, involved addressing the presence of neighbors or armed actors that were not mentioned in interviews. To address these silences I followed up with people from neighboring communities and searched for news articles via the internet.

Another limitation of working in the Afro-Pacific was local politics, particularly in Guapi. I arrived at a time when PCN was at odds with another Afro-descendant organization, COCOCAUCA. I fully intended to interview people from both organizations but quickly realized that I would have to choose a side or risk being alienated by both ${ }^{48}$. Some community councils in Guapi are split between these two groups, which means that they have two overlapping sets of representatives at odds with

${ }^{47}$ Chinkunguña is a viral disease transmitted by the same mosquitos (Aedes aegypti or Aedes albopictus) that carry dengue. The symptoms are quite similar to dengue (fever and arthritis in joints) although there are no fatal strains of chinkunguña. The virus is believed to have originated in Africa, however, the current outbreak in Latin America has inspired a wide variety of myths about its origins. The Colombian Ministry of Health has an entire webpage dedicated to refuting these 'urban myths', which include "chinkunguña is not transmitted by particles suspended in air" $<$ https://www.minsalud.gov.co/paginas/Losmitos-urbanos-sobre-el-virus-del-chikunguña-.aspx $>$, perhaps a reference to myths about chinkunguña being a product of aerial eradication.

${ }^{48}$ Having not spent enough time in Guapi to fully understand the dynamics of local politics, I will abstain from elaborating further on this particular conflict. Oslender (2015; 2016 b) provides some insight on this situation, dating back to his own dissertation fieldwork in Guapi. 
each other and making different decisions against the will of the other group. The difficult decision to work with PCN was made easier by the fact that I had already developed a rapport with people in the organization and it serves the entire Pacific region, whereas COCOCAUCA's focus is the Pacific Coast of the Department of Cauca.

As result of my connections this research project presents an "Afro-Pacific perspective" grounded in PCN-thinking. Interview questions about some of the key themes of the project - territory, biodiversity, and security — elicited similar responses throughout the Afro-Pacific and echoed what I had previously read in the writings of Arturo Escobar, who has also worked mostly with PCN leaders (1998; 2006; 2008). At times this made it difficult to distinguish between opinions molded by the PCN versus an interviewee's opinion, independent of PCN. As Sayer explains, "It is not merely that beliefs are shaped by others, but that they are constructed in terms of intersubjectivelyavailable meaning" (1992, p.32). Thus it should not have been surprising to hear many similar responses because PCN prides itself on building consensus around the key themes of this project as well as how to address difficult issues that communities share in common. To be clear, however, PCN members and their supporters reject the notion that the organization has an official philosophy or that all members think the same way. As the name 'Process of Black Communities' suggests, the organization is foremost about the process in which communities are developed. PCN leader José Santos Caicedo emphasized that this process should be egalitarian and is constantly shaped by the diversity of opinions of the organization's constituents and supporters ${ }^{49}$.

\footnotetext{
${ }^{49}$ Author conversation with José Santos Caicedo at PCN office in Bogotá on March 5, 2015.
} 
A major challenge, therefore, in conducting fieldwork in the Afro-Pacific was to identify interviewees willing to share their thoughts on these more divisive topics. While aerial eradication was almost universally criticized in my interviews, the cultivation of coca was the subject of intense debates that challenged my own understandings of what territory and biodiversity mean to the PCN. As Benford describes in his discussion of social movements, researchers have a "tendency to focus on the framings of movement elites to the neglect of rank-and-file participants, potential recruits, bystanders, and others" (1997, p.421). This was certainly true of my experience as I initially gravitated towards interviewees I understood the best, which were often more educated and more involved in PCN leadership. In the first place I had trouble understanding some accents and colloquialisms. In the second place PCN leaders and community council representatives were more comfortable speaking with outsiders than those without previous experience doing so. Therefore, in the beginning of fieldwork in the Pacific, I mostly spoke with PCN leaders who left me with the impression that the entire organization was opposed to the cultivation of coca. Benford refers to this as the 'reification problem' in which social movements are conceptualized by their collective framing of issues to the detriment of consideration of human agency (ibid., p.418). Gradually, through persistence, repeatedly showing my face at PCN functions and securing more interviews with everyday people not involved in PCN leadership, I met farmers that grew coca themselves and a few community council representatives with alternative views on the subject.

At the end of my fieldwork I was delighted to be the first person to inform my PCN contacts that the aerial eradication program had been terminated. However, this 
sense of relief was tempered by the fact that aerial eradication was just one of a number of problems compromising black territoriality (discussed in Chapters 4-6).

\section{Processing Qualitative Data}

I transcribed the vast majority of these interviews in the field in case I had any follow-up questions. Within the text of the transcriptions I highlighted difficult-tounderstand segments (mostly because of pronunciation and sometimes because of background noise). When I moved to Cali later in the year I had a friend revise the accuracy of the transcriptions. I completed the remaining transcriptions within a month of returning home from the field. I spent another month analyzing the transcriptions and color coding quotes from interviewees according to the three central themes of this dissertation: how Colombian territoriality and aerial eradication impacted the conceptualization of black territory (Chapter 4); the security-related justifications for aerial eradication and the insecurities that aerial eradication exacerbated in black communities (Chapter 5); how both coca cultivation and aerial eradication were conceptualized as external impositions on black territory through a political ecology of difference that challenged the justification of aerial eradication as a form of environmental conservation (Chapter 6). I then compiled those quotes into separate Word documents, which I then placed into the outlines I developed for each of those chapters.

I also edited four videos recorded in the field, which I initially recorded so that alternative narratives about aerial eradication — different from what one might encounter on the Colombian news or press releases from the U.S. or Colombian governmentscould be disseminated through social media. However, approximately ten days before my scheduled flight to return home, I learned that the aerial eradication program would be 
terminated the very same day of my flight. I then edited the videos with the intention of utilizing them in presentations/conferences. Thus far I presented two of the videos at an academic conference on the Colombian peace negotiations, Desafios Para la Paz, at the University of Toronto (October 2-3, 2015). I uploaded all of the videos and some of the maps I have created on my research website $<$ contestednatures.com $>$. The site also provides a bilingual synopsis of my dissertation for people interested in my research.

\section{Analyzing, Collecting \& Mapping Geospatial Data}

In the empirical chapters of this dissertation I analyze official mappings of security, biodiversity, and territoriality to highlight how the aerial eradication program had been justified in Colombia. Utilizing official data I then present some of my own maps to create alternative narratives about these topics. The Geographic Information Systems (GIS) program that I used to create maps for this project is ArcGis by Esri.

The timeframe for the geospatial data collected in this study is $2000-2015$ because aerial eradication became the principal strategy to eradicate illicit crops -primarily coca and to a much lesser extent, opium poppies - with the implementation of Plan Colombia in 2000 and because the aerial eradication program ended in 2015. I chose to solely focus on the eradication of coca because it is the main illicit crop in Colombia and the focus of U.S.-supported counternarcotics efforts. I also made this decision because of my interest in the Afro-Pacific, most of which is at lower altitudes not suitable for opium poppy cultivation.

The majority of the data was collected through personal requests made to UNODC, IGAC, and INCODER once I established relationships with people in these respective offices. I had, however, actually begun searching for whatever data Colombian 
government institutions made available online beginning in 2012. It was fortuitous to have begun data collection so early because the most important variable, aerial eradication, was available in spreadsheet format from the UNODC in 2014 but was subsequently removed from their website in 2015 .

The geospatial data collected in this project can be categorized in a number of ways. In terms of the presentation of information, however, the most important distinction is data collected in shapefile format versus data collected in spreadsheet format. A shapefile is a "vector data storage format for storing the location, shape, and attributes of geographic features" (ArcGIS Online). To begin mapping aerial eradication in Colombia I first obtained shapefiles of the two primary political divisions in Colombia: departments (there are 32 total, excluding Bogotá which is its own district) and municipalities (there are approximately 1,120). It should be noted again that municipalities are not cities but more akin to counties in the U.S. as they include both urban and rural spaces. While most of the data collected for this project is in shapefile format, a number of key variables are only available in spreadsheet format. The municipality shapefiles (smaller and much more numerous than department shapefiles) are the better container for the data only available in spreadsheet format. All of the spreadsheet data collected in this project is municipal data. Table 2.3 lists each principal variable, its format, and the data source:

Table 3.1: Geospatial Data

\begin{tabular}{|c|l|l|l|l|l|l|}
\hline $\begin{array}{c}\text { Principal } \\
\text { Variables }\end{array}$ & $\begin{array}{l}\text { Aerial } \\
\text { Eradication } \\
\text { (hectares) }\end{array}$ & $\begin{array}{l}\text { Coca } \\
\text { Cultivation } \\
\text { (shapefiles) }\end{array}$ & $\begin{array}{l}\text { Manual } \\
\text { Eradication } \\
\text { (shapefiles) }\end{array}$ & $\begin{array}{l}\text { Afro } \\
\text { Territories } \\
\text { (shapefiles) }\end{array}$ & $\begin{array}{l}\text { Indigenous } \\
\text { Reserves } \\
\text { (shapefiles) }\end{array}$ & $\begin{array}{l}\text { Armed } \\
\text { Groups } \\
\text { (\# of } \\
\text { actions) }\end{array}$ \\
\hline Source & UNODC & UNODC & UNODC & INCODER & INCODER & $\begin{array}{l}\text { V.P. of } \\
\text { Republic }\end{array}$ \\
\hline
\end{tabular}


Other prominent variables featured in these maps include: alternative development projects (UNDOC), explosive mine casualties $\left(\right.$ PAICMA $^{50}$ ), typology of violence $\left(\right.$ CERAC $^{51}$ ), national parks (IGAC), basic needs unmet (IGAC), topography (IGAC), paved roads (IGAC), and waterways (IGAC).

The most important variable listed in the table above is hectares of aerial eradication per municipality. Though I requested the data from DIRAN, they would not release the shapefiles (flight paths) of the aerial eradication missions ${ }^{52}$. So the maps I have created do not show the exact locations aerially sprayed, rather they show the total amount of hectares of aerial eradication per municipality where it was conducted.

The second most important variable in the table above is coca cultivation, which I was able to collect in shapefile format at various scales of grillas. Grillas are pixelated squares that mark where coca was detected in satellite images. There are a number of reasons why DIRAN and the INL are distrustful of these representations of coca cultivation and one reason is that grillas are the metaphorical equivalent of rounding numbers to make calculations easier; they do not capture the exact location of where the coca was growing, rather they represent the approximate location. Nevertheless, the grillas provide an idea of the location and amount of coca cultivation in comparison to aerial eradication and other variables.

\footnotetext{
${ }^{50}$ Program for Integrated Action Against Anti-personal Mines

${ }^{51}$ Conflict Analysis Resource Center

${ }^{52}$ DIRAN would not release the shapefiles as these files could have been used in a court case against DIRAN.
} 
I requested the shapefiles of Afro-descendant and indigenous territories on a yearby-year basis. This means that I can chart the growth of ethnic territories every year since they began being established and at the same time map other variables on a year-by-year basis. For instance, I can compare the presence of ethnic territories, coca cultivation, and aerial eradication in 2001 versus 2011 or create an animated map in Graphics Interchange Format (GIF) of the same variables for every year from 2001 to 2011. Such comparisons are useful for demonstrating how coca cultivation and subsequent aerial eradication have increasingly shifted into ethnic territories in recent years.

\section{Limitations of Geospatial Data}

In this section I will discuss some of the main limitations of the geospatial data employed in this study. In each empirical chapter I will address other limitations that specifically pertain to the individual maps presented in those chapters.

I had originally proposed comparing maps of where aerial eradication was conducted in Colombia versus maps (that I would have created) of where aerial eradication should have been conducted according to aerial eradication guidelines. The main reason that I never followed through with the aforementioned comparison is that I could not gain access to the shapefiles of aerial eradication. A secondary reason is that even if I did gain access to those shapefiles, such maps would not necessarily reflect an accurate portrayal of what was aerially eradicated. The satellite images of coca fields processed by UNODC were normally recorded once a year (with some exceptions that are explained in a later chapter). UNDOC publishes these images to report increases or decreases in illicit crop cultivation in comparison to previous years. This means that between the newest image and the previous image, a duration of one year, new coca 
fields could have appeared or disappeared without showing up in these official images. Therefore my original idea ran the risk of unfairly judging the legality of aerial eradication missions without access to the correct data.

The data on alternative development and manual eradication is also incomplete, but for different reasons. The UNODC alternative development shapefiles do not distinguish between the different types of programs offered every year, which is important as some programs are oriented towards the substitution of illicit crops and some are not. Furthermore, the UNODC shapefiles only reflect alternative development programs conducted through Colombian government institutions and the United States Agency for International Development

(USAID). There are numerous other alternative development projects happening in Colombia that are not represented in these shapefiles. The same is true of manual eradication as the UNDOC only tracks involuntary manual eradication and not voluntary manual eradication efforts.

Finally there are a number of variables in this study for which data were only available for a specific year or a specific set of years. A major challenge, therefore, in the creation of maps is choosing which year(s) to map and then providing a justification for solely focusing on that time period.

\section{Thinking Collaboratively Moving Forward}

Though my initial aspirations to conduct a collaborative mapping project were unrealistic, I eventually made enough connections to suggest some collaborative work in the future. One idea that I have already shared with PCN leaders -José Santos Caicedo (Bogotá), Gerardo Orobio Bazán (Guapi), Mario Angulo (Buenaventura), and Charo 
Mina-Rojas (Cali) — as well as with academics -Arturo Escobar and Ulrich Oslenderis to conduct a project to document some of the other issues that continue to compromise black territoriality (e.g., coca cultivation, industrial mining projects conducted without permission, and the local impacts of megaprojects such as the expansion of the port of Buenaventura) that are largely ignored by Colombian and international media outlets.

This idea was inspired by two experiences I had in the field. The first experience was a visit to Río Cajambre near Buenaventura with my friend Bayeté Ross Smith, a professional photographer interested in the African diaspora in the Americas, who took photographs and recorded a video of our visit ${ }^{53}$. He suggested a return trip to the Pacific region in 2017 in which photos could be exhibited at art galleries to raise awareness and money for whatever cause the PCN saw fit. The second experience was a PCN workshop I attended, Encuentro AfroPazifico ${ }^{54}$, where I had an opportunity to observe participants create maps of their communities as part of the presentation of the issues that each community was facing at the moment. During the activity I circulated about the room and had a chance to listen and participate in conversations about the issues and maps. This experience (described in further detail in Chapter 4) provided an interesting contrast to the high-tech digital maps I observed being produced in the offices of Project SIMCI. I then came up with an idea to use something that most people carry with them at all times, cellphones, to document whatever stories people wanted to tell (aspects of culture, problems in the community...etc.) and eventually embed these stories into a digital map of the Pacific region. The larger vision for this project, therefore, would be to combine

${ }^{53}$ Bayeté Ross Smith's work can be found at <http://www.bayeterosssmith.com/>.

${ }^{54}$ Encuentro AfroPazifico took place in Piendamó, Cauca on August 27-28, 2015. 
photovoice (Wang \& Burris 1997; Hergenrather et al. 2009) with GIS technology for a hybrid methodology that I am not sure anyone has employed to this point.

I must stress that this is merely an idea and not something that will be seriously pursued without the interest and collaboration of the PCN. Though some might consider this proposed idea a form of PAR, Oslender (2015) mentions some of the stigmas attached to this particular methodology that would probably not sit well with an organization that prides itself on leveling the power dynamics of its membership ${ }^{55}$. To make this project happen will require a great deal of more time in the Pacific so that the PCN and the communities they work with can mold this initial idea into something valuable to the participants. In this regard, this project would more likely become a product of the 'political ecology of difference' framework (Escobar 2008), which is discussed in the next chapter.

55 "Others may find a perceived hierarchy troubling, in which the external researcher as 'catalytic agent' seems to play a deterministic, possibly patronizing role" (Oslender 2015, p.70). 


\section{CHAPTER 3 \\ Conceptualizing Territory, Security, and Environmental Conservation through Difference}

The irony of history, and even more so of geography, is that the regions demarcated as units of conservation with limited use, almost always defined as such by conventional science, are exactly those regions because they have existed at the margins of the market and have been occupied by traditional populations with other matrices of knowledgeharboring the majority of the wealth in water and biodiversity on the planet (Porto-Gonçalves et al. 2012, p.25).

This chapter is largely about addressing this geographic irony by theorizing the deconstruction of dominant geographic narratives as well as the construction and recognition of alternative geographies. It is organized according to three fields -political geography, political ecology, and critical geopolitics - that correspond to the three empirical chapters of this dissertation -“Territorialities", "Contested Natures", and "Insecurities". A fourth and final section of the chapter, Critical and Constructive Cartographies, briefly overviews critical cartography and countermapping theory before explaining how maps are employed and theorized in this project.

Each section begins with a brief overview of some of the characteristics, trends and limitations of the respective theoretical fields followed by a discussion of the specific literature relevant to each empirical chapter. The intent behind the overviews is not to define the respective fields per se, but rather to signal the characteristics of these fields that resonate with the greater objectives of this dissertation. It also should be stated that these overviews are not meant to be exhaustive as this would be way beyond the scope of this dissertation. The first section presented is political geography because all of the fields and literatures engaged in this project can be subsumed under the broader category of 'political geography'. 
The territorial discussion begins with the theorization of territorial concepts in recent political geography scholarship. This first part of the discussion is meant to provide context for the second part of the discussion, the theorization of 'black territories' in Colombia. The entire territorial discussion is fundamental to this project because the theorization of territory continues throughout the rest of this dissertation. The political ecology discussion specifically addresses dominant ecological discourses that displace people and epistemologies from territory. It then transitions to an explanation of Escobar's 'political ecology of difference' framework, which is useful for not only deconstructing these discourses but also constructing different understandings of terms such as 'conservation' and 'biodiversity'. The critical geopolitics discussion examines how 'security' is articulated at the level of dominant geopolitical discourses and considers whether alternative forms of geopolitics are possible through the articulation of local security concerns.

\section{Discourses, Displacement, and Dispossession}

'Discourses' is a term employed often throughout the rest of this dissertation. For the purpose of this study, discourses refer to systems of thought composed from both textual and non-textual sources, including, but not limited to: field interviews, academic scholarship, reports, court documents, documentaries, statements, policy decisions, reactions, and silences. As Neumann argues, “...discourses are not simply a set of ideas. By defining categories and creating and limiting possibilities a discourse has historical, material consequences..." (2004, p.816). Discourse in this dissertation, therefore, is understood as "the process through which social reality inevitably comes into being" (Escobar 1996, p.46). 
'Displacement' in this dissertation connotes the physical movement of people (i.e., the forcible displacement of Colombians) discussed in the first two chapters as well as in the abstract sense (i.e., the displacement of knowledge or epistemologies). In choosing to use the word 'displacement' across these different contexts I am intentionally linking forcible displacement, a topic of considerable study in Colombia, to a more abstract discussion of 'technologies of displacement' that I develop later in this chapter and in subsequent chapters.

'Dispossession' is also a term frequently encountered in the pages that follow; however, it does not mean the same thing as 'displacement' in the context of this dissertation. Dispossession specifically refers to material losses in the form of land and/or resources commonly experienced by displaced persons or communities. Therefore, dispossession normally factors into but is not necessarily a precursor to forcible displacement. In this dissertation, the term dispossession is most often employed in Chapters $5 \& 6$ to describe PCN leaders' thoughts about aerial eradication as an 'instrument of dispossession.'

\section{Political Geography}

No different than other fields continuously shaped by new currents of social science thinking - postmodern, postcolonial, poststructural, feminist...etc.- there is some confusion about what it means to do political geography nowadays. For much of its history political geography has been about examining the political organization of states without questioning why or how the world came to be ordered in such a manner. However, these new currents of social science thinking have been transforming the field since the 1960s, raising the profile of the field while simultaneously complicating its 
definition (Agnew et al. 2003, pp.2-3). In describing 'contemporary political geography', political geographer John Agnew notes that the field is united by "a set of concepts and research questions" but divided by "theoretical and methodological differences over how to best define concepts and pursue research questions" (2003a, p.603).

In Blackwell's A Companion to Political Geography, Agnew, Mitchell, and Ó Tuathail approximate a definition of the field according to the topics that resonate with their understanding of political geography's past and its present trajectory:

For us, political geography is about how barriers between people and their political communities are put up and come down; how world orders based on different geographic organizing principles (such as empires, state systems, and ideological-material relationships) arise and collapse; and how material processes and political movements are re-making how we inhabit and imagine the "world political map" (2003,p.2).

Though it is quite lengthy, this definition is broad enough to encompass both old ways of understanding political geography without betraying the possibility for new understandings of the field.

The literatures presented in this dissertation conform to the above definition. This research project critiques the normalization of barriers, geographic organizing principles and imaginations of the "world political map" that defined political geography in the past, while attempting to integrate these critiques into new approaches to the field. However, rather than attempt to resolve the theoretical and methodological differences that make it difficult to explain what political geography $i s$, the literatures discussed in this chapter further contribute to the plurality or messiness of what political geography can be. 


\section{Theorizing the Territorialization of the Global South}

The theorization of territorial concepts is fundamental to this dissertation because black communities of the Pacific region of Colombia objected to aerial eradication, and continually object to the cultivation of coca in their communities, based on the notion that both practices are violations of their territorial rights. They thus articulate these objections as a 'defense of territory.' This position, however, is clearly compromised by external actors -INL, DIRAN, FARC, BACRIM...etc.- seeking to enforce their own territorial logics within the same space. This section first explores recent territorial conceptualizations in political geography scholarship before transitioning to a discussion of the theorization of 'black territory' in the Pacific region of Colombia.

In the last few decades oft-used terms such as 'territory' and 'territoriality' have been thoroughly re-conceptualized by political geographers frustrated that these terms have been taken for granted. Sassen explains, "In much scholarly writing, territory has largely ceased to work analytically because it has been reduced to a singular meaningnational-state territory" (2013, p.22). While Painter reasons, "It seems plausible to suggest that among critical human geographers the concept of territory may even have been seen as something of an embarrassment" (2010, p.1091). This frustration, combined with "increasing theoretical pluralism", eventually contributed to the recent wave of territorial scholarship that might be considered "something of a golden age of reflection on territory and territoriality" (Delaney 2009, p.196).

\section{Territorial Terminology}

French geographer Jean Gottmann is credited as being a thinker ahead of his time in calling for a more critical analysis of territory (Elden 2013b; Sassen 2013). While 
most theorists of his day were content to treat territory as a passive container of the state, Gottmann sought to diversify understandings of territory by emphasizing the way territory is socially produced by different populations, especially those actually occupying the territory in question. In The Significance of Territory, he explains what territory means in different contexts - political, military, juridical, and geographical— and then describes what it signifies to "the specialist interested in political geography":

...territory appears as a material, spatial notion establishing essential links between politics, people, and the natural setting... The important aspect of territory as the unit in the political organization of space that defines, at least for a time, the relationships between the community and its habitat on one hand, and between the community and its neighbors on the other, has been little explored (Gottmann 1973, p.ix).

This statement is noteworthy because Gottmann acknowledges the contingent and temporal spatial relations between different entities implicated in the conceptualization of territory. In doing so he appears to forecast more recent theorizations of territory developed from a larger constellation of conceptual frameworks.

Political geographers theorizing territoriality normally begin with behavioral geographer Robert Sack's description of 'human territoriality' as, “...the attempt by an individual or group to affect, influence, or control people, phenomena, and relationships, by delimiting an asserting control over a geographic area" $\left(1986\right.$, p.19) ${ }^{56}$. This theory is titled 'human territoriality' because it was adapted from theories of animal territoriality popularized by zoologists in the 1970s. Sack describes ten tendencies of territoriality, three of which — classification of territory, communication of territory, and enforcement

\footnotetext{
${ }^{56}$ Soja's discussion of human territoriality (1971) preceded Sack's discussion (1983), though Sack is more often cited in the literature I have reviewed.
} 
of territory — are "essential attributes of any territory" (1983, p.58). He then outlines different combinations of these tendencies and explains the types of territorialities associated with these combinations. What is exciting about this theorization, in comparison to earlier state-centric understandings of territoriality 'as the control of territory', is that Sack is able to apply his theory to "innumerable kinds of territoriality and levels of hierarchies, forms of technology, and historical conditions and reasons for control" (ibid.). Less exciting, for human geographers, is the formulaic layout of the theory and, less exciting for pacifists, the suggestion that the theory could be used to enhance the efficiency of territorial control ${ }^{57}$.

Political geographers citing Sack's work in the development of their own theorizations have dropped the 'human' from 'human territoriality' and have taken the concept into both familiar and unfamiliar territory (pun intended). Ruggie (1993), seeking to introduce territoriality to international relations, and Taylor (1994), bringing worldsystems theory to political geography, both weigh in on the state-centered focus of territorial theory in political geography. Ruggie coins the term "unbundled territoriality" to explain how the modern political system is being transformed by various forms of markets, regimes, and political communities (e.g., the European Union) negating the "exclusive territoriality" of nation-states in "postmodern" international politics (1993, p.171-174). While Ruggie looks beyond the state to envision another form of territoriality, he avoids defining territory, spending more time defining the "nonterritorial region" -“a decentered yet integrated space-of-flows, operating in real time, which exists

\footnotetext{
${ }^{57}$ Sack dedicates a section of his original article on human territoriality to an explanation about how the theory could be useful to the U.S. Army (1983, p.69-71).
} 
alongside the spaces-of-places that we call national economies created by unbundled territoriality" (ibid., p.172). Countering the "premature dismissal of territoriality", Taylor proposes the following two theses: 1) territory is a container for the state and "the state has acted as like a vortex sucking in social relations to mold them through its territoriality" and 2) state territoriality has never been more relevant despite claims that post-Cold War peace and globalization have nearly rendered state-centered discussions of territoriality obsolete (1994, pp.152-161). In Taylor's opinion, "The threat to the state comes not from the cause of globalization, an economic one world, but the consequence, the destruction of the environmental one world" (ibid., p.161).

In stark contrast to Taylor's call to refocus on the state in the theorization of territory, political geographer John Agnew argues, "The dissolution of the Cold War, the increased velocity and volatility of the world economy, the emergence of political movements outside the framework of territorial states (arms control, human rights, ecological, etc.), all call into question the established understanding of the spatiotemporal framing of 'inter-national relations'" (1994, p.55-56). He introduced the concept of the territorial trap as both a corrective to "territorial state" as "the singular actor of modern world politics and as a call "to stop associating 'geography' with territory as the only modality for the spatial organization of politics" (Agnew 2015, p.43). It consists of three geographical assumptions -1) states as fixed units of sovereign space, 2) the domestic/foreign polarity, and 3) states as 'containers' of societies— that have led unsuspecting thinkers to fall into the 'territorial trap' (Agnew 1994). To fall into this trap is to subscribe to the myth that nation-states have always existed and had exclusive power within their boundaries (Agnew 2003b, pp.49-50). In his view, "Putting geography into 
international relations must necessarily address this assumption” (Agnew 2015, p.43).

Thus, in later correcting for the territorial trap but perhaps not fully committing to a comprehensive definition of territory, Agnew describes territory as "an important type of spatial arrangement through which power is deployed and experienced but which is not limited to the state as such" (2013, pp.1-2, my emphasis).

Perhaps no political geographer has contributed more to current Anglophone understandings of territory and territoriality than Stuart Elden. Elden argues that too often scholars attempt to understand territory through the lens of territoriality -the control of territory - whereas his approach is "an examination of the relation of the state to the emergence of a category of "space"' (2010, p.810). Citing the logic of spatial thinkers such as Lefebvre and Soja, who purposefully avoid explicit definitions of space, Elden similarly refuses to define territory in absolute terms. Rather, he thinks of territory as a question that must be approached politically "in its historical, geographical and conceptual specificity" (ibid., p.812). "Territory then should not be understood as the static backdrop or container of political actions. Nor is it the passive object of political struggle. It is something shaped by, and a shaper of, continual processes of transformation, regulation and governance" (Elden 2013a, p.17).

Yet, despite the fact that Elden professes to view territory through a different lens than territoriality, he cannot avoid the subject of territorial control. He writes, "Creating a bounded space is already a violent act of exclusion and inclusion; maintaining it as such requires constant vigilance and the mobilization of threat; and challenging it necessarily entails a transgression" (Elden 2009, p.xxx). This leads to a discussion of two words that share a common root, 'terror' and 'territory', which Elden suggests are historically and, 
possibly, etymologically related. "To control a territory is to exercise terror; to challenge territorial extent is to exercise terror" (ibid.). Similar to his discussion of territory, Elden does not attempt to explicitly define territoriality, however he does elaborate on the relationship between territory and violence.

Concerned that not enough has been written about the conceptual history of territory, Elden takes a Foucauldian approach to exposing the origins of the term. He draws inspiration from The Birth of Biopolitics, viewing territory as "an effect of perpetual territorialization" just as Foucault understood the state as "an effect of perpetual stratification" (2013a, p.17). In the following quote he provides a brief synopsis of the origins of territory and hints at a potential reason why it should be not intrinsically associated with the state:

Territory emerges in Western thought relatively late as a concept, not taking on a recognisably modern sense until the late middle ages, and not appearing as a central theme in political theory until the seventeenth century. It thus postdates the notion of the state, and unlike politics itself, comes from Roman, rather than Greek roots" (ibid., p.7).

So if the state predates territory, then why would one consider territory vital to defining the state or vice versa?

Thus in more recent literature, political geographers have avoided the territorial trap by emphasizing the factors contributing to the conceptual production of territorial terms rather than the material results of territorial production. For instance Passi builds on Sack's explanation of territoriality to describe territories "as social processes in which social space and social action are inseparable" (2003, p.110). Citing Mitchell's theorization of the state as "social practices" (1991) and Latour's actor-network theory, Painter understands territory as an "effect" of "socio-technical practices" produced by 
"networked relations involving both human and non-human actors" (2010, p.1096).

Sassen conceptualizes territory in Deleuzian terms, "As a capability it is part of diverse complex organizational assemblages, with variable performance in relation to authority and rights, depending on the properties of such assemblages" (2013, p.23). Putting aside differences in the vocabulary used in this small sample -territory as "social processes" vs. territory as "effect" vs. territory as a "capability" - there is clearly a trend towards more and more intricate conceptualizations of territory.

Is it fair to wonder then if the concept of territory is gradually becoming less useful? After all Gottman did state, "Under a purely analytical approach, the notion of territory would break up and dissolve into a multitude of different concepts such as location, natural resources, population density, settlement patterns, modes of life, and so forth" (1973, p.ix). Or are these theorizations simply reflective of the need to adapt territory to a wider variety of spatial logics and disciplines? As Antonsich signals, part of the reason territorial terms are so challenging to define is because - thanks to the postmodern and post-structural turn - meanings are no longer fixed. Another reason is because territorial terms have multiple meanings, serving as key concepts in a number of different disciplines such as law, ethology, anthropology...etc. (Antonsich n.d.).

Political ecologists have advanced understandings of the conceptual and material implications of territory by focusing on how governance, citizenship, and the distribution of resources have factored into the territorialization of the Global South. Vandergeest and Peluso expanded the theoretical and geographical reach of territorial theory by repurposing these terms -traditionally the domain of political science, international relations, and political geography — for political ecology. They begin by adapting Sack's 
theory of territoriality to explain the ways people are included or excluded within geographic boundaries as well as "controlling what people do and their access to natural resources within those boundaries" (Vandergeest \& Peluso 1995, p.388). Vandergeest and Peluso also adapt the term 'territorialization' to explain, “...the internalization of state power and its relation to the allocation and realization of access rights" (ibid., p.387). Their theorization, situated in the context of modern state formation in Southeast Asia, largely frames territorialization as an oppressive set of practices that states conduct to control people and property. Those building upon Vandergeest and Peluso's original theorizations, however, nuance local agency in governance as well as the growing power of non-state actors in ways that acknowledge changes in and changing perceptions of territoriality and territorialization. For instance, $\mathrm{Li}$ reasons that territorialization is "a normal activity of governments" and that state power is not necessarily malevolent in nature. She cautions against assuming traditional communities are oppositional to state power because one runs the risk of overlooking individuals seeking "the benefits of fuller citizenship" (Li 1999, p.21). Peluso and Lund then redefine territorialization as a collaborative claim that produces a 'collectivity', which they reason can be interpreted as the act of controlling "by claiming the power to govern territorially" (2011, p.673).

\section{The Territorial Turn}

Another emergent form of territorial scholarship -attuned to the participation of traditional communities in territorial governance and the political ecology of the Global South - more specifically deals with the creation of autonomous territories within nation-states. A small group of scholars researching the establishment of ethnic territories, which includes both indigenous and Afro-descendant peoples, in Latin 
America have referred to this scholarship as the territorial turn (Offen 2003; Hale 2011; Bryan 2012) $)^{58}$

For geographer Karl Offen, the territorial turn not only signifies the recognition of a new type of spatial formation - ethnic territories - but, more importantly, a new understanding of territoriality. Here he explains his rational for coining the term, "What is at issue, then, in understanding what I am calling the territorial turn in the lowland tropics of Latin America, is not just land or who gets what land, but rather, as Arturo Escobar puts it, 'the concept of territoriality itself as a central element in the political construction of reality' (Offen 2003, p.48 citing Escobar 1998, p.78). The territorial claims of ethnic communities "are about power, an assertion of identity, autonomy, and a measure of control over encompassed natural resources" and "thus, seek to impose a new territoriality within 'national space' to redefine a people's relationship to the state" (Offen 2003, pp.47-48).

Another perspective on the establishment of ethnic territories, however, is that these territories form part of changing paradigms of neoliberal governance and therefore are only as independent as state institutions permit them to be. Geographer Joe Bryan, reflecting on the implications of the territorial turn after Offen's original article, writes, "This transfer of land and resources would have once been construed as sacrificing national sovereignty through the loss of territory. Neoliberalism has altered that perspective by recasting the role of the state as coordinating the interests of the private

\footnotetext{
58 The 'territorial turn' is employed in this dissertation as an abbreviated term for this specific type of scholarship, although it should be noted that only the authors cited here refer to the term in their own writings.
} 
sector and civil society in order to maintain the socio-spatial order necessary for the functioning of markets" (Bryan 2012, p.215). Similarly, anthropologist Charles Hale -in his discussion of black and indigenous territorial struggles in Central America — laments that indigenous autonomy "is increasingly entangled with the very structures of dominance that these communities intend to resist" (2011, p.189). Hale explains, “...states devolve authority to far-flung spaces, recognize the inhabitants' rights and let them govern themselves, which has the effect of constraining their political participation beyond the local level, especially in relation to broader structures of political-economic inequity" (ibid., p.195). Therefore, the struggle for land rights runs the risk of complicity with neoliberal governance, while at the same time "organizations that avoid these entanglements through radical refusal often have trouble meeting their members' immediate material needs and risk forgoing the substantial benefits that the territorial turn entails" (ibid., p.202). For Bryan this is problematic because:

...the right to have rights remains contingent on one's belonging to a group. That group has long been that of the citizen whose rights are protected and guaranteed by a state. The territorial turn and human rights law have transformed this arrangement somewhat, recasting it as a task of multiple sovereignties whose jurisdictions spatially overlap (2012, pp.221222).

In other words, Bryan takes issue with the territorialization of ethnic communities because it operates as both a form of exclusion and a necessary condition for the state to intervene to guarantee human rights. Thus both Hale and Bryan seem to agree that the territorialization of ethnic communities in Latin America "constrains the conceptualization and enjoyment of rights" (Bryan 2012, p.223). 
Colombian anthropologist Flórez López raises some key points about territoriality in his country that deserve mention in this context: 1) for ethnic communities the process of having their territories recognized is understood as the most recent phase of a 500-year history of colonialism; 2) the idea of 'Colombian territoriality' is based upon the interests of the ruling elite in the Andean highlands of the central-occidental and northern regions of the country, an elite class only concerned with other regions of the country for the sake of economic development; and 3) there is an active territoriality of foreign capital within Colombian borders that represents neocolonialism and the reprimarization of the continent $^{59}$. Paramilitarism is another layer connected to this capital-oriented territoriality, one that has involved the invasion and occupation of space for economic development, a phenomenon that is particularly emblematic of the Pacific region (Flórez López 2012, p.291).

Agnew and Oslender (2013) make no mention of the 'territorial turn' but employ the concept overlapping territorialities to describe this dynamic of different territorial authorities controlling the same spaces or parts of the same spaces within a nation-state's boundaries. They define territoriality as "the use and control of territory for political, social, and economic ends", with consideration of the geo-historical context in which it is produced (Agnew \& Oslender 2013, p.123). Using Colombia as an example, Agnew and Oslender describe the overlap between various territorial groups -ethnic communities (indigenous and Afro-descendant), the national armed forces (not necessarily representing the interests of the national government), the guerrillas, paramilitary forces,

\footnotetext{
${ }^{59}$ Reprimarización refers to the return to primary commodities as the main source of export revenues.
} 
and criminal networks - vying for the control of space. "What these examples show is that the nation-state is very much an unfinished, constantly evolving space of contention between different regionally situated social groups" (ibid., p.127). They conclude that place-based social movements, such as the Process of Black Communities (PCN), create the possibility of a "radical redefinition of the state itself", one that is more democratic and inclusionary (ibid., p.136).

\section{The Co-Production of Black Territory-Identity}

The more positive take on the territorial turn, therefore, is that the establishment of ethnic territories may facilitate the recognition of alternative ontologies, epistemologies, and/or forms of politics that, historically, have been marginalized (Escobar 2008; Blaser 2009, 2010). Scholars that write about the establishment of ethnic territories in the Afro-Pacific region of Colombia have paid special attention to the ways identity and territory have been co-produced in this process.

It is important to note that indigenous and Afro-descendant communities were first divested of their traditional lands before the collective titling of communities was achieved years later. As Oslender explains, "patterns of traditional landownership were ignored and made invisible by national legislation in 1959 that declared rural untitled lands in the Pacific lowlands as tierras baldías, or unoccupied state-owned public lands" (2016b, p.64). Informal agreements, the norm in rural Colombia and many other rural

parts of the world, were disregarded, essentially making these lands "unoccupied" despite generations of occupation and use by these respective communities. The eventual establishment of collective ethnic territories could therefore be understood as a reterritorialization of traditional lands that had been converted into tierras baldías. 
The PCN understands this re-territorialization as a product of struggle. This struggle, in which black activists mobilized for Afro-descendant rights, eventually contributed to "a substantial reform of the national Constitution in 1991, which, among other things, granted the black communities of the Pacific region collective rights to the territories they have traditionally occupied" (Grueso et al. 2003, p.430). The PCN emerged as a national organization from a network of 120 local organizations coordinating local community responses in support of the establishment of collective ethnic territories. These organizing efforts culminated in the law for the collective titling of black communities, also known as Law 70, which was passed in 1993 (ibid., pp.432433). Thus the titling of lands was not simply gifted by the Colombian state, but produced through the efforts of activists, organizations such as the PCN, and networks of supporters. "Broadly stated, the law's objectives are the protection of black communities' ethnic identity and rights as well as the promotion of their economic and social development in order to guarantee equality" (Cárdenas 2012, p.309).

However, it is important to note that Law 70 does not, at any point, mention 'black territory'. The law specifies that black communities that have occupied tierras baldías, in accordance with their traditional practices of production, have a right to collective property (Article 1 of Law 70) and these collective titles will be known as "Lands of Black Communities" (Article 4 of Law 70). Thus, 'black territory' or 'Afrodescendant territory' are not actual terms employed by the Colombian state, rather these terms originated through the efforts of black activists seeking more autonomy afforded than what the state established through the recognition of 'Lands of Black Communities'. Three articles within Law 70 (Articles 22, 38, 58) also specify that black communities 
should be consulted in specific situations about activities conducted in their lands, without any mention of International Labour Organization's Convention 169 of 1989, an international agreement requiring previous consultation for indigenous and tribal peoples (discussed in Chapter 4). Therefore, in producing 'black territory' or 'Afro-descendant territory', black communities “counter the state's agenda by putting forth the idea of territoriality as opposed to land title" (Asher 2009, p.59) because only territoriality "encompasses the idea of territory as a social, cultural and material space" (Asher \& Ojeda 2009, p.299). Throughout the rest of this dissertation then, terms such as 'black territory' or 'Afro-descendant territory' or 'the territory' (discussed in Chapter 4) will connote the perspective of black activists engaged in the struggle for territorial autonomy in black communities versus the Colombian state's understanding of the territorial rights of black communities.

The production of black territory also involves the physical bounding of space in map form (discussed in Chapter 4) as well as a historical imagination of space. For example, Oslender notes how the PCN has woven the theme of resistance into the historical imagination of black territory:

The Pacific lowlands, once considered a territory of indigenous resistance against the colonizers of the Spanish Crown and of black resistance against slavery, is now seen by PCN activists as a territory of AfroColombian resistance against dominant development models fueled by the logic of displacement-inducing modernity (2016b, p.103).

Furthermore, beliefs and the activities of daily life are also connected to the imagination of black territory. "This may be most evident in everyday cultural practices such as traditional healing, the performance of oral tradition, and funeral rites. It is precisely these spatial practices that social movement leaders evoke in their political project, intent 
on resisting the further penetration of capital into the region" (ibid., p.29). Reflecting on how the territorial turn has impacted the conceptualization of territories, Offen states, "Place meanings and spatial organizations are not ontological givens but are bound up with the lived experiences that give them sustenance" (2003, p.48).

Identity is fundamental to the production of black territory because Afrodescendants of the Pacific have historically been excluded from the majority whitemestizo population's imagination of Colombia. As Wade explains, "Ideologies of mestizaje and blanqueamiento tend to envision blacks and indians as retrograde inputs to a modernizing future of mixedness, or increasing whiteness, but mestizaje...attempts to gloss over ethnic difference entirely in assertions about Colombian mixedness" (1993, pp.35-36). The new Colombian constitution of 1991,"presented as the construction of a pluriethnic and multicultural nation", provided an avenue for the articulation of an "AfroColombian' identity rooted in the Pacific region (Grueso et al. 2003, p.432). However, black activists first had to confront the perception that their communities merited recognition as an ethnic group. "Black communities, it was argued out of ignorance, did not conform to the definition of an 'ethnic group' since they lacked their own language and forms of right and authority; they were fully integrated as citizens into the mestizo life of the country; and they had adopted alien cultural elements" (ibid.). In other words, black communities did not fit the mold of indigenous communities, some of which had been recognized with special territorial and political rights as early as 1890 (Arocha 1992, p.41). In fact, historically Afro-descendants have been characterized as illegal occupants of the Pacific, due in part to the fact that freedmen settlements in the region were never formerly recognized as territories and because of legislation meant to protect 
indigenous territories from encroachment (ibid., p.45). Ng'weno argues that AfroColombian territorial claims challenged the mestizo category of national belonging, which "is bound up in ideas of mixture as a sign of modernity on the one hand and a sign of Indigenous roots (and therefore legitimate claims to territory) on the other" (2007, p.12).

Therefore scholars studying the Afro-Pacific have understood the articulation of 'black communities', 'Afro-Colombians' and 'Afro-descendants' as both a territorial and political strategy. Restrepo refers to this as a process of 'ethnicization' in which ethnic communities are imagined through ideas about ancestry, territoriality, and cultural identity. This ethnic identity exists as the 'other' in contradistinction to 'us', a nonmarked Colombian identity that is supposedly Western and modern (Restrepo 2013, p.23). For Ng'weno (2007), the creation of an Afro-Colombian identity is critical because it "does not contain the historically associated and regionally specific hierarchies of class, progress, race, and region that the other categories contain" (p.10) and because this ethnic identity operates as "the legal linchpin in the relationship between territory and authority" (p.84). Cárdenas explains:

In a nutshell, ethnic territoriality took the indigenous rights model that argued for land rights on the basis of autochthony and applied it to black Colombians. This meant emphasizing the black communities' traditional cultural practices and arguing that their preservation was inherently tied to the land from which they sprouted. In this way, cultural difference became tethered to particular territories $(2012$, p.310).

Hoffman wonders whether such an identity, so intimately connected to place, is beneficial if the majority of Afro-descendants in Colombia live in urban areas and not in 
these rural territories ${ }^{60}$. In her opinion, this dynamic limits the potential of Afrodescendant rights by blurring the distinction between territory and territoriality (Hoffman 2002, p.365). The PCN, on the other hand, emphasizes the ontological potential of the territory-identity nexus, "The social movement of black communities can be described as one of cultural and ecological attachment to a territory, even as an attempt at creating new existential territories" (Grueso et al. 2003, p.443).

In conclusion of this section, the trend towards more intricate theorizations of territorial terms provides the conceptual space to articulate new forms of territory and territoriality that challenge the assumptions of the 'territorial trap'. The territorial turn scholarship, however, raises questions about whether ethnic territories are constrained by the state or represent new configurations of the state.

Chapter 4 integrates the empirical details of aerial eradication and coca cultivation into the theorization of black and national territorialities. The chapter conceptualizes two sets of activities - the cultivation of coca and aerial eradication - as the imposition of external territorialities. It details how conceptions of black and national (both Colombian and U.S.) territorialities have been mobilized to implement, regulate, and/or terminate the cultivation of coca and aerial eradication.

\section{Political Ecology}

Remembering nature - recognizing theoretically its historical significance - allows us to recast dominant histories of Western historical development and to question the notion that modernity is the offspring of a self-propelled West (Coronil 1997, p.7).

\footnotetext{
${ }^{60}$ Hoffman cites $70 \%$ Afro-descendants living in urban areas at the time of her article (2002, p.354).
} 
Conceptualizations of 'nature' or 'the environment' are fundamental to the territorial turn because development-directed conservation discourses factored in the establishment of black identity and territory in the Pacific region. Oslender explains, "The contemporary ecological crisis has triggered a shift in discourse from 'nature' to 'environment,' from timber-rich resource base to 'strategic ecosystem,' and from rural black riverside dwellers to guardians of 'this great ecosystem.' This discursive realignment is a crucial precursor for turning idle capital into profitable investment" (2016b, p.166). In response to this 'discursive fix', black communities have produced alternative discourses of development and conservation that challenge both the physical and epistemological displacement of black communities ${ }^{61}$.

Political ecology is an interdisciplinary field useful for revealing the ontological and epistemological disagreements that factor into conflicts over land, resources, livelihoods, and ways of being. Eric Wolf (1972), an anthropologist known for his research on peasants in Latin America, is credited as the first academic to popularize the term 'political ecology' (Robbins 2012, p.14), although other academics as well as journalists also used the term to stress the politicization of the environment in the 1970s (Neumann 2005, p.32). Blaikie and Brookfield, however, are the first credited with attempting a methodology and theoretical basis for the field (Neumann 2005, p.33) and they are frequently cited for their succinct definition of political ecology as "the concerns of ecology and a broadly defined political economy" (1987, p.17). Following this initial effort, political ecology has been the subject of continual debates about the basis for its

\footnotetext{
${ }^{61}$ Oslender adapts the 'discursive fix' from Harvey's (1982) discussion of the 'spatial fix'.
} 
theory and methodology. On the topic of theory, Peet and Watts state, "From its inception, political ecology was never a coherent theoretical position for the very good reason that the meanings of ecology and political economy and indeed politics, were often in question" (2004, p.9). With regard to methodology, Robbins writes, "In short, there are very few techniques, technologies, or analytics not used in political ecology, again suggesting the elusiveness of coherence in the field" $(2012, \mathrm{p} .85)$. The most probable reason for this lack of coherence can be attributed to the diversity of scholarship that political ecology originated from, which includes critical development research, peasant studies, environmental history, cultural ecology, and postcolonial theory (ibid., p.5). In tracing the roots of political ecology and locating the field within human geography, Neumann highlights other contributions such as geography's humanenvironment tradition, the critique of natural hazards, and scholarship on Third World environmental degradation (2005, pp.15-32).

Definitions of political ecology similarly reflect the diversity of its origins. For instance, Spanish economist Joan Martínez-Alier, writes, "Political ecology studies the ecological distribution conflicts. By ecological distribution is meant the social, spatial and inter-temporal patterns of access to the benefits attainable from natural resources and from the environment as a life support system, including its 'cleaning up' properties" (2002, p. 73). Escobar $(2006,2008)$ builds upon Martínez-Alier's definition of political ecology in his own work, yet offers a drastically different description of the field in an earlier writing, "Defined as the articulation of biology and history, political ecology examines the manifold practices through which the biophysical has been incorporated into history - more accurately, in which the biophysical and the historical are implicated 
with each other" $(1999$, p.4). Stonich views political ecology as an alternative to popular paradigms seeking to explain tropical forest degradation, "As an alternative framework, the arguments presented here seek to integrate environmental issues into a politicaleconomy approach that delineates the close linkages between social processes and environmental deterioration in the region" (1989, pp.272-273). Robbins explains how political ecology can function as critique, noting, “...political ecology seeks to expose flaws in dominant approaches to the environment favored by corporate, state, international authorities, working to demonstrate the undesirable impacts of policies and market conditions, especially from the point of view of local people, marginal groups, and vulnerable populations" (2012, p.99). Despite the varied origins of political ecology scholarship and, likewise, the ways the field is variously defined, the above-cited definitions are not necessarily contradictory of one another.

My exploration of political ecology literature has revealed three major characteristics of the field that resonate with this dissertation. The first characteristic is an engagement with and skepticism of scientific knowledge. Robbins refers to political ecologists as a "diverse community of skeptical researcher practitioners" that tell stories, "Such stories are political precisely because they disrupt normal expectations, undermine inherited assumptions, and do not deny the inevitable political roots of all environmental knowledge" (2012, p.98). This disruption has extended to the very definitions of environment and nature as Peet and Watts point out, “...what political ecology has done obviously is to open up the category of the environment itself and explore its multiform representations" (2004, p.19). Furthermore, political ecology scholars have expanded the interrogation of "scientific knowledge" beyond natural sciences concerned with the 
study of ecology to question the framing of environmental problems across the domains of the social sciences and "development experts".

The second characteristic is a preoccupation with socio-environmental justice. Political ecology, "something people do" (Robbins 2012, p.4), “...characterizes a kind of argument, text, or narrative, born of research efforts to expose the forces at work in ecological struggle and document livelihood alternatives in the face of change" (ibid., p.21). Political ecologies stand in stark contrast to apolitical ecologies, "This is the difference between identifying broader systems rather than blaming proximate and local forces; between viewing ecological systems as power-laden rather than politically inert; and between taking an explicitly normative approach rather than one that claims the objectivity of disinterest" (ibid., p.12). Political ecology attempts to answer the questions, “...who has the power to impose decisions on resource extraction, land use, pollution levels, biodiversity loss, and more importantly, who has the power to determine the procedures to impose such decisions?" (Martínez-Alier et al. 2010, p.2). In highlighting the preoccupation with socio-environmental justice, this dissertation interprets the political in 'political ecology' to mean a situatedness and a commitment to an academic form of activism. Therefore the challenge for this project, “...lies in understanding both environmental and political change in ways that enhance social justice, but which do not impose a priori notions about each" (Forsyth 2008, p.763).

The third characteristic is a focus on populations marginalized by environmental concerns. In this context 'marginalized' means treated as insignificant by actors, both state and non-state, with the power to impact populations at various scales. Political ecologists, therefore, often share a collective sense of responsibility about revealing how 
these populations are marginalized in the framing of environmental problems. Not only does this involve dispelling myths and misconceptions propagated by environmental 'experts' and authorities, but it also consists in recognizing alternative epistemologies that challenge uneven relations of power. For political ecologists Porto-Gonçalves, Walter and Leff, the Latin American contribution to political ecology is the attention paid to culture, which reveals the power dynamics implicit in the theorization of nature and territory (2012, p.34).

\section{Theorizing Environmental Conservation as a Technology of Displacement}

The theorization of ecological conservation discourses is critical to this dissertation because much of the controversy about aerial eradication hinged on conflicting perspectives of what it means to conserve the environment or biodiversity. Some of this disagreement stems from the fact that peasant populations of the developing world are often blamed for environmental degradation and scarcity without proper attention to the First World assumptions and Third World material conditions that factor in to such conclusions (Hartman 2001). This section of the chapter will engage literature that explains both how ecological conservation discourses operate as mechanisms of displacement and contribute to the production of Afro-Pacific territory-identity through the political ecology of difference framework.

Political ecology has a history of revealing the mechanisms that state and nonstate actors employ to seize control of the resources and property of indigenous and peasant peoples (Erazo 2013, p.17). Much of this literature first draws on the work of scholars that reveal how terms such as "nature" and "wilderness" became conceptualized as categories of space devoid of human inhabitants (Smith 1984; Cronon 1995; Harvey 
1996). Following this work, another wave of scholarship emerged that addresses how the designation of space as "nature", "wilderness", "a national park", or "a forest" displaces those who traditionally occupy or utilize those spaces (Neumann 1998; Braun 2002; Kosek 2006; Mathews 2011).

In his study, Braun utilizes the term technologies of displacement to explain how forest management experts in British Columbia have situated the temperate forest within geographies of 'the nation', 'the market', and 'the global biosphere.' In situating the temperate forest as a domain separate from the cultural geographies of Native communities already inhabiting the forest, new actors have been authorized to "speak for the forest" (Braun 2002, p.32). Braun references an argument of radical ecologists who state that advanced capitalism has violently abstracted and displaced specific entities as commodities from their surroundings. He follows by explaining, “...nature becomes displaced into systems of meaning, production, and exchange that have no intrinsic relation to an underlying ecological order" (ibid., p.35). Thus timber is extracted from its ecological surrounds with damaging effects on local ecosystems, and 'the forest' is abstracted as a unit of production with equally damaging effects on local Native communities (ibid., pp.35-36). Braun's intent is not to speak on behalf of Native voices but to investigate how colonial relations persist through forest discourses intertwined with other discourses such as "conservation", "nationalism", "wilderness," and the “indigenous” (ibid., pp.32-33).

In the Colombian Pacific region there are a number of discourses operating as technologies of displacement, signifying both the forcible relocation of bodies as well as the displacement of local epistemologies. For example, as outlined in the works of 
Colombianist scholars (Escobar 2003, 2008; Oslender 2008a; Rojas 2009), the rise of the palm oil industry in the Pacific region exemplifies how 'development' violently subordinated black and indigenous territorialities to the imperatives of a "modernizing state". Large-scale African palm companies financed paramilitary groups to conduct campaigns of terror meant to annihilate, dispossess, and intimidate local communities (Oslender 2008a), which -at the same time - co-opted institutions of local governance (Grajales 2011; Ballvé 2012). Such projects authorized new actors (palm oil companies) to "speak for the forest" in ways that compromise the lives and livelihoods of predominately black and indigenous communities of the Pacific region. The establishment of palm oil plantations, however, is just one of several examples of how development discourses have violently transformed the Pacific region.

Grueso, Rosero and Escobar trace the contemporary origins of these discourses, explaining how scientists, environmentalists, governments, and NGOs promoted "the radical opening of Colombia's economy to world markets after 1990, particularly in the ambit of the country's integration into the Pacific Basin economies" (2003, p.430). They understand these development plans as "no more than material interventions on behalf of national and international economic interests" (ibid., p.442). Similarly, Asher and Ojeda argue that state-directed strategies in support of this integration - the Plan Pacífico development initiative, the Proyecto BioPacífico conservation program, Ordenamiento Territorial (the constitutional law for territorial zoning) and Law 70 for the establishment of ethnic territories:

...mobilized a certain discourse, a set of ideas and institutional structures through which life and territory in the Pacific was to be imagined as part of the Colombian nation. These projects (re)imagine and (re)fashion 
"marginal" and "backward" areas of the Pacific to integrate them into a

"central" and "modern" Colombian state apparatus (2009, p.300).

Furthermore, Asher and Ojeda contend, “...these interventions helped constitute state hegemony by conceptualizing nature as a target of development and a means of capital accumulation" (ibid., p.294).

PCN leaders and supporters have countered these interventions by constructing alternative understandings of 'development,' and 'conservation'. To this end, the PCN views the Pacific region as a "region-territory of ethnic groups", which "challenge the conventional political culture harbored in the practices of the traditional political parties and the state, unsettle the dominant project of national identity construction, and defy the predominant orientation of development" (Grueso et al., 2003, p.431). "If the territory is the space of effective appropriation of the ecosystem, the region-territory is conceived of as a political construction for the defense of the territories and their sustainability" (Escobar 2006, p.130). Therefore, the term 'region-territory' signals, “...both a conceptual innovation and a political project, what could be called a subaltern strategy of localization. It located biological diversity within an endogenous perspective of the ecocultural logic of the Pacific" (Escobar 2008, p.158).

\section{The Political Ecology of Difference}

Escobar describes the 'political ecology of difference' as both a practical and theoretical framework that creates the space for the articulation of local knowledge production. As he explains, “Anthropologists, geographers, and political ecologists are demonstrating with increasing eloquence that many rural communities in the Third World 'construct' nature in strikingly different ways from the prevalent modern forms" (Escobar 
1998, p.61). More than just a theoretical framework, the political ecology of difference emerges as a collaborative effort with radical implications for how political ecologies can be conducted. As detailed in the preface to Territories of Difference, this framework is the product of multiple ongoing projects involving Escobar's engagement with black activists of the Colombian Pacific as well as academics in Latin America and the U.S. "One thing these projects have in common is that they take the production of knowledge itself as a problematic; in a way, they all represent a social movement within the academy for a different kind of knowledge production” (Escobar 2008, p.xii).

The goal of this framework is to lay the groundwork for "historically specific and contingent" political ecologies that challenge "the alleged universality of modernity and globalization"(2008, p.18). Escobar draws on the Modernity/Coloniality/Decoloniality (MCD) project (Argentine cultural anthropologist Walter Mignolo also formed part of and has written on this) to explain how cultural differences are suppressed as a result of colonialism and colonialist ideas about modernity. The MCD project describes two parallel processes: 1) "the systematic suppression of subordinated cultures and knowledges (el encubrimiento del otro) by dominant modernity" and 2) the emergence of "particular knowledges shaped by this experience that have at least the potential to become the sites of articulation of alternative projects" (Escobar 2008, p.12). The latter process speaks to Escobar's convictions that a poststructural political ecology requires a new language for Third World perspectives, “...a language of transformative selfaffirmation that allows the Third World to reposition itself in the global conversations and processes that are reshaping the world, without submitting passively to the rules of the game created by them" (1996, p.61). Therefore the political ecology of difference 
framework functions by "reading world events for difference, rather than just for dominance, and by weaving connections among languages and practices of economic, ecological, and cultural differences" (Escobar 2008, p.18). In re-conceptualizing cultural difference, this framework offers the "possibility of alternatives to modernity" (Escobar 2003, p.165). Thus Escobar views "the construction of a new political subject, black communities" as part of a larger movement towards these alternative versions of modernity (2008, p.201).

The construction of this new political subject necessarily involves the identification and deconstruction of technologies of displacement that subordinate the knowledge produced by black communities. As is the case elsewhere in the tropics, the Pacific region of Colombia has been labeled a biodiversity hotspot in the last thirty years. “Terms such as 'biodiversity', 'endemism', 'biological diversity', 'genetic resources', 'bioregion', virtually unheard not long ago, become referents of a different theoretical and political imagination of the region" (Restrepo 2013, p.208). "This is a reason why communities -particularly ethnic and peasant communities in the tropical rainforest areas of the world - are finally recognized as the owners of their territories (or what is left of them), but only to the extent that they accept seeing and treating territory and themselves as reservoirs of capital" (Escobar 1996, p.57). Similar to Braun's example of timber being removed from the context of the forest in British Colombia, the genetic material extracted from these tropical regions is "displaced into systems of meaning, production, and exchange" (2002, p.35) far removed from Afro-Pacific ecological sensibilities. As Escobar explains, "From a discursive perspective, then, biodiversity does not exist in an absolute sense. Rather, it anchors a discourse that articulates a new relation between 
nature and society in global contexts of science, cultures, and economies" (1998, p.55). In this new relationship biodiversity should be conserved by local ethnic populations so that scientists can maximize the utility and profitability of the genetic material found within biodiverse regions. Biodiversity is therefore understood by development-minded experts as a "national resource" capable of generating enough wealth to lift Colombia out of its poverty (Restrepo 2013. p.202).

The PCN and its supporters' response to this imagination of development-oriented biodiversity is to conceptualize the PCN as a black social movement in defense of the "social and biophysical landscapes of the Pacific region", which "advances through a slow and laborious construction of Afro-Colombian identities that articulate with alternative constructions of development, territory, and biodiversity conservation" (Grueso et al. p.443). In this alternative construction, humans and non-humans do not exist separately from biodiversity; rather they are an integral part of the biodiversity that constitutes territory. As Harvey suggests, "It is fundamentally mistaken, therefore, to speak of the impact of society on the ecosystem as if these are two separate systems in interaction with each other" (Harvey 1996, p.186, original emphasis). Thus for Escobar, biodiversity is "a construction constituting a powerful interface between nature and culture and originating a vast network of sites and actors through which concepts, policies, and ultimately cultures and ecologies are contested and negotiated" (1998, p.75).

In the context of the War on Drugs in the Pacific region, 'biodiversity' and 'security' were the principal discourses (technologies of displacement) cited in the justification of the aerial eradication of illicit crops. To the astonishment of critics, proponents of aerial eradication argued that this strategy curtailed deforestation and the 
degradation of biodiversity caused by the cultivation of coca and processing of coca paste. Another way to conceptualize these pro- aerial eradication arguments, however, is to think about them in geopolitical terms. As Taylor explained, the real "threat to the state" is not globalization, but "the destruction of the environmental one world" (1994 p.161).

Critical geopolitics scholar Dalby believes that environmental security, "where sovereign power meets biopower", is insufficiently theorized in the study of geopolitics (2010, p.285). In his opinion, critical geopolitics should link with critical ecopolitics, “...to understand contemporary environmental dangers as being, in part, about the political boundaries that produce both nature and space" (Dalby 2002, p.xxvi). Dalby posits this scholarship as a challenge to Malthusian-inspired visions of environment fostered by contemporary scholars such as Kaplan and Homer-Dixon— which mobilize a “"we' against a supposedly threatening 'them"” mentality (ibid., p.10). He argues that scholars should shift away from focusing on this mentality, a vestige of Cold War geopolitics preoccupied with territorial security, to focus on human security "in terms of sustainable human development" (ibid., p.8).

The next section of the literature review, therefore, takes Dalby's suggestions serious by deconstructing conceptualizations of national security in the context of the U.S.-supported War on Drugs in Colombia, discussing how 'environmental security' factored into the territorial turn in the Afro-Pacific, and by then shifting the focus of this discussion to the theorization of alternative geopolitical narratives more relevant to human security. The final section of this chapter on mapping and Chapter 6 "Contested Natures" will continue this discussion of how "environmental dangers" shape "political 
boundaries that produce nature and space"(Dalby 2002, p.xxvi) in the context of coca cultivation and aerial eradication in black territories.

\section{Critical Geopolitics}

Critical geopolitics performs the important tasks of documenting and deconstructing geopolitical discourses, while also problematizing how space is continually re-imagined through a "geopolitical gaze" (Ó Tuathail 1996). Like many critical fields informed by poststructuralism, critical geopolitics interrogates and problematizes meanings and taken-for-granted assumptions, including the motivations and assumptions behind critical geopolitics itself. It emerged in the 1990s out of the efforts of:

...a number of scholars in the fields of geography and international relations who, over the last decade, have sought to investigate geopolitics as a social, cultural and political practice, rather than as a manifest and legible reality of world politics. Critical geopolitics is informed by postmodern critiques that have placed the epistemological limits of the ethnocentric practices underpinning Cold War geopolitics in question (Dalby \& Ó Tuathail 2002, p.3).

Critical geopolitics, however, has "never connoted a clearly delimited or internally coherent research programme" (Dodds et al. 2013, p.6). What distinguishes the field is not its empirical focus, but rather "its theoretical and methodological underpinnings" that, in addition to post-structuralism, borrow from other critical approaches such as Marxism, feminism and postcolonial theory (ibid., pp.6-7).

Nevertheless, Gerard Ó Tuathail's Critical Geopolitics: the Politics of Writing Global Space (1996) could be considered the first substantial attempt at defining critical 
geopolitics as a field of study ${ }^{62}$. There are three aspects of post-structuralism that strongly emerge in Ó Tuathail's conceptualization of critical geopolitics. The first is the focus on texts and the deconstruction of text (or language) to reveal hidden assumptions or meanings. For instance, he initially mentions the alternative spelling "geo-politics" in defining 'critical geopolitics,' stating, “The hyphen ruptures the givenness of geopolitics and opens up the seal of the bonding of the 'geo' and 'politics' to critical thought." The second aspect is the questioning of academic disciplines themselves. Ó Tuathail not only problematizes geography as a discipline, but also notes that critical geopolitics itself is "enmeshed" in relations of power (ibid., p.142). Lastly, critical geopolitics takes on the wider task of highlighting how knowledge creates power and, conversely, how power creates knowledge. "It is parasitical on that which it addresses, working within the contextuality it explores to displace the infrastructures of geopolitics" (ibid., p.68).

Ó Tuathail goes into considerable detail to emphasize the ocularcentrism or Cartesian perspectivalism associated with classical geopolitics. He states, "Only European seeing man had the power to summon places before his eyes and write them up as sites" (Ó Tuathail 1996, p.80). Geopolitics has been plagued by Western ocularcentrism that privileges space at the expense of time and produces the two synchronically. To this point, "The teaching of geography is not about the teaching of signification (reading and writing) but about the cultivation of visualization" (ibid.,

\footnotetext{
${ }^{62}$ French geographer Yves Lacoste is regarded as a key figure in the revival of the term 'geopolitics' in the 1970s. In his book, Ó Tuathail discusses Lacoste's contributions under a section entitled "Geopolitics as a Form of Geographical Reasoning" (1996, pp.160-168).
} 
p.94) ${ }^{63}$. 'Critical geopolitics,' on the other hand, problematizes the relationship between "subject, object, and text, or, more prosaically, that between sight, sites, and cites" (ibid., p.71). In his conclusion Ó Tuathail argues that geopolitics must document and deconstruct the new "congealments" of geo-power and problematize how space is reimagined (ibid.,p.249).

Since Ó Tuathail's seminal work, scholars (including Ó Tuathail himself) have debated the purpose of critical geopolitics and expanded the field's horizons. In Rethinking Geopolitics, Ó Tuathail and Dalby (2002) introduce five arguments that critical geopolitics has advanced in its brief history, which are also relevant to this dissertation.

1) Confronting and analyzing the geopolitical imagi-nation of the state - Dalby and Ó Tuathail view the establishment of the state as a national community as a geopolitical act. An argument that critical geopolitics has advanced, therefore, is to disrupt the notion that nation-states as 'imagined communities' (Anderson 1983) possess fixed identities (Dalby \& Ó Tuathail 2002, p.3). Critical geopolitics thinkers therefore share "a sense of scholarship as itself a textual intervention, disrupting the easy narratives of state power" (Dahlman 2009, p.107). To that end, critical geopolitics departs from the state-centered scholarship of international relations and political science, instead focusing "on the effects of geopolitical statecraft on the lives of those who endure the messy reality it produces" (ibid., p.107).

\footnotetext{
${ }^{63}$ It should also be mentioned that Agnew's discussion of the modern geopolitical imagination echoes many of the same sentiments. "World politics was invented only when it became possible to see the world (in the imagination) as a whole and pursue goals in relation to that 'scale"'(Agnew 2003, p.2),
} 


\section{2) Paying attention to the boundary-drawing practices and performances that}

characterize the state - "States are not prior to the inter-state system but are perpetually constituted by their performances in relation to an outside against which they define themselves. Foreign policy involves the making of the 'foreign' as an identity and space against which a domestic self is evoked and realized" (Dalby \& Ó Tuathail 2002, p.4). Gregory -not a self-proclaimed scholar of critical geopolitics but whose recent work could be labeled as such — expands on Said's imaginative geographies (1978) in a manner that is evocative of this point, "These are constructions that fold distance into difference through a series of spatializations," furthermore, they are employed to demarcate "the same" from "the other" (2004, p.17). Gregory stresses that these imaginative geographies are not static — they are performed. In this regard he writes, "representations are never merely mirrors held up to the world; they enter fully into its formation" (ibid., p.xiii) and "imaginative geographies are not only accumulations of time and, sedimentations of successive histories; they are also performances of space" (ibid., p.19). For example, Gregory's central example of a 'performance of space' is the Bush administration's reaction to the $9 / 11$ attacks. In the first place, there was the projection of America as a confined space that involved sealing the borders and airspace of "the homeland". Secondly, al-Qaeda, a fluid network spread throughout over forty countries, was fixed to the bounded space of Afghanistan, which then became a point of attack for a U.S. military response (ibid., p.50). Critical geopolitics, therefore, “....approaches geopolitics not as a neutral consideration of pre-given 'geographical' facts, but as a deeply ideological and politicized form of analysis. It shows that geographical 
claims are necessarily geopolitical, as they inscribe places as particular types of places to be dealt with in a particular manner" (Dodds et al. 2013, p.6).

3) Acknowledging that geopolitics is a plurality - In his call for a more localized geopolitics, Ó Tuathail laments that critical geopolitics scholarship has tended towards the macro level of analysis, localizing in a limited sense when considering, “...the closeted world of decision makers, a largely secret world only available at a distance through public statements, journalistic treatments and insider books" (2010, p.257). Three years later, Dodds, Kuus, and Sharp's sentiment would seem to indicate that the field is moving in the right direction, “...critical geopolitics shows that there is no single tradition of geopolitical thought or practice. There are rather different geopolitical cultures owing to specific geographical contexts and intellectual traditions around the world" (2013, p.9). For example, feminist geopolitics emerges as a critique of critical geopolitics, enhancing the field by revealing how international geopolitics functions at the local and personal levels and thus shifting the focus of attention from the analysis of states to other referents such as 'the body'. Dowler and Sharp explain that the purpose of feminist geopolitics is, “...to link international representation to the geographies of everyday life; to understand the ways in which the nation and the international are reproduced in the mundane practices we take for granted" (2001, p.172). Inspired by feminist geopolitics, “...the term 'subaltern geopolitics' opens up a space to explore those not outside or against the geopolitical system, but who are nevertheless disadvantaged in the global webs of power and their 'subordinating modes of representation"” (Craggs 2014, p.42 citing Sharp 2011a, p.272). Koopman (2011) coins the term 'alter-geopolitics', which she theorizes as a reconstructive form of feminist geopolitics, in her analysis of 'protective accompaniment' in which privileged bodies of the Global North protect endangered Colombian bodies (p.274). 
Feminist geopolitics and its variants, therefore, underscore the notion that territorial geopolitics "is contextualized and sustained by a more pervasive cultural geo-politics" (Dalby \& Ó Tuathail 2002, p.4).

4) Acknowledging that the practice of studying geopolitics can never be politically neutral - Critical geopolitics is 'a 'situated knowledge' that intervenes to disturb the 'god trick' of traditional geopolitics, which claimed to represent effortlessly the drama of international politics as an intelligible spectacle without interpretation" (Dalby \& Ó Tuathail 2002, p.6). Furthermore, critical geopolitics works, “... to insist on the situated, contextual and embodied nature of all forms of geopolitical reasoning" (ibid.). In referencing Haraway's notion of 'situatedness' and the feminist term 'embodied', Dalby and Ó Tuathail remind us that we cannot escape our own subjectivity, however, it behooves us as critical scholars to disclose our predilections, disallowing the possibility of one god trick being replaced by another. Smith argues that Ó Tuathail himself is guilty of presenting "pre-existing geopolitical texts viewed and read by the detached theoretical eye/I" (2000, p.368, original emphasis). This may be the case, particularly because scholars can only strive to acknowledge their situatedness and can never actually do so completely. Smith's contention that Ó Tuathail does a nice job of discussing the racial and gendered undertones of geopolitical discourses while neglecting class, is illustrative of this point (ibid., p.367). In counterpoint, scholars writing in this field must continually remind readers that critical geopolitics is itself a form of geopolitics (Dalby \& Ó Tuathail 2002, p.6).

5) 'In conceptualizing geopolitics as 'situated reasoning' a critical perspective also seeks to theorize its broader socio-spatial and technoterritorial circumstances of 
development and use" (Dalby \& Ó Tuathail 2002, p.6). Such circumstances include the ways traditional geopolitics has influenced society and the state through: the adoption of visualization techniques (e.g., cartography and geography), techno-territorial networks (e.g., highways and the internet) as well as military strategies and technologies (e.g., defensive perimeters and strategic bases). To that end, critical geopolitics situates its analysis of geopolitics by drawing upon literatures focused on the historical expansion of states, techniques of governmentality, and histories of technology and territoriality (ibid., p.6).

\section{The Critical Geopolitics of Security in the War on Drugs}

Officials in both the U.S. and Colombian governments promoted aerial eradication — the illicit crop eradication strategy most frequently employed, especially in "dangerous" and difficult-to-reach parts of the country with the least amount of state presence - as a means to "secure Colombian territory". The theorization of security discourses, therefore is critical to this dissertation because conflicting notions of security factor into the establishment of ethnic territories, the justifications for aerial eradication in the defense of national territory, and the defense of ethnic territories. For the most part, this section does not cite the critical geopolitics literature discussed above. Rather, the intent here is to perform critical geopolitics by deconstructing these different security discourses, mostly understood as expressions of traditional or dominant geopolitics, and suggesting that alternative forms of geopolitics are possible.

National security in the context of this dissertation refers to two sets of discourses -Colombian national security and U.S. national security - that serve the respective territorial interests of each country. As explained in the introduction chapter, the 
declaration of the War on Drugs as a matter of national security served to legitimize U.S. intervention in "unstable" drug-producing regions of the world. Colombia, a country with a protracted civil conflict related to land distribution, has struggled to maintain control of the entirety of its territory throughout its history (Richani 2002). As Le Billon explains in his 'political ecology of war', “...the greater the distance or difficulty of access from the centre of control, the greater the cost of control and the higher the risk of losing the resource to the adversary” (2001, p.570). Thus 'Colombian territoriality' -the territorial control of the ruling elite rooted in the Andean highlands (Flórez López 2012)— has historically been limited in its reach. Of the various armed groups at play in the control of Colombian territory in the last few decades -the military, guerrilla groups, paramilitaries, criminal bands - it has been the guerrillas that have most explicitly challenged Colombian territoriality. Thus large portions of the Colombian countryside, conceived in U.S. think tanks as "lawless areas" or "ungoverned territories" (Vargas 2011, p.3), have been 'imagined geographically' (Gregory 2004) as spaces of chaos and danger.

From a critical geopolitics perspective, it could be argued that both the aerial eradication of illicit crops and the recognition of ethnic territories have served U.S. and Colombian national security interests. In the first place, aerial eradication has been explicitly justified as matter of national security in accordance with the counterinsurgency and counternarcotics objectives outlined in Plan Colombia. In the second place, the connection between national security and the establishment of ethnic territories is not well established but is worth developing here. Mason, for instance, cites the example of Peace Communities established with the Emberá population and the Catholic Church in Colombia because the national government is unable to protect this 
indigenous community. She concludes, "alternative sociopolitical agreements are not always competing claims to authority that imply state diminishment, but rather, under certain conditions, may actually contribute to the reaffirmation or enhancement of state legitimacy" (Mason 2005, p.50). Ng'weno argues that the establishment of collective ethnic territories contributes to Colombian territoriality and ideology in two ways:

First, it grants legitimacy to local groups (and thus also to the state), who provide an alternative power center within the territory. Second, it physically fragments the territorial control of armed groups and reestablishes the state as the dispenser of jurisdictions. The combination of enfranchisement and fragmentation enables the state to extend its reach and jurisdiction (2007, pp.189-190).

These assertions appear more rooted in Ng'weno's theorization of territoriality and the production of Afro-Colombian identity, however, than official discourses that explicitly define this connection between establishing ethnic territory as a means of national security.

Nevertheless, scholars that describe the territorial turn as a form of neoliberal governance (Hale 2011; Bryan 2012), argue that global lending institutions (namely the World Bank) encouraging the titling of ethnic territories are attempting to integrate these isolated regions of the world into the global capitalist market. "Economically, these 'empty spaces' become grey zones, which sequentially or even simultaneously encompass both fabulous profits from unregulated economic activity and the constant threat of economic breakdown due to the absence of effective state presence" (Hale 2011, p.193). This fits well with Le Billon's assertion that the Global South "has effectively reintegrated itself into the liberal world-system through a 'non-liberal' inclusion consisting in the spread and deepening of all types of parallel and shadow transborder 
activities many of which requiring in turn specific forms of governance" (2001, p.576 citing Duffield 1998).

In the context of state geopolitics, the unregulated economic activity conducted in these empty spaces poses a security threat. Mitchell's observations about the dominant geopolitical imagination of ungoverned space echo that sentiment, "...secure space is space which is globally integrated. Insecure space, by contrast, exists in 'the gap,' the neighborhoods or regions which remain disconnected from the global market" (2010, p.294). As Hale notes, these spaces are not actually empty "in the literal demographic sense" but they are for capital investors in the sense "that neither the people nor the places play important roles in the newly globalized economy" (2011, p.192). The titling of property to ethnic communities then "does achieve the key goal of replacing chaos and contention with an intelligible, predictable and market friendly grid of property rights" (ibid., p.195).

The above theorization of the territorial turn in the national security context makes little sense, however, when one considers the violence ethnic territories have endured in Colombia. Indigenous and Afro-descendant communities in Colombia have suffered some of the worst violations of human rights and that continues to be the case, even after the territorial turn. In what sense has the establishment of ethnic territories enhanced national security then? From a critical perspective, 'national security' only applies to those imagined as part of the nation. In this particular context "the descendants of the criollos - literate, modern, urban, and preferably Andean elites - are the ones who have historically incarnated the state in Colombia. Since their imagination embodies what the nation is, it also defines the antonymous non-nation, the wild 'Other' that is in need of 
taming” (Serje de la Ossa et al. 2007, p.39). For Ramírez, strong state presence in the central areas of the country is contrasted by 'the state's and armed forces' metanarrative of reconquering marginal territories in which the influence of the central state is compromised by the presence of illegal crops and nonstate armed actors" (2010, p.104). She argues that this dynamic has sustained, what is sometimes referred to as "one of Latin America's oldest and strongest democracies" because this reconquest seeks to eliminate political alternatives to Colombia's "long-term exclusive duopoly of traditional political parties" (ibid., pp.85-86).

Critiques of former President Álvaro Uribe's democratic security policy (20022007) support this conceptualization of a divided Colombia with limited political alternatives. Under this policy, military and police presence was increased across the country in an effort to intensify the war against the guerillas (Elhawary 2010, p.394). However, as Elhawary notes, democratic security refers to the stabilization of the state and not necessarily the protection of all civilians. While Uribe's campaign drastically reduced the number of guerilla soldiers and improved security in urban areas, the situation for the rural poor actually deteriorated because of increased paramilitary activity and associated human rights violations (ibid.) (further discussed in Chapter 5).

Oslender's geographies of terror framework is in part a response to studies that lauded 'democratic security' as a success while glossing over "the unequal geographies" inherent in the presentation of statistics, which indicated a reduction in certain types of violence but only told one side of the story (2008a, p.79). In broader terms, his framework challenges the conception of 'terror' in dominant contemporary geopolitical discourses, which “...define terrorism exclusively as directed against the Western 
neoliberal democratic state, while at the same time hiding 'other terrorisms,' including those applied by these very same Western neoliberal democracies" (ibid., p.81). The framework thus seeks to "help us to understand the manifold manifestations of terror on the ground" and the ways local populations resist terror (ibid., p.80). In doing so, Oslender also theorizes the spatial implications of the massive displacement of rural peasants thereby subverting the normalization of 'displaced person' as a category Colombians have become accustomed to (2007b, p.756). Citing the concept of 'territorial conditioning' (Bejarano et al. 2003), he writes, “...these lands have to be 'prepared' emptied- for the entrance of capital-induced development in the Pacific coast region that would otherwise meet with local resistance" (Oslender 2007b, p.759).

The above quote underscores the perception, especially amongst activists supporting ethnic communities, that the displacement of poor rural communities in Colombia is intentional. Escobar frames such violence in the larger context of neo-liberal capitalist expansion. He employs the concept 'imperial globality', to detail how mechanisms of U.S. imperialism have evolved since the first Gulf War, facilitating, "...the rise of an empire that increasingly operates through the management of asymmetrical and spatialized violence, territorial control, sub-contracted massacres, and 'cruel little wars,' all of which are aimed at imposing the neo-liberal capitalist project" (Escobar 2004, p.7 citing Joxe 2002). In explaining how imperial globality translates to the local context of the Pacific region of Colombia, Escobar writes, "To put it bluntly, the Pacific is being subjected to the territorial and cultural imperatives of imperial globality; this project must be seen as a simultaneously economic, ecological, and cultural 
reconversion, a reconfiguration of the biophysical and cultural landscapes of the Pacific" (2008, p.64, his emphasis).

\section{The Two-headed Monster of Imperial Globality}

This dissertation further adapts the concept of imperial globality and applies it to the wider context of the War on Drugs globally. The two-headed monster of imperial globality is a metaphor I have invented to explain the extent to which the counternarcotics efforts and the demand for drugs wreak havoc on bodies, ecosystems, and ways of being. One head of the monster is drug production and trafficking, largely mobilized to satisfy the demands of U.S. and Western European consumers. This head is composed of non-state armed actors, corrupted state actors, cultivators, violence, chemicals, and many other components that factor into the drastic transformation of the 'biophysical and cultural landscapes' of drug-producing regions. The other head of the monster is the War on Drugs, the "Euro-Americanist" (Slater 2004) framing of narcotics as an external threat emanating from the 'Third World', and therefore a mandate for U.S. intervention in Latin America.

In Colombia this war has been mobilized by the criminalization of drug production and trafficking, which historically has been conflated with the counterinsurgent objectives of the ongoing civil conflict. In distinction to Peru and Bolivia, both with longer histories of recognizing legal coca cultivation and developing alternative strategies in lieu of forceful eradication, the Colombian War on Drugs has resulted in a "blanket stigmatization and criminalization" of drug-producing and trafficking regions linked to the FARC (Ramírez 2011, p.56). In the context of her case study on aerial eradication protests in the 1990s, Ramírez explains, "Seen from the Colombian center, Amazonia is an internally homogenous region, 
'the Other Colombia' according to the state, or 'the New Colombia' in the discourse of the FARC, reflecting its own presence and control"' (ibid., p.82). The criminalization of these peripheral drug-producing regions, therefore, becomes the basis for the denial of citizenship, displaced person status, and basic human rights. This relates to Fraser's 'membership principle', in which, 'Justice is by definition a political concept. Its obligations apply only to those who stand to one another in a political relationship. So determination of the 'who' of justice depends on what exactly counts as a political relationship" (2010, pp.288-289, original emphasis).

\section{The Geopolitics of Knowledge Production}

Ramírez's theorization of the coca grower movement in the Colombian Amazon is illustrative of the ways that marginalized populations can respond to such political exclusion by performing geopolitics through identity construction. In her study she details how certain Colombian state institutions viewed coca growers as 'criminals' for growing an illegal crop and, at the same time, labeled coca growers 'insurgents' or insurgent 'auxiliaries' because they resided in areas occupied by guerillas (Ramírez 2010, p.94). Coca growers responded by adopting two identities in defiance of these perceptions. They unified under the name cocaleros (coca leaf growers) in protest of the aerial fumigation conducted to eradicate illicit crops (Ramírez 2011, p.2) and called themselves campesino colonos (peasant settlers) or campesino cocaleros (peasant coca leaf growers) to distinguish themselves from the violent activities of mafias that process and traffick coca paste (ibid., p.35). Thus Ramírez describes

how cocaleros demanded their rights as Colombian citizens through protests, reasoning, “...it can be argued that the cocaleros were simultaneously inside and outside the law. As coca growers they were considered criminals, yet they rejected that status by exercising their right to 
participate as citizens" (ibid., p.8). Thus Ramírez's assertions reinforce the notion that subalterns can embody "an ambiguous and shifting relationship to dominant geopolitics" in which "geopolitical identities can be performed" (Craggs 2014, p.42).

Afro-Pacific communities have responded to the two-headed monster differently than Amazonian communities, though it can be argued that both sets of communities have employed their own geopolitics of knowledge as a means of contesting these impositions. For Escobar this term represents the type of knowledge produced through the political ecology of difference. He writes, "Besides questioning Western discourses, these trends pay attention to the epistemic potential of local histories embedded in or arising from the colonial difference, locating there some of the most meaningful sources for political action and for alternative world constructions" (Escobar 2008, pp.22-23). In a similar regard Slater describes the 'geopolitics of memory' as, “...the deployment of a critical memory that re-invigorates previous oppositional imaginations as well as re-examining past events that official narratives sometimes erase or belittle" (2004, p.230). Both the geopolitics of knowledge and memory are relevant to the 'subaltern geopolitics' framework Sharp (2011b) has developed, which highlights the presence of marginalized voices in geopolitical discourses. All three of these terms - geopolitics of knowledge, geopolitics of memory, and subaltern geopolitics- could be used to describe the struggle to establish black territory, the ways 'black territory' challenges dominant political narratives, and the ways black communities have positioned themselves as geopolitical actors articulating alternate ways of understanding, using, and regulating space.

Thus, returning to the two-headed monster of imperial globality, Afro-Pacific communities perform geopolitics in three important ways. In the first place, they reject the stigmatization of drug-affiliated criminality by calling attention to the fact that coca cultivation 
and eradication are driven by external demands. In doing so, they draw on a history of "colonial difference" (Escobar 2008) and operationalize "oppositional imaginations" (Slater 2004) to challenge the conceptualization of black territories as lawless spaces of illegal activity. In the second place, black communities challenge technologies of displacement discourses of development, conservation, biodiversity, and security — by articulating alternative versions of these discourses. These alternative discourses both validate local epistemologies and mark technologies of displacement as 'foreign' concepts, not applicable to the context of black communities in the Pacific region. Lastly, Afro-Pacific communities not only "confront and analyze the geopolitical imagi-nation of the state" (Dalby \& Ó Tuathail 2002), but also participate in the "radical redefinition of the state itself" (Agnew \& Oslender 2013) by leveraging domestic and international laws designed to protect ethnic territorial rights.

Chapter 5 "Insecurities" will further elaborate on this discussion, further examining the security concerns that factored into the promotion of aerial spraying as the predominant form of illicit crop eradication in Colombia and presenting some of the alternative security concerns articulated by black communities (e.g., human security, food security). As mentioned earlier, critical geopolitics pays close attention to the limits of cartographic representations of the world and the bias towards visual modes of representation -both products of dominant geopolitics - that maps perpetuate. Thus, chapters 4,5 , and 6 will also integrate theory about how maps are looked upon as a particular mode of geopolitical performance.

The final section of this chapter discusses literature that critiques dominant geopolitical imaginations of space in map form and briefly reviews mapping literature that suggests alternative forms of geopolitics are possible. 


\section{Critical \& Constructive Cartographies}

The challenge of most maps of the last five hundred years is that in trying to make sense of the universe, they do not account for 'loose ends and ongoing stories' (Massey 2005, p.109).

The term 'cartography' originated in the 1800 s when numerous trades became 'professionalized' through the Latinization of their titles. 'Gravediggers turned into morticians. Newsmen became journalists. Teachers turned into educators. Mapmakers became cartographers"(Wood et al. 2010, pp.156-157). Critical cartography became known as a field in the 1980s and 1990s "in opposition to post-war epistemologies of mapping" (Crampton \& Krygier 2006, p.16). Crampton argues that other forms of critical mapping have existed long before then as "subjugated knowledges" disqualified as "not scientific" in many instances (2010, p.4 citing Foucault 2003). Occasionally these 'subjugated knowledges', "sometimes speaking out from below", surface and "it is the reappearance of these local knowledges alongside the official grand narratives that actually allows critique to take place" (Crampton 2010, p.4). Critical cartography, therefore, challenges the power claims made when states and other authoritative institutions visually establish 'knowledge' through maps when other forms of knowledgemaking demand recognition.

Crampton outlines four characteristics of critical cartography: 1) maps are useful ways of organizing and producing knowledge but also incorporate "unexamined assumptions" which act as limits that deserve to be challenged; 2) one way to challenge the ordering of knowledge is through the "historicization of knowledge" and another way is to demonstrate the "spatialization of knowledge" between different places and 
cultures; 3) critical mapping holds that geographic knowledge exists in relation to power and maps are political; and 4) critical mapping has an activist, "emancipatory flavor to it" (2010, p.17, original emphasis.).

The limitations of critical cartography as an activist form of geography are quite apparent, however. "There seems to be a tendency among critical theory informed geographers to simply deconstruct maps, rather than to construct them" (Herb et al., p.332). There are a number of approaches that have developed in the spirit of constructing maps based on local knowledge -countermapping (Peluso 1995; Walkers \& Peters 2001; Wainwright \& Bryan 2009; Dalton \& Mason-Deese 2012), social cartography (Paulston \& Liebman 1994; Offen 2003), and indigenous mapping (Bryan and Wainwright 2015) — that have answered the call of this criticism. Such approaches often go hand-in-hand with critical cartography as "social movements employ spatial and cartographic knowledges in order to analyze and transform existing spaces and prefigure alternative ones" (Herb et al. , p.339, my emphasis). In this dissertation, these approaches are subsumed under the term countermapping because it is broad enough to encompass other forms of community-based mapping while signaling the political intentions of these approaches.

Peluso (1995) coined the term 'counter-mapping' to describe an alternative approach to the types of maps created by government forest agencies and development institutions involved in the Indonesian timber industry. In the most basic sense, 'countermaps' or 'alternative maps', as Peluso suggests, “...greatly increase the power of people living in a mapped area to control representations of themselves and their claims to resources" (ibid., p.387). Furthermore, "Counter-maps thus have the potential for 
challenging the omissions of human settlements from forest maps, for contesting the homogenization of space on political, zoning, or property maps, for altering the categories of land and forest management, and for expressing social relationships in space rather than depicting abstract space in itself" (ibid.).

It is important to recognize, however, that countermapping carries its own theoretical and methodological concerns, especially with regard to the cartographic forums where ethnic communities determine the boundaries of their territories. In the first place, mapmaking often entails uneven participation that may reflect the hierarchies already present within the communities making maps (Offen 2003; Wainwright \& Bryan 2009). In the second place, a community defining its borders is also a process of exclusion, which may lead to territorial conflicts with neighboring communities (Offen 2003; Wainwright \& Bryan 2009; Oslender 2016b). And finally, "In the worst case, countermapping could reinforce existing property boundaries while obscuring nonterritorial resource rights" (Walker \& Peters 2001, p.422). These concerns call attention to the fact that countermapping, an approach that challenges the uneven dynamics of power and distribution of resources, can replicate some of the same conditions at the local scale of knowledge production. These concerns are also worth mentioning because the 'struggle for black territory' is not just a territorial struggle against external actors but is also an internal struggle to maintain open participation, negotiation, and consensus decision-making. Such struggles are not at all unique to black territory and reflect the challenges of ethnic communities elsewhere in the Americas, striving to "enact sovereignty" (Erazo 2013). 


\section{The Cartographies of Aerial Eradication in the Afro-Pacific}

In this dissertation, which first describes the construction of Afro-Pacific territory as a means to explain the 'defense of territory', it is important to discuss countermapping because all forms of maps shape "identities and spaces" and because "the cartographic imagination has influenced the very structure and content of language and thought itself' (Pickles 2004, p.12). For example, Offen describes his impressions of the territorial turn in the Afro Pacific, "As with participatory mapping projects elsewhere in Latin America, much of the territorial consciousness arises through and during the process of talking about space and its meaning in cartographic forums" (2003, p.61). The critical and constructive cartographies in this project are largely inspired by the types of 'subjugated knowledges' that surface when countermapping is employed in the defense of black territory. However, having only been exposed to elements of countermapping and the territorial consciousness, through interviews and observation, and not actually participated in a community-level mapping project, it would be disingenuous to claim that this project employs countermapping or somehow represents local knowledge through maps.

This study then interrogates the assumptions upon which a particular cartography of power relations is based (aerial eradication in the War on Drugs) and generates new maps that challenge those assumptions. It pays special attention to the way "...territories are produced by the overlaying of inscriptions we call mappings" (Pickles 2004, p.5) and the implications for overlapping forms of territoriality (Agnew \& Oslender 2013). It problematizes the dominant geopolitical imagination of 'insecure space', which can often 
cause different types of insecurities for local populations (further discussed in Chapter 5).

Lastly, this project produces new maps, which do not purport to represent local

knowledge; rather these maps are presented as alternative narratives of aerial eradication, what might be considered 'constructive cartography for socio-environmental justice'. The next three chapters feature some of these critical and constructive cartographies of the aerial eradication of coca in Afro-Pacific Colombia. 


\section{CHAPTER 4}

\section{Territorialities: Aerial Eradication and the Overlap between Colombian Territoriality and Black Territoriality}

Global anti-drug policy is unidirectional in that it is often imposed without the consultation of local governments or civil society in affected regions. This reinforces pre-existing constraints on attempts by the marginalized population to make itself visible through demands for citizenship in civic, political, social, and cultural terms (Ramírez 2011, p.229).

Unfortunately, María Clemencia Ramírez’s reflections on the protests against aerial eradication in the 1990s remain relevant today. What happened in Putumayo (a department of the Colombian Amazon region) twenty years ago set the stage for the eventual expansion of coca cultivation to the Pacific region in the 2000s. Despite the protests the aerial eradication program also expanded its reach into the Pacific, increasingly affecting black and indigenous communities supposedly basic human and environmental rights by the Colombian constitution.

This chapter overviews the development of territorial consciousness of black communities, the spread of coca cultivation to the Afro-Pacific, reasons why black communities would like to participate in the eradication process, the right to previous consultation, some of the logistics of aerial eradication operations, the problems with the aerial eradication complaint process, and some of the territorial repercussions of aerial eradication. I argue that, in the process of asserting 'Colombian territoriality', the aerial eradication program simultaneously obscured the presence of black communities and undermined black territoriality.

\section{Social Cartography and Territorial Consciousness in the Afro-Pacific}

As noted in Chapter 3, black communities prefer to think about their collectively titled lands in terms of 'territoriality' versus 'land titles' because only territoriality 
"encompasses the idea of territory as a social, cultural and material space" (Asher \& Ojeda 2009, p.299). PCN leaders often speak of 'the territory' (el territorio), which can be confusing because this term may refer to an individual community, all black communities of the Pacific region, or the collection of values, traditions, and beliefs that PCN espouses as important to black communities. 'The territory' is synonymous with 'black territory' or 'Afro-descendant territory' (discussed in Chapter 3) as well as life itself (See Figure 4.1). 'The territory' has not only been constructed discursively -by drawing upon a history of freed and escaped slave settlement in the region, establishing an ecological connection to the land, and articulating 'black community' as a political unit (discussed in Chapter 3) - but also through the material processes of marking and labeling the space of the territory.

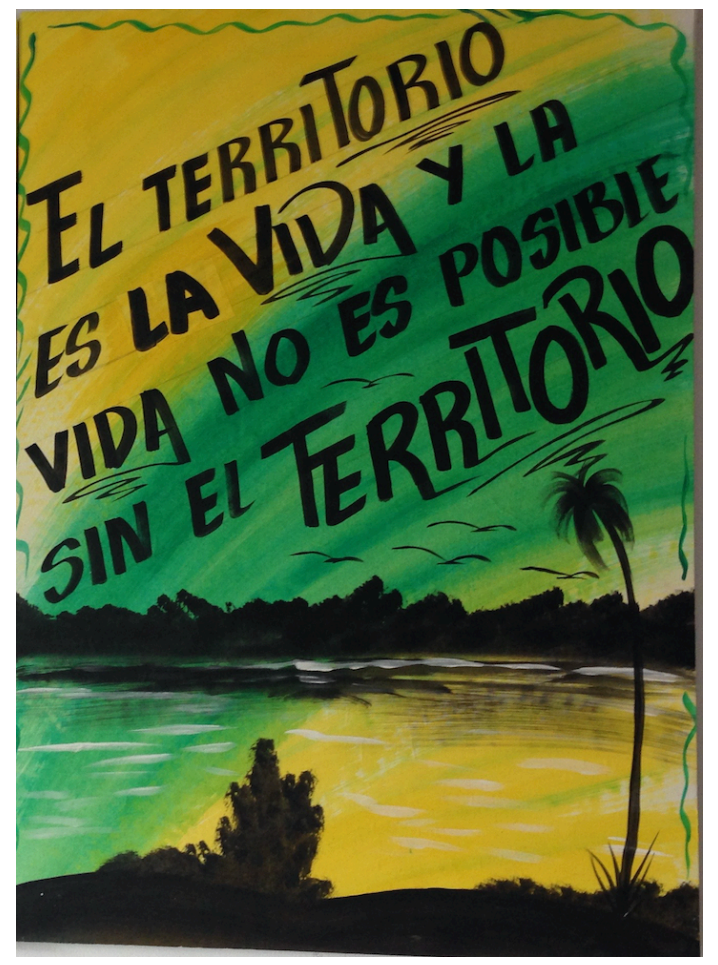

Figure 4.1 - Painting inside of PCN office in Buenaventura It reads, "The territory is life and life is not possible without the territory." (photo credit: Alexander Huezo) 
Escobar describes how these processes began after the issue of a constitutional reform (Transitory Article 55), which enabled the passage of Law 70, the law that allowed for black communities to be invested with the rights to collective titling. He describes two important moments that resulted from these events. With regard to the first moment:

...local organizations developed a series of technologies, such as monteos, literally traversing the monte or forests/territory with the entire community to recognize places of habitation, cultivation, and hunting and gathering, past and present; the collective drawing of color maps on large sheets of paper, not infrequently done by the young under the instructions of old people; the gathering of oral histories and traditions...(Escobar 2008, p.55).

The second moment entailed the participation of external actors such as NGOs, academics, experts, and international organizations in workshops in which local-based participatory workshops became intertwined with satellite and GIS-based cartography (ibid, p.55-56). In these workshops, which eventually became known as 'social cartography forums', Afro-descendants sketched hand drawn maps (croquis) of how they conceive their community from memory under the direction of national government agencies. Escobar juxtaposes these 'mental maps', which encompassed social and ecological aspects of the territory such as, “...production systems, history of the settlement, tenancy, local projects, hunting and gathering, visions of the territory, local knowledge of plants and animals, informal borders, commerce...", with the more technical satellite-based maps that highlighted geomorphology and vegetation (ibid. p.56). 
Offen observes that territorial units were formed according to 'the logic of the river', which involved drawing boundaries around settlements connected by waterways and traditional patterns of land use that date back generations (2011, p.290 citing Oslender 2002). It is important to note that African slaves were originally brought to the Pacific region to mine gold at the end of the 1600 s because the native population was decimated by disease, war, and the hardships of the mining camps (Motta González 2005, p.96). Slaves obtained their freedom through self-manumission via income generated from mining during leisure time and by maroonism (escaping away into the wilderness), which led to the consolidation of freed slaves into settlements known as palenques (Escobar 2008, pp.46-47). Offen mentions that troncos, social networks formed from newly freed black miners following the abolition of slavery in 1851 , played a role in the boundaries drawn during the mapmaking process because the troncos consist of "groups of families who trace their origin to a common ancestor with rights to live, mine, fish, and farm in a specific watershed" (Offen 2011, p.290 citing Friedemann 1998). Oslender notes, “...there is a degree of flexibility in the ways a person may 'activate' these rights: 'An individual can choose to affiliate with one tronco in preference to another through options provided by either a maternal or a paternal link" (2016b, p.117, citing Friedeman $1985, \mathrm{p} .211)$

These social cartography forums not only factored into the conceptualization of 'the territory', but also into the new material realities that resulted from the demarcation of space. On the one hand Offen observes that these forums were intrinsic to the development of territorial consciousness: 
For leaders to articulate black territoriality is one thing, but for communities to come together to define their collective boundaries based on historical and contemporary land use, as well as estimations of future needs, is quite another. As with participatory mapping projects elsewhere in Latin America, much of the territorial consciousness arises through and during the process of talking about space and its meaning in cartographic forums (2003, pp.60-61).

On the other hand, Offen notes that the demarcation of space can affect social relations in unpredictable ways, "When locally negotiated space is rigidly territorialized, it creates a binary order of inclusiveness and exclusiveness that necessarily modifies social relations that once spanned spatial boundaries" (2003, p.64). Oslender expresses mixed feelings about the rigidity of this territorialization because "this act of marking boundaries of inclusion and exclusion has at times led to tensions in interethnic relations between indigenous and black communities," while at the same time "given the increasing penetration of capital in the region, the drawing of clearly established boundaries does protect the land rights of both indigenous and black communities (at least on paper)" (2016b, p.182). With regard to his comment "at least on paper", Oslender tellingly remarks in an earlier publication, "Yet it was precisely at the moment when rural black communities began to receive their first collective land titles that they were pushed off their lands" (2007b, p.754). Thus when PCN leaders spoke of 'the territory', it was most often in the context of the 'defense of the territory'. 


\section{The Defense of Territory}

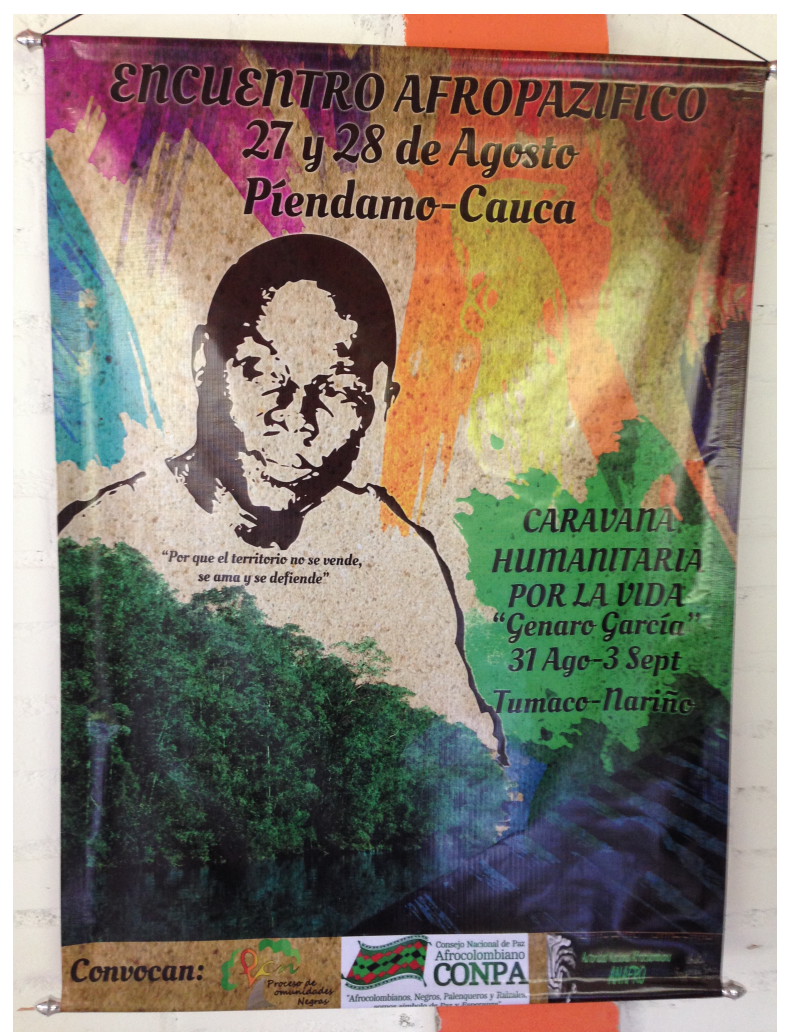

\section{2 - Poster for Encuentro AfroPazífico}

This event preceded the Humanitarian Caravan for Life (mentioned on the right side of the image). The man pictured in the poster is Genaro García, a PCN leader and president of the community council of Alto Mira y Frontera in Nariño. Described as a tireless defender of black community rights, he was assassinated on his way to meet with FARC officials on August 3, 2015 (Arias 2015). The quote beneath his image states, "The territory is not for sale, it is to be loved and defended". The caravan -constituted of Afro-descendants, indigenous, and campesinos - traveled from Pasto to Tumaco to deliver food and supplies in the wake of multiple FARC attacks on Tumaco. (photo credit: Alexander Huezo)

PCN organized a workshop entitled Encuentro AfroPazifico on the $22^{\text {nd }}$ anniversary of the passing of Law 70 in Piendamó, Cauca (see Figure 4.2). The workshop was comprised of residents from eight black communities throughout the southwestern Pacific region that came together to discuss different issues affecting their communities. In honor of the occasion PCN leader José Santos Caicedo spoke about the history and continued importance of 'the territory': 
We are a community, a black community, because we have a shared history and because our grandparents and great grandparents had to sacrifice so much in the construction of this country... The construction of freedom requires territory. So every man and woman from our community will have to continue this struggle. Because if it is not our reborn that will have our territory to construct freedom, it will be the multinationals, the governments, the insurgents, and the paramilitaries that will want those territories to hand them over to others... ${ }^{64}$.

'The territory' -from this point of view - then not only signifies the space in which life takes place but also the struggle to protect lives and ways of life. Human rights and socioenvironmental justice are built into the 'defense of territory' in the face of other territorialities seeking to dispossess black communities of this inheritance.

Following José's speech, PCN leader Harrison Cuero gave a PowerPoint presentation about major issues affecting the territory throughout the Pacific region. He highlighted coca cultivation, aerial eradication, and illegal mining as three central issues impacting currently impacting many black communities. 'Illegal mining' is a massive problem in the Pacific nowadays, especially in ethnic territories. Armed groups (FARC, BACRIM) began mining for gold in the late 2000s when the price of gold soared as an alternative source of income. Illegal mining disrupts traditional gold mining practices that serve as source of income ${ }^{65}$. The giant excavation machines that are brought in wreak havoc on forests and pollute waterways with mercury that is used to separate the gold from other minerals. Illegal mining has caused 19,000 hectares of deforestation in the

\footnotetext{
${ }^{64}$ Paragraph excerpted from José Santos Caicedo's speech at Encuentro AfroPazifico in Piendamó, Cauca on August 28, 2015.

${ }^{65}$ See (Oslender 2008b) for a description of traditional mining practices in the Pacific region.
} 
Chocó department alone and has been associated with human health problems such as muscle tremors and memory loss (Ebus 2016).

The eight community groups separated to different parts of the room to discuss problems in their respective communities, which then had to be presented to the rest of the workshop. Each group was given a large sheet of paper and markers to organize their presentation. Circulating about the room, I noticed that every group immediately began mapping their community, despite the fact that I never heard any instruction about what to do with the paper and markers ${ }^{66}$. Nemesio, a gentleman from Río Guajuí, Guapi, noticed that the neighboring group, comprised solely of teenagers (the rest of the participants at the event were adults), made a map of their community that only featured streets and no waterways. Other adults overheard this conversation and agreed with Nemesio, insisting that the teenage group include the river that their community is named after so that everyone else could understand where this community was located (see Figure 4.3). In the end the teenage group reluctantly drew the river on their map (see Figure 4.4), eventually conforming to the logic of 'aquatic space' that ties the region together (Oslender 2016b). Without the inclusion of waterways it was impossible for the rest of the workshop members to know how this particular community connected to their own communities.

\footnotetext{
${ }^{66}$ José Santos confirmed that each group decided to make a map because that is what they were accustomed to doing, not because they were instructed to do so.
} 


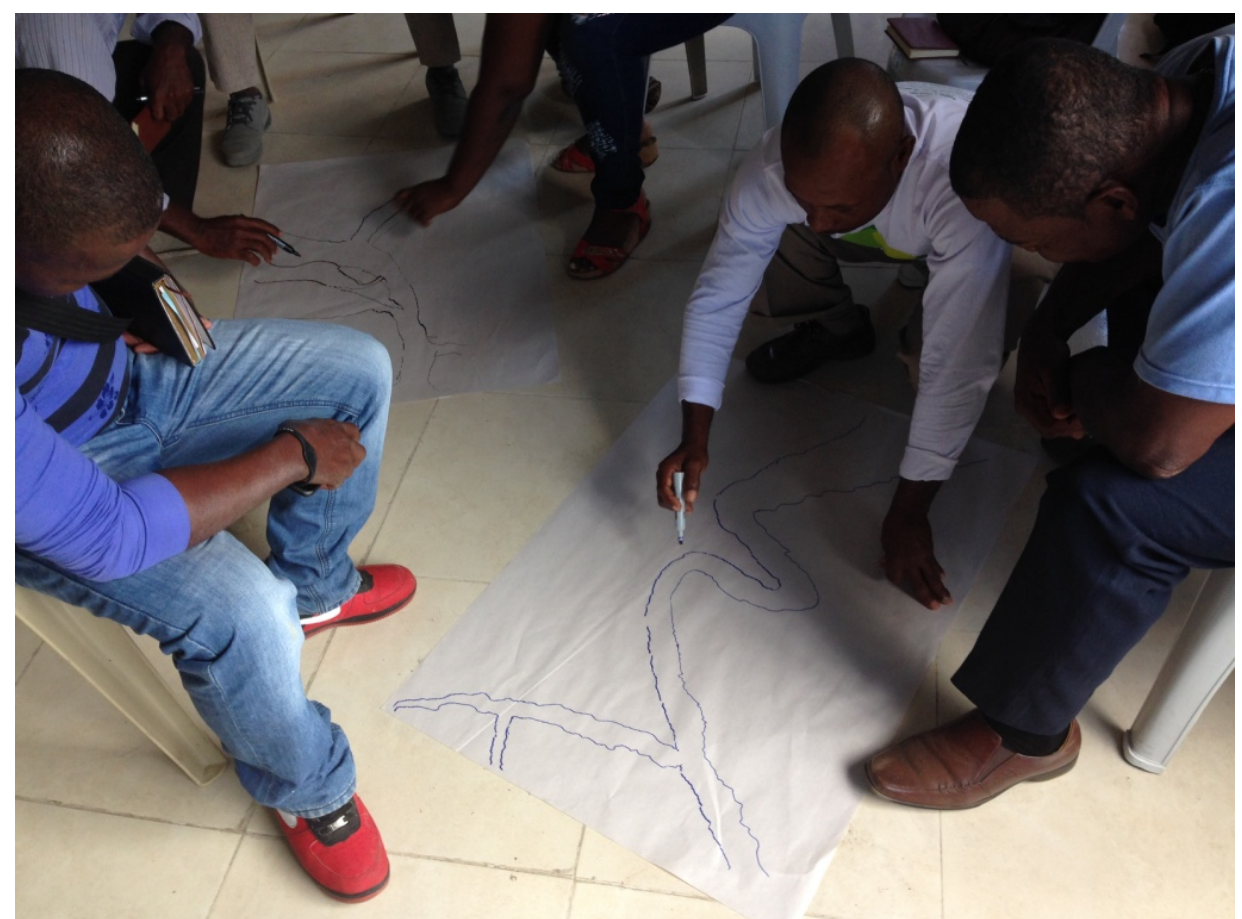

Figure 4.3 - Two groups working on maps at Encuentro AfroPazífico In both cases the groups first drew the main waterways running through their communities before drawing houses or other landmarks.

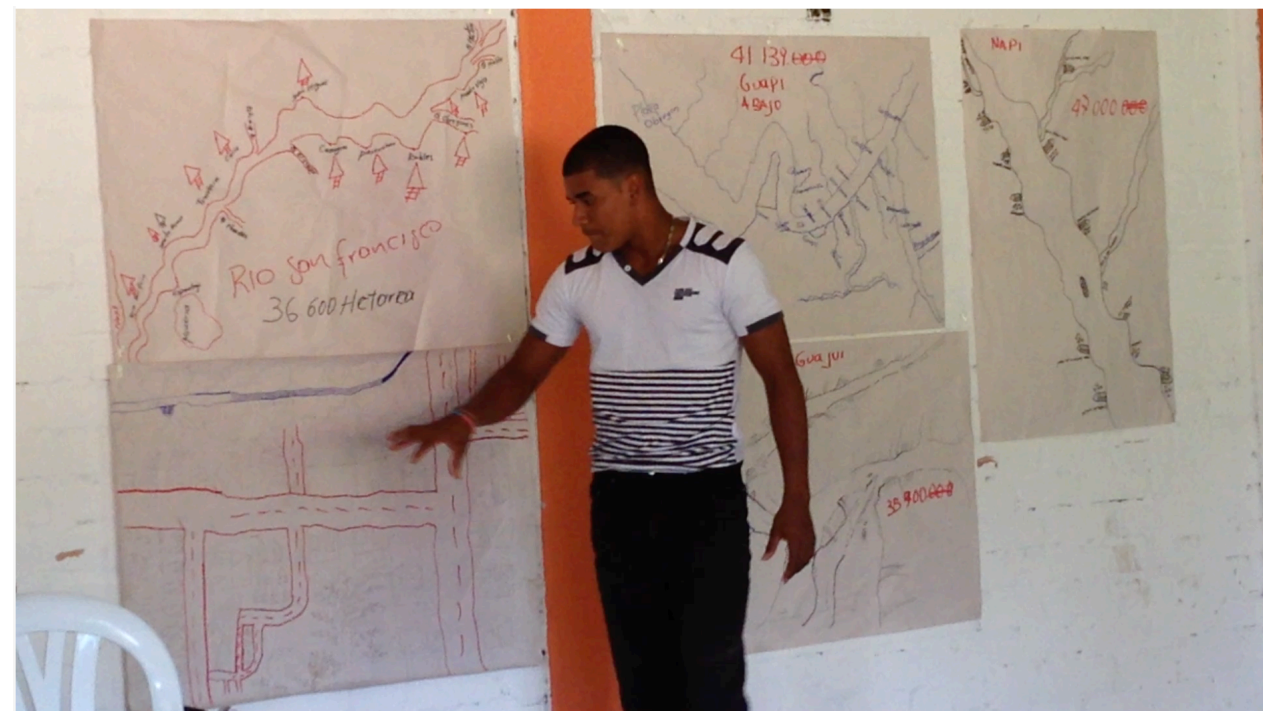

Figure 4.4 - Teenage group poster at Encuentro AfroPazífico

The most outspoken member of the teenage group was chosen to present his community to the audience. Notice that, in contrast to the other community maps, the streets are the central feature of this map. The river that the adults wanted to see is the thin blue line at the top of the map he is motioning to. 
These informal mapping exercises also provided an avenue for communities to informally label and geo-reference the actors disrupting or threatening to disrupt local notions of territory (e.g., armed groups, mining companies, BACRIM...etc.). Disruption in these cases included -but was not limited to- physical harm and forcible displacement as well as the invisible barriers that limit the mobility of community residents ${ }^{67}$. These mapping exercises foster a sense of Afro-Pacific solidarity by allowing participants from throughout the region to share their respective communities' challenges and discuss potential solutions based on common experiences. Coca cultivation and the aerial eradication of coca were two such challenges heavily discussed at Encuentro AfroPazifico and other PCN functions I attended.

\section{Coca Cultivation in the Afro-Pacific}

A common criticism about U.S.-supported illicit crop eradication in Latin America is that these efforts have failed to decrease the amount of illicit narcotics being exported from the region and that the supply has remained relatively steady over time (Moreno-Sánchez et al. 2003; Dion \& Russler 2008; Rincón-Ruíz \& Kallis 2013). The "balloon effect" refers to the phenomenon of illicit crop cultivation being reduced in one region, only to increase in another region (Dion \& Russler 2008, pp.400-401; RincónRuiz \& Kallis 2013, pp.64-65). This effect occurs between the three predominant cocaine-producing countries -Colombia, Peru, and Bolivia - and within these countries. For instance, illicit crop eradication efforts in Peru and Bolivia contributed to a massive increase in the amount of coca cultivated in Colombia in the 1990s-2000s, while more

\footnotetext{
${ }^{67}$ See Oslender (2008a) for a more nuanced discussion of the numerous ways that AfroPacific communities experience 'geographies of terror'.
} 
recent eradication efforts in Colombia contributed to Peru and Bolivia surpassing Colombia in 2012 (The Economist 2013). Within Colombia, coca was cultivated in 12 departments in 1999, which expanded to 23 departments by $2003^{68}$ (UNODC 2004, pp.7\&11).

Restrepo outlines how coca cultivation spread to the Nariño department of the Pacific region in the 1990s following massive aerial eradication campaigns in the Amazonian region $^{69}$ (also discussed in Chapter 1). With the implementation of Plan Colombia, which made aerial eradication a central strategy of counternarcotics efforts, as well as the proliferation of FARC and paramilitary conflicts in the Amazon, many of these colonos (settlers from the Andean region who had moved to the Amazonian region) and raspachines (coca harvesters) left the departments of Putumayo and Caqetá to resettle in Nariño (Restrepo 2013, pp.268-269). For example, in 1999 the town of Llorente had a population of 1,500 inhabitants, which within two years grew by 20,000 with the influx of displaced migrants (ibid., p.269 citing Jiménez 2001). Restrepo specifically identifies three municipalities -Llorente, Barbacoas, and rural Tumaco (Río Chagüí) - as the sites where the majority of coca cultivation shifted to in Nariño (ibid., citing CODHES 2003, p.4).

${ }^{68}$ Colombia is comprised of 32 departments and one capital district.

${ }^{69}$ Coca cultivation first spread to Nariño via Putumayo, a department with strong FARC presence in the most heavily fumigated region of the country in the 1990s and 2000s. I created an animated map in Graphics Interchange Format (GIF) that illustrates the expansion of coca cultivation into southwestern Colombia in the 2000s $<$ https://contestednatures.com/coca-density-in-afro-territories-2000-2013/>. 
As a result of this history, PCN leaders view the cultivation of coca as an extraterritorial activity, something that paisas brought to the region, either through coercive or corruptive means ${ }^{70}$. It should be noted, however, that coca cultivation in Guapi and Buenaventura is typically grown on a much smaller scale than the plantation style coca cultivation found in the Amazonian region (discussed in Chapter 6). Nevertheless, when I asked interviewees about coca cultivation in their community, I had to be very mindful of the fact that someone may not want to answer that question honestly, may only want to discuss the topic in private, or may not want to discuss the topic at all for fear of retribution by non-state armed actors (discussed in Chapter 2). "That is not our culture" was a popular refrain from residents asked their opinion about coca being grown in their communities. As Meertens explains, "In a situation where it is not safe to assume any responsibility nor to make any accusation, the only way to refer to acts and perpetrators of violence is in a neutral form: violence came here yesterday, as if it were an autonomous force and not a human act" (2001, p.138, original emphasis).

For instance, Héctor from Río Naya, Buenaventura, was open to discussing coca cultivation in his community but certainly cautious about identifying the actors involved in this activity:

AH: When did people start to cultivate coca in your community?

Héctor: Around 1995 armed groups begin arriving and with them came the coca and after that, the fumigation.

AH: Did the armed groups force people to participate in the cultivation?

\footnotetext{
${ }^{70}$ Paisa is the Colombian nickname for someone from the state of Antioquia. In the Pacific region it refers to Colombians not from the Pacific (i.e., obviously not black or indigenous)
} 
Héctor: No, they accomplish participation through pedagogies, political pedagogies that achieve a certain consciousness in the community; market politics, economics and business, that reach people and they decide for themselves if it is good or bad, according to their conscience. So it's promoted like this vision of economic income and development that will allow people to change their lives, like when people launch a small company.

AH: So it was viewed as something positive?

Héctor: No, not in any sense was it good. It was great for those that bought into a foreign concept of development, based on a culture that has nothing to do with ours. It could have been great for them but, no, it was not good for the community or the territory. Let's say the community and the territory together are a system and that system is composed of subsystems...so when they arrived (armed groups) they ruined many of these subsystems, so there is no benefit. For those that now subscribe to this new independent system, they benefit, but not at the community level.

AH: So that's how coca cultivation began in your community. What about nowadays? Is it still the same people growing coca or do certain armed groups have more influence over the cultivation?

Héctor: Let's just say it's a system, when one can't define who is and who is not guilty ${ }^{71}$.

By referencing different 'systems' Héctor conceptualized coca cultivation as a destructive logic -foreign to black communities - without incriminating the growers or the armed groups implicated in the regulation of coca. For Héctor, the coca plant itself was not the problem, rather it was the logic behind growing the plants to process them into cocaine that he took issue with. To this point, he later admitted that he has three coca plants that he uses for medicinal purposes, citing the examples of how he cured a knee problem with coca leaf and that he and his young daughter chew coca leaves every morning for a boost

${ }^{71}$ Author interview with Héctor Marino Valencia from Río Naya, Buenaventura at PCN office in Buenaventura on September 22, 2015. 
of energy. I asked Héctor about how he learned the about the medicinal uses of the plant and he explained that it was passed to him through ancestral knowledge ${ }^{72}$.

PCN-affiliated community council representatives, however, were not only outspoken about not wanting coca in their communities because it represented a foreign economic logic, but also because aerial eradication planes often sprayed large swaths of licit crops in attempting to wipe out coca crops (discussed in Chapter 5). Nemesio Torres of Río Guajuí, Guapi remembers how the warnings against coca cultivation fell on deaf ears and how aerial eradication compromised the agricultural productivity of his community and its most profitable crop, chontaduro (peach palm):

To this day folks have not been able to recover, that is the downfall that accompanied it... It is an absolute crisis; the price of goods has increased. What we saw coming, those of us who knew what had happened in the eastern plains...we told everyone that this was bad business because it would result in downfall but folks did not listen ${ }^{73}$.

According to Nemesio, part of the problem stemmed from the fact that the community council was not as organized and did not have the power that it has today. Both in the case of coca cultivation and illegal mining, which also eventually became a serious problem in the community, an outsider approached a community resident who was convinced to act as a liaison to the rest of the community. While some community members rejected the offer to grow coca or permit the operation of mining machinery, others agreed. Once the cultivation or mining began it was difficult to challenge these

\footnotetext{
${ }^{72}$ Héctor's interview, however, was exceptional in the sense that he is the only interviewee who mentioned growing coca for medicinal purposes.

${ }^{73}$ Author interview with Nemesio Hurtado Torres of Río Guajuí, Cauca at Encuentro AfroPazífico in Piendamó, Cauca on July 28, 2015.
} 
decisions without putting lives in danger as non-state armed groups were backing these investments.

In other cases, the coca growers were outsiders who threatened locals with violence upon their arrival. I interviewed four gentlemen -Tulio, Juan, Adolfo, and Teodoro- who explained how coca arrived to the village of El Penitente near their village in Temuey, Guapi:

Juan: It arrived from Cali, Nariño, Antioquia...people from Medellín...who came to our region...

Tulio: Imagine this, you have your plot of land and they begin to harvest coca. You cannot say anything because they threaten you. They took your lands and you just have to remain silent...

Adolfo: They look for the weakest, least wise person in the community.

Teodoro: They offer them money to rent the land and like that, they start taking our land.

Juan: One does not want to create problems by speaking out.

Tulio: Something could happen to you. We cannot say anything.

Juan: You may be threatened or killed ${ }^{74}$.

The farm belonging to these gentlemen was sprayed despite the fact that they claimed to have no coca themselves (described in Chapter 5).

Lastly, I interviewed a few coca growers that harvested the plant because of economic desperation. One older gentleman from Guapi Arriba argued that he would have not grown coca if the government had invested in agriculture in Guapi instead of

\footnotetext{
${ }^{74}$ Author interview with Juan Alturo, Adolfo Sánchez, Tulio Montaño, and Teodoro Montaño on their farm in Temuey, Guapi on July 20, 2015.
} 
aerial eradication. He then created a hypothetical dialogue between himself and his frustrated neighbors to illustrate his point:

In those times when I had some plants, if they said to me, "Hey, why are you doing that, what is up with that?" and I would explain, "I don't have any money, I'm an old man." So they if they asked, "How much money do you need to survive?" And one says, "Well, with a million pesos (approximately \$350 USD) I could have enough to plant my subsistence crops." And if they said, "Ok, take this money. You have land, go and get to work." I would have done that and I would be willing to do that and I think many people could have avoided putting themselves in danger that way $^{75}$.

So for this gentleman his decision to grow coca was about meeting his basic needs when he felt that he did not have other options. The same was true of the other interviewees growing coca, all of which did so by intermixing unos palitos (some coca plants) with their legal crops (yucca, white taro root, peach palm, mango, plantains, guava...etc.) (a traditional agricultural practice of the Pacific region discussed in Chapters $5 \& 6$ ).

While these interviews revealed some of the different dynamics of coca growing in the Afro-Pacific, PCN leadership was very clear that black communities should have a say in how the coca cultivation problem should be addressed. This point was repeated over and over by both farmers that claimed to only have legal crops and those that cultivated coca. For instance, when I explained to Silvano of Río Anchicayá, Buenaventura that eradication authorities preferred aerial eradication over manual eradication because it puts many less lives in immediate danger, he responded that

\footnotetext{
${ }^{75}$ Author interview with gentleman that preferred to remain anonymous at the Hotel Masgorgona in Guapi, Cauca on March 15, 2015.
} 
communities could learn to manually eradicate the coca themselves, “...they should send us a video or find some legal mechanism through the United Nations"

However, black communities also encountered problems with authorities in instances where the community itself organized to voluntarily eradicate. Albert Arroyo of Yurumanguí, Buenaventura detailed how in 2007 his community council urged residents to form a minga (collective effort) and manually eradicate 27 hectares of coca being grown by an outsider ${ }^{77}$. The community council argued that this man was putting much more than his own farm at risk because the authorities would simply fumigate everyone's crops without any warning. After the eradication the man demanded payment from the community, which was promptly denied on the grounds that he was trespassing and conducting illegal business within the territory. Dismayed, the man then went to speak with the Colombian military and denounced the community as a bunch of testaferros (collaborators), implying that the community had been working with FARC. Though the military ultimately sided with the community, several PCN leaders were subject to investigation because of the man's accusations. Community leaders were not only outraged that they were under investigation, but that the real criminal initially had the support of the Colombian military ${ }^{78}$.

\footnotetext{
${ }^{76}$ Author interview with Silvano Caicedo, resident of Río Anchicayá, Buenaventura in downtown Cali on June 22, 2015.

77 This voluntary manual eradication is documented in the following video, produced by the community council of Yurumaguí: <https://www.youtube.com/ watch? $\mathrm{v}=\mathrm{UZPsmlBsSQI \& \text {feature } = \text { youtu.be } >}$

${ }^{78}$ Author interview with Albert Arroyo, resident of Yurumanguí, Buenaventura at PCN headquarters in Buenaventura, Valle del Cauca on September 9, 2015.
} 
On the one hand, this case was exceptional because it was only one person — an outsider - growing coca in a community with strong PCN leadership ${ }^{79}$. For other black communities in the region -those where outsiders have violently established coca cultivation within territorial boundaries and/or those with multiple community residents cultivating coca themselves - negotiating voluntary eradication would have been much more difficult, if not impossible. On the other hand, PCN leaders mentioned the efforts in Yurumanguí as an example where the community initiated voluntary manual eradication as proof that black communities should and can be more involved in counter-narcotics efforts $^{80}$.

\section{Why not more Voluntary Eradication or Alternative Development?}

The majority of U.S. and Colombian government officials I spoke with outwardly expressed support for alternative approaches to eliminating illicit crops besides aerial eradication. For instance in 2014 I asked William Brownfield, former U.S. Ambassador to Colombia and the current INL Assistant Secretary, about his take on the future of the aerial eradication program in Colombia and he mentioned voluntary manual eradication and alternative development as part of his response:

The ideal is voluntary eradication. And voluntary eradication I acknowledge, you don't just say "please do it because it's the right thing," you have to find a way to make it in the interest of the individual

\footnotetext{
${ }^{79}$ For instance, I had the pleasure of meeting and conversing with longtime black activist, PCN leader, and yurumangueño Naka Mandinga. I was absolutely floored by the fiery eloquence of the speech he delivered at the Association of five communities in Guapi.

${ }^{80}$ This is not the only instance when PCN posited Yurumanguí as a model of resistance for black communities. Describing a project to strengthen the organizational dynamics of black communities in southern Pacific region, Escobar writes, "PCN bet on the Yurumanguí and Pílamo projects to both develop and demonstrate the validity of their ethnoterritorial approach in the face of conflict and displacement" (2008, p.302).
} 
campesino or subsistence farmer in Afghanistan to understand why he or s he wants to eradicate. They've got to get something, whether it's alternative development, an additional livelihood, schools, clinics, paved roads, water, sewage, electricity... something. They have to have some reason to understand why it is in my interest to eradicate this stuff even though I know that if I grow corn I'm only going to make $25 \%$ as much as I'm making by growing coca ${ }^{81}$.

What Brownfield did not mention in his complete response to my question is that voluntary eradication and alternative development have been the least prioritized strategies in the history of U.S. supported counter-narcotics efforts in Colombia. In fact the reason the UNODC does not have any data on voluntary manual eradication in Colombia is because the impetus for and coordination of such efforts has come from the communities themselves ${ }^{82}$.

Map 4.1 illustrates the prevalence of every illicit crop eradication strategy except voluntary manual eradication in 2011 . Notice that alternative development programs ${ }^{83}$ and small-scale involuntary manual eradication are the most common strategies through the Andean highlands, which is very connected by roadways in comparison to the Pacific region.

${ }^{81}$ William Brownfield, Assistant Secretary of the Bureau of International Narcotics and Law Enforcement Affairs, responded to author's question at "Drugs, Security, and Latin America: The New Normal for the $21^{\text {st }}$ Century?" at Florida International University on September 26, 2014.

${ }^{82}$ Author visit to the Office of Alternative Development at the United Nations Office of Drugs and Crime in Bogotá on April 28, 2015.

${ }^{83}$ Only a percentage of the alternative development data presented here is representative of crop substitution as UNODC data on these programs is combined. See Chapter 11 of Illegal Drugs, Economy, and Society in the Andes for a nuanced discussion of the difference between alternative development and its predecessor, crop substitution (Thoumi 2003). 


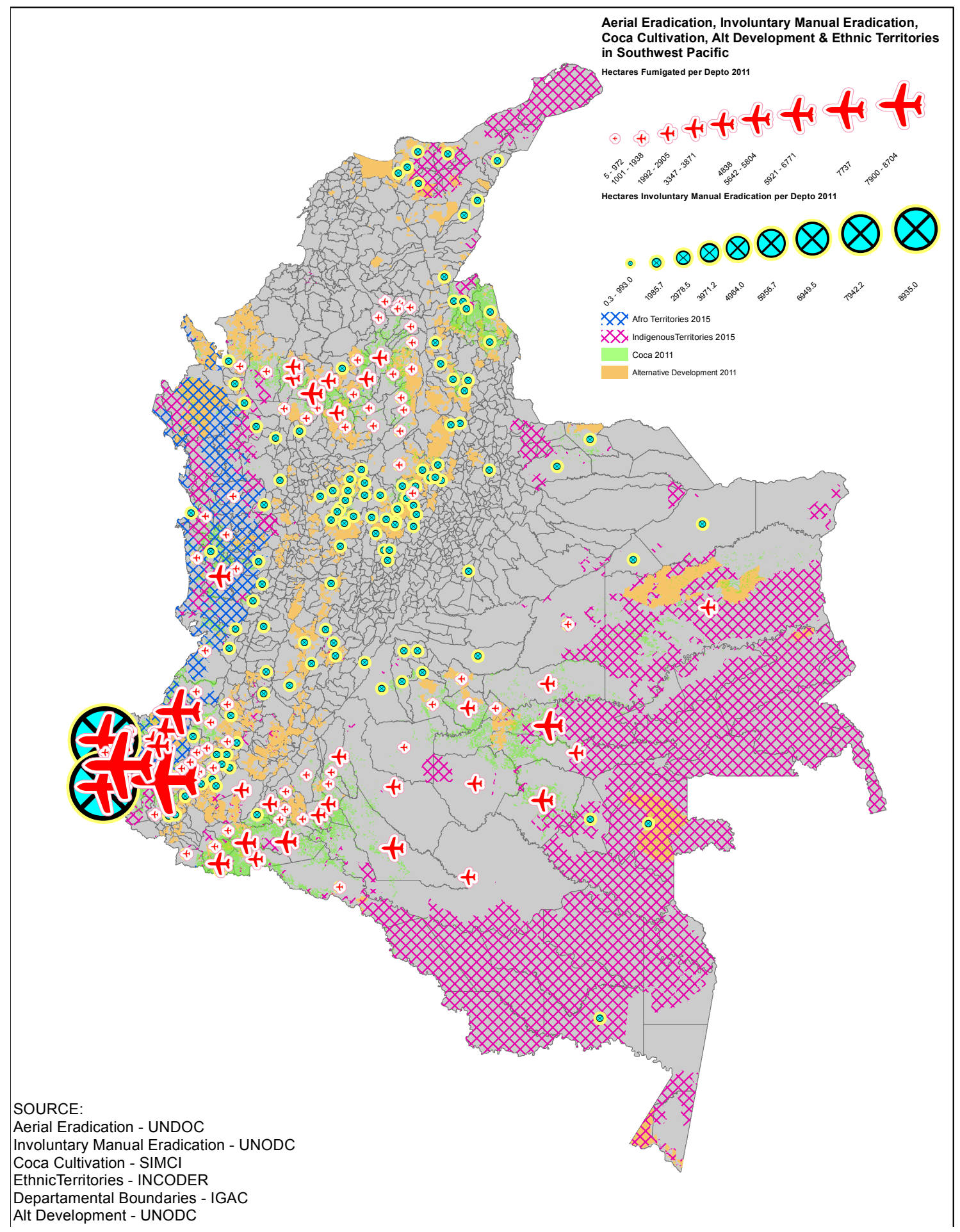

Map 4.1 - Aerial Eradication, Involuntary Manual Eradication, Coca Cultivation, Alternative Development \& Ethnic Territories in Colombia (created by Alexander Huezo) 


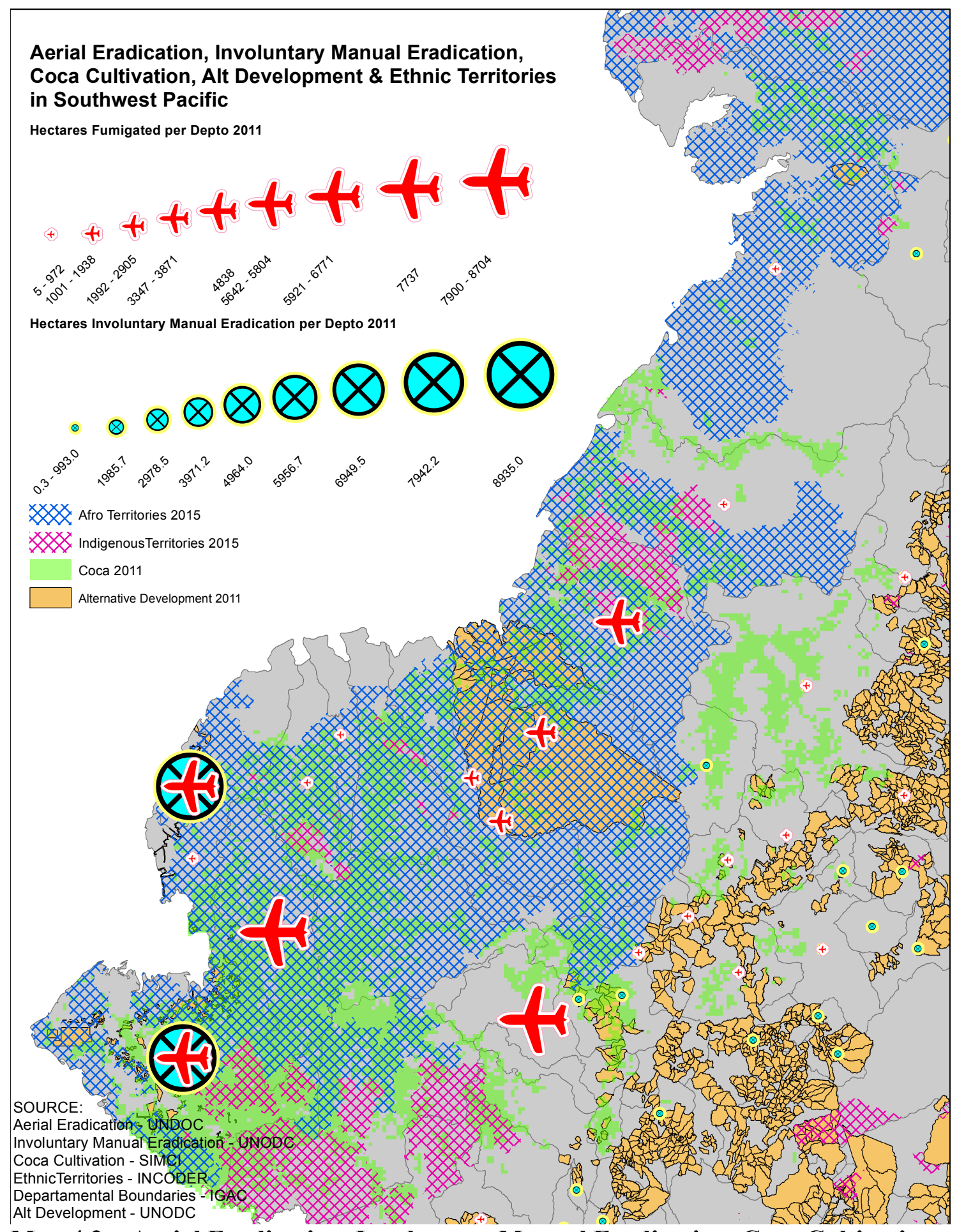

Map 4.2 - Aerial Eradication, Involuntary Manual Eradication, Coca Cultivation, Alternative Development \& Ethnic Territories in Southwest Pacific Region (created by Alexander Huezo) 
Also take note in Map 4.1 that the southwestern corner is clearly the most heavily fumigated region of the country. Map 4.2 is a closer look at the data presented in Map 4,1. Notice the dearth of alternative development projects happening in ethnic territories with the exception of a few scattered areas in Tumaco (bottom left) and the large swaths of orange in Guapi. Also notice that despite the presence of these alternative development projects, aerial eradication was also conducted in Guapi.

While there have been an array of crop substitution programs supported by the UNODC, USAID, and various NGOs, the INL stated that these fields can be aerially fumigated if any illicit crops are detected amongst the substitute crops ${ }^{84}$. In addition to the farmers I spoke with that claimed their coca-free farms had been unjustly fumigated, I also heard numerous accounts of alternative development fields being sprayed. A resident of Río Napi, Guapi explained:

Sometimes the community councils initiate their own projects to cultivate subsistence crops such as plantains, rice, corn...but they fumigate the fields and we are left with nothing, just like what happened with our cacao project. So if they fumigate, what are we to do? There should be some guarantee from the government that they will not fumigate these projects $^{85}$.

At a PCN gathering for five communities forming a joint association, frustration set in amongst the participants when the subject of a new agricultural project was introduced ${ }^{86}$.

\footnotetext{
${ }^{84}$ Author interview with INL at US Embassy in Bogotá on August 4, 2015.

${ }^{85}$ Author interview with anonymous resident of Río Napi, Cauca in Guapi, Cauca on March 14, 2015.

${ }^{86}$ I recorded one gentleman expressing his frustration in the following video: https://contestednatures.com/guapi-cauca-ii/
} 
"Why even bother if it is going to be aerially fumigated?" was the question repeated throughout the ensuing discussion ${ }^{87}$.

I spoke with attorney Carlos Barrios Herrera who represented three black communities of Tumaco -Río Chagüí, Río Mejicano, and Río Rosario - in a lengthy court case involving crop substitution fields that had been fumigated. Carlos explained that these community councils formed an association and signed agreements with the national government via Programa Presidencial to launch a crop substitution project with the support of USAID, the UNODC, and Acción Social (Colombian agency that assists victims of violence). After enduring seven years of aerial eradication, the association cited the voluntary eradication of 500 hectares of coca plants as well as the establishment of 5,500 hectares of agroforestry products, 1,200 hectares of cacao, and 750 hectares of coco palm (Carta abierta 2009). Part of the agreement was that DIRAN promised to demarcate the project as off limits to aerial eradication so long as the fields were inspected and certified as being coca-free by the UNODC. Despite this certification the fields were fumigated ${ }^{88}$.

The case went to court in 2009 and ended unsuccessfully for the communities in 2013. Carlos commented that DIRAN offered various explanations for why the fumigation was conducted. One explanation was that a particular field within the project contained coca while another explanation was that the project was very close to nearby coca fields targeted for aerial eradication and that the wind had blown the spray off

${ }^{87}$ Author observation from PCN meeting for the association of five communities in Bocas de Temuey, a community of Guapi, on March 14, 2015.

${ }^{88}$ Author interview with attorney Carlos Barrios Herrera at author's residence in Bogotá on March 21, 2015. 
course. When I asked Carlos why he thought they lost the case he responded that the first explanation was surprising because an agreement had been signed and a UNODC technician was permanently assigned to verify that the fields were coca-free. He then asked:

If there are resources for crop substitution and there are resources for DIRAN, then why are there not resources for the coordination between these two entities? These are institutional errors. And (black) communities are supposedly guaranteed constitutional protection with the backing of international agreements.

In Carlos's opinion, the fundamental difficulty in taking this type of collective action to trial is gathering evidence of culpability. The aerial eradication program was a counternarcotics priority for both the U.S. and Colombia so holding either government accountable via the Colombian justice system was a monumental task.

\section{Eradication without Prior Consultation}

In response to communities that wanted to have some say about how coca was eradicated from their communities, aerial eradication authorities preferred not to disclose any details about their intended targets. There were a number of strategies that cocagrowers employed to protect or save some of their sprayed harvests. Aerial eradication was not intended to kill coca plants, rather the intent was to lower the alkaloid content of the coca leaf to the point that it was no longer profitable ${ }^{89}$. As much as aerial eradication authorities attempted to surprise coca growers, however, sometimes coca growers knew about an aerial eradication operation before it happened. The older gentleman from Guapi Arriba explained:

${ }^{89}$ Author interview with INL staff on August 4, 2015. 
People knew, not exactly where the fumigation would occur, but yes they would see that preparations were underway in Guapi...the planes and helicopters at the airport. Because people had seen it before, they knew. People did not know where exactly was going to be sprayed though because they would spray in some parts but not in others. They mixed things up ${ }^{90}$.

A fleet of helicopters and planes arriving to the nearest airport, flying overhead to take pictures, or the bombing of an area in anticipation of an eradication mission was ample warning (discussed in Chapter 5), especially if aerial eradication missions had already been conducted in the area.

In these instances certain products -such as Pony Malta (a popular Colombian soda) or molasses - could be applied as a coating to protect the plants from absorbing the glyphosate ${ }^{91}$. If the coca growers were caught off guard by the fumigation then cutting the sprayed top leaves of the plant or washing off the glyphosate could also work ${ }^{92}$. For instance, in a town in Antioquia, a department with a reputation for entrepreneurism, a local business was set up to rent water pumps to coca farmers whose harvests had been sprayed $^{93}$. For these reasons and others, targeted areas were often aerially fumigated multiple times to produce the desired effects ${ }^{94}$. Alerting a community prior to aerial

${ }^{90}$ Author interview with anonymous gentleman on March 15, 2015.

${ }^{91}$ Author interview with Leonardo Correa, Technical Coordinator of Project SIMCI, at the United Nations Office of Drugs and Crime in Bogotá on April 28, 2015.

${ }^{92}$ Author interview with INL staff on August 4, 2015.

${ }^{93}$ Author interview with Leonardo Correa on April 28, 2015.

${ }^{94}$ Author interview with INL staff on August 4, 2015. I also asked Julián Wilches, exCNE director, how many times an area was typically fumigated and he believed it was once or twice a year, depending on the level of glyphosate concentration used the first time around. Author interview with Julián Wilches on March 11, 2015. Most of the 
eradication would have also put the lives of pilots and associated personnel in danger, as eradication aircraft were frequently the targets of ground fire (discussed in greater detail in Chapter 5). At the same time, black and indigenous communities were supposedly guaranteed the right to determine the activities conducted in their territories.

This right -the primary legal instrument that black and indigenous communities have to assert control over what happens within the boundaries of their territories- is known as consulta previa (the right to previous consultation). In 1991 Colombia ratified an international treaty known as Indigenous and Tribal Peoples Convention 169, created by the International Labour Organization (ILO). Convention 169 establishes that staterecognized ethnic territories need to be consulted before the extraction of resources, the implementation of projects, or any other activities that might jeopardize residents' rights to occupy their land and practice local traditions (ILO 1989). Despite the fact that Convention 169 was ratified the same year as the new Colombian constitution, consulta previa was never made an explicit law within this constitution. Instead, consulta previa has been developed through case law in constitutional courts where Convention 169 has been invoked on behalf of black and indigenous communities. With respect to aerial eradication, Decision 383 of 2003 determined that because many indigenous communities consume coca leaf as part of their traditional culture, aerial eradication without prior consultation was a violation of their right to cultural identity (Colombia 2003) In theory, all indigenous communities in Colombia had the right to be consulted

farmers I interviewed, on the other hand, complained about being sprayed two to three times a year. I did not locate any explicit explanation of the frequency of spray missions in the resolutions that defined the parameters of the aerial eradication program. 
prior to aerial eradication as counter-narcotics authorities (DIRAN, CNE, INL) did not keep a list of which communities consumed coca leaf as part of their traditions ${ }^{95}$.

The question of whether black communities should have been consulted prior to aerial eradication was an extremely divisive one. Pablo Rueda, former Director of Consulta Previa in the Ministry of the Interior, described a disagreement between himself and Farid Benavides, the Vice Minister of Criminal Policy in the Ministry of Justice, which took place during an academic conference. Rueda argued that black communities should always be consulted if an activity is being conducted in their territory that will directly affect their community ${ }^{96}$. Benavides countered that granting black communities the right to previous consultation would set a problematic precedent for Colombian law because black communities do not consume coca leaf as part of their traditional practices. According to his logic, any community -black, white or mestizo- could then demand the right to be consulted prior to aerial eradication ${ }^{97}$.

Regardless of where one stood in the aforementioned disagreement, the government officials I spoke to agreed that consulta previa does not work the way it should in Colombia. Previous consultation is meant to be a mutual conversation between national government officials and representatives of the respective ethnic communities. What happens much of the time is that the consulta never comes to fruition or the ethnic

${ }^{95}$ Author interview with Leonardo Correa on April 28, 2015.

${ }^{96}$ Author interview with Pablo Rueda, former Director of Consulta Previa in the Ministry of the Interior, at Parque de la 93 in Bogotá on April 7, 2015.

${ }^{97}$ Author interview with Farid Benavides, Professor of Law and the Vice Minister of Criminal Policy \& Restorative Justice in the Ministry of Justice, at his office in La Universidad de los Andes in Bogotá on March 10, 2015. 
communities are simply informed of what will happen in their territory ahead of time ${ }^{98}$. Pablo Rueda complained that Ministry of Justice officials only attended approximately 3 of the 30 consultas he oversaw during his time as the director of consulta previa ${ }^{99}$. An employee of the Ministry of Justice cited personal concerns about safety in the communities and other job responsibilities as possible reasons for the poor attendance. She added that most people employed in governmental agencies are contracted and that there is sometimes a shortage of personnel to delegate to attend the consultas ${ }^{100}$.

According to Lt. Colonel Tunjano of DIRAN, there was no formal mandate to inform local authorities (besides indigenous communities) that an aerial eradication mission was about to take place. He did, however, state that part of the aerial eradication protocol is to inform departmental and municipal authorities as a matter of courtesy ${ }^{101}$. An analyst for La Defensoría del Pueblo (Defense of the People), the state's human rights agency, explained that DIRAN was supposed to inform the municipal administration, who would then inform relevant municipal officials such as the personero (ombudsman). The analyst also explained that this protocol was often ignored, especially in the Pacific

${ }^{98}$ Author interview with Pablo Rueda on March 11, 2015. Author interview with Julián Wilches, ex-director of the Colombian National Council of Narcotics (CNE) at his office in the Fiscalía General de la Nación, Bogotá on March 11, 2015.

${ }^{98}$ Author interview with INL staff on August 4, 2015.

${ }^{99}$ Author interview with Pablo Rueda on March 11, 2015.

${ }^{100}$ Author interview with Erika Padilla, contracted employee of the Ministry of Justice, at the Ministry of Justice offices in Bogotá on March 4, 2015.

${ }^{101}$ Author interview with Lieutenant Colonel Miguel Tunjano of the Colombian Counternarcotics Division (DIRAN) at the Hotel Tequendama in Bogotá on May 8, 2015. 
region where transportation to and communication with municipal authorities can be difficult. He believed this was problematic because each municipality should have been prepared in the case of an accident during an aerial eradication mission or in the event that affected residents would subsequently protest the fumigation ${ }^{102}$.

I acquired three sets of flight logs for aerial eradication missions conducted in the Pacific municipalities of Cauca for the years 2005, 2009, and 2013 (as part of a court case discussed in Chapters $2 \&$ 6). The 2005 and 2009 flight logs contained signatures from a judge in Popayán, the capital of Cauca and the location of the airport where the aircraft departed from. The 2013 flight logs contains a space for "the Personero or the delegated Departmental Attorney" but does not specify from which municipality. For every mission conducted in this particular series of operations, the words "no asignado" (not assigned) are written in lieu of a signature in that space. The missions for 2013 departed from an airport in Buenaventura, which is in a different province (Valle del Cauca) from where the aircraft eventually fumigated (Cauca). I asked the Defensoría analyst why these signatures were missing and he cited two possible reasons. He explained that the first possible reason is that DIRAN was not able to track down the official in a timely manner prior to each mission. He also said that it is not possible that a municipality did not have an ombudsman because every municipality, by law, had a personero since the 1991 constitution took effect. The second reason he cited is that the decisions to conduct these

${ }^{102}$ Author telephone interview with Felipe Vernaza Pinzón, Early Alert Analyst of the Defensoría del Pueblo, on August 10, 2015. 
missions were made behind closed doors and local municipal administrations were only notified if the missions had been aborted ${ }^{103}$.

\section{Aerial Eradication Operations}

The first phase of an aerial eradication mission was detection. The United Nations Office and Drugs and Crime (UNODC) is the agency that issues annual reports on illicit crop cultivation in Colombia through SIMCI (the Integrated System for the Monitor of Illicit Crops). I met with Leonardo Correa, the technical coordinator of SIMCI, who overviewed SIMCI's role in the detection and verification processes. SIMCI analysts in the UNODC offices in Bogotá first scan infrared satellite images of illicit crop-growing regions, identifying swaths of coca or opium poppies (see Figure 4.5). Leonardo noted that it is fairly easy to distinguish between coca grown for traditional consumption versus coca to be processed in cocaine. The coca cultivated for cocaine is typically clear of additional foliage (weeds) because the growers apply herbicides, whereas herbicides are not applied to coca grown for traditional purposes ${ }^{104}$.

103 ibid.

${ }^{104}$ Author interview with Leonardo Correa, the technical coordinator of Project SIMCI, at UNODC office in Bogotá on April 28, 2015. 


\section{Detección Cultivos llícitos}

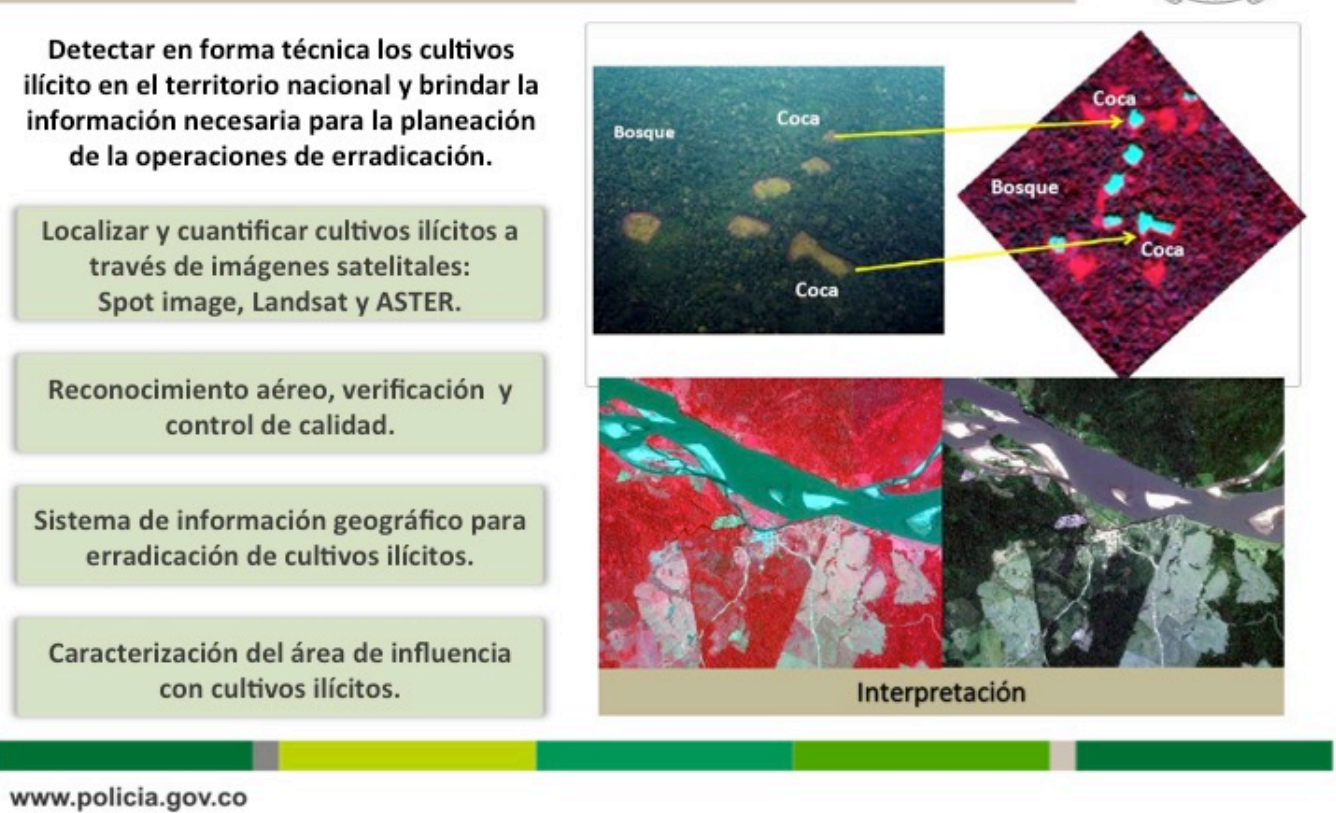

Figure 4.5 - DIRAN PowerPoint slide explaining the detection process

Notice that coca shows up as bright blue in the infrared image on the top right.

Leonardo explained that the process of detection is "an imperfect science" and that there are a number of technical factors that presence a challenge to the process. Most importantly, the satellite images processed by the UNDOC are normally captured on December 31 of every year and in some cases, on other dates as well. The landscape of the area in question could change quite a bit between the December 31 image and whenever the aerial eradication mission occurred. After several months coca could be replanted where it had been eradicated or another crop could be replanted in its place or the land could be used for something altogether different (e.g., grazing field). To this point, the Washington Office on Latin America (WOLA) published an article after the termination of the aerial eradication program that cites outdated maps as a reason pilots were mistakenly spraying fields that contained no coca in the department of Guaviare 
(Schaffer \& Youngers 2015). Leonardo also explained that detection is most difficult in Nariño and invited me to sit with the analyst assigned to that department, which is the epicenter of coca cultivation in the southwest Pacific region.

I sat with the Nariño analyst while she edited satellite images and she explained that the Pacific region is the most difficult to analyze because constant cloud cover and forest canopy make it impossible to get an unobstructed satellite image of the areas in question ${ }^{105}$. She was tasked with making digital maps by combining multiple images into one composite image, free of clouds or forest cover ${ }^{106}$. Detection is also very difficult in the Pacific region because the lots tend to be smaller and intermixed with legal crops (e.g., plantains, corn...etc.) (discussed in Chapter 5). The presence of legal crops, however, was not a deterrent to marking a target. Both DIRAN and INL officials explained that growing illicit crops is illegal and that licit crops may be fumigated if mixed within plots with illicit crops ${ }^{107}$.

Despite these challenges, Leonardo cited the following estimates that speak to his office's confidence in the detection process: a) $90 \%$ of the crops detected as coca are actually coca; b) of all the coca in Colombia, SIMCI only detects $82-83 \%$ of the total; c) $60 \%$ of all fields aerially eradicated in one year were also sprayed the prior year; and d) $43 \%$ of the fields manually eradicated in one year are replanted with illicit crops the

${ }^{105}$ The high frequency of cloud cover is not surprising as the Colombian Pacific ranks as one of the rainiest regions of the world inhabited by people.

${ }^{106}$ Author visit to Project SIMCI offices at the United Nations Office of Drugs and Crime in Bogotá on April 28, 2015.

${ }^{107}$ Author interviews with Lt. Colonel Miguel Tunjano on May 8, 2015 and INL officials on August 4, 2015. 
following year. In other words, SIMCI correctly identifies coca nine out of ten times but does not identify $17-18 \%$ of the coca in the country in any given report. Furthermore, manual eradication is $17 \%$ more effective than aerial eradication at eliminating illicit crops $^{108}$.

While SIMCI is responsible for the data processed for DIRAN and the Colombian government, the U.S. Office of National Drug Control Policy (ONDCP) conducts its own detection processes that it uses to report on the effectiveness of counter-narcotics operations in Colombia. ONDCP records satellite images multiple times very whereas, SIMCI works from the satellite images recorded December 31 of every year. ONDCP accounts for the total amount of hectares of coca cultivated at the times they record satellite images and do not adjust for eradication efforts, whereas SIMCI adjusts for eradication efforts. ONDCP also uses a different type of satellite imagery and a different methodology that Leonardo Correa says is not shared with the UNODC ${ }^{109}$. In either case, these are two different sets of data on coca cultivation in Colombia that have been employed in often contradictory narratives about the effectiveness of U.S.-supported aerial eradication and other counternarcotics strategies in Colombia.

\footnotetext{
${ }^{108}$ Author interview with Leonardo Correa on April 28, 2015. 109 ibid.
} 


\section{Franjas de Seguridad 100 Mts.}

Decreto 1843 de 199I, Ministerio de Salud

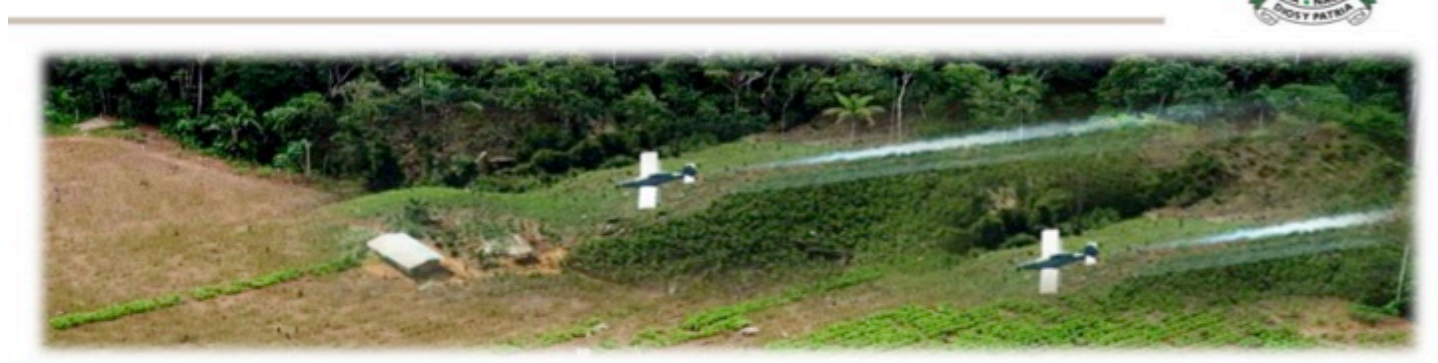

- Parques Nacionales Naturales

- Resguardos Indígenas
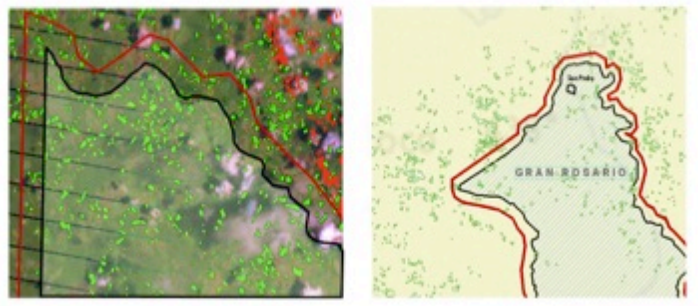

- Centros poblados

- Fuentes de agua

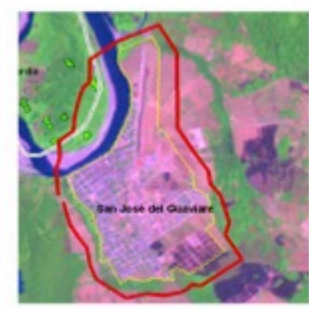

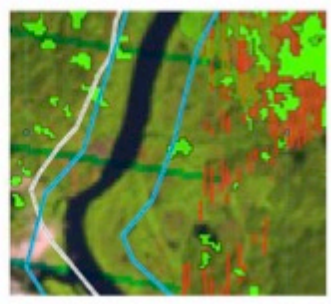

、www.policia.gov.co

Figure 4.6 - DIRAN PowerPoint slide aerial eradication buffer zones

This slide shows four areas that require a 100 meter buffer zone around them during an aerial eradication mission. In the four small images below (from left to right: a national park, an indigenous reservation, a human settlement, and a waterway), the red line marks the buffer zone, except for the waterway in which the buffer zone is marked in light blue.

SIMCI edited the satellite images identifying illicit crops for DIRAN, which would be used when pilots conducted flyovers to confirm the presence of illicit crops. Once the targets were confirmed, franjas de seguridad (buffer zones) were then transposed onto the digital maps to protect bodies of water and populated areas from any spray that may drift from the target ${ }^{110}$ (see Figure 4.6). These buffer zones were 100 meters wide despite the recommendation of much larger buffer zones by the Colombian

${ }^{110}$ Author interview with Lt. Colonel Miguel Tunjano on May 8, 2015. 
Ministry of Health ${ }^{111}$. The only areas specifically off limits to aerial eradication were national parks and nature reserves. Aerial eradication was only supposed to be conducted with the permission of indigenous communities via consulta previa, although that process was often not completed because of the administrative reasons and safety concerns (described in the previous section).

The second phase of an aerial eradication mission was the actual fumigation. Each plane was equipped with a mapping system that would guide pilots to their targets. Pilots also followed specific protocols regarding the wind speed and the altitude of their trajectory to guarantee that the spray reached the target. (details of the aerial eradication mission are described in detail in Chapters $5 \& 6$ ).

The third phase of an aerial eradication mission was verification. During flight the onboard computer recorded both the path of the aircraft and the path of the chemical release (see Figure 4.6). It should be noted that pilots had to press a button to begin recording the path of the chemical release. In other words the mechanism for releasing the chemical did not automatically record when spraying began. Project SIMCI analysts would receive this recorded flight data and subsequently edit the flight path to account for the fact that pilots would forget to press the button that signaled when spraying began or

${ }^{111}$ For instance, a 2000-meter buffer zone was recommended for any areas of human settlement and a 1600-meter buffer zone was recommended for areas of 'socio-economic interest'. These recommendations are described in Artículo 5, Literal D of Resolución 1065, of the Plan de Manejo Ambiental (Colombia 2001). 
ended. The analysts I spoke with also stated that they had personally visited fumigated areas to assess the success of various missions ${ }^{112}$.

The final phase of an aerial eradication operation was the management of complaints. Residents and representatives of black communities were largely frustrated by the lack of transparency of the government institutions managing the complaint process and generally distrustful of these institutions. Silson Carabilí, the personero of Guapi, explained the steps that local governing entities would take towards filing a complaint for a black community. The mayor, the personero, and the community council would form a committee with other relevant government entities to determine whether individual complaints were valid. Based on that evaluation the committee would then declare a complaint. However, the process would never go any further in Guapi because the committee did not have any success finding a "competent authority" to process and resolve the complaint ${ }^{113}$. In the municipality of Buenaventura, which unlike the municipality of Guapi is not entirely compromised of black territory, the relationship between black communities and the local administration is more tenuous. Mario Angulo, the director of PCN in Buenaventura, explained that the office of the Secretary General organized spaces where the communities could conduct estimates of the damages caused, file the complaints, and meet with DIRAN. However, DIRAN evaded culpability by

${ }^{112}$ Author visit to Project SIMCI on April 28, 2015. I am, however, not certain as to whether this was protocol or how frequently this occurred

${ }^{113}$ Author interview with Silson Carabalí, the Personero of Guapi, at his office in Guapi, Cauca on July 19, 2015. By choosing the term "competent authority" Silson underscores the extremely low expectations for DIRAN, the agency handling complaints. 
claiming the aerial eradication missions were conducted on presidential orders and the communities could not count on the municipal government for support ${ }^{114}$.

Lastly, it is extremely important to note that according to Article 3, Paragraph 3 of Law 1448 of 2011 -the law that defines the victims of the civil conflict and the terms of restitution - people that have suffered a violation of their rights are not considered victims if the damages caused to them were the result of their participation in criminal activity (Colombia 2011). This law has precluded people displaced by aerial eradication from being considered victims and earning whatever restitution or benefits might be available to them. Essentially, people displaced by aerial eradication are guilty by association, whether they were growing illicit crops or not. Not only did people displaced by aerial eradication not receive any benefits, but they also did not figure into the official registry of displaced persons. Therefore, the estimates of people displaced by aerial eradication (discussed in Chapter 2) are quite varied and difficult to disentangle from the larger numbers of people displaced by violence from the very same places ${ }^{115}$.

\section{Complaints about the Complaint System}

Throughout the history of this system the number of successful complaints that received restitution were an extremely small percentage of the number of complaints filed. For instance in 2008, only 31 of 987 (3.1\%) complaints received restitution

${ }^{114}$ Author interview with Mario Angulo, director of PCN Buenaventura, at his office on September 9, 2015.

${ }^{115}$ Oslender (2016a) addresses some of key issues with displacement discourses in Colombia, highlighting the limitations of statistics in reporting the circumstances of the internally displaced persons (IDPs) in general and, in particular, with regard to the AfroColombian population. 
(DIRAN website) and the average number of successful aerial eradication complaints over the last few years was still roughly $3 \%$. INL personnel attribute this low percentage to a high incidence of unjustified claims such as complaints for: days when fumigation was not conducted, lots where coca was identified on the premises, claimants that did not properly follow complaint protocols, and, in recent years, FARC encouraging campesinos to register false complaints to thwart the aerial eradication program ${ }^{116}$.

There are a number of mitigating factors, however, that undoubtedly contributed to the low success rate of complaints filed. The number one factor to consider, which had been a major criticism of the complaint process since its inception, is that complaints were verified by the same agency (DIRAN) that conducted aerial eradication. Furthermore, while local government authorities participated in the receipt of complaints and other government agencies might have been requested to participate in the evaluation of the complaint process, the claimant had to furnish evidence to prove that DIRAN mistakenly fumigated someone's property.

For poor farmers with limited education living in rural areas, many of which are extremely remote, the complaint process was an altogether daunting task that required: access to a computer with internet to download the "easily accessible complaint form"; a GPS device to record the coordinates of the property; property titles for a population that typically lives on land that it does not possess the title to; money and time travel to the nearest municipality and make numerous photocopies; photographic evidence and monetary estimations of damages; and trust in local government officials that are supposed to accept, assess, and forward the documents to DIRAN if they deem the claim

${ }^{116}$ Author interview with INL officials at US Embassy on August 4, 2015. 
is valid. Leonardo Correa of SIMCI was critical of complaint process in general, explaining:

If a person is wrongly affected by aerial eradication there is a very small of probability of being compensated for that error. That is because we do not definitively know how many errors there have been. So many people complain that they do not even begin the complaint process because it is so complicated. So many of complaint requirements are absurd. Very few people have GPS and are able to provide the coordinates of their farm, so right there, a large number of complaints die. If the complaint is successfully registered then what they do is schedule a visit. The visit can happen two months later and someone arrives and says, "No, we cannot find evidence of glyphosate." And obviously after two months it is very likely that you will not find traces of glyphosate in the plants. This complaint mechanism does not really work and we have no idea have often it this is the case ${ }^{117}$.

As one might expect, many farmers simply do not bother or trust the process to begin with. At the end of the day the claim could have been rejected for any number of reasons without DIRAN having to submit any evidence unless compelled to do so by the court system.

Within the black territories of the Pacific the collective titling of community lands means that in addition to local government authorities, residents must also place their trust in their representative councils. In theory, the process of receiving restitution for collectively titled lands would seem more manageable than the process for an individual complaint because elected community council representatives collected all of the information required for the community and facilitated the entire process. Robinson and Orfilio, residents of Río Iscuandé, Nariño, described the great lengths they went to in order to gather the proper documents for submission to their local representatives. Orfilio claims that when he traveled to the local mayor's office to find out what happened with

${ }^{117}$ Author interview with Leonardo Correa on April 28, 2015. 
their case he was informed that the restitution had already been awarded to the community council. He was then given the phone number of a lawyer to inquire further but he never called, not sure about whom to trust on the matter. Robinson explained, "Us campesinos, we have always been subject to deception. People know that, yeah, the benefits we might receive are not much but actually receiving them is another matter."118

While I could not confirm that the local community council withheld the restitution, I did speak with several residents of Guapi, Cauca, who expressed similar distrust in local government authorities and the restitution processes. These residents had submitted evidence in a class action court case against the aerial eradication program that began in 2008. While the case is still being litigated in courts, many of the people I spoke with have either forgotten about it or lost faith in the process. Even if the case is resolved in the coming year, it will have taken as long as nine years for some people to be awarded restitution $^{119}$.

Whether the acquisition of restitution lasted as little as a month (absolute best case scenario) or several years, a great deal of effort and patience was required for a process that did not work in the claimant's favor about $97 \%$ of the time. Carlos Herrera, a lawyer who spent eight years representing three Afro-Pacific communities seeking restitution for the aerial fumigation of an alternative development project, sadly acknowledged,

\footnotetext{
${ }^{118}$ Author interview with Orfilio Carabalí and Robinson Paz of Río Iscuandé, Nariño in Guapi, Cauca on March 13, 2015.

${ }^{119}$ Author interview with Germán Ospina, lawyer representing 40,000 people from Cauca in class action suit against aerial eradication program. Interview conducted in Popayán, Cauca on August 19, 2015.
} 
"Unfortunately, black organizations simply do not have the financial support necessary to win these battles." 120

\section{The Territorial Repercussions of Aerial Eradication}

For black communities, territory is the 'political technology' (Elden 2010; Bryan 2012) that makes their history and struggles visible within the map of the Colombian civil conflict. 'The territory', however, had disappeared before the aerial eradication pilot began his mission. DIRAN officials conducting aerial eradication operations solicited the signatures of municipal authorities where the airbases were located but did not inform the authorities of the municipalities and representatives of the communities where the spraying was conducted. The pilot's onboard computer map had already highlighted the coca fields; the pilot would spot the bright green color he was looking for during flight. He only needed to know that he was not flying over a national park or that he had permission to spray in indigenous territory. Contrast Map 4.2 with Map 4.3 and notice how black territories and alternative development projects disappeared from the pilot's view of the aerial eradication mission.

Furthermore, the complaint process, which in theory was in place to rectify the damages caused by aerial eradication, accentuated the disconnect between the rural AfroPacific sensibilities and counter-narcotics bureaucracy because it demanded a technoeconomic literacy more suitable for large-scale plantations owners than poor farmers.

${ }^{120}$ Author interview with attorney Carlos Herrera at author's residence in Bogotá on April 21, 2015. 


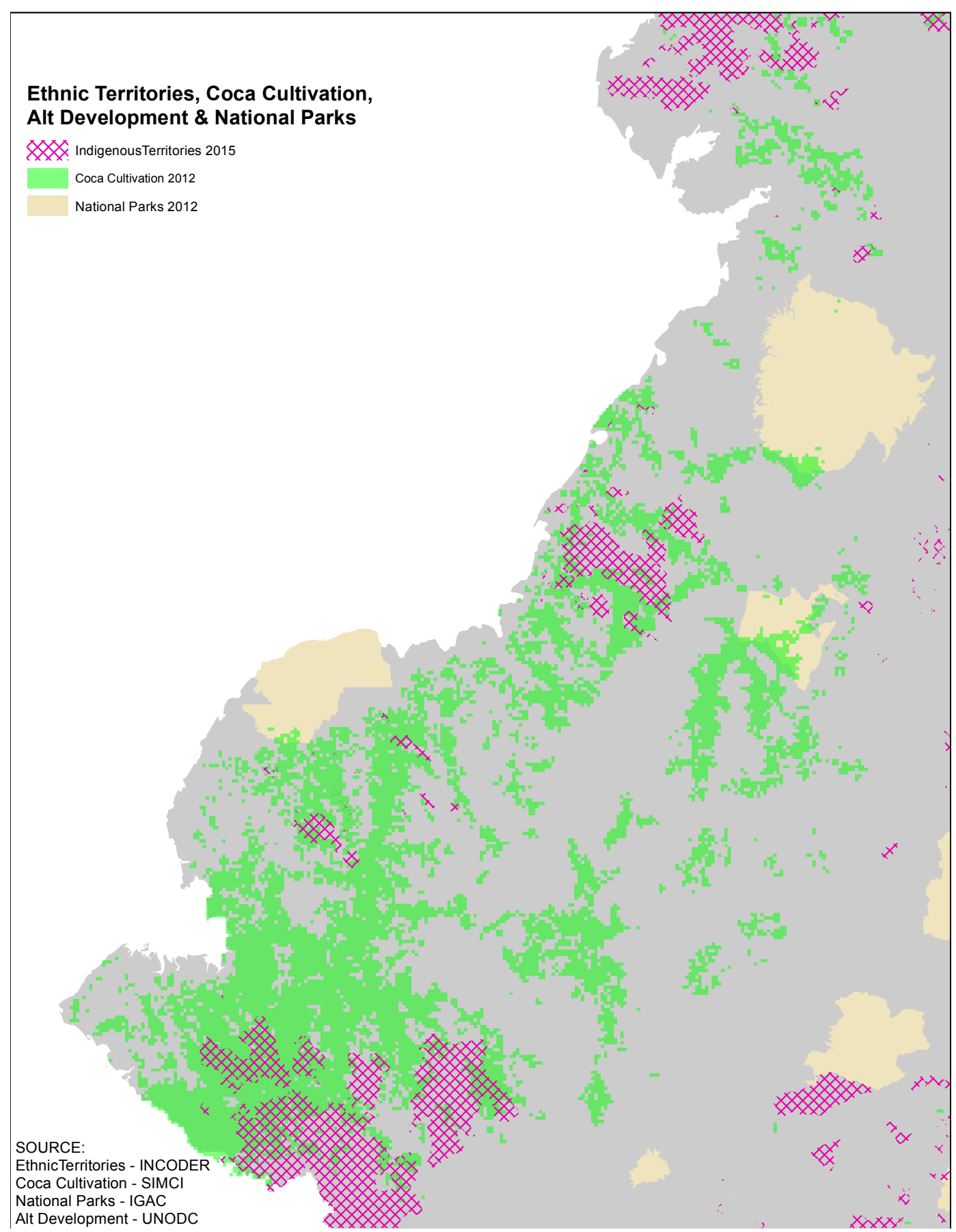

Map 4.3 - Ethnic Territories, Coca Cultivation, Alternative Development \&

National Parks in Southwest Pacific Region (created by Alexander Huezo) 
'The territory' was not only undermined by the aerial eradication program, but also by the lack of recognition by and communication with national and local government agencies. Daniel Goez, president of the community council of Río Cajambre, had this to say about aerial eradication:

I don't know how they come up with...it is human error to think that the city of Buenaventura functions the same as Cajambre. Although both places are part of the same municipal district, they are two completely different things. That is the error. They are thinking about this from over there and establishing standards for how to deal with this situation from Bogotá, from the city. It is a mistake. So their strategy and everything that it involves...they never think about the reality of the territory; their thinking is based on other realities ${ }^{121}$.

Goez expresses a common sentiment among PCN leaders, which is that problems such as aerial eradication are merely symptomatic of the root issue, the lack of effort and consideration for that which national authorities are unfamiliar with, the circumstances of rural black communities of the Afro-Pacific.

In theory, black communities should have always been consulted about the best way to eradicate illicit crops grown in their territory. However, after years of deliberations in Colombian courts, black communities still had not been granted the right to be notified of aerial eradication operations happening in their territory. Ironically, coca cultivation not being part of Afro-Pacific traditions was both part of black communities' argument for previous consultation and the Ministry of Justice's decision to deny consultation prior to aerial eradication. Meanwhile DIRAN, the very same agency

${ }^{121}$ Author interview with Daniel Goez, president of the community council of Río Cajambre at PCN headquarters in Buenaventura, Valle del Cauca on September 9, 2015. 
conducting aerial eradication, demonstrated little interest in working with communities or holding itself accountable.

Whether intentionally or not, the aerial eradication program obscured the presence of black communities and compromised 'the territory'. Within black communities, major challenges such as coca cultivation, aerial eradication, and illegal mining also highlight why the 'defense of territory' is clearly both a struggle against external actors and logics as well as an internal struggle to define 'the territory' through a sense of shared responsibility. As Oslender explains, “...the message of mobilization should alert us to the fact that local subjectivities are multiple and cannot be molded easily into a homogeneous whole as a single "black community"' (2016b, p.198). Thus simple acts, such as explaining to a group of teenagers how the rivers unite the region, or bolder acts, such as eradicating an outsider's coca against his will, all count towards the formation of this community.

The next two chapters continue this territorial narrative, explaining how externally conceived notions of 'security' (Chapter 5) and 'environmental conservation' (Chapter 6) have been re-conceptualized in the defense of territory. 


\section{PROLOGUE: CHAPTERS 5 \& 6}

For black communities national security has no meaning! When they fumigate what they do is displace us. Why? What does a community living on a river do when they have nothing to eat? The fish are dying so the fisherman comes home with nothing. Plantains, potatoes... subsistence crops are ruined and people survive off of that, so they are forced to move. Therefore, this is a case of the State running roughshod over black communities. - Gumercindo Quiñónez of Río Guajuí, Guapi ${ }^{122}$

In her ethnography of policymaking under Plan Colombia, Tate argues, “...policymaking consists of producing narratives that justify political action in the present and unite disparate bureaucratic projects" $(2015, \mathrm{p} .4)$. In the case of aerial eradication, two prominent narratives were produced to justify this controversial strategy: aerial eradication as vital to the 'security' and 'biodiversity' of the Colombian nation. For black communities of the Pacific region, however, aerial eradication was antithetical to their understandings of both of these concepts. The next two chapters, in an attempt to go beyond the obvious reasons for this disconnect, trace the roots of these incongruities.

Chapter 5 juxtaposes dominant geopolitical understandings of 'security' with alternative perspectives of this term, grounded in the testimonies of the black communities that experienced aerial eradication as various forms of 'insecurity'. Chapter 6 performs a similar task, contrasting the PCN's articulation of Territory-CultureBiodiversity with the assertion that aerial eradication functioned as a form of environmental conservation.

${ }^{122}$ Author interview with Gumercindo Quiñónez of Río Guajuí in Guapi, Cauca on March 14, 2015. 


\section{CHAPTER 5 \\ Insecurities: Thinking Critically about the Geopolitics of Security}

This chapter begins by deconstructing the 'security' discourses that factored into the implementation of the aerial eradication program -national security, democratic security, regional security, citizen security, territorial security — and revealing why these discourses did not apply to the safety of poor rural communities, who have often been implicated as security threats in the Colombian civil conflict and the War and Drugs. By deconstructing these discourses (which include maps) and revealing the uneven relations of power that they perpetuate, I am performing critical geopolitics, conducting a "textual intervention" focused "on the effects of geopolitical statecraft on the lives of those who endure the messy reality it produces" (Dahlman 2009, p.107).

The chapter then transitions to a discussion of some of those messy realities that resulted from aerial eradication in the Afro-Pacific, which I present as the security concerns of black communities, such as food security/sovereignty and personal safety. Thus the intent of this second half of the chapter is to perform what Sharp calls 'subaltern geopolitics', "reworking dominant geopolitics not simply through critique, but through offering up lived alternatives (2009b, p.271). The chapter concludes by introducing a perspective that I heard on multiple occasions while conducting fieldwork: Aerial eradication was conducted to intentionally dispossess black communities of their territory.

I should state that I personally do not believe this opinion about aerial eradication to be true. However, one of the objectives of this dissertation is to explain the disconnect between drug policy authorities and black communities affected by aerial eradication. 
This perspective, that aerial eradication was an intentional form of dispossession, is certainly emblematic of that disconnect. I do not dismiss this perspective as some sort of conspiracy concocted by people with limited education, prone to exaggeration. On the contrary, I attempt to explain why this perspective, put forth by prominent PCN leaders, makes sense given the socio-environmental impacts of aerial eradication and in the context of the PCN's mantra, 'to defend the territory'.

\section{(Trans)National Security(s)}

'National security' is actually a plural concept in the context of U.S. drug policy in Colombia as it refers to both U.S. national security and Colombian national security, the latter of which has more recently been framed as vital to the security of a transnational region. Prior to embarking on fieldwork, I attended a seminar entitled "Regional Perspectives on Transnational Organized Crime in Latin America and the Caribbean”, which was co-sponsored by U.S. Southern Command and the Center for the Administration of Justice at Florida International University ${ }^{123}$. Amongst the free materials available at the sign-in table I spotted a glossy book with a strongly worded title: FARC: Degrading Security, Impending Prosperity and Violating Human Rights Since 1964. Though the title unequivocally suggests an unfavorable history of FARC, it does contain some ambiguous wording subject to interpretation. In the first place, 'security' and 'human rights' are separate terms, which raises the questions: Are those two concepts separate because they are meant to be mutually exclusive? Whose security is being degraded? Secondly, 'prosperity' is also mentioned as a separate term but it is

${ }^{123}$ The seminar took place on September 12, 2012. 
similarly not clear whose prosperity is being impended by FARC. The opening pages of the book shed some light on the answers to these questions:

Colombia's stability is vitally important to the U.S. government for reasons of security, prosperity, and the protection of human rights. The U.S. is clearly invested in Colombia's efforts to succeed in the fight against cocaine production and trafficking and the destabilizing effects of those activities. Colombia also provides the U.S. a strategic political and geographic foothold from which to combat significant security concerns in the region...FARC represents one such threat to U.S. stability and security that must not go unchallenged (FARC, p.vi).

Within this passage, 'security' simultaneously refers to U.S. national security, Colombian national security, and "significant security concerns in the region". A few pages later, "weak security" is framed as a deterrent to outside investment because "companies and individuals are less willing to do business in areas where security cannot be assured" (ibid., pp.3-4). Thus, 'security' also refers to investment security, which at least partially explains why FARC is viewed as a roadblock to 'prosperity'. While the publication hardly appears to represent official U.S. policy in Colombia ${ }^{124}$, the purpose of this brief analysis has been to introduce 'security' as a concept with many different meanings in the context of drug policy in Colombia.

With regards to Colombian national security, the U.S. War on Drugs did not gain traction with the Colombian armed forces until counternarcotics operations became conflated with its own counterinsurgency objectives (Ramírez 2010, p.94). The coining of the terms 'narcoguerilla' was useful to this end as it mischaracterized the FARC as the

${ }^{124}$ The publication credits for this book claim that it was "produced for the Under Secretary of Defense for Intelligence" However, right beneath that line there is a disclaimer that the publication has no connection to official U.S. government agencies. The 'Under Secretary of Defense for Intelligence' is a high-ranking civilian advisor within the Office of the Secretary of Defense. 
primary drug trafficking organization in the country, “...in the process erasing the larger presence of the paramilitary traffickers allied with the Colombian military" (Tate 2015, p.32). This mischaracterization was particularly disastrous for poor rural Colombians who have suffered the brunt of human rights abuses in the civil conflict while caught in the crossfire of guerilla, paramilitary, and the national military forces. Furthermore, as Ramírez signals in her ethnography of the protests against aerial eradication in the 1990s, the conflation of counterinsurgency-counternarcotics objectives had lasting consequences for drug policy in Colombia because the armed forces "impeded the implementation of policies for the eradication and substitution of drug crops in a process that would meet the needs of small growers. Instead, it has privileged repressive policies and the criminalization of coca growers not only as drug traffickers but as guerilla auxiliaries" (2010, p.94). In other words, this conflation also implicated poor rural Colombians growing coca as threats to national security, thus justifying any collateral damage caused by aerial eradication.

\section{Democratic Security: Participation without Representation}

State efforts to defeat the guerillas and destroy one of their main sources of income, the regulation of cocaine production, intensified under President Álvaro Uribe (20022010), whose father was killed by FARC during a botched kidnap attempt in 1983 (McDermott 2010). Uribe's administration framed the state's objectives as a matter of 'democratic security'. Ojeda explains:

A state project of securitization that stands in accordance to the War on Drugs and the War on Terror, Democratic Security has been framed as the answer to the urgent necessity to 'restore order and the dominion of law' in all corners of the national territory. Officially defined by former President Álvaro Uribe as 'the concrete possibility for all citizens to enjoy their 
fundamental rights...Democratic Security has indeed relied on coercion, among other securitization mechanisms (2012, p.360).

The term 'coercion' is employed to describe 'democratic security' because, as Ramírez notes, "Democratic security openly presupposed civilian involvement in security functions through the establishment of informant networks. Campesinos could be labeled 'terrorist auxiliaries' if they did not collaborate as military informants (2011, pp.230231). Poor rural Colombians had to make the difficult decision between choosing to report the activities of dangerous guerilla groups in their communities or being treated as enemies of the Colombian state. Ramírez argues that this approach not only justified the tactics of the Colombian military but also legitimized the actions of the paramilitaries (2010, p.94).

As explained in Chapter 3, Oslender's 'geographies of terror framework' was in part a response to studies that lauded the successes of democratic security. These studies cited statistics, for instance, on the reduction of guerilla forces and the incidence of kidnappings, while neglecting the fact that other armed groups (namely, paramilitaries) had emerged to perpetuate equally disturbing, if not more egregious, violations of human rights in rural Colombia (Oslender 2008a, p.79). Thus Elhawary argues that 'democratic security' had little to do with civilian safety and was intended "to protect the state and its international backers against the threats posed by non-state armed groups, particularly guerrilla and organised crime entities" (2010, p.393). To this point, he cited Colombian NGO Acción Social's statistic that two million people had been displaced since the implementation of democratic security in 2002 (ibid., p.396). 
Furthermore, Oslender signals that when the label 'terrorism' is exclusively applied to the actions of non-state armed actors against modern Western democracies, it obscures the fact that these very same states may also conduct actions that could be considered forms of terrorism (2008a, p.81). Aerial eradication, therefore, stands out as one potential example of the Colombian state conducting terrorism against its own civilian population (an idea explored later in this chapter and in Chapter 6). Table 5.1 highlights the most intense years of aerial eradication under the years of democratic security (2002-2007), and one year after this approach ended in 2008.

Table 5.1 - Aerial Eradication during Plan Colombia (data: SIMCI)

\begin{tabular}{|c|c|}
\hline Year & Hectares Fumigated \\
\hline 2000 & 58,074 \\
\hline 2001 & 94,153 \\
\hline 2002 & 130,364 \\
\hline 2003 & 132,817 \\
\hline 2004 & 136,551 \\
\hline 2005 & 138,775 \\
\hline 2006 & 172,025 \\
\hline 2007 & 153,134 \\
\hline 2008 & 133,496 \\
\hline 2009 & 104,772 \\
\hline 2010 & 101,940 \\
\hline 2011 & 103,303 \\
\hline 2012 & 100,549 \\
\hline 2013 & 47,052 \\
\hline 2014 & 31,105 \\
\hline
\end{tabular}

While FARC has been persistently labeled a threat to U.S. national security and the biggest threat to Colombian national security, the changing dynamics of drug trafficking in Latin America have shifted the security discourse from national security or 'democratic security' to 'regional security' or 'transnational security'. DIRAN's publication COCA: Deforestation, Pollution, and Poverty provides an overview of the history of drug trafficking in Colombia. It describes how FARC concentrated its efforts 
on the regulation of coca cultivation as a means to further legitimize control of its social base, poor rural populations. Paramilitary organizations focused on blocking the territorial expansion of FARC, eventually exercised over control of coca cultivation, processing laboratories, and trafficking corridors, mostly in the northern region of the country. In some instances, these warring non-state armed actors -FARC and paramilitary organizations - actually developed business agreements for the regulation of the drug trade (Coca: Deforestación 2014, pp.24-28). This section of the book goes on to describe how criminal bands (BACRIM) emerged from the 2006 de-mobilization of paramilitary groups as locally established criminal networks devoid of counter-insurgent ideology:

Nowadays drug trafficking does not have the same repercussions for national security, democracy, and institutions and, on the contrary, has become a social problem at the local level with direct repercussions for citizen security... Their principal sources of revenue are drug trafficking, illegal mining, kidnapping, and extortion, amongst others. Because of these economic activities, their illegal and illicit conduct has transnational reach (ibid.,pp.28-29).

The section concludes by stating three interrelated impacts that have resulted from DIRAN's efforts to stamp out drug trafficking in Colombia: 1) In contrast to how the cartels operated in the 1990s, neither FARC nor BACRIM have control of the entire drug production chain, which has forced these organizations to rely on connections to outside organizations. 2) Drug production is increasingly concentrated near borders with neighboring countries (i.e., Venezuela and Ecuador) and on the Pacific and Atlantic coasts. These areas serve as points of exportation and are also difficult to reach because 
of complicated topography ${ }^{125}$. 3) Mexican cartels have replaced Colombian

organizations as the primary organizations in the transnational distribution of drugs (ibid.

p.29). Therefore, Colombian drug production and trafficking organizations are now

considered threats to regional or transnational security because of their connections with

other illegal organizations located in South America, Central America, the Caribbean, and Mexico.

\section{The Business of Security}

Global intelligence firms such as Stratfor keep tabs on security issues -for instance, coca cultivation and drug trafficking routes in Colombia - as a service to businesses and foreign governments wanting to ascertain the risk of potential investments.

Map 5.1, published in November of 2015 during the midst of the peace negotiations with FARC, was featured in a Stratfor article about how the potential disbanding of the guerilla organization would not end drug-trafficking in Colombia because, "Even if FARC militants by and large lay down their arms, many will stay active in criminal activities such as drug trafficking in the name of profit rather than in the name of Marxist-Leninist ideology" $(2015)^{126}$. The article goes on to explain that these newly emergent criminal groups -also engaged in "illegal mining, extortion, and smuggling of

${ }^{125}$ The publication does not explain what is meant by "complicated topography" though exportation routes are normally from isolated points on both coasts (i.e., The rivers surrounding Buenaventura and Tumaco on the Pacific Coast; La Guajira Peninsula and Gulf of Urubá on the Atlantic Coast).

${ }^{126}$ The recent peace negotiations with FARC began in 2012 and ended with an agreement in 2016. The ratification of the agreement was originally put to popular vote but narrowly lost. However, President Juan Manuel Santos then brought the agreement directly to Congress who ratified the 310-page agreement to end the 52-year conflict with FARC (The Guardian 2016). 
food and fuel from Venezuela"- will continue to threaten foreign investment in Colombia, especially in the areas demarcated in reddish brown as coca-growing regions (ibid.).

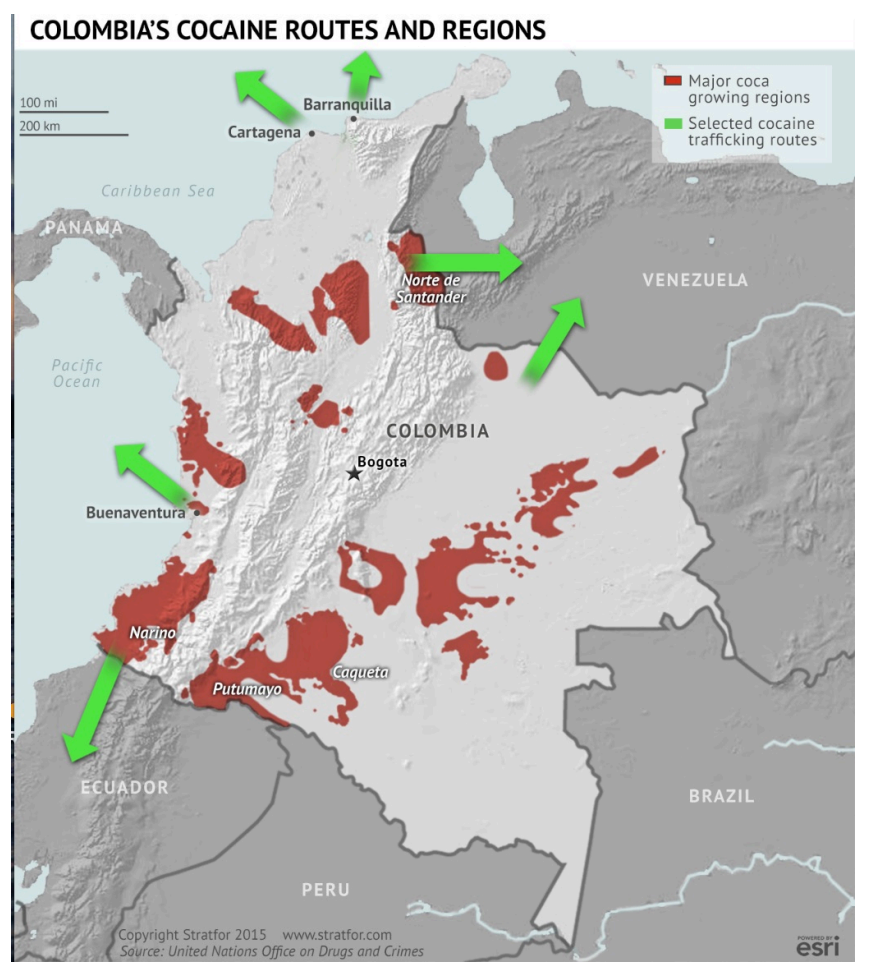

\section{Map 5.1 - Stratfor: Colombia's Cocaine Routes and Regions}

Putting this map into the context of the territorial discussion outlined in Chapter 3, the reddish brown areas signify the exclusion of 'Colombian territoriality' because the Colombian state does not control these spaces and does not benefit from the revenue generated by the organizations regulating the cultivation of coca. The light green arrows highlight one of the ironies of conceptualizing 'non-integrated', 'empty' or 'insecure spaces'; these spaces are not completely disconnected from the global market. If that were truly the case, then the majority of cocaine produced in Colombia would stay in Colombia and there would be no light green arrows connecting Colombian drug 
organizations to other illegal networks abroad, organizations which not only pose a threat to "regional security" but also profit from Colombian cocaine.

\section{Colombia Labors to Weed out Coca Crops}

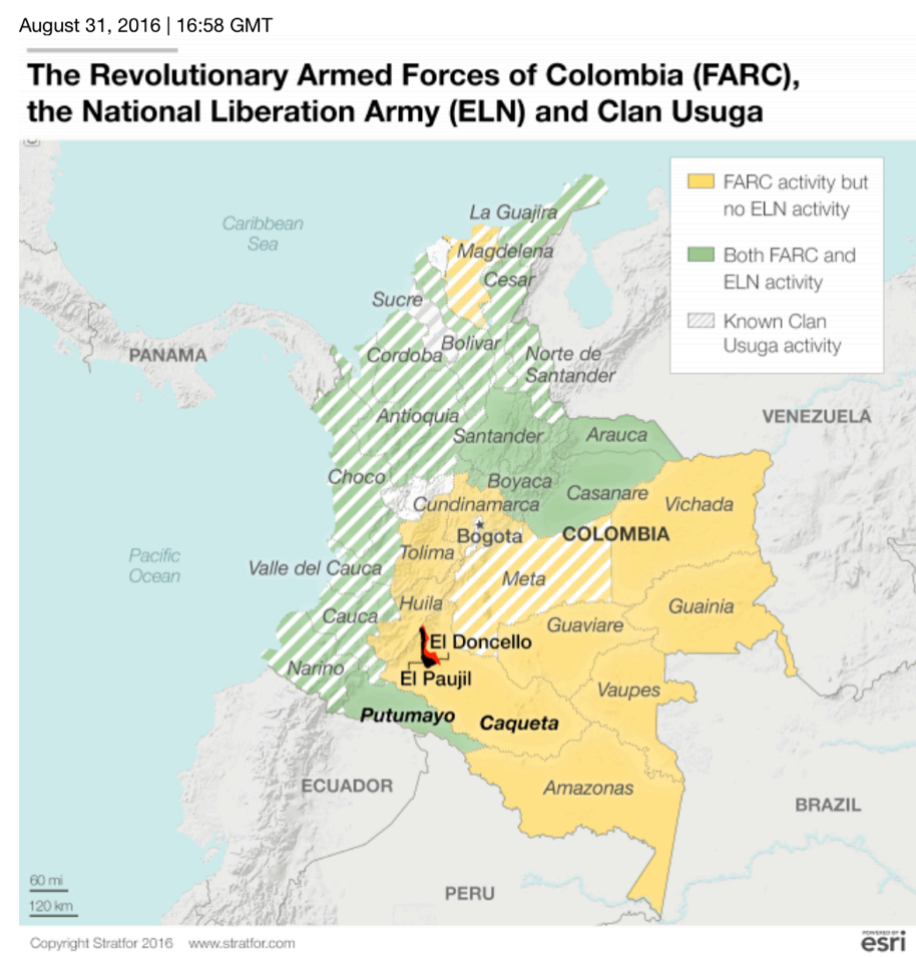

\section{Map 5.2 - Stratfor: The Revolutionary Armed Forces of Colombia (FARC),} National Liberation Army (ELN) and Clan Usuga

Map 5.2, published in August of 2016 as the peace negotiations with the FARC were closer to settlement, rehashes the concerns of the 2015 article while also mentioning other armed actors complicating the efforts to manually eradicate illicit crops in Colombia. Map 5.2 marks the spaces controlled by the different armed actors -which include the FARC, the ELN, and the Usuaga Clan (BACRIM) — that control the "manufacture and trade of illicit drugs, a major driver of instability in some areas of the country" (Stratfor Aug 2016). Notice that this map portrays almost the entirety of Colombia's territory as under the control of non-state armed actors, implying that the Colombian state only controls small pockets of gray on the map. 
The problem with maps such as Map 5.2 is that the shading of areas under the control of armed actors can also color the perception of the people that live in those areas. In explaining the rational behind the history of the U.S. military mapping in the Americas, Bryan and Wood explain that counterinsurgency relies on the ability:

...to identify threats to security and to manipulate the vulnerability of life in settings where the battlefield is everywhere... Indeed it is often only through maps that the U.S. military has been able to aggregate individual lives into populations, defining societies in a manner capable of identifying threats to them, both external and internal (2015, p.xvi).

In the context of the Colombian civil conflict, Pécaut problematizes the assumption that the occupation of areas by non-state armed actors, what he terms the 'fragmentation of Colombian territory', signifies that local populations are uniformly complicit with the actions of armed groups that control different parts of the country (1999, p.145). He cites the example of access to employment, which is sometimes conditional on allegiance to the armed groups that control local territory (ibid.. p.150). "In some ways, the division of the country under the control of the armed groups and their power networks can be seen as an ordinary, banal situation. The logic of protection, though, cannot be regarded as if it were purely and simply a response to demand that put into place a mechanism for ensuring trust" (ibid. p.151). In other words, it is mistaken to assume that just because residents of a particular community have a protection agreement with an armed group that the community is loyal to that group. Furthermore, Pécaut continues on to explain how the fact that armed groups in Colombia are in competition, renders the boundaries between different groups "complex and fluid" and that the group asserting control over a particular community could change rather quickly without notice. Within these shifting 
dynamics of territorial control, a certain group may regulate activities in one neighborhood while another group controls other neighborhoods in the same village, town or city (ibid., pp.151-152). Therefore when virtually the entire country is labeled under the control of non-state armed actors, as is the case in Map 5.2, it simplifies the complicated dynamics between local communities and these armed groups. While Stratfor does not represent the views of the U.S. Department of Defense nor the Colombian Ministry of Defense, it does create such maps for the sake of investors with the potential to influence defense policy in Colombia.

Map 5.2 precedes a short article, which puts the map into the context of investment security in Colombia. The article contains the following paragraph:

Because multiple criminal groups finance themselves through the production, taxation and sale of coca, destroying the bushes is an integral part of Colombia's public safety strategy. The criminals' practice is unlikely to soon change, and so despite the problems that manual eradication efforts could cause, they are likely to continue. The difficulty of destroying the illegal crops portend a rise in the production of coca and cocaine something the United States will likely seek to counter. But at a regional level, the Colombian drug fight also poses a risk to local business activity. Despite the relative isolation of coca-growing areas from the country's population centers, the government's strategy for dealing with the crop could stoke social unrest capable of interfering with energy exploration and production in areas where coca growing and energy production overlap (Stratfor Aug 2016).

The phrase "But at a regional level", which follows a sentence referencing the United States, suggests that 'regional' has nothing to do with the U.S. The article then goes on to mention "local business activity", which is hardly locally owned when it comes to "energy exploration and production." For instance, under President Uribe's administration, foreign investment in the Colombian oil industry increased from $\$ 278$ million (USD) in 2003 to $\$ 4.3$ billion in 2011 (The Economist 2012). 
Map 5.3, published in December of 2016, is the same as Map 5.2 with three major oil pipelines superimposed over the spaces controlled by armed actors. Following the map, the article describes the security dynamics surrounding the respective pipelines and other areas under consideration for oil speculation. With regards to the Transandino pipeline (labeled \#3 in the map), the article reports, "In the country's southwest, another oil production hub, FARC's demobilization could actually increase the incidence of extortion and violence against the petroleum sector" (Stratfor Dec 2016).

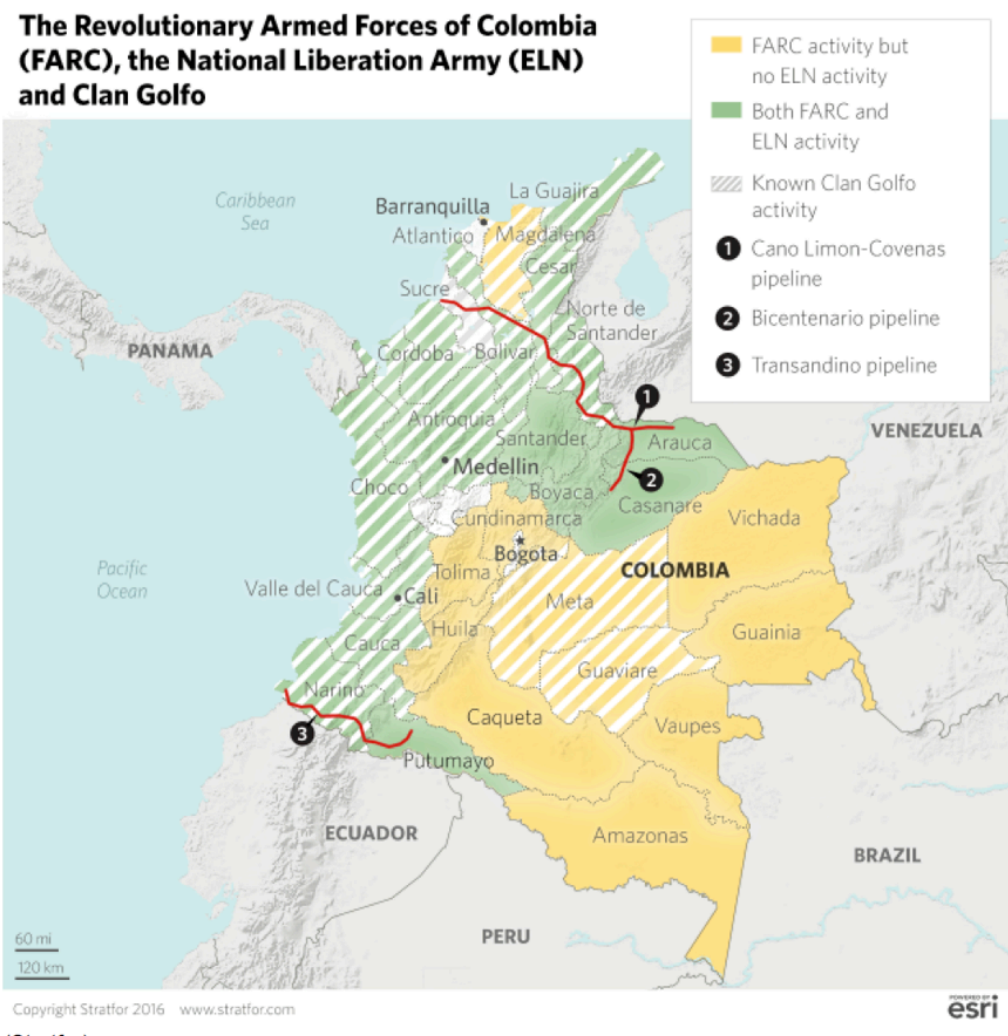

(Stratfor)

\section{Map 5.3 - Stratfor: The Revolutionary Armed Forces of Colombia (FARC), National Liberation Army (ELN) and Clan Golfo}

The point of showing this progression of maps - coca cultivation and cocaine trafficking (Map 5.1) to non-state armed actors (Map 5.2) to non-state armed actors and oil pipelines (Map 5.3) — is to signal that 'investment security’, or what Flórez López 
calls "the active territoriality of foreign capital" (2012, p.291), also plays a role in the perception of the communities where coca is grown and the strategies employed to eradicate coca. From this perspective, whatever eradication strategy is considered the most effective means to protect the oil pipelines or whatever other natural resources that companies seek to invest in, then that is the strategy that will offer the most stability to the region. Phrases such as "destroying the bushes is an integral part of Colombia's public safety strategy" and "the Colombian drug fight also poses a risk to local business activity" (Stratfor Aug 2016), belie the fact that investors could care less about the actual safety of poor rural Colombians actually affected by Colombian security policies.

\section{Keeping Communities Safe from the Bad Guys?}

Meanwhile in that southwestern corner of Colombia (the location of pipeline \#3 in Map 5.3)—more specifically, in the black communities surrounding Guapi and Buenaventura where I conducted the bulk of my interviews - residents were understandably cautious on the topic of armed actors. While every community has a unique history with non-state armed actors, FARC -commonly referred to as los señores in hushed tones during my interviews - were extremely active in the region as are BACRIM. Local opinions about how to protect communities from these actors, however, differed greatly from the government strategies employed to drive these groups out of the region.

Both U.S. and Colombian authorities argued that aerial eradication made rural communities more secure by driving out non-state armed actors, sometimes referred to as los malos or "the bad guys" or "bad people" in interviewees (cited below). While critics of aerial eradication contended that there should have been more investment in crop 
substitution via alternative development programs, the Colombian Plan for the National Consolidation of Territory placed emphasis on the forceful eradication of illicit crops as a means to "territorial security", which would make these areas safe for alternative development and new forms of economic activity (DPCI 2012, p.20).

DIRAN and the INL officials stated that the aerial eradication program bought time for people in rural areas to get the services they needed from the Colombian government. For example, Lt. Colonel Tunjano of DIRAN addressed the rational behind aerial eradication in black communities:

If we successfully eradicate coca from those territories, we are guaranteeing that the groups operating at the margin of the law cannot view coca as a source of income and has to leave. The state can them come in and guarantee Afro-descendants the rest of their rights ${ }^{127}$.

At the time of my interview with the INL - while the fate of the aerial eradication program was being debated by the Colombian government - Jorgan Andrews, INL director of the Narcotics Affairs Section (NAS), asked two rhetorical questions:

If the chemical in aerial eradication is replaced after October or the program is simply replaced by the manual eradication program: Does that change the dynamic between poor people and the Colombian government? Or does it simply put them more at the risk of bad people? ${ }^{128}$

In other words, Andrews believed that aerial eradication was more effective than manual eradication at driving out the various non-state armed actors implicated in the regulation and trafficking of illegal narcotics.

${ }^{127}$ Author interview with Lieutenant Colonel Miguel Tunjano Villaraga on May 8, 2105.

${ }^{128}$ Author interview with INL officials at US Embassy on August 4, 2015. 
In some areas aerial eradication was preceded by aerial bombardment to drive out non-state armed actors and make aerial eradication operations safer. I mentioned the official perspectives about aerial eradication being a step towards guaranteeing black communities their rights to Julio González, a resident of San Isidro, Río Calima, who emphatically responded:

No, they are not doing us a favor; they are causing us harm. Because besides that, on top of the fumigation, they cordon off the area and the bombardment begins. If, for instance, they are going to fumigate and an armed group is present and this group is trying to shoot down the fumigation plane, then the military is hitting this area with bombs and machine gunfire beforehand. Who is really being punished? The community is ${ }^{129}$.

Furthermore, Julio explained that during bombardment and subsequent fumigation residents were sometimes forced to retreat from their homes and camp in the wilderness until it was safe to return. If the bombardment did not successfully drive out the armed group in question and it was not safe to conduct an aerial eradication operation, then the bombardment was often repeated. Julio commented that families in his community had been forced to retreat to the wilderness for 10-15 days at a time under these circumstances.

Other interviewees described similar events involving running from helicopter fire or planes spraying overhead. Robinson of Río Iscuandé, Nariño explained, "Yes, there were times when they were fumigating and you had to run and also because the helicopters were shooting their machine guns. I have no idea why that was necessary.",130

${ }^{129}$ Author interview with Julio González in Bajo Calima, Valle del Cauca on July 1, 2015.

${ }^{130}$ Author interview with Robinson "El Cubano" Paz at the Montaño residence in Guapi on March 13, 2015. 
Héctor of Río Naya stated, “ The last time they fumigated this year, they also sprayed people...we were at the schoolhouse that day and I told everyone, 'Watch, within a month everyone is going to get sick.' And that's what happened."131

It is important to note, however, that bombardment and forced retreat certainly did not occur in every community ${ }^{132}$. In contrast to these accounts, about half of the farmers I interviewed did not find out their farm lots had been fumigated until days later. Farm lots in many communities are located away from homes because farmers seek out the most fertile soil. Whereas soils in more accessible areas (i.e., closer to homes and well-traveled paths and waterways) tend to be cultivated more often and thus are less productive for farming. For instance, I visited two farm plots in Temuey, Guapi via a boat equipped with a motor and each trip required approximately twenty-five minutes of river travel from the respective farmers' homes and twenty minutes of hiking through heavy vegetation while clearing the path with a machete (see Figure 5.1). Normally these farmers row themselves to their farms, which required an hour of rowing each way. We travelled by motor that day because I was paying for the gas ${ }^{133}$.

${ }^{131}$ Author interview with Héctor Marino Valencia of Río Naya at PCN office in Buenaventura on September 22, 2015.

${ }^{132}$ The Colombian authorities I interviewed declined to address any details about these bombardment missions. However, there are a number of organizations that document incidences of state and non-state armed group activity in the countryside such as the Rural Press Agency $<\mathrm{http}: / /$ prensarural.org $>$ and the Inter-Church Commission for Peace and Justice $<$ http://justiciaypazcolombia.com/>.

${ }^{133}$ Author interview with Juan Alturo, Adolfo Sánchez, and Tulio Montaño on their farm in Temuey, Guapi on July 20, 2015. 


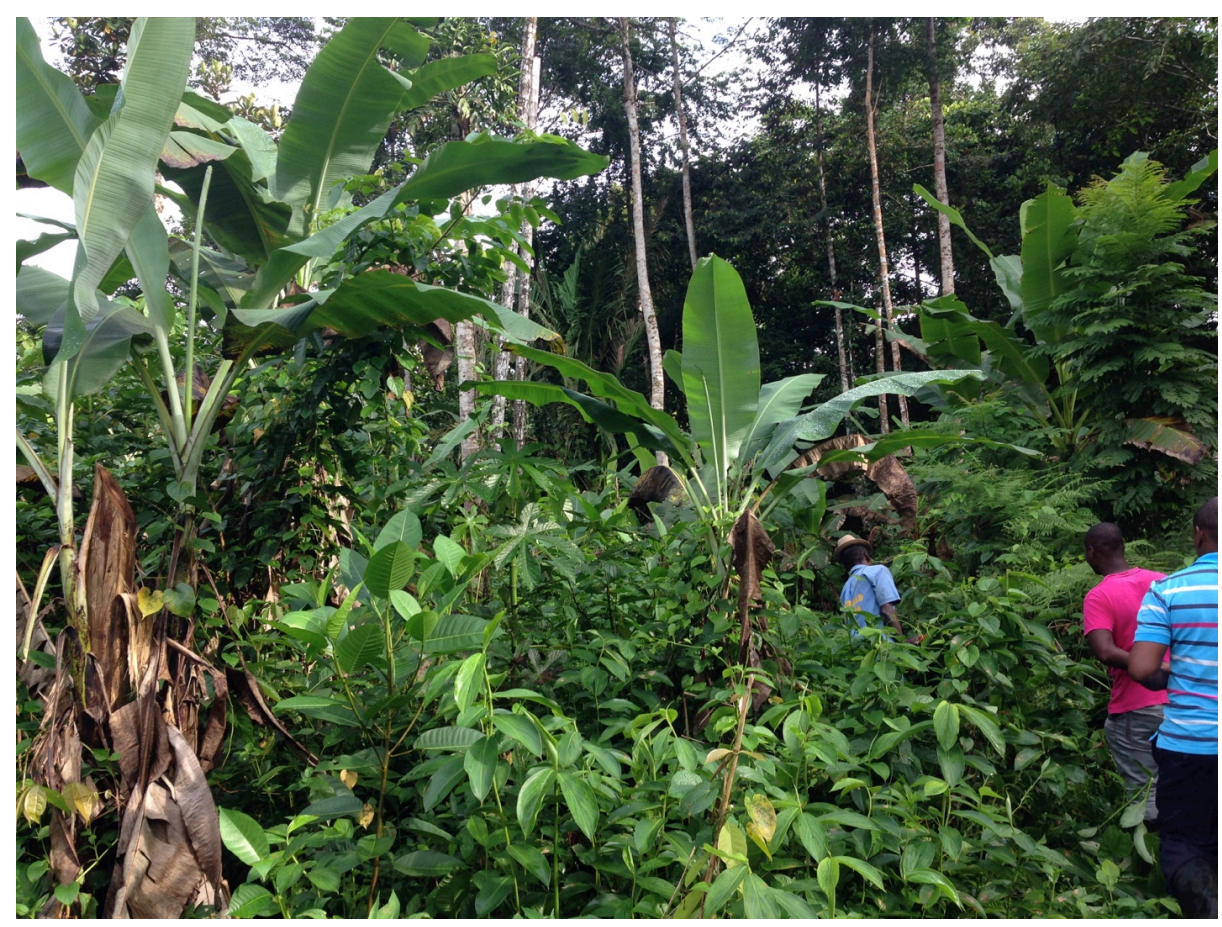

Figure 5.1 - Hacking a path through vegetation to visit a farm plot in Temuey, Guapi (photo credit: Alexander Huezo)

The INL staff questioned the validity of stories about people running from planes spraying overhead precisely because coca is not usually cultivated close to people's homes. In fact, before allowing me to ask the INL staff any questions, NAS director Jorgan Andrews stated ten "facts" about aerial eradication to clear up some common misperceptions about how the aerial eradication program works. Two of these "facts" were meant to dispel "the myth" that people and their homes were sometimes sprayed: $\# 1)$ the vast majority of coca is grown far away from where people reside and \#2) coca is increasingly grown in national parks and other natural reserves, also places far removed from where people reside. These assertions, however, did not detract from the number one complaint I heard from interviewees, which was that aerial eradication was disastrous for communities that heavily relied on farming and fishing. 


\section{Food Insecurities}

Rich in natural resources but considered the poorest region of Colombia, $85 \%$ of people in the Pacific are living with basic needs unmet (El País 2011). It is not an exaggeration to say that many of the amenities we take for granted in the U.S. electricity, running water, potable water - are luxuries in the riverine hamlets of the Pacific. Nevertheless, the residents I interviewed spoke proudly of agricultural and fishing traditions that have been practiced for generations, enabling communities relatively disconnected from other regions of Colombia to sustain themselves through their own food production.

Dagoberto, of the Association of Producers \& Marketers of the Pacific (ASPROPACÍFICO), was the most informative interviewee on the topic of 'food security', discussing food production in the contexts of Afro-Pacific traditions and his own experiences coordinating food-related projects in the region. He prefers the term 'food sovereignty' as opposed to 'food security' to refer to the problems caused by aerial eradication. In outlining the etymology of 'food sovereignty', Patel first describes the evolution of 'food security' discourses, which "moved from being simply about producing and distributing food, to a whole nexus of concerns around nutrition, social control, and public health"; furthermore, he notes, "Critically, the definition of food security avoided discussing the social control of the food system" (2009, pp.664-665). Whereas 'food sovereignty', “... focuses on local autonomy, local markets, local production-consumption cycles, and farmer-to-farmer networks that promote agroecological innovations and ideas" (Altieri \& Toledo 2011, p.607). Therefore, Dagoberto associates 'food security' with a certain national government discourse that 
describes the type of temporary welfare assistance doled out when someone is displaced or facing an emergency situation. Whereas 'food sovereignty' connotes the type of agricultural activity in which a community first guarantees its own sustenance and explores commercial possibilities once the basic needs of the community are met ${ }^{134}$. As Patel explains, food sovereignty “is a call for peoples' rights to shape and craft food policy" (2009, p.663).

Dagoberto first mentioned the huerta (personal garden for familial consumption) as a form of food sovereignty within the Afro-Pacific tradition of subsistence agriculture. Huertas typically contain subsistence crops -corn, plantains, taro root, yucca...etc.- as well as fruit trees -mango, chontaduro (peach palm), borojó (a citrus fruit), lemons, coconuts...etc. — and a rooster with four to five hens. The huertas are sometimes complemented by another form of garden known as an azotea, "a raised platform garden typically kept near the main lodging and planted with medicinal and alimentary herbs" (Oslender 2016b, p.128). Both Oslender and Asher discuss azoteas as a form of gardening promoted by Matamba y Guasá, a women's organization that espouses selfsufficiency and female empowerment as heads of households (Oslender 2016b, p.128; Asher 2009, pp.145-148). The huertas and azoteas seem related to the slave household plots Carney describes in her study of the African Diaspora in the Caribbean, “...dooryard garden plots operated as botanical nurseries of the dispossessed...hidden laboratories of crop experimentation and selection" (2006, p.105). In a similar vein,

${ }^{134}$ Author interview with Dagoberto Hurtado at Hotel Masgorgona, Guapi on July 18, 2015. Despite this distinction, Dagoberto said he employs the term food security more frequently than food sovereignty to avoid sounding leftist to government officials he often deals with. 
Escobar identifies azoteas as an example of the link between food autonomy and biodiversity that PCN activists have promoted, "Often, local agriculturalists and farmers have played an active role in maintaining diversity in situ by saving and managing local seeds and landraces in such a way that gene-rich pools of food crop species are maintained" $(2008, \text { p.152) })^{135}$.

Dagoberto spoke of the importance of community encounters, whether formally in meetings or informally in one's neighborhood, for the maintenance of these gardens:

It is when the community gets together that we begin to share experiences. So if I have this plantain tree and such and such pest is attacking it, like the gusano tornillo (screw worm)... so that's when other families start to discuss how you control that pest. We're talking about a biological way of dealing with the problem, without chemicals, because not everyone has money to buy a kilo of that stuff (chemicals) to control that gusano tornillo.

Thus both huertas and azoteas are vital to that first step of food sovereignty that Dagoberto mentioned, residents first guaranteeing their own sustenance, which is not only important for nutrition, but also the personal interactions that develop a sense of community. He then went on to describe larger farm lots for cash crops or alternative development projects represented as commercial possibilities, which normally involved community-wide collaboration or, in the very least, collaboration with other farmers.

For Dagoberto, seafood is a complimentary aspect of food sovereignty. Fishing is a daily activity for many men and, because refrigeration units are not common, they will catch two to three pounds of fish at a time with nets or a fishing line with a hook. Colombian anthropologist Arocha explains that fishing and shellfish collection are also complimentary to agriculture, not just in nutritional terms, but because it may be too risky

${ }^{135}$ Escobar, citing Rhoades and Nazarea (1999), defines landraces as "folk or indigenous plant varieties that are the result of many generations of farmer selection" (2008, p.152). 
to fish at high tide so that is when farm plots attended. Meanwhile men often fish during low tide because it is both safer and more difficult to reach distant farm plots (Arocha 1999, p.58). The women that traditionally collect shellfish from the mangroves are referred to as concheras (shellfish collectors) or piangüeras (mussel collectors). They rely on the rhythm of the tides to reach distant collection areas (high tide) and to plod through mangroves to collect shellfish and crabs stuck in the mud (low tide) (ibid., p.73). Part of the conchera's catch is sold for profit while what is left is usually cooked at home in coconut milk (Oslender 2016b, p.126).

While interviewees often explained that aerial eradication was bad for fishing and shellfish collection, when first asked about the impacts of aerial spraying, nearly every interviewee would first list the crops they lost-some combination of corn, rice, plantains, yucca, taro, peach palm, avocado...etc. - and then continue on to detail the hardships that resulted from these losses. For instance, I asked Robinson of Río Iscuandé, Nariño about the repercussions of aerial eradication in his community, "Well when aerial eradication happened, that which is our culture... bananas, plantains, yucca, taro root... it left us without anything to eat brother. Without anything to eat." ${ }^{\text {"136 }}$ Gumercindo of Río Guajuí lamented, "So after the fumigation we passed through all of the communities and noted the damages. The taro root was ruined, plantains, sugarcane... everybody in Río Guajuí was left without food." ${ }^{137}$ Tulio of Temuey, Río Guapi told me that he cried when his farm was fumigated. He had invested so much effort and money over the years, only

\footnotetext{
${ }^{136}$ Author interview with Robinson Paz on March 13, 2015.

${ }^{137}$ Author interview with Gumercindo Quiñónez on March 14, 2015.
} 
to lose his harvest in one day. "I grabbed an armful of dead crops to show people at the mayor's office but they looked at me like I was crazy and didn't help me."

While some farmers could salvage crops fumigated one time, many areas were aerially fumigated two to three times a year to guarantee that coca plants were sufficiently damaged, which also meant that legal crops would not survive. A report created for a collective action suit against DIRAN explains why aerial eradication was so devastating to the agricultural practices of the communities of Guapi and Timbiquí in the department of Cauca:

Mixed farming was the base of subsistence agriculture. Here, every family nucleus has its parcel of land for crops. The partial or total destruction of these crops, inflicted by aerial eradication with glyphosate, caused shortages of food, seeds, and the resources to replant; nevertheless, some people did manage to replant, but before the new plants could be harvested they were sprayed again and destroyed (Impactos 2011, p.47-48).

Notice in Figure 5.2, a photo taken two weeks after a farm lot was sprayed, that the leaves of the plantain tree in the center are almost completely brown but that there are still many green plants surrounding it. Both coca and certain licit crops could have been salvaged immediately after one aerial spraying through a variety of techniques such as cutting the fumigated top leaves or washing off the glyphosate. Aerial eradication was not intended to kill coca plants; rather the objective was to lower the alkaloid content of the coca leaf to the point that it is no longer profitable ${ }^{139}$. Even though legal trees or plants might have still been standing after aerial fumigation, many farmers stated that the fruits

${ }^{138}$ Author interview with Tulio Montaño of Temuey, Río Guapi at his farm on July 20, 2015.

${ }^{139}$ Author interview with INL staff on August 4, 2015. 
or vegetables could not be consumed or that the trees or plants would simply not bear fruit after fumigation (see Figure 5.3). "El árbol no se da," was a common refrain.

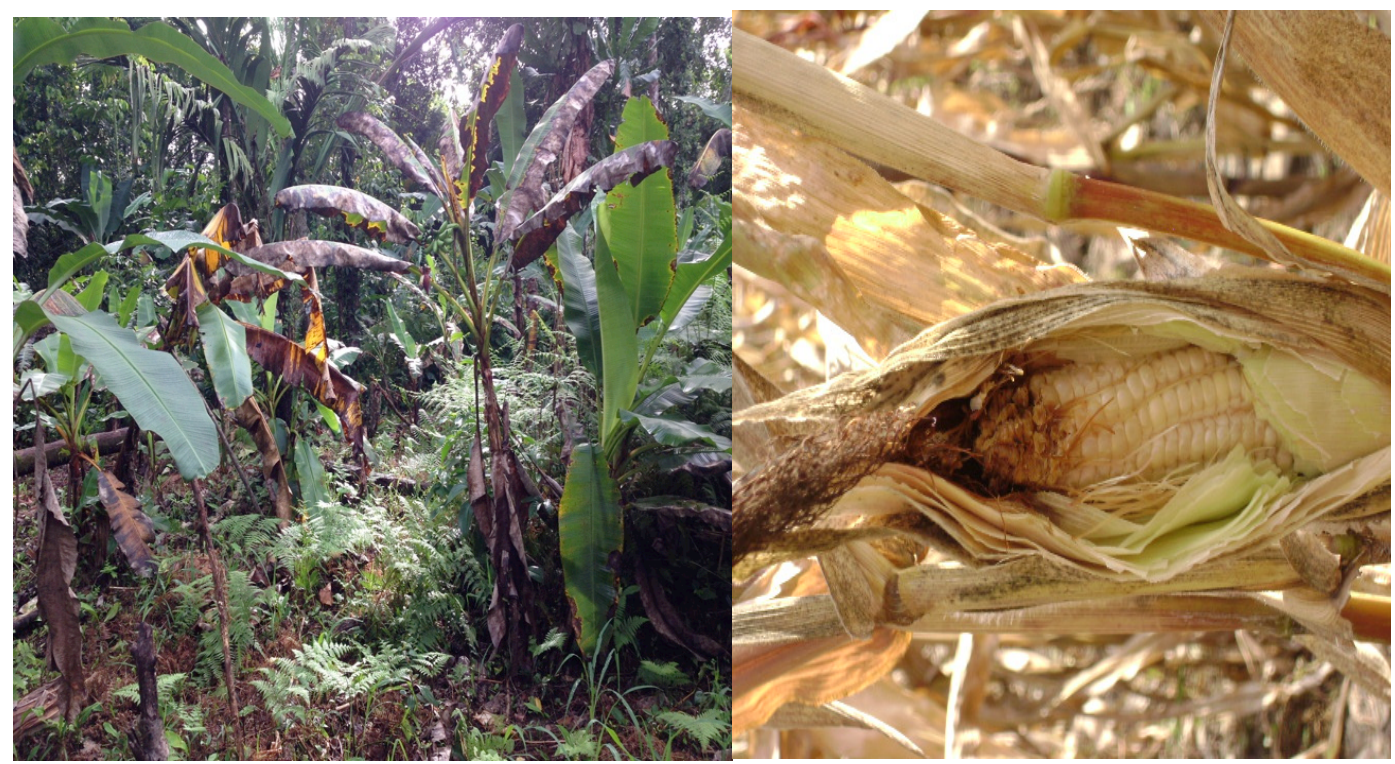

Figure 5.2 - Plantain tree with dead

Figure 5.3 - Corn singed by aerial leaves 3 months after aerial fumigation fumigation spray

(photo credit: Alexander Huezo)

(photo credit: Germán Ospina)

Farmers also complained that the contamination left soils less fertile and that the

seeds from fumigated farm lots were worthless, forcing them to purchase expensive seeds from distant communities. Yolanda Garcia of Timbiquí, Cauca explains how this situation impacted the cultivation of rice, an activity predominately carried out by women:

Women, for instance, are responsible for the cultivation of rice. Rice has been the crop most affected because, in their hurry to fumigate, what they do is spray between the riverbank and the mountains. Rice is always cultivated near the riverbanks, downstream. And it is one of those crops that even the seeds are ruined. So it falls on the women to get new seeds and it requires us to use our connections with other rivers to do so ${ }^{140}$.

${ }^{140}$ Author interview with Yolanda García at Petronio Álvarez Music Festival in Cali, Valle del Cauca on August 16, 2015. 
Other interviewees complained of having to import foods that used to grow plentifully in the region.

For instance, chontaduro (peach palm) that was once a profitable, locally grown product in the communities of Río Calima, Valle del Cauca, is now imported from elsewhere. Milton, a farmer whose land has never been sprayed, claims that his chontaduro palms had been indirectly harmed by aerial eradication. His hypothesis is that beetles have migrated from aerially fumigated palm trees in neighboring communities to his farm. Forced out of its original habitat, this beetle, locally referred to as picudo negro, has taken to hollowing out sections of chontaduro palms in its new habitat, thereby killing the trees ${ }^{141}$. I asked Claudia María, a chontaduro vendor that I would frequently talk to near my apartment in Cali, about Milton's theory. She had been living in Cali for twenty-five years and selling chontaduro for the last twelve years. She said that chontaduro was more expensive than ever but did not agree with Milton's theory, "If the spray is supposed to kill the coca then how could the beetle survive? I don't think this has anything to do with the fumigation. It is the word of god being fulfilled. If people followed the word of god, then this would not be happening."142 Claudia María is originally from Charco, Nariño, where her father cultivated chontaduro for a living. She then went on to explain that no one cultivates chontaduro in Charco anymore because the guerilla ruined everything. She also lamented that people do not grow other food crops

${ }^{141}$ Author interview with Milton on his farm in Bajo Calima on July 1, 2015. Local biologists are currently investigating the validity of this claim.

${ }^{142}$ Author interview with Claudía María in Cali on September 4, 2015. 
anymore, insinuating that the beetles were god's way of punishing people for growing coca.

INL officials contended that people blame aerial eradication for all sorts of maladies and environmental problems that are completely unfounded. The failure of licit crops can be attributed to fungi, insects, or insecticides used on other crops ${ }^{143}$. Rather than view the numerous claims against the aerial eradication program as an indictment of the program, however, they regarded the controversy as a lack of communication between the Colombian government agencies in charge of the program and a rural population with limited knowledge of how the program works and how dangerous it is to eradicate coca manually ${ }^{144}$.

\section{Aerial Eradication: The Safest Way to Eradicate Illicit Crops?}

Aerial eradication was lauded as the safest and most cost-effective means to limit the cultivation of illicit crops, which are increasingly cultivated in areas considered dangerous and out of reach. From the perspective of eradication authorities, cultivators grow coca plants and opium poppies in these areas -difficult to access because of limited infrastructure and rugged terrain - so as to avoid detection and eradication ${ }^{145}$. Lieutenant Colonel Miguel Tunjano of DIRAN, explained that the average number of hectares manually eradicated in one day is miniscule ( 8 hectares) compared to the one-day

${ }^{143}$ For instance, Oslender mentions the anillo rojo (red ring) plague contributed to the failure of coconut crops for export in the river basins surrounding Guapi during the 1960s (2016b, p.63).

${ }^{144}$ Author interview with INL officials at US Embassy on August 4, 2015.

${ }^{145}$ ibid. 
average for aerial eradication ( 800 hectares). He also had this to say about the difference between manual eradication and aerial eradication:

I will put it to you from a captain's perspective. You have three tools. Voluntary eradication with crop substitution works in certain places as illicit crops are disappearing. In other places those methods do not work because there is local resistance or because it does not make sense to invest in areas where you will not see any profits... because these places are so far removed from access to transportation routes. The people not born in those places, they came to cultivate coca. So you, the captain, have to decide whether you will attempt manual eradication or aerial eradication. You decide on manual eradication and your crew gets sick because the water is contaminated. At night you hear tatucos, homemade explosives made from gas tanks, being thrown in your direction. Or somebody walks into a coca lot and steps on an explosive mine. So you say to yourself, "I'm not doing that.",146

As one manual eradication monitor explained to me, "You are always in the sniper's sight. The Colombian army can promise that an area is secured but cannot guarantee it" $^{\prime 147}$. In addition to being shot in the leg and seeing several coworkers wounded, this particular gentleman also complained about frequently suffering from dehydration, the mental toll of living in a state of paranoia, and the prevalence of tropical diseases such as dengue and leishmaniasis ${ }^{148}$.

${ }^{146}$ Author interview with Lieutenant Colonel Miguel Tunjano Villaraga, in charge of aerial eradication detection group. Interview conducted at Hotel Tequendama in Bogotá on May 8, 2105.

${ }^{147}$ Author interview with eradication monitor contracted by UNODC, who preferred to remain anonymous. Interview conducted via Skype on April 29, 2015.

148 "Leishmaniasis is a parasitic disease that is found in parts of the tropics, subtropics, and southern Europe...Leishmaniasis is caused by infection with Leishmania parasites, which are spread by the bite of phlebotomine sand flies" (CDC website). 
When one factors in that it normally takes 90 people on the ground - 30 manual eradicators +60 soldiers ( 2 soldiers for every manual eradicator) — to manually eradicate one square kilometer of coca, aerially eradicating coca crops with a few planes and helicopters, at least on the surface, seems like a safer alternative than putting a greater quantity of lives in immediate danger ${ }^{149}$. Between 2005-2013 the total number of casualties for manual eradications operations in Colombia -soldiers, police, and eradicators - was 627 injuries (including amputations) and 184 deaths (DIRAN website).

Every year the explosive landmines planted to protect coca fields and laboratories contribute heavily to those casualty numbers. Despite various campaigns to deactivate these mines and a decline in the number of total victims in recent years, Colombia still had 219 new victims -the second most in the world — in 2015 (UN Mine Action). Lt. Colonel Tunjano explained that part of the problem is that the FARC has planted a lot of handmade mines that are not detected by minesweepers. In these instances bomb-sniffing dogs are employed, yet in either case eradication teams are understandably concerned about whether all mines have been detected and deactivated ${ }^{150}$.

In discussions with the Colombian government, $\mathrm{PCN}$ leaders were informed that aerial eradication was favored over manual eradication in the Pacific region because of

${ }^{149}$ Author interview with Lieutenant Colonel Miguel Tunjano Villaraga on May 8, 2105.

${ }^{150}$ ibid. When I pressed Lt. Colonel Tunjano about the extent to which the newly emergent criminal bands (BACRIM) are also implicated in manual eradication casualties he explained that the FARC and ELN are primarily responsible for these casualties. Though he could not confirm any statistics on the matter he stated that the BACRIM do not have the capacity to attack directly so they mostly plant landmines and organize communities to block the passage of eradication teams, the latter of which is also a strategy employed by the FARC. 
the FARC's proclivity to plant explosive mines. The PCN responded that it was the Colombian government's responsibility to remove the mines so that manual eradication was possible ${ }^{151}$.

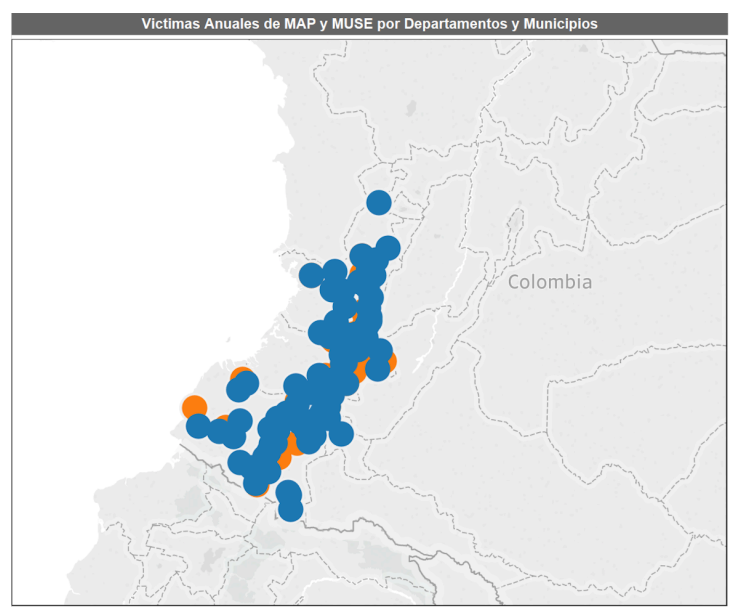

Map 5.4 - Victims of MAPS (Anti-personal Mines) and MUSE (Unexploded Munitions) in the departments of Valle del Cauca, Cauca, Nariño (source DAICMA)

Map 5.4 highlights victims of MAPS (Anti-personal Mines) represented by blue dots and victims of MUSE (Unexploded Munitions) represented by orange dots in the three departments of the southwestern Pacific -Valle del Cauca, Cauca, Nariño (listed from north to south) - from 2000 to 2015. Mine casualties serve as an indicator for the presence of mines, which cannot be accurately mapped precisely because the mines are hidden. Notice that victims of MAPS and MUSE are prevalent throughout the region but are more highly concentrated inland as opposed to the Pacific Coast. This is especially the case in Cauca, which is the most isolated of the three departments. Map 5.5 combines explosive mine casualties, ethnic territories, coca cultivation and aerial eradication in the SW Pacific region for the year 2013. The map shows that aerial eradication was not

${ }^{151}$ Author interview with Mario Angulo, director of PCN Buenaventura at his office on September 9, 2015. Mario did not specify which governmental institutions were part of this conversation. 
necessarily conducted in areas with mine casualties, especially in the municipality of

Buenaventura where Julio resides.

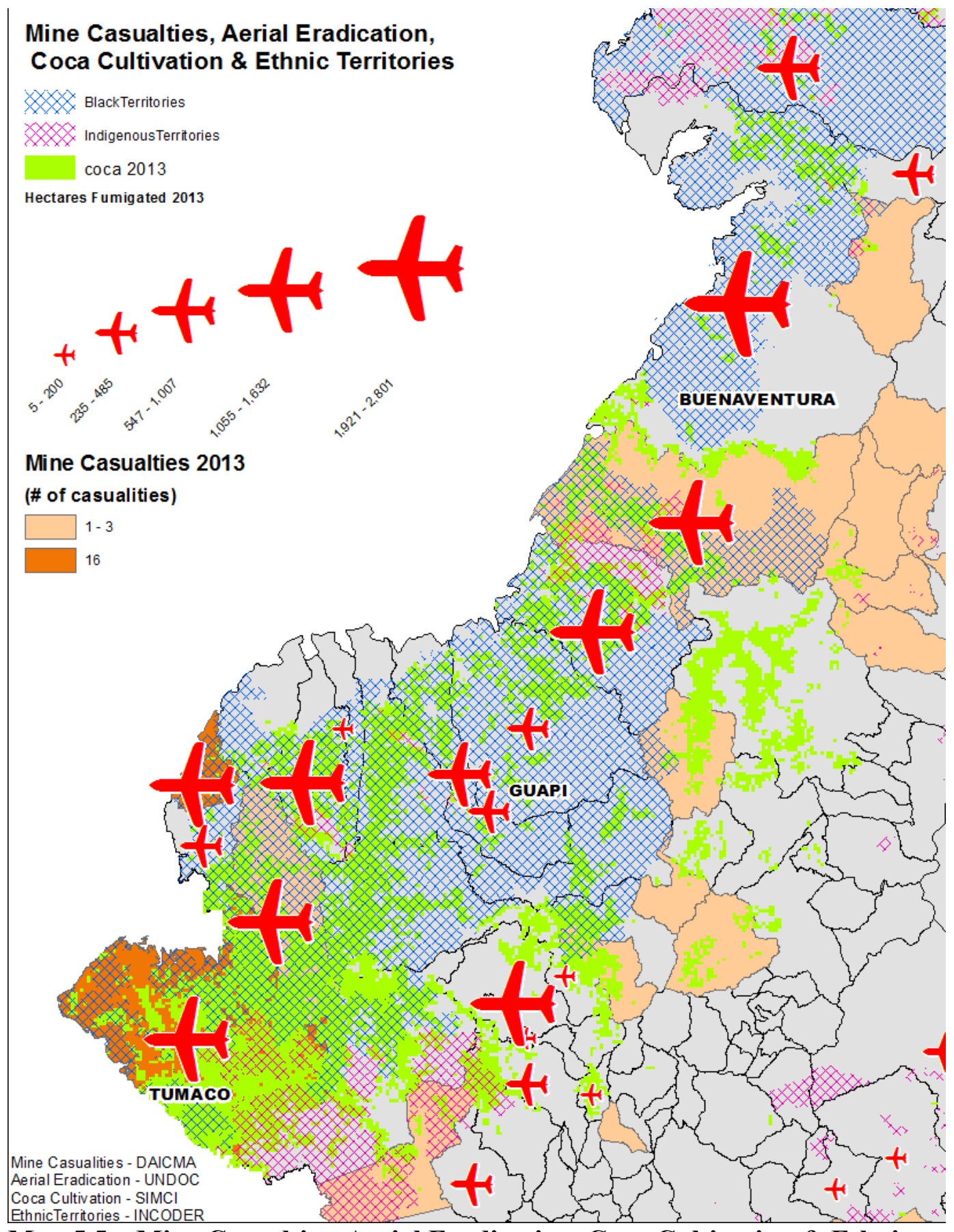

Map 5.5 - Mine Casualties, Aerial Eradication, Coca Cultivation \& Ethnic

Territories in Southwest Pacific Region (created by Alexander Huezo)

Citizen Security? 
The general perception amongst PCN leaders that I spoke to was that the safest way to eliminate illicit crops would have been to never let outsiders come into ethnic territories to begin with. This perspective is rooted in a general distrust of the Colombian military, which -aside from its history of permitting paramilitary groups to perpetuate violence against poor rural communities - is viewed as unwilling to protect the boundaries of ethnic territories. Escobar mentions the military's passivity in the context of coca cultivation in the Pacific, "Not infrequently, one finds in some areas a river controlled by guerillas next to another controlled by paramilitaries, both pushing people to plant coca, while the army keeps watch a few kilometers downstream" (2008, p.64). Mario Angulo, the director of the PCN office in Buenaventura, expressed a similar sentiment while reflecting on the history of counternarcotics in Buenaventura:

If we consider the current state of counternarcotics policy, instead of resolving the problem what has really happened is the problem has worsened. Before, here in the Pacific, there was only trafficking but now the plant is being cultivated and processed. The police have actually limited the mobility of the farmer and not the people responsible for the production. In our case in Buenaventura, in the communities of Calima and Anchicayá, native residents were not responsible for the majority of the production; outsiders were primarily responsible. Native residents were the auxiliaries and they helped secure supplies. The supplies were transported through the territory without any problems, but the difficulties occurred when they tried to send remittances... Our point is that there has never been a military decision to rid the territory of coca cultivation and trafficking, because if they wanted to do that they could have done that already. The only way to reach the Pacific from the interior is through Buenaventura or Tumaco. So if you controlled those roads, the Pacific region would be free of all this; not just the coca crops but also the illegal mining ${ }^{152}$.

${ }^{152}$ Author interview with Mario Angulo on September 9, 2015. 
In other words, aerial eradication would have never been necessary if the Colombian military had prevented traffickers from entering the region in the first place. Abraham of Río San Francisco, Guapi complained. "The government should be responsible for removing these outsiders cultivating coca or bringing in their mining machinery!"153

In his speech at Encuentro AfroPazifico, José Santos proposed the idea of forming a local armed guard to keep black territory safe from unwanted intruders:

The National Autonomous Congress of the Black Community in Quibdó commissioned a mechanism, the Cimarrón Guard, which is similar to the state's armed forces. It was formed so that there is no trespassing on or meddling in their territory. We, as members of community councils, should create our own security structure, which would allow us to exercise control. So that when someone enters our territory, they are required to ask us permission and we may authorize or reject their request to enter ${ }^{154}$.

In other words, if the Colombian military is not going to protect communities by keeping illegal armed actors out of black territory then black communities should take steps towards guaranteeing their own safety ${ }^{155}$.

I asked Silson Carabalí, who had already expressed his frustrations dealing with the Colombian government in the aerial eradication complaint process, to speak candidly about the coca situation in Guapi. In his opinion the fundamental problem with aerial

${ }^{153}$ Author interview with Abraham Sinisterra of Río San Francisco, Guapi at the Hotel Río Guapi on July 19, 2015.

${ }^{154}$ Paragraph excerpted from José Santos Caicedo's speech at Encuentro AfroPazífico in Piendamó, Cauca on August 28, 2015.

${ }^{155}$ The Cimarrón Guard is dedicated to ensuring the safety, rights, and cultural patrimony of the residents of the community of San Basilio de Palenque, Bolívar (approximately $50 \mathrm{~km}$ southeast of Cartagena on the Atlantic Coast). It is compromised of young people mostly males, though open to women - whom are not members of the Colombian police, military, or any other armed group in Colombia (Observatorio). 
eradication, as was the case with many other problems plaguing Guapi, was that black

communities were not guaranteed the same rights as others:

SC: A gentleman that works for the Colombian police told me that only $3 \%$ of all crops in Guapi are coca. Our lands are fertile, very fertile. So it would be easy to substitute one crop for another but the national government has not proposed this solution.

AH: I want you to answer this next question with your personal opinion and not as the ombudsman, an employee of the municipal government. If there are so few illegal crops here then why do they keep fumigating?

SC: If you asked the plantation owner if he would prefer aerial eradication over some other form of eradication, he would say, "Go ahead and fumigate," because he could rest assured that his sugarcane fields are not going to be fumigated, that his cotton fields are not going to be fumigated... However, our plantains, our yucca...our sustenance crops, that doesn't matter to them. And they (the plantation owners) are the ones the government is thinking about with regards to citizen security. Citizen security is not a public benefit; it is a private benefit ${ }^{156}$.

Silson made a point of mentioning 'citizen security', a term increasingly used by DIRAN and other Colombian police agencies, with whom Silson has to interact with on a daily basis in his capacity as ombudsman. Focusing on 'citizen security' certainly seems like an improvement over counternarcotics discourses of the 2000s oriented towards 'national security' or 'democratic security'. However, in terming citizen security a 'private benefit', Silson references the preferential treatment for the plantation owner -a type of landowner found outside of Guapi, typically imagined as a white or mestizo member of the Andean elite — who represents 'Colombian territoriality' (Flórez López 2012). So it would seem that whatever type of 'security' was employed in these discourses did not encompass black communities.

${ }^{156}$ Author interview with Silson Carabalí, Guapi’s Personero, at his office on July 28, 2015. 


\section{Cruel Intentions}

Thus many interviewees understood aerial eradication as not only undermining the safety and rights of black communities, but also as an intentional form of discrimination and punishment. For example, Miguel of Rosario, Guapi complained:

You have a small farm and they come to fumigate despite the fact that there are no illicit crops present... You know that the government is always after the illicit crops but if I don't have a single illicit crop on my parcel, then they shouldn't have a reason to fumigate it. And it's something that they do, probably intentionally, because they know where the illicit crops really are. They see us here without illicit crops but, nevertheless, they continue fumigating ${ }^{157}$.

Héctor of Río Naya, Buenaventura mentioned a video recorded in his community that showed aerial eradication planes making three passes, each time spraying legal crops. I asked him if coca crops were targeted as well and he responded:

In that case the objective was the subsistence crops, not the coca. The fumigation spray also landed on the river and you can see in the video that they meant to spray the water. The ranchers were happy because they were not sprayed. What they did was use the fumigation of coca as an excuse to complete another plan. The objective was to do away with our legal crops to provoke disintegration, displacement and hunger. The intention is something different than they say it is ${ }^{158}$.

I watched the video, (posted here: https://www.youtube.com/watch?v=vWPo6PUZQxs), and one can see the planes spraying but hardly tell what is being sprayed. The point of referring to Héctor's testimony and the video, however, is not to measure the validity of this particular claim. His assertion that aerial eradication was intended to ruin legal crops

${ }^{157}$ Author interview with Miguel Vanguera Montaño Ángel in Bocas de Temuey, Guapi on March 14, 2015.

${ }^{158}$ Author interview with Héctor Marino Valencia of Río Naya, Buenaventura on September 22, 2015. 
and to inflict harm on black communities is taken seriously here precisely because it was an extreme, but not uncommon opinion.

Longtime PCN leaders Konty Bikila and Benjamín Mosquera of Río Anchicayá, Buenaventura expressed similar, strongly worded sentiments about aerial eradication being a means to dispossess black communities of territory. Konty reasoned, "It is not only that they want to get rid of the coca, it is that there are other intentions behind this... so we think, actually we know, that there is a strategy in place to expropriate our territories.” Benjamín followed up Konty’s argument, by stating, "There are capitalist, extractivist models...ways to expropriate our communities and develop megaprojects, which eliminate our very guarantee to life itself ${ }^{159}$.

\section{Thinking Critically about the Geopolitics of 'Security'}

To a person unfamiliar with the histories of black and indigenous communities in Colombia, the assertion that aerial eradication was an intentional form of dispossession might seem ridiculous. However, this perspective is certainly not out of the ordinary amongst residents of the Afro-Pacific whom have heard politicians and military officials espouse numerous security discourses, none of which seemed to have anything to do with the safety of black communities, while the Colombian military turned a blind eye towards the violent transgressions of non-state armed actors in the region.

${ }^{159}$ Author interview with PCN leaders Konty Bikila and Benjamín Mosquera at the Cali bus terminal on August 12, 2015. Konty Bikila is mentioned for his activism in Black and Green (Asher 2009, p.74) and in the acknowledgements of Territories of Difference (Escobar 2008, p.xiii). Mosquera has worked as an ethno-educator in the field of education and rural development for the last fifteen years. He is also a member of the Social Science Research Council's Working Group on Mining in Colombia (see http://gdiam.ssrc.org/somos.html). 
I introduced this chapter by stating that it performs critical geopolitics through the deconstruction of security discourses that factored into the implementation of aerial eradication. In the first place, this deconstruction is visible in many of the subheadings of the chapter, which employ not-so-subtle wordplay and, sometimes, odd punctuation to challenge terms (national security, democratic security, regional security, citizen security) often taken for granted in the fields of political science and international relations. Secondly, I reveal the contradictions inherent in these 'security' discourses, which on the surface sound utopian but in practice have been invoked to incriminate or exclude poor rural Colombians. I then transitioned to the security concerns of those communities most affected by aerial eradication. In doing so I shifted focus from those security discourses, what could alternatively be labeled "subordinating modes of representation" (Sharp 2011a, p.272), articulated by dominant geopolitical actors (drug policymakers, military strategists, and foreign investors) to the security concerns of black community residents (food security or food sovereignty and personal safety) living through two overlapping conflicts - the Colombian civil conflict and the War on Drugs. Along the way I detailed why aerial eradication was considered the safest form of illicit crop eradication, in terms of putting the least amount of eradicators and soldiers in immediate danger. "Danger", however, in the context of aerial eradication was an extremely subjective term; it was a justification that ignored the long-term repercussions of the chemicals sprayed and the fact that many communities were bombarded prior to eradication missions to decrease the probability of the aerial eradication pilot being shot down. Finally, I concluded by presenting a controversial opinion I heard from several PCN leaders, that aerial 
eradication was an intentional form of dispossession to remove black communities from their territory.

While I personally do not think aerial eradication was an intended as such, I completely understand why it was perceived that way. Aerial eradication endangered whole communities in a number of different ways, some of which have been explored here and some of which will be explored in the next chapter. Chapter 6 continues this discussion of aerial eradication as an intentional form of dispossession and describes how this counternarcotics strategy was justified as a form of environmental conservation, while disrupting the unity of the Afro-Pacific conception of territory-culture-biodiversity. It begins by approaching "The Business of Security" from an entirely different angle. 


\section{CHAPTER 6}

\section{Contested Natures: Aerial Eradication as Environmental Conservation?}

'Contested Natures' is an intentionally ambiguous term in this chapter's title. In the first place, the term signals the role of political ecology in this dissertation, as a form of critique meant to "disrupt normal expectations, undermine inherited assumptions," and which also acknowledges "the inevitable political roots of all environmental knowledge" (Robbins 2012, p.98). Secondly, 'contested natures' implies that terms such as 'nature' or 'environment' or 'biodiversity' will be deconstructed in order 'to open up the category of the environment itself and explore its multiform representations" (Peet \& Watts 2004, p.19). In the third place, 'contested natures' draws attention to the struggles for natural resources happening in rural Colombia, which entails the, “...the social, spatial and intertemporal patterns of access to the benefits attainable from natural resources and from the environment as a life support system..." (Martínez-Alier 2002, p.73). These struggles not only consist of access to material resources such as food and water but also the traditions or practices that people have developed to sustain themselves in their environs.

Therefore, in the fourth place, 'contested natures' connotes conflicting perspectives about what traditions or practices people define as part of their culture. In the case of black communities of the Pacific region, these conflicting perspectives are both about the external perception of what happens in black communities (e.g., "Coca, an illicit crop, is being cultivated in black communities.") and the internal struggle to define how life is carried out in black communities (e.g., "Coca cultivation is not part of the cultural heritage of black communities."). In this regard, 'contested natures' refers to the central importance of culture in the theorization of nature and territory, an attribute of Latin 
American political ecology (Porto Gonçalves et. al 2012, p.34). Lastly, 'contested natures' highlights disagreements about the ecological impacts of aerial eradication, which eventually materialized as collective action suits in the Colombian judicial system.

This chapter first continues the explanation of the argument set forth in Chapter 5, which is that PCN perceived aerial eradication as an instrument of dispossession. It outlines this argument in the context of the PCN's conceptualization of biodiversity and the issues affecting black territory as articulated through the political ecology of difference framework (Escobar 2008). The chapter then transitions to the justifications for aerial eradication as a strategy to conserve the environment. The chapter concludes by discussing aerial eradication protocols and the hierarchies of credibility that subordinate local knowledge in the struggle to defend 'the territory'.

\section{Contextualizing the Political Ecology of Difference}

Cornered by transnational capital and national subsidiaries attracted by the scent of metals, petroleum, biodiversity and the market for services provided with cheap labor... today these aboriginal and ancestral communities (indigenous and Afrodescendants) are trying to make Colombian society understand what the government has not wanted to accept. That participation is the foundation of democracy... these communities demand respect and protection of the ecosystems in this country because, in addition to sustaining our existence on earth, these ecosystems sustain the Colombian economy and are not just estates destined to enhance the coffers of extractivist multinational companies, which are principally responsible for bringing this planet and its population closer to global disaster. - PCN leader Harrison Cuero (choco.org 2015)

This quote is from an article celebrating Sentence T-576, a 2014 Constitutional

Court ruling that guaranteed black communities the right to previous consultation.

Chapter 4 explained why black communities insisted that any externally driven activities 
conducted without permission in black territory, such as aerial eradication, were a violation of the right to previous consultation. However, the denial of previous consultation for aerial eradication was also considered problematic because this counternarcotics strategy generated hardships, such as the insecurities mentioned in Chapter 5 (i.e., personal safety, food insecurities). Those insecurities -which in many cases already existed because of the civil conflict, but that were exacerbated by aerial eradication - have, either directly or indirectly, factored into the massive displacement of afro-descendant and indigenous people from their respective communities. This displacement in turn has left these populations that much more vulnerable to exploitation by "transnational capital and national subsidiaries" interested in exploiting the Pacific region's natural resources.

Therefore, to further explain why many residents of black communities perceived aerial eradication as an instrument of dispossession, it is important to remember that the creation of black territories entailed two dramatically sets of conservationist discourses (discussed in Chapter 3). The first set of discourses, state conservationist and development-oriented — articulating the need to protect a biodiverse Pacific region, viewed as a resource-rich area important to the advancement of the Colombian economy - partially factored into the circumstances that facilitated the establishment of ethnic territories in Colombia. The second set of conservationist discourses, articulated by black activists and scholars who study the Afro-Pacific challenging some of the assumptions behind the first set, conceptualized biodiversity as much more than just the flora, fauna, and natural resources contained within the Pacific region. As PCN leader Benjamín of Río Anchicayá explained: 
We do not separate territory from biodiversity because, for us, the territory is the guarantee of sustenance as well as what we are. We have learned this through coexistence with the territory. Therefore the biodiversity of species we have here forms part of the collective of life. Essentially we are that, everything existing together. And we defend biodiversity not because a species is becoming extinct but we do so because it affects the habitat, the entire ecosystem ${ }^{160}$.

According to this perspective, biodiversity is inseparable from territory and encompasses everything within the "collective of life", which includes the flora, fauna, and natural resources as well as people and their activities.

This conceptualization of biodiversity has been articulated through a political ecology of difference framework (also discussed in Chapter 3), which challenges the dominant conception of biodiversity being imposed on black communities and refuses to displace human beings from their surroundings (Escobar 2008). The 'displacement' referenced here is both conceptual and physical. It is conceptual in the sense that the PCN understands human beings and their traditions as part of a biodiverse, multicultural Colombian nation; thus to imagine 'biodiversity' as something separate from people and traditions is to displace biodiversity into "systems of meaning, production, and exchange that have no intrinsic relation" to the "underlying ecological order" of the Afro-Pacific (Braun 2002, p.35).

This displacement is physical in the sense that armed actors seeking to exploit the Pacific region's resources have forcibly displaced people from their communities:

It is important to highlight that, from the perspective of black-movement organisations and organisations of the displaced, all of the external actors - including guerrillas, paramilitaries, capitalists and the state - share the same project, namely, the appropriation of territories for the radical

${ }^{160}$ Author interview with Benjamín Mosquera of Río Anchicayá, Buenaventura at Cali bus terminal on August 12, 2015. 
reconfiguration of the Pacific along the lines of the capitalist modernity project of extraction and exploitation of natural resources. This project does not coincide with the interests or reality of the black and indigenous communities (Escobar 2003, p.161).

Furthermore, this displacement is not only understood as intentional but also racist:

The Association of Displaced Afro-Colombians (AFRODES) and indigenous and black organisations see in this situation a racist strategy, and a failure of the government to protect their human and ethnic rights as stipulated in international agreements and national legislation. AfroColombians see their situation of displacement, and that of indigenous people, as unique because of, first, the uprooting of their cultural attachment to place and territory; second, the connection between megadevelopment projects and ethnic groups in the Pacific; third, the deleterious impact of Plan Colombia on the ethnic territories; and fourth, the long-standing situation of pervasive discrimination (ibid., p.160).

For instance, referencing aerial eradication in the context of unfair state policies applied to black communities in the midst of the civil conflict, one gentleman publicly complained:

They came to dump all that glyphosate and we think to ourselves: It is a banned chemical but they have to exhaust it to satisfy the United States. The United States finances it, so they dump it on us in the Pacific Coast. They dump it on us blacks, on our houses. So we are punished two or three times, not just because of the war but also because of state policies $^{161}$.

In mentioning "on us blacks, on our houses", this gentleman also expresses the common perception that aerial eradication intentionally targeted black bodies and black communities. "They" references the Colombian government, which is perceived as submissive to the will of U.S. influence.

${ }^{161}$ Comments from Luis Caicedo Balanta, a resident of Rio Napi, who vented his frustrations about aerial eradication at a PCN meeting for the association of five communities in Bocas de Temuey, Guapi, on March 14, 2015. I subsequently interviewed Luis and asked his permission to post the video I recorded of his initial discourse, which can be seen here: https://contestednatures.com/guapi-cauca-ii/ 
Thus while DIRAN and the INL understood aerial eradication as a means to protect ethnic communities and their rights, $\mathrm{PCN}$ understood aerial eradication as a racist instrument of displacement imposed by the Colombian government to satisfy U.S. interests. This displacement not only resulted in the movement of bodies but has also compromised the biodiversity-culture of the territory.

\section{The Scourges of the Two-headed Monster}

A few residents of black communities employed the term flagelo to describe problems occurring in their communities. Citing the impacts of aerial eradication on different species of trees and birds, Nemesio lamented, “...this has been one of the flagelos brought by fumigation, the flora and fauna have deteriorated, putting them on the path to extinction." 162 The term was also used more generally to describe the repercussions of many different issues affecting black territory. Julio stated that neither the mayor's office in Buenaventura, the governor, nor local law enforcement were aware of the "operations to attack the flagelo of coca" (by "operations" he was referring to aerial eradication missions). He similarly described illegal mining as "another flagelo invading the territory" ${ }^{\prime 163}$.

According to Webster's New World Spanish Dictionary, a flagelo is a "whip", "scourge" or "calamity" (1992, p.220). Thus the use of the term flagelo could harken back to the days of slavery when the whip of slave master was employed in the administration of punishment. In the case of aerial eradication, the whipping was being

${ }^{162}$ Author interview with Nemesio Hurtado at Encuentro AfroPazifico in Piendamó, Cauca on July 28, 2015.

${ }^{163}$ Author interview with Julio González in Bajo Calima, Buenaventura on July 1, 2015. 
administered by an unjust Colombian state that was punishing black communities for the cultivation of coca happening within their territory. 'Scourge' is synonymous with 'whip' but can also mean a 'plague' or 'misfortune', whereas 'calamity' is synonymous with 'disaster'. In the Old Testament, plagues and calamities were often explained as punishments that God administered to populations that were not living according to his laws. This was certainly what Claudia María (Chapter 5) intimated when she stated that chontaduro was disappearing from the Pacific region because, "It is the word of God being fulfilled."164 Therefore, flagelo with regards to the cultivation of coca, often mentioned in tandem with aerial eradication by interviewees, could be interpreted as a plague that has cursed black communities. Collectively these definitions and the original statements that included the term flagelo suggest that the different issues affecting black communities (i.e., aerial eradication, coca cultivation, and illegal mining) represented the imposition of external forces with disastrous repercussions.

Hearing the term flagelo in these interviews I was immediately reminded of the theoretical concept I had developed prior to fieldwork, the two-headed monster of imperial globality. As noted in Chapter 3, the two-headed monster represents the violent imposition of the demand for illegal drugs and the war against drugs - both largely emanating from the Global North - on communities of the Global South. PCN leadership emphasized that neither of these activities are part of traditional Afro-Pacific culture nor welcomed in black territory.

Thus when interviewees described the dual impacts of coca cultivation and aerial eradication on their communities they consistently spoke of the 'effects on the territory'.

${ }^{164}$ Author interview with Claudía María in Cali on September 4, 2015. 
As Yolanda of Timbiquí explained, "It is not just land, for us the territory is the space of life. It is the space where culture is created and re-created." Daniel Goez, president of the community council of Cajambre, Buenaventura, likened black territory to a piñata repeatedly being bashed:

So there are now other logics functioning with regard to the use of territory — violence, coca, illegal mining - every one of these logics has brought... it's like the territory is a piñata that you take hits at. There comes a point when the piñata cannot take any more hits and the goodies spill out. And when that piñata breaks, everyone jumps in to tear it $\operatorname{open}^{165}$.

So while the piñata is black territory in Daniel's analogy, the goodies are the natural resources that external actors -guerillas, paramilitaries, BACRIM, multinationals, state subsidiaries - are vying for. And the hits are those "logics" or other sets of principles transforming the territory physically and culturally.

\section{The Effects on Black Territory-Culture}

Therefore, in addition to leaving communities vulnerable to the intrusion of outsiders (described in Chapter 4) and security threats (described in Chapter 5), the PCN frowned on the cultivation of coca and resulting aerial eradication because these activities undermined the culture of black territory. I asked Daniel whether he believed the introduction of coca cultivation changed his community's relationship to the land. He argued that, fundamentally, it did not. Whether growing plantains for subsistence or coca leaf for profit, the Earth is providing for the community, albeit on a more lucrative scale for coca leaf. I was initially surprised by his response, which seemed to contradict the more common reaction from PCN leadership that coca cultivation was a threat to black

${ }^{165}$ Author interview with Daniel Goez on September 9, 2015. 
communities. Daniel countered that what had dramatically changed was people's relationships to each other:

Before it was not like that, it was more minga (collective effort). Someone would say, "I have a plot of land that is too big for me, let's all go and work... and you can participate when you need to." There was more sharing back then. Now things are changing, not just because of the money but also because of the violence... ${ }^{166}$.

On the one hand, it makes sense that there would be less collective effort with the cultivation of coca compared to legal crops if some or most in the community frowned upon this practice. On the other hand, Daniel also mentions that coca cultivation is associated with violence, which could imply a number of different scenarios such as people trusting each other less, being afraid to work together, or simply less present because of injury, death, or displacement.

Furthermore, coca cultivation is a risky investment of time, energy, and resources with potentially disastrous consequences for local crops and agricultural traditions. As Ramírez notes in her ethnography of coca growers in the Colombian Amazon, the cultivation of coca is an extremely demanding form of agriculture that requires proper attention to the spraying of fungicides and insecticides as well as the timing of fertilization and harvest (2011, p.67). Raúl of El Tambo, Cauca complained that coca was changing local agriculture in two major respects. In the first place, farmers spent less time growing subsistence crops and were shifting more towards coca monoculture. Thus people started to buy a lot of food that they used to harvest themselves. The 2008 report on the effects of aerial eradication created by AsoManosNegra states:

${ }^{166}$ Author interview with Daniel Goez on September 9, 2015. 
We reject every type of mono-crop that threatens the life and dignity of our communities. We are conscious of the fact that we live in a region with fragile ecosystems that cannot withstand those types of practices without endangering biodiversity, cultural identity and the region's economy. In that sense, we reject coca, oil palms and the practices employed for their implementation in Afro-Colombian territories (p.19).

Secondly, Raúl argued that growing illegal plants not only puts one's own legal crops in danger of being fumigated, but the entire communities' crops and homes as well ${ }^{167}$. Even the threat of aerial eradication escalated tensions between those growing coca and those not growing coca, fostering distrust amongst neighbors.

This was particularly the case, not only because of food security, but also because aerial eradication impacted employment opportunities with serious implications for communities already economically stressed by the civil conflict. For instance, many of the farmers I interviewed hired peones (laborers) to clean unwanted foliage or to assist with planting or harvests, tasks typically performed by young men in need of work. The collective action suit report for the communities of Timbiquí and Guapi (discussed in Chapter 5) explains how aerial eradication impacted such employment opportunities with far-reaching social implications:

This forced people to abandon their lots and in many places there was not any work left for laborers... While those that could not, wander in search of opportunities. In this landscape, young women and men are easily recruited by the illegal armed groups present in the region; so many of them end up joining their ranks and, almost always, these women end up becoming mothers at a young age, single and hopeless, exacerbating the already difficult conditions that they live in (Impactos 2011, p.47-48).

${ }^{167}$ Author interview with Raúl Figueroa of El Tambo, Cauca at Encuentro AfroPazífico in Piendamó, Cauca on August 27, 2015. 
The shortage of employment opportunities not only leaves residents vulnerable to recruitment by non-state armed groups but also vulnerable to participate in unlawful forms of economic activity such as coca cultivation, drug trafficking, or illegal mining.

The influx of income generated by these activities, combined with the influence of non-state armed actors, has facilitated the conditions for conspicuous consumption and prostitution. Daniel describes how these circumstances impacted his community in Río Cajambre:

We started to see motorboats that we have never seen before, motorboats with big motors...huge quantities of alcohol...prostitution. Not that kind of prostitution where you go to a place and there are prostitutes, but that kind of hidden prostitution where the girls do favors to resolve things...in order to be invited to parties or have things paid for ${ }^{168}$.

Nemesio of Río Guajuí, Guapi, lamented that many men engaged in coca cultivation or illegal mining "lose their way", thinking themselves better than others because of the money they have made, mistreating family and community members as a result ${ }^{169}$.

For these reasons and others, Yolanda argued that women, who she described as the guardians of cultural traditions, are the most impacted by the cultivation of coca and aerial eradication:

The repercussions for women are much more...double or triple the repercussions of men from the same community; in what sense? The woman in the Pacific is the bearer and protector of culture. She is the one that transmits traditional knowledge from generation to generation... that has always been the responsibility of women ${ }^{170}$.

${ }^{168}$ Author interview with Daniel Goez on September 9, 2015.

${ }^{169}$ Author interview with Nemesio Hurtado Torres of Río Guajuí, Cauca at Encuentro AfroPazífico in Piendamó, Cauca on July 28, 2015.

${ }^{170}$ Author interview with Yolanda García on August 16, 2015. 
In the role of bearer and protector of culture women not only nourish their families by preparing most of the food but also educate children in the cosmology of the region, the various rites associated with stages of life (i.e., birth, adulthood, death), and the folkloric songs and dances associated with those rites.

Yolanda's testimony speaks to the differential gendered impacts of coca cultivation and aerial eradication, which in some ways are analogous to Meertens's observations about forcible displacement in Colombia. To begin, Meertens cites two important ways that life is experienced differently for women than men in traditional rural communities: 1) rural women have less social and geographic mobility and 2) rural women typically have lower participation in civic or communal organizations in comparison to men but higher participation in "close, informal networks of neighbours and kin" (2001, p.140). Later Meertens explains how forcible displacement impacts these circumstances, "These ruptures of social identity and social texture at the level of family and community produced the sensation of being completely adrift, or, as a woman from the Atlantic Coast expressed her feelings, like a ship without a harbour (ibid., p.141). In terms of coca cultivation and aerial eradication, it is important to remember that these activities not only contributed to the physical displacement of individuals, families, and communities, but also to the disruption of the spaces where women interact with each other and their children.

For example, Yolanda also reasoned that women were the most impacted by aerial eradication because they perform many daily activities uniquely connected to water: 
Nowadays in our communities we do not have aqueducts as they do in other places. So we do everything at the river: fill up containers for water to make food, wash clothes, bathe...everything. And us women of the Pacific have that daily connection with the river. So they fumigate the river and logically, we are the ones most affected ${ }^{171}$.

Thus, aerial eradication both made the river unsafe and disrupted an important space where 'informal networks of neighbors and kin gather'. The collective action suit report for the communities of Timbiquí and Guapi describes how many people reacted the first time they saw aerial eradication:

Many people, mostly women and children, not knowing the seriousness and toxicity of the substance falling on them, happily went outside to observe, for the first time, the novelty of the airplanes flying close by their homes and crops, discharging what they called "white rain" and this toxic mixture landed directly on a lot of these people (Impactos 2011, p.40).

Furthermore, Yolanda explained that not only were outdoor activities disrupted by aerial eradication but that women in her community attributed birth defects to the spraying. She cited the example of a stillbirth baby that emerged with enlarged skull and lips in Boca de Patía, Timbiquí. Community members claimed that the woman had been washing clothes in the river when fumigation planes sprayed. This was certainly not the only example of birth defects I heard about while conducting interviews. For instance, Nemesio of Río Guajuí attributed the birth of a child without a rectum to aerial eradication $^{172}$. While I cannot confirm that these birth defects happened or that they were caused by aerial eradication, the point of mentioning this anecdotal evidence is to signal

171 ibid.

${ }^{172}$ Author interview with Nemesio Hurtado Torres on July 28, 2015. 
that aerial eradication was not only perceived as an imposition that disrupted the recreation of culture, but also the re-creation of life itself within the territory ${ }^{173}$.

\section{Aerial Eradication as Environmental Conservation}

Ironically then, in addition to 'security' reasons, the aerial eradication program was also justified through an environmental conservation discourse that posited aerial eradication as the antidote to the much more damaging effects of cultivating coca and processing coca paste. This discourse consisted of three central arguments:

- Coca growers destroy the environment by cutting down vegetation to clear land, using chemicals to cultivate coca, and using even more chemicals to process the coca into paste.

- The chemical mixture sprayed during aerial eradication was really not that harmful (See Figure 6.1). Glyphosate, also known as Monsanto's Roundup, was the primary chemical used in the mixture. It is one of the most common herbicides in the world.

- The perception that the aerial eradication chemicals were harmful was misguided because what really caused the environmental harm were the chemicals used to cultivate and process coca, which seeped into the soil and waterways before any aerial eradication was conducted.

\footnotetext{
${ }^{173}$ One quantitative study, discussed later in this chapter, separated the effects of aerial eradication from coca cultivation, "Our findings coincide with the medical literature and robustly indicate that aerial spraying of Glyphosate increases the probability of having dermatological and respiratory problems and miscarriages" (Camacho \& Mejía 2015, p.3).
} 


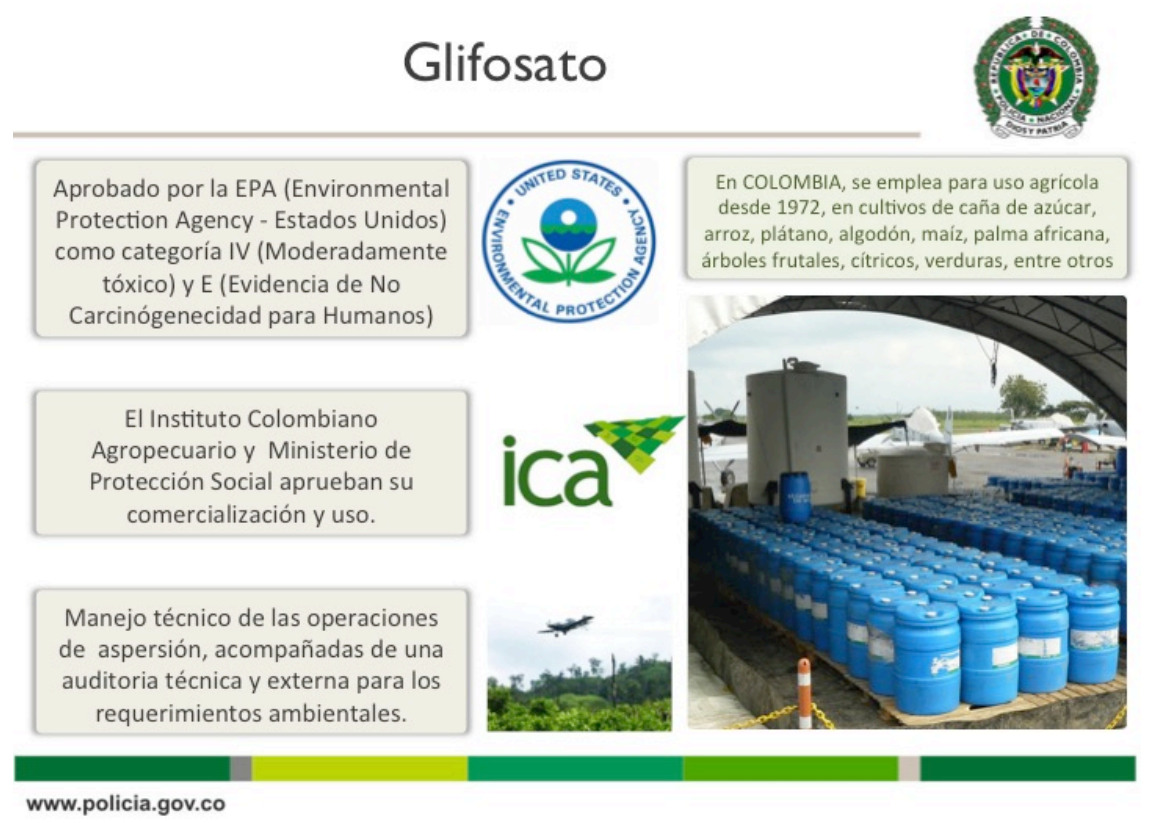

Figure 6.1 - DIRAN PowerPoint slide explaining why glyphosate is not harmless The slide notes that the chemical is approved by the U.S. Environmental Protection Agency as a "moderately toxic" substance with evidence that is it not carcinogenic for humans.

The following excerpt is from the Spanish version of the U.S. Embassy in Bogotá webpage entitled "Narcotic Affairs":

What do the bad guys do? To plant coca, drug traffickers first go to a place and have to clear away forest or jungle, using fire, using chemicals, axes, whatever they have. They are the first to destroy the environment. Aerial fumigation will only destroy the coca, which is not a native plant in most places where it is planted and when they remove the coca, vegetation and forest, natural forest can grow back because glyphosate has no residues in the soil, which means that after one week there are no traces that glyphosate had ever been there because it converted into a very natural innate chemical, mostly nitrogen.

DIRAN's publication Coca: Deforestation, Pollution and Poverty echoes this sentiment; the book details how plots of tropical forest are burned and cleared for the establishment of coca fields, which require the application of pesticides, fungicides, herbicides (including glyphosate), and fertilizers that seep into the soil and waterways. The 
laboratories where the coca is processed into paste are normally adjacent to the fields and employ a long list of chemicals -such as gasoline, kerosene, ether, ammonia, hydrochloric acid and sulfuric acid - that also make their way into the soil and waterways (Coca: Deforestación, p.138).

In the eyes of eradication authorities, whatever potential damages brought on by aerial fumigation were negligible compared to the deforestation and the loss of biodiversity caused by the $80+$ chemicals used in the cocaine production chain (U.S. Embassy website). DIRAN estimates that every hectare of coca cultivated causes 1.46 hectares of deforestation (Coca: Deforestación, p.70).

\section{Indiscriminate Spraying?}

Residents of affected communities largely rejected the environmental conservation arguments made by eradication authorities. Numerous interviewees mentioned that their homes and rivers had been sprayed, which compromised drinking water, bathing water, and water for cooking. People bathe and wash clothes in the rivers and drinking water is typically collected from a container connected to the roof or on the side of one's home (See Figures 6.2 and 6.3). Gumercindo of Río Guajuí complained, "The children, when they would bathe, would get rashes and other signs of skin irritation...the fumigation caused diarrhea because we didn't have potable water and everyone washes with the water from the river. So yes, it was a disaster" ${ }^{\prime 14}$. The photos in Figure 6.4 - of a child in the community of Río Chagüí in Tumaco, Nariño- were given to me as evidence of the effects of aerial eradication on the skin.

${ }^{174}$ Author interview with Gumercindo Quiñónez on March 14, 2015. 


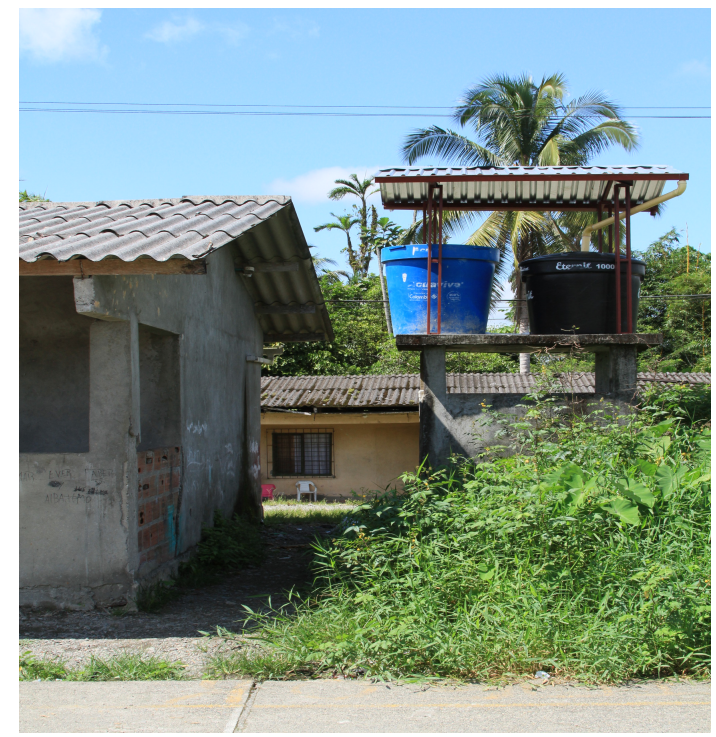

Figure 6.2 - Containers to collect rainwater in Bajo Calima, Buenaventura

(photo credit: Bayeté Ross Smith)

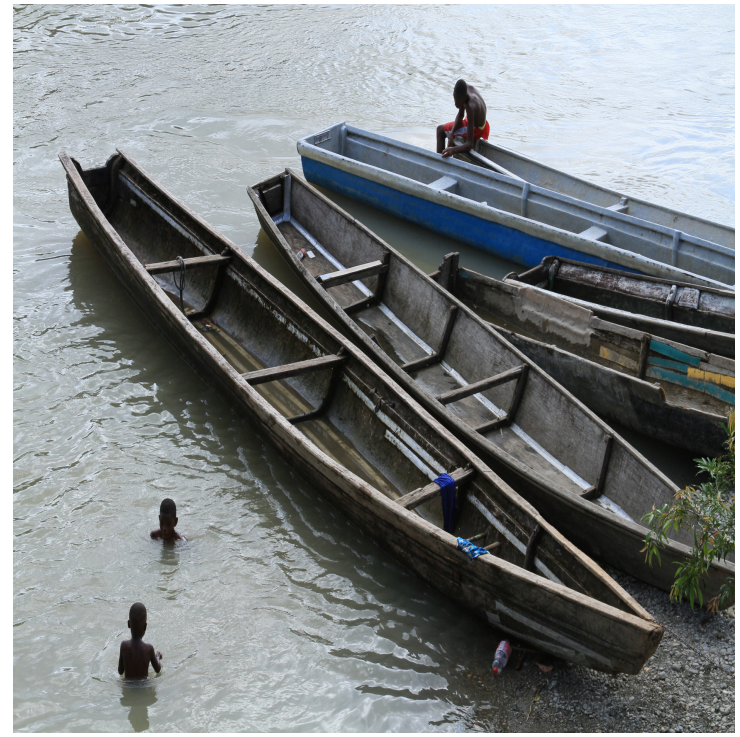

Figure 6.3 - Children bathing in Río Calima, Buenaventura

(photo credit: Bayeté Ross)

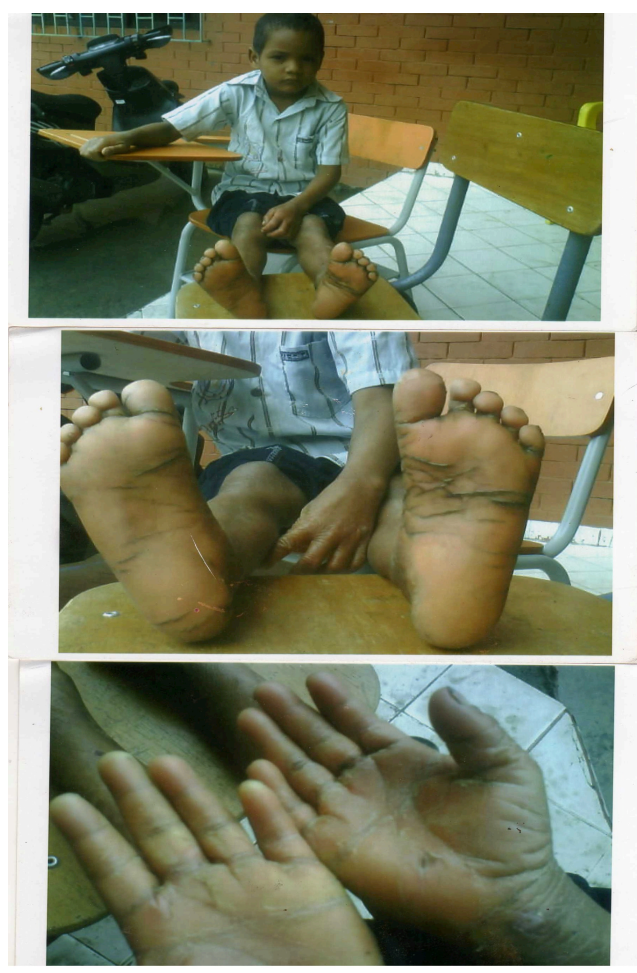

Figure 6.4 - Child with irritated skin, allegedly from aerial eradication (photo credit: PCN office in Bogotá) 
However, many people I spoke with conceded that the chemicals used in the cultivation of coca and processing of coca paste cause considerable harm. For example, Andrés of El Tambo, Cauca was introduced to me because of the large rash covering his chest and neck. In his estimation, $40 \%$ of the people living in his community also suffer from allergic reactions to the contamination of the rivers they bathe and wash their clothes in for lack of running water. Coca has been grown in his community, San Juan de Micay, since the 1990s but aerial eradication ceased in 2007 to protect the surrounding natural reserve. The rashes on his body and on others in his community have persisted despite the fact that aerial eradication had not been conducted recently, which suggests that the chemicals employed in the cultivation of coca and the processing of coca paste are the main reason for the outbreak of rashes ${ }^{175}$.

On the other hand, most residents disagreed with the argument that the effects of aerial eradication were somehow negligent in comparison to the chemicals employed in coca cultivation and processing of coca paste. In response to that assertion, Eladio of Río Calima stated, "No, because the coca is growing over there and over here you can harvest plantains, good quality plantains. But if the fumigation planes come, forget about it. It kills both the coca and the plantains and you are left with bare land"176. Julio of Río Calima reasoned that aerial eradication did not eliminate the pollution caused by coca cultivation, but actually doubled it:

${ }^{175}$ Author interview with Andrés of Tambo, Cauca conducted at Encuentro AfroPazífico in Piendamó, Cauca on August 8, 2015.

${ }^{176}$ Author interview with Eladio Ballesteros of Guadual, Calima in Bajo Calima on July $1,2015$. 
Every time that they plant coca on a large scale... so that the coca plants give good yield you have to use herbicides and right there they are acting against the territory, against what is in the territory, the waters, the rivers...everything, plus all of the pollution that comes with fumigation. It is double pollution! ${ }^{177}$

Thus most interviewees argued that aerial eradication exacerbated rather than alleviated environmental damages.

With regards to the argument that coca cultivation causes deforestation, some residents reasoned that cultivating coca is not much different from clearing out vegetation to cultivate legal crops. A resident of Alto Guapi, Cauca explained, "They talk about the fact that coca destroys trees because to cultivate coca you have to cut down trees. But in their place you plant other trees...because when you cultivate coca you also grow avocado trees, mango trees...but even when there is no coca they sometimes fumigate" ${ }^{\text {178 }}$. Fernando Castrillón of Grupo Semillas -a Colombian environmental NGO that works with indigenous, afro-descendant, and campesino communities on issues of environmental conservation and sovereignty — wondered whether cultivating coca was less harmful than when ranchers completely deforested plots of land for grazing ${ }^{179}$.

Ultimately, the above testimonies do not negate the assertion that the chemicals used in coca cultivation and the processing of coca paste are harmful; rather these responses speak to the perception that aerial eradication impacted much more than the

${ }^{177}$ Author interview with Julio González in Bajo Calima, Buenaventura on July 1, 2015.

${ }^{178}$ Author interview conducted at Hotel Río Guapi in Guapi, Cauca on March 14, 2015 with interviewee that preferred to remain anonymous.

${ }^{179}$ Author interview with Fernando Castrillón, Project Coordinator at Grupo Semillas. Interview conducted via Skype on June 15, 2015. 
coca crops targeted for aerial eradication. In fact, the vast majority of residents I interviewed claimed that their farm lots, homes, or communities had been fumigated without coca present. For instance, Juan, Adolfo, and Tulio claimed that the nearest lot with coca was five to six kilometers from their farm ${ }^{180}$. Thus a common sentiment amongst affected residents was that if an aerial eradication mission was not intentionally targeting their legal crops then these operations were being conducted indiscriminately and irresponsibly.

\section{Understanding Aerial Eradication Protocols}

DIRAN and INL officials flatly rejected the notion that aerial eradication was conducted indiscriminately or irresponsibly. I sought the answers to three important questions in order to ascertain why this was a common perception amongst the residents I interviewed: 1) The officials I spoke to explained that pilots were trained to spray the areas targeted on their onboard maps, but did pilots strictly follow those maps? 2) How prevalent was the incidence of aerial eradication spray drifting away from its intended target? 3) How often did pilots dump their chemical cargo for fear of being shot down by non-state armed groups? In lieu of asking the pilots themselves, whom I did not have access to, I asked some of the officials who worked with the pilots. The answers to these questions evoked some conflicting responses.

With regard to the first question about pilots' decision-making, Leonardo Correa -the Technical Coordinator of Project SIMCI, the agency that supplies DIRAN with maps created from satellite images of coca cultivation and previous eradication efforts-

${ }^{180}$ Author interview with Juan Alturo, Adolfo Sánchez, and Tulio Montaño on July 20, 2015. 
indicated that it was ultimately the pilot's decision whether to open the spray valve or not. While the onboard maps could guide the pilot to the areas identified in the detection process, the pilot ultimately made the decision about what to spray or not spray, which is why certain areas not identified in the detection process might have been fumigated. For instance, the pilot could have sprayed coca not identified on his map or, vice versa, could have not seen coca where his map indicated that there was coca ${ }^{181}$. Putting himself in the pilot's seat Leonardo reasoned, "In the moment of making my decision, at the speed of 300 kilometers per hour, while flying over different lots and mindful of the bullets coming my way, of the weather conditions, of the clouds... well, it is difficult"182 .

In contrast, Lt. Colonel Tunjano of DIRAN downplayed the pilot's capacity for decision-making, stating that pilots were in constant communication with mission operations to verify their targets. He added that pilots were highly trained, routinely evaluated, and subject to re-training if they sprayed somewhere besides the targets indicated on their maps ${ }^{183}$. INL officials agreed with Lt. Colonel Tunjano's assertions and added that it would be very difficult for pilots, whom are very experienced, to mistakenly spray the wrong crops as the onboard maps were constantly updating during flight. The bright green color of the coca plants is visible from the air and only pepper and young cacao plants can be mistaken for coca ${ }^{184}$. However, without access to the pilots or

${ }^{181}$ It is important to remember that maps identifying areas with coca are created by images collected on December 31 every year.

${ }^{182}$ Author interview with Leonardo Correa on March 28, 2015.

${ }^{183}$ Author interview with Lt. Colonel Miguel Tunjano on May 8, 2015.

${ }^{184}$ Author interview with INL officials at U.S. Embassy on August 4, 2015. 
documentation of disciplinary actions it is difficult to ascertain how much pilot error factored into the fumigation of lots without coca ${ }^{185}$. In addition, as explained in Chapter 4, the low percentage of successful complaints processed was not a reliable indicator of whether pilots had erred or not.

Furthermore, it is not at all clear how the pilots differentiated one farm lot from the next. Article 1 of Colombian Resolution 13 of 2003 establishes, "Areas with illicit crops interspersed and/or mixed with licit crops, which correspond to cultivation strategies employed to evade action on the part of the aerial eradication program (PECIG), also will be subject to aerial eradication." In places where mechanized farming is the norm it is quite easy to differentiate one plot of land from the next; the trees or plants are neatly organized into rows that form square or rectangular fields when viewed from aircraft. After flying over Guapi (see Figure 6.5) and visiting farm plots in the black communities near Guapi and Calima (near Buenaventura), I have no idea how a pilot would be able to distinguish one person's plot from their neighbor's. I did not see many fences in these visits and the informal boundaries that separated one lot from the next were often natural (a stream, a few tall trees...etc.). Furthermore, the landscape is so lush with vegetation that I am not sure how a pilot moving so fast could make those distinctions. So while the pilot had the right to spray legal crops when mixed with coca plants on any given farm, how did the pilot differentiate the farm with coca from the farm without coca?

${ }^{185}$ No official was interested in jeopardizing any pilot's anonymity by supplying contact information. 


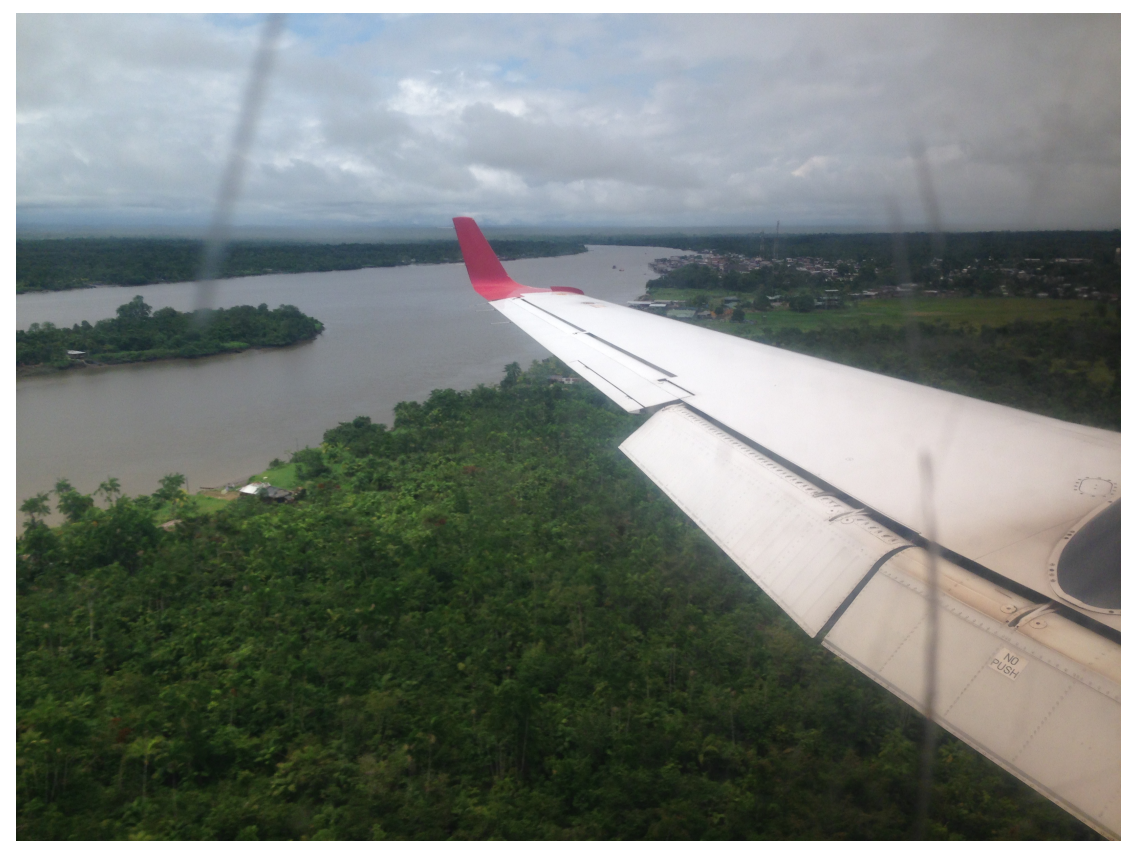

Figure 6.5 - View from commercial flight approaching the Guapi air strip (photo credit: Alexander Huezo)

With regard to the second question about aerial drift, the wind blowing the chemical spray off its intended target, the following protocols were employed: 1) pilots released a plume of smoke to test the velocity of the wind and would not discharge the chemical mix if the winds are stronger than 5 knots, 2) pilots flew no higher than 50 meters from the ground to guarantee that the spray hit its target (adjusted to obstacles that might be blocking the flight path), and 3) the spray mixture included a chemical that made the droplets heavier and thus more likely to reach the intended target (PECIG 2003). Given these procedures and other precautions, INL officials argued that the damages caused by aerial drift were exaggerated ${ }^{186}$. For instance, Lt. Colonel Tunjano noted that many residents mistakenly believe that their house or the river was being

${ }^{186}$ Author interview with INL officials at U.S. Embassy on August 4, 2015. 
sprayed, when in fact the pilot was emitting a smoke plume to measure the wind velocity before the actual spraying ${ }^{187}$.

Despite that assertion, the highest profile aerial eradication lawsuit to date Ecuador v. Dyncorp Aerospace Technology — resulted in a \$15 million dollar settlement on the basis that aerial spraying in Colombia had drifted across the border and caused massive damages in Ecuador. The terms of the settlement also prohibited aerial eradication within a specified range of the border ${ }^{188}$. In this particular case, tried in the U.S. court system because DynCorp is the U.S.-based corporation through which aerial eradication pilots were contracted, court records indicate, "The plaintiffs argued that the aerial spraying reports omit events that injured them by excluding missions during which the spraying mechanism malfunctioned" (International Court 2012). Such allegations were problematic because there was no external agency overseeing aerial eradication operations. In other words, all kinds of accidents or mishaps could have potentially been erased without a paper trail. DynCorp also resisted disclosing the flight patterns of the operations in question, citing "the security risks attendant to releasing the data" (ibid.). While the plaintiffs were interested in determining whether the planes had crossed into Ecuadorian airspace, making the flight patterns public information posed a 'security risk' because armed actors attempted to shoot down the planes to prevent aerial eradication.

Finally, with regard to the third question, 'dumping' was the term used to describe what happens when pilots unloaded their chemical cargo somewhere besides the intended

${ }^{187}$ Author interview with Lieutenant Colonel Miguel Tunjano Villaraga on May 8, 2105.

${ }^{188}$ The original $10 \mathrm{~km}$ strip could be narrowed to $5 \mathrm{~km}$ and later $2 \mathrm{~km}$ if Colombia followed through with certain promises according to Appendix 1 of the settlement agreement (Meléndez 2013). 
target for fear of being shot down. Between 2002-2013, 650 aircraft were impacted by ground fire and 4 were shot down during aerial eradication operations (DIRAN website). There is a lengthy procedure for dumping described in Colombian Resolution 1054 of 2003. According to INL officials, dumping was an increasingly rare occurrence because newer planes were heavily armored, so much so that a pilot would often land without knowing that bullets had impacted their plane during a mission. They estimated that dumping had occurred at most four to five times in the last three years ${ }^{189}$. Once again, however, the prevalence of dumping was classified information and it is difficult to tell how often it actually occurred.

Fortunately, I was able to obtain flight logs from aerial eradication missions conducted in 2005, 2009, and 2013 as part of a court case I participated in (described in Chapter 2 and later in this chapter). All logs note how much chemical mixture was in the tank of each plane before and after the mission. In the 2005 mission logs, there are spaces for "observations" and "incidents that happened during the mission." Of the eleven flight logs listed (each log recorded usually 1-3 missions in a day), one log mentioned "dumping" under "observations" and another log mentioned that a plane was "impacted." This latter mission also mentioned "wrong swath", presumably indicating that an area was sprayed that should not have been. The 2009 logs are more detailed than the 2005 logs. For instance, "dumping" became its own category though the vast majority of missions recorded " $0 \mathrm{~s}$ " for the amount of glyphosate dumped with the exception of one $\log$ that recorded 182 liters of glyphosate dumped after the spray aircraft was impacted by "hostile fire." The 2009 also included a category “crop", which presumably was

${ }^{189}$ Author interview with INL officials at U.S. Embassy on August 4, 2015. 
introduced because opium poppy cultivation also became targeted for aerial eradication. The $2013 \operatorname{logs}$ were very similar to the $2009 \operatorname{logs}$ and recorded no dumping. While the 2005 logs featured handwritten responses, the 2009 and 2013 logs featured mostly typed responses under "observations", the majority of which appeared identical from one mission log to the next (i.e. copied and pasted).

What to make of all of this information? The flight logs are filled with numbers coordinates, wind speed, hectares, liters, number of missions...etc.- along with signatures and coded descriptions that legitimize these missions in a court of law. If a farmer in Guapi wanted to argue that his lot should not have been sprayed, then he had to compete with this level of logistical details in order to receive consideration for his claim. It is no surprise then that farmers like Tulio, who showed up to the mayor's office very upset with an armful of dead crops (described in Chapter 5), never received restitution. In a hypothetical situation where DIRAN did receive a complaint from Tulio, they could have pointed to the coordinates and said, "No, as you can see we did not fumigate over your farm." Or DIRAN could have pointed to the coordinates and responded, "Yes, we fumigated your farm and the log says you had coca plants."

\section{Hierarchies of Credibility}

U.S. and Colombian authorities highlighted the environmental impacts of coca cultivation and processing coca in order to deflect criticism of the aerial eradication program. The focus on these concerns also contradicted unfavorable scientific findings. The INL consistently maintained that there was no evidence that aerial eradication with glyphosate was harmful to humans or the environment. Studies that stated the contrary were rejected for three major reasons: 1) the scientists conducting said studies did not 
have access to the exact mixture of chemicals employed during aerial eradication operations; 2) the studies conducted in the field ignored the fact that it was impossible to separate the damage caused by coca cultivation/laboratories from the damages caused by aerial fumigation; and 3) none of the studies in question had ever been subject to the peer review process. For instance, INL officials rejected the validity of a recent econometric study, which separates the effects of aerial eradication from the chemicals used in coca cultivation and cocaine processing laboratories on the Colombia-Ecuadorian border (Camacho \& Mejía 2015), on the grounds that the article was not peer reviewed ${ }^{190}$. Even after the Colombian Ministry of Health deemed glyphosate "likely carcinogenic" in May of 2015, the INL remained steadfast that there had never been a single case of health problems proven to be caused by glyphosate ${ }^{191}$.

In her ethnography of U.S. policymaking in Colombia, Tate mentions 'credibility' as an epistemological category of study in anthropology that functioned "as a form of social capital involving not only accuracy but also institutional origins, qualities, and larger political agendas" (2015, p.64). She then discusses the 'hierarchies of credibility' that the U.S. government employed to determine what sources of information were more reliable than others. For instance, "The U.S. government considered Colombian government agencies to be inherently more credible than NGOs. Among the NGOS, the hierarchy of credibility was as follows: international over national groups, national groups over regional ones, and professionally run over volunteer led" (ibid.). A 2014

${ }^{190}$ Daniel Mejía is a distinguished professor of Economics and the director of the Center for Studies of Security and Drugs (CESED) at La Universidad de los Andes.

${ }^{191}$ Author interview with INL officials at U.S. Embassy on August 4, 2015. 
report by the Diocese of Tumaco, Nariño estimates that, on average, every hectare of coca destroyed by aerial eradication destroys 20 hectares of forest or crops in the region (pp.31-33). However, locally generated information on the effects of aerial eradication such as the aforementioned report and other local reports that I gathered during fieldwork - would rank at the bottom end of the hierarchy that Tate outlines and therefore carry little weight in the eyes of U.S. policymakers.

Likewise, PCN leaders were frustrated that locally generated documentation of the impacts of aerial eradication mattered little to the Colombian government officials they had met with. While sifting through evidence for an aerial eradication court case (discussed in the next section), I encountered a 2008 report on the effects of aerial eradication in Timbiquí, Cauca. I asked Yolanda García -also a PCN leader and leader of Asociación Manos Negra, which created the report—how government officials reacted to the information:

I remember testifying in front of a judge about the effects of aerial fumigation in Cauca and all the officials were there... from the military, to the Ministry of Health... all of the government ministries were there. And they insisted on knowing how I, an ordinary resident of the Pacific, would know that aerial fumigation with that liquid, that they denied was glyphosate, was having such and such effect, causing such and such damage in the communities when there was not any evidence. I remember telling them about a child born with deformities that tested for high levels of chemicals and an older gentleman that passed away from exposure to glyphosate... The purpose of our report was to make these problems visible but they did not take it into account in any of their own reports. I know this because, yes, we did make sure that all of the institutions received our report... Yet when I was there in front of the judge...they denied knowing anything about our report and then said that it did not meet the standards of technical validity. I guess they only accept the studies from the big time academic scholar, contracted by Harvard, and so forth...so our reports were not valid ${ }^{192}$.

${ }^{192}$ Author interview with Yolanda García on August 16, 2015. 
The report- the first of a series developed in conjunction with the Regional Autonomous Corporation of Cauca $(\mathrm{CRC})^{193}$, the respective community councils of Guapi and Timbiquí, and the Institute for Environmental Research in the Pacific (IIAP) — consisted of 833 surveys, 36 interviews, and visits to 17 different parcels of land (CITE). In other words, much effort was put forth into a study that was not taken seriously according to Yolanda's account. This particular example was by no means exceptional and further contributed to the perception that local knowledge was not valued in the Colombian legal system, particularly with regard to the rights of black communities.

The recent legal victory of the black communities of Anchicayá in Valle del Cauca versus the Pacific Energy Company (EPSA) and the Autonomous Corporation of the Cauca Valley (CVC), however, has offered a sliver of hope that this dynamic might improve. In 2001 EPSA opened the gates of the Anchicayá dam, which released an estimated $50,000 \mathrm{~m}^{3}$ of sediment that polluted waterways, killed marine life, and ruined crops (Velasco 2016, p.707). In 2009 the Superior Tribunal court of Buenaventura ordered EPSA and the CVC to pay the plaintiffs, which totaled $6000+$ residents of these communities, an $\$ 83$ billion USD settlement (ibid., p.716). However, this victory was short-lived as the verdict was appealed and a constitutional court overturned the ruling in 2012. In a situation reminiscent of Yolanda's experience testifying against the aerial eradication program, “The court's environmental jurisprudence gave preferential

${ }^{193}$ Regional Autonomous Corporations are decentralised environmental management authorities in Colombia and serve as the principle environmental authority at the regional level. These institutions also coordinate economic stimulus plans that map the development of municipalities in each respective department. 
treatment to the company's rights to due process and sidestepped the collective legal and political rights of a historically marginalised community whose intermediaries could not reasonably offer the technical and scientific evidence favoured by the courts" (ibid., p.709). The 2012 decision was repealed in 2015 and the plaintiffs finally received payment fourteen years later, thanks to the support of the Colombian Attorney General, La Defensoría del Pueblo, and a number of international organizations (Marín Correa). Germán Ospina, the lawyer for the case, credited much of the success to his partnership with one particular international organization, a U.S.-based NGO named Earth Economics.

\section{Validating Local Evidence}

When Germán invited me to participate in his latest collective action case -in which he is representing seven municipalities in the Department of Cauca suing DIRAN for damages caused by aerial fumigation, including the black communities of Guapi and Timbiquí (discussed in Chapter 2) — he indicated that he again collaborated with Earth Economics to employ a similar methodology in the collection of data. This involved personally traveling to community after community over a span of several years, accompanied by a researcher from Earth Economics, to conduct interviews and administrate surveys. While reviewing the case evidence at the courthouse in Popayán I encountered dozens of binders that listed estimates for the $42,000+$ residents represented in the case.

In Germán's opinion, this methodology is uniquely suited to properly compensate the victims for two major reasons: 1) These calculations ascribe an aura of technical validity -in the form of "X damaged, with a market price of Y", conducted by a trained 
statistician - that rivals the mountain of logistical evidence presented on behalf of the defense (which includes the aforementioned aerial eradication flight logs). 2) The calculations not only ascribe values to the damages incurred on individual properties (e.g. cash crops, farm animals...etc.) but also to the loss of utility of communal spaces (e.g., rivers, estuaries, forests, creeks...etc.) where day-to-day activities are conducted (e.g., fishing, gathering wood, bathing, traveling along waterways...etc.). Germán signals the importance of including the value of those communal spaces, which would normally be overlooked by a Colombian justice system disconnected from the circumstances of poor rural communities, as the most comprehensive approach to assessing the totality of the damages caused ${ }^{194}$.

The Cauca aerial eradication case poses some challenging questions about the intersection of state politics and local epistemologies. As Velasco, who conducted ethnographic research on the Anchicayá dam case, notes, “...if Colombia adapted multiculturalism as a principle, courts must carefully balance different types of evidence when deciding on the fundamental rights of historically marginalised and currently discriminated peoples (2016, p.725).

For instance, Yolanda highlighted the disconnect between local knowledge and state policies when she described why it was difficult for residents of black communities to file complaints against the aerial eradication program:

We don't measure by the 'hectare' and it is not even in our vocabulary because it is a term used in other regions for the commercialization of land. We do not even know in most cases how much area we have in territory. For us territory is much more than the stretch of land that one

${ }^{194}$ Author interview with Germán Ospina at courthouse in Popayán, Cauca on August 19, 2015. 
inherits from family. 'Territory' also includes where the neighbor lives, it includes the river, the mountain....all of that is territory. So that vocabulary used to describe our territory is not only different, but also exclusive. When they define those complaint policies without consulting us... those policies are categorically Western, strictly capitalist, with a logic that is distinct from ours... so logically that has repercussions, which make us even more vulnerable ${ }^{195}$.

Germán agreed with Yolanda's explanation, stating that this disconnect has produced "silent victims" incapable of articulating their grievances in a manner legible to state bureaucracy $^{196}$.

\section{Aerial Eradication as Environmental Conservation?}

The assertion that aerial eradication served as a means of environmental conservation sounds equally ridiculous now, after the completion of fieldwork, as it did in 2015 when I embarked on fieldwork. As Oslender complains, "How pathetic the state that issues legislation obliging black communities to 'protect and conserve the species of fauna and wild flora threatened or in danger of extinction' (Law 70, Chapter 4, Article 21) and then goes and fumigates forests, lands, and rivers, pushing these species closer to extinction" (2016b, p.171). The 'aerial eradication as environmental conservation' discourse served two major purposes that mask the contradiction Oslender signals in his statement: 1) to further criminalize the cultivation coca, an activity already constructed as a threat to various forms of security, which was then articulated as a threat to "the environment" and 2) to shift attention from the ecological effects of aerial eradication to the ecological impacts of coca cultivation and the processing of coca paste.

\footnotetext{
${ }^{195}$ Author interview with Yolanda García on August 16, 2015.

${ }^{196}$ Author interview with Germán Ospina on August 19, 2015.
} 
This chapter began by continuing the argument set forth in Chapter 5 , which was that the PCN understood aerial eradication as an instrument of dispossession that allowed external actors to exploit the Pacific region's natural resources. This perspective was articulated through a political ecology of difference framework that emphasized that black communities are intrinsic to the region's biodiversity and not merely in the capacity of 'guardians of the environment'. In this particular sense, the political ecology of difference resonates with the work of political ecologists who problematize the invisibilization of humans in natural spaces (Smith 1984; Cronon 1995; Harvey 1996) as well as the designation of natural spaces to the detriment of local populations (Neumann 1998; Braun 2002; Kosek 2006; Mathews 2011). The fact that aerial eradication was posited as a form of environmental conservation then begs the question: If black communities are not part and parcel of the region's biodiversity, then who are they protecting this biodiversity for?

This chapter also discussed how black communities articulated difference by rejecting coca cultivation and aerial eradication as the impositions of external forces on 'the territory', which I have conceptualized as the two-headed monster of imperial globality. These activities were perceived as the disruption of traditional cultural practices that define people's relationships to each other and their surroundings, not only undermining a sense of community in the present but also for future generations.

The chapter then went on to detail some of key questions about aerial eradication protocols that further problematize the 'aerial eradication as environmental conservation' discourse, in the process revealing why it was difficult for local experiences to be validated in the Colombian court system. For black communities to prove that aerial 
eradication was indeed harmful to humans, flora, fauna, and their ecosystems was a nearly impossible task given their limited resources and disadvantaged position within this 'hierarchy of credibility’ (Tate 2015).

The next chapter concludes this dissertation by further reflecting on the disconnect between local epistemologies and state policies. It considers how the 'geopolitics of knowledge' and 'political ecologies of difference' intertwine to not only challenge but also reshape state policies that function as 'technologies of displacement'. The final chapter also details new developments in illicit crop eradication since the termination of the aerial eradication program in Colombian 


\section{CHAPTER 7 \\ Conclusion: Recognizing Technologies of Displacement and the Struggle Black Territory}

This dissertation pursued three primary objectives: 1) it examined the disconnect between U.S. and Colombian authorities involved in the oversight of the aerial eradication program versus black communities of the Pacific region affected by this counternarcotics policy; 2) it explained how these communities conceptualized a territorial identity articulated through a political ecology of difference, which pitted 'the territory' against external forces -transnational drug policy, the Colombian civil conflict, and narco-culture — violently transforming black communities; and 3) it deconstructed two prominent discourses employed in the justification of aerial eradication -'security' and 'environmental conservation' — and explained how black communities re-imagined these discourses in 'the defense of territory'.

Chapter 1 introduced and overviewed a few central narratives of the dissertation ethnic territorial rights in Colombia, the U.S. War on Drugs in Latin America, the Colombian conflict — that explained why aerial eradication was eventually conducted in the black communities of Colombian Pacific region. Chapter 2 laid out the research design for this project and detailed how I positioned myself as researcher, what concerns I had about conducting this research, how I went about fieldwork, the limitations of the data I collected, and how I processed the data. I also reflected on my positionality going into fieldwork, how my research may have affected the people I interviewed, and how my experiences in the field impacted my outlook on this project. Chapter 3 discussed the theoretical concepts and approaches that informed this research, including: the theorization of territory in political geography; the territorialization of black communities 
of the Pacific region; the critical geopolitics of security discourses in the War on Drugs; political ecology theory relevant to the framing of environmental issues and local knowledge production, in particular, Escobar's political ecology of difference framework (2008); and some critical mapping theory that informed how I analyzed and created maps in this dissertation. Chapter 4, the first empirical chapter of the dissertation, expanded upon the territorial literature introduced in Chapter 3 to explain the development of territorial consciousness in the Afro-Pacific. The chapter then went on to detail how aerial eradication protocols and the Colombian government's refusal to guarantee black communities the right to previous consultation (ILO Convention 169) impacted this territorial consciousness. Chapter 4 also introduces a conceptual metaphor I invented, the two-headed monster of imperial globality, to explain how both coca cultivation and aerial eradication were perceived as the imposition of foreign, extra-territorial logics that compromised black territoriality. Chapter 5 analyzed the various security discourses articulated by dominant geopolitical actors to justify aerial eradication and then shifted attention to the security concerns of black communities affected by this strategy. This chapter also introduced the fact that some PCN leaders perceived aerial eradication as an intentional means to dispossess black communities of their territory. Chapter 6 further contextualized why aerial eradication was perceived as an instrument of dispossession, deconstructing the argument that aerial eradication functioned as a form of environmental conservation and re-conceptualizing the socio-environmental impacts of the strategy through the political ecology of difference. Chapter 7, this final chapter of the dissertation, reflects on the different ways aerial eradication represented a technology of 
displacement and also describes what has happened since this counternarcotics strategy was suspended.

\section{Recognizing Technologies of Displacement}

For residents of the geographically and culturally isolated communities of the Afro-Pacific, an aerial eradication plane flying overhead might have been one of the only tangible forms of national government presence experienced from time to time. This dissertation has argued that that aerial eradication — justified by notions of security and environmental conservation that had little to do with black communities of the Pacific region - operated as a technology of displacement (Braun 2002).

Looking down at the map of coca cultivation in the Pacific region, Colombia would not be secure until guerilla forces and other armed groups had been driven out. Aerial eradication was posited as a safer alternative to manual eradication, which puts a greater number of lives (manual eradicators and soldiers) in immediate danger-explosive mines, sniper attacks, tropical diseases...etc. - relative to the handful of pilots in danger of being shot down during an aerial eradication operation. The cultivation of coca and processing of coca paste have caused deforestation in a tropical rainforest region, and aerial eradication, it was argued, limited deforestation by driving coca cultivators out of this region. Furthermore, the chemicals employed in aerial eradication "were never proven to be harmful humans or the environment". Yet, even if the chemicals had never been proven harmful, which they eventually were, coca cultivation shifted to other locations. So at what point did the people living in these areas come into focus on the map? 
Looking up at the aircraft from the ground, this plane had very little to do with the 'security' of black communities or the 'environmental conservation' of a biodiverse Pacific region. If anything, aerial eradication had compromised the health and personal safety of communities already distressed by the presence of non-state armed actors and the civil conflict. The argument that aerial eradication was important to the 'environmental conservation' of the Pacific region, discounted Afro-descendants and their traditional practices as part of the region's biodiversity. Furthermore, given the damages to productive lands brought about by the cocaine production chain, the gradual shift away from sustenance farming and the trend towards non-agricultural practices such as illegal mining, food sovereignty is an increasingly important concern for these communities. Basic food crops that were historically grown locally (e.g., rice, sugarcane, peach palm) are now being imported into many municipalities in the Pacific.

The complaint process, which in theory was in place to rectify the damages caused by aerial eradication, accentuated the disconnect between the rural black communities' sensibilities and counter-narcotics bureaucracy because it demanded a techno-economic literacy more suitable for large-scale plantations owners than poor farmers. Farms had to be measured in a unit not employed in the Afro-Pacific (hectares) and sustenance crops not intended for sale had to be monetized. Local practices such as informal property agreements — established orally with local geo-referencing (i.e., "My property starts at the river and ends where the creek meets the hill") and handshakeswere not considered valid in the restitution process. This was particularly problematic because, as already mentioned, any lot with coca found on it, whether solely planted with coca or mixed with other crops, was subject to eradication. Yet how did the aerial 
eradication pilot distinguish the farm with coca from the farm without coca if it is difficult to tell from the ground and the property lines were not marked on the on-board mapping system? Pilots could have simply sprayed both illicit and licit crops and the farmer was burdened with proving that they have the title to a farm with no coca on it, figuring out the Global Positioning System (GPS) coordinates of their farm, calculating the sum of the damages caused...etc. It is no wonder then - given the doubts about the accuracy of aerial eradication missions, the denial of previous consultation, and the problems with the complaint process - that aerial eradication was largely experienced as a form of punishment within these rural black communities.

Therefore, the 'displacement' in 'technology of displacement' was literal in the sense that aerial eradication made life difficult for people to live in affected communities by disrupting food production, livelihoods, and traditional practices, all of which contributed to the physical displacement of black residents from their collectively titled lands. This displacement was figurative because local conceptualizations of territory, security, and environmental conservation were displaced into foreign contexts that had nothing to do with the "underlying ecological order" of the region (Braun 2002, p.35). Furthermore, evidence that aerial eradication was harmful to the health and safety of people and their surroundings was pushed aside in favor of external interpretations of the effects of this counternarcotics policy.

Within PCN, aerial eradication was conceptualized as a challenge to black territory, another issue threatening the sense of community that the Process of Black Communities sought to engender. At the same time, community is also created through such challenges, which requires a collective effort in the defense of territory. This 
defense is ongoing and certainly did not end with the suspension of the aerial eradication program on October 1, 2015.

\section{Life After Aerial Eradication}

Similar to many of the chapter titles and subheadings in this dissertation, this final section subheading can be interpreted a number of different ways.

In the first sense, 'Life After Aerial Eradication' refers to developments in Colombian counternarcotics policy since the aerial eradication program was suspended on October 1, 2015. It is important to remember that the aerial eradication program was halted during the midst of peace negotiations with FARC, which eventually resulted in an agreement ratified by Colombian Congress in November of 2016. The Washington Office on Latin America (WOLA), a U.S.-based NGO that advocates for human rights in the Americas, has vigilantly reported on these developments as well as the current state of drug policy in Colombia. Adam Isacson, WOLA's Senior Advocate for Defense Oversight and an expert on U.S.-Colombian relations, notes that Colombia is the midst of perhaps its largest coca boom ever, which raises concerns that aerial eradication might be implemented again at some point. One reason for the boom is that as early as 2014, when the Colombian government announced it would offer benefits -such as land titles and access to markets - to coca-growing families as part of the peace settlement, FARC encouraged campesinos to grow more coca (Isacson 2017). Other reasons why coca cultivation and cocaine production are booming are a decrease in manual eradication efforts due to budget restraints, the price of gold falling (making the cultivation of coca leaf a relatively better investment), the U.S. dollar getting stronger (making cocaine more profitable), and organized resistance to manual eradication operations in many areas 
(ibid.). For instance, El Tiempo reports that 400 manual eradication missions have been blocked by campesinos in the heaviest coca-growing regions (Nariño, Putumayo, Cauca, Caquetá y Guaviare) within the last year (2016). I spoke with Adam Isacson and he explained that all illicit crop eradication efforts had slowed during the FARC negotiations because the Colombian government was wary of sparking another conflict that could have jeopardized the settlement process ${ }^{197}$.

In the meanwhile, the immediate future of illicit crop eradication in Colombia is still somewhat nebulous. Colombian Attorney General Néstor Humberto Martínez made it a point to declare that the prohibition of aerial eradication was not part of the latest negotiations with FARC (Noticias RCN Sept. 2016). Furthermore, Martínez's recent appeal to CNE to consider reinstating the aerial eradication program -in light of the increase in coca cultivation and the difficulties with manual eradication — is a reminder that members of the Colombian government are still actively debating the merits of this approach (Martínez Hernández y Salgar Antonílez 2016). At the same time, President Santos has insisted that aerial eradication is not coming back under any circumstances (Noticias RCN Sept. 2016). Santos has promised to eradicate 100,000 hectares of coca in 2017, a massive leap from the 18,000 hectares eradicated during FARC negotiations in 2016 (Isacson 2017). Of those 100,000 hectares, Santos has declared that 50,000 hectares will be eradicated through forceful eradication and 50,000 will be eradicated voluntarily (ibid.). The CNE approved manual fumigation with glyphosate (handheld spraying) in 2016 despite ANLA's 2015 ruling that glyphosate is likely a carcinogenic chemical

${ }^{197}$ Author interview with Adam Isacson at Washington Office on Latin America in Washington D.C. on April 11, 2017. 
(Noticias RCN May 2016). Manual spraying had been conducted in the past on a trial basis in certain areas though and it appears to be slightly safer than pulling the plants out by hand because it decreases the likelihood of triggering explosive mines, which are not only planted in the ground but also sometimes tied to the roots of coca plants (though there are also obvious concerns about the eradicators' exposure to glyphosate). Isacson believes that the plan for forcible eradication, now happening with an increased military role and the use of handheld sprayers, is more feasible than the plan for voluntary eradication (2017). He believes this is particularly the case because the Santos administration does not have the financial means to fulfill the agreements set forth under the terms of voluntarily eradication and because this administration will soon end its tenure in 2018 (ibid.).

The aerial eradication program, therefore, could be reinstated at some point, albeit most likely with a different spray mixture that does not contain glyphosate. Isacson believes that whether aerial eradication will return or not depends on the success of current eradication efforts and the politics of the incoming administration (i.e., if the new president is a member of former president Uribe's Democratic Centre party then there is a higher probability of the aerial eradication being reinstated $)^{198}$. It is also possible that a new mixture, whether a new chemical or a fungus, would never be approved out of fear of repeating the same problematic pattern as aerial eradication with glyphosate and, its predecessor, paraquat.

In the second sense 'Life After Aerial Eradication' refers to ongoing the challenges in the black communities Pacific region. The demobilization of FARC has

${ }^{198}$ Author interview with Adam Isacson on April 11, 2017. 
left a vacuum of authority in rural Colombia, with armed gangs and "dissident rebels refusing to hand in their guns" attempting to fill the void, in the process killing approximately 100 community leaders and activists in 2016 alone (Graham-Harrison 2017). For instance, Afro-Colombian human rights leader Emilsen Manyoma, who fought against coca cultivation and cocaine trafficking in the rural black communities of Buenaventura, was murdered with her husband in January of 2017. Manyoma was allegedly killed by her own brother, a member of los Urabeños (a BACRIM group), in Bajo Calima, where I conducted fieldwork. In Yurumanguí, also a black community of Buenaventura (discussed in Chapter 4), the community council is launching an internet campaign to raise money to fight coca cultivation and illegal mining. Frustrated by the lack of government support for crop substitution and alternative development projects, community leaders have already raised 3 million of the 20 million Colombian pesos required to finance a local rice project (Verdad Abierta 2017). The article describing this project concluded by quoting the mantra of local leaders, "Yurumangueño que se respete, no consume ni cultiva coca" or "A respectable person from Yurumanguí, neither consumes nor cultivates coca" (ibid.).

Lastly, 'Life After Aerial Eradication' refers to my own research agenda, which has also been shaped by the suspension of the aerial eradication program. While I am hopeful that aerial eradication will never be conducted again, there is certainly a disconnect between political promises and policy descriptions versus the experiences of people having to live with those decisions. Moving forward, I hope this research and future projects contribute to the validation of local knowledge production in the formation of trans/national politics. 


\section{BIBLIOGRAPHY}

Agier, Michel, Manuela Alvarez, Odile Hoffmann y Eduardo Restrepo. 1999. Tumaco, haciendo ciudad. Bogotá: ICANH-IRD-Univalle.

Agier, Michel, Olivier Barbary, Odile Hoffmann, Pedro Quintín, Héctor Fabio Ramírez, y Fernando Urrea. 2000. "Espacios regionales, movilidad y urbanización, dinámicas culturales e identidades en las poblaciones afrocolombianas del Pacífico Sur y Cali. Una perspectiva integrada". En Documento de Trabajo no.52. Centro de Investigaciones y Documentación Socioeconomica (CIDSE) Facultad de Ciencias Sociales y Económicas Universidad del Valle.

Agnew, John. 2003a. "Contemporary political geography: intellectual heterodoxy and its dilemmas". Political Geography. 22(6): 603-606.

---. 2003b. Geopolitics: re-visioning world politics. London: Routledge.

---. 2015. "Revisiting the territorial trap". Nordia Geographical Publications. 44(4): 4348.

---. 1994. "The territorial trap: The geographical assumptions of international relations theory". Review of International Political Economy. 1(1): 53-80.

---. 2013. “Territory, Politics, Governance”. Territory, Politics, Governance. 1(1): 1-4.

Agnew, John, and Ulrich Oslender. 2013. "Overlapping territorialities, sovereignty in dispute: empirical lessons from Latin America”, in Nicholls, Walter, Justin Beaumont, and Byron Miller. Spaces of contention spatialities and social movements. Farnham: Ashgate: 121-140.

Agnew, John, Katharyne Mitchell, and Gerard Toal. 2003. "Introduction”. In $A$ companion to political geography. Malden, MA: Blackwell Publishers: 1-9.

Altieri, Miguel, and Víctor Manuel Toledo. 2011. "The agroecological revolution in Latin America: rescuing nature, enduring food sovereignty and empowering peasants". Journal of Peasant Studies. 38 (3): 587-612.

Anderson, Benedict. 1983. Imagined communities: reflections on the origin and spread of nationalism. London: Verso.

Antonsich, Marco. n.d. (forthcoming). "Territory and Territoriality". In International encyclopedia of human geography. Oxford: Wiley-Blackwell.

Arboleda, Santiago. 1998. Le dije que me esperara, Carmela no me esperó: El Pacífico en Cali. Cali: Univalle. 
"ArcGIS Online." ArcGIS Online. Accessed August 10, 2016.

https://doc.arcgis.com/en/arcgis-online/reference/shapefiles.htm.

Arias, Diego. "¿Quién era Genaro García, el líder afro asesinado por las Farc?". El Tiempo. August 22, 2015. Accessed August 25, 2015. http://www.eltiempo.com /archivo/documento/CMS-16270036.

Arocha, Jaime. 1992. "Los negros y la nueva constitución colombiana de 1991”. América Negra 3: 39-54.

---. 1999. Ombligados de Ananse: hilos ancestrales y modernos en el Pacifico colombiano, Bogotá: CES.

Asher, Kiran. 2009. Black and green: Afro-Colombians, development, and nature in the Pacific lowlands. Durham: Duke University Press.

Asher, Kiran and Ojeda, Diana. 2009. Producing nature and making the state: ordenamiento territorial in the Pacific lowlands of Colombia. Geoforum 40(3): 292-302.

AsoManosNegra. 2008. "Informe de Aso Manos Negra sobre la campaña adelantada en Consejos Comunitarios de Guapi y Timbiquí para evaluar los efectos generados por las fumigaciones en territorios colectivos de las comunidades negras del Pacífico caucano".

Ayala Osorio, Germán y Hernando Llano Ángel. 2004. Análisis del tratamiento periodístico dado por seis medios masivos colombianos a los hechos relacionados con el Plan Colombia.

Ballvé, Teo. 2012. "Everyday state formation: Territory, decentralization, and the Narco Landgrab in Colombia". Environment and Planning D: Society and Space. 30(4): 603-622.

Barnes, Trevor. 2009. "Not Only ... But Also": Quantitative and Critical Geography". The Professional Geographer. 61(3): 292-300.

Benford, Robert.1997. “An insider's critique of the social movement framing perspective”. Sociological Inquiry. 67(4): 409-30.

Bejarano, Edgar, Bernardo Pérez Salazar, and Cesar Velásquez Monroy. 2003. "Megaproyectos, corporativismo global y violencia en Colombia". Unpublished report. Bogotá: Universidad Externado de Colombia. 
Blaikie, Piers, and Harold Brookfield. 1987. Land degradation and society. London: Methuen.

Blaser, Mario. 2009. "Political ontology: cultural studies without 'cultures'?". Cultural Studies. 23(5-6): 873-896.

Blaser, Mario. 2010. Storytelling globalization from the Chaco and beyond, Durham: Duke University Press.

Blickman, Tom. The Transnational Institute, "Coca leaf: Myths and Reality." Last modified 2014. Accessed May 12, 2016. http://www.tni.org/primer/coca-leafmyths-and-reality.

Blocher, Julia. "IDMC » IDMC's Annual Flagship Report Reveals Record Breaking IDP Figures for Second Year Running." Internal Displacement Monitoring Centre. May 14, 2014. Accessed August 05, 2016. http://www.internaldisplacement.org /blog/2014/a-record-33-3-million-now-displaced-by-conflict-and-violenceworldwide-as-one-family-flees-inside-syria-every-60-seconds.

Borda Guzmán, Sandra. 2010. "The Internationalization of the Colombian Conflict during the Uribe Administration". In Reuveny, Rafael and William R. Thompson (eds.). Coping with Contemporary Terrorism: Origins, Escalation, Expansion, Counter Strategies, and Responses. Albany: State University of New York Press.

Braun, Bruce. 2002. The intemperate rainforest: nature, culture, and power on Canada's west coast. Minneapolis: University of Minnesota Press.

Brodzinsky, Sibylla. "Plan Colombia's Mixed Legacy: Coca Thrives but Peace Deal May Be on Horizon." The Guardian. February 03, 2016. Accessed July 22, 2016. https://www.theguardian.com/world/2016/feb/03/plan-colombia-cocainenarcotics-farc- peace-deal.

Bryan, Joe. 2012. "Rethinking Territory: Social Justice and Neoliberalism in Latin America's Territorial Turn". Geography Compass. 6(4): 215-226.

Bryant, Joseph M., and Denis Wood. 2015. Weaponizing maps: indigenous peoples and counterinsurgency in the Americas. New York: The Guilford Press.

Camacho, Adriana y Daniel Mejía. 2015. "Consecuencias de la aspersión aérea en la salud: evidencia desde el caso colombiano". CEDE.

Cárdenas Roosbelinda. 2012. "Green multiculturalism: Articulations of ethnic and environmental politics in a Colombian 'black community'". Journal of Peasant Studies. 39(2): 309-333. 
Carney, Judith. 2006. "Landscapes and places of memory: African Diaspora research and geography". In Tejumola Olaniya, James and Madeleine Wong (eds.). African Diaspora studies and the disciplines. Bloomington: Indiana University Press

"Carta abierta desde el Pacífico Sur a los colombianos y colombianas y a la opinión pública mundial”. 2009. www.colombiasupport.net/2009/Carta_Final_mayo_ 12_09.pdf.

Ceballos, Marcela. 2003. "Fumigación de cultivos de uso ilícito y vulneración de los Derechos Humanos en la frontera colombo- ecuatoriana". Consultoria para los Derechos Humanos y el Desplazamiento (CODHES). En: AMICUS Curiae. Ante el tribunal constitucional del Ecuador durante el primer foro de las Américas realizado en Quito, Ecuador.

Cederstav, Anna and Astrid Puentes. Asociación Interamericana para la Defensa del Ambiente (AIDA). Last modified 2007. Accessed December 3, 2012. http://www.aida-americas.org/es/release/fumigación-aérea-del-plan-colombia-noha-probado-ser-segura-para-el-ambiente-nota-de-prensa-.

Centers for Disease Control and Prevention. "Parasites - Leishmaniasis." January 10, 2013. Accessed March 19, 2017. https://www.cdc.gov/parasites/leishmaniasis/.

Coca: Deforestación, contaminación y pobreza. 2014. Bogotá: Policía Nacional.

Colombia. "Ley 1448 de 2011". Accessed October 15, 2015. http://www.alcaldiabogota.gov.co/sisjur/normas/Norma1.jsp?i=43043.

---. "Plan de Manejo Ambiental, Resolución 1065 de 2001". Accessed May 29, 2015. http://www.odc.gov.co/Portals/1/Docs/pecig/Resolucion1065nov2001MinAmbie nte.pdf.

--- “Sentencia 383 de 2003”. Accessed October 12, 2015. http://www.corteconstitucional.gov.co/relatoria/2003/su383-03.htm.

Constitución Política De Colombia. Accessed August 03, 2016. http://www.procuraduria.gov.co/guiamp/media/file/Macroproceso Disciplinario/Constitucion_Politica_de_Colombia.htm.

Consultoria para los Derechos Humanos y el Desplazamiento (CODHES). 2013. "Estadísticas Históricas de Desplazamiento". Accessed September 7, 2014. http://www.codhes.org/index.php?option=com_si\&type $=1$.

Coronil, Fernando. 1997. The magical state: nature, money, and modernity in Venezuela. Chicago: University of Chicago Press. 
Craggs, Ruth. 2014. "Postcolonial geographies, decolonization, and the performance of geopolitics at Commonwealth conferences". Singapore Journal of Tropical Geography. 35(1): 39-55.

Crampton, Jeremy. 2010. Mapping: a critical introduction to cartography and GIS. Chichester, U.K.: Wiley-Blackwell.

Crampton, Jeremy and John Krygier. 2006. "An Introduction to Critical Cartography." ACME Journal. 4(1): 11-33.

Crang, Mike, and Ian Cook. 2012. Doing ethnographies. Los Angeles: Sage.

Cronon, William. 1995. Uncommon ground: toward reinventing nature. New York: W.W. Norton \& Co.

Cuero, Harrison. "Momento histórico para un nuevo y decidido aporte afro a la consolidación del Estado colombiano." Chocó.org. 17 de febrero de 2015. Accessed March 14, 2017. https://choco.org/?p=266.

Dahlman, Carl. 2009. “Geopolitics”. In Gallaher, Carolyn. Key concepts in political geography. London: SAGE.

Dalby, Simon. 2002. Environmental security. Minneapolis, Minn: University of Minnesota Press.

---. 2010. "Recontextualising violence, power and nature: The next twenty years of critical geopolitics?". Political Geography. 29(5): 280-288.

Dalby, Simon, and Gerard Ó Tuathail. 2002. "Introduction”. In Dalby, Simon, and Gerard Ó Tuathail. Rethinking geopolitics. London: Routledge.

Dalton, Craig, and Liz Mason-Deese. 2012. "Counter (Mapping) actions: Mapping as militant research". ACME. 11(3): 439-466.

Dávalos, Liliana, Adriana Bejarano, and Leonardo Correa. 2009. "Disabusing cocaine: pervasive myths and enduring realities of a globalised commodity". The International Journal on Drug Policy. 20 (5): 381-6.

Delaney, David. 2009. “Territory and Territoriality”. In Kitchin, Rob. International encyclopedia of human geography. Amsterdam: Elsevier.

Departamento Nacional De Planeación. 2010. Bases Del Plan Nacional De Desarrollo 2010-2014: Prosperidad Para Todos Más Empleo, Menos Pobreza Y Más Seguridad. Bogotá, D.C. 
Diócesis de Tumaco. "Qué nadie diga que no pasa nada! Una mirada desde la Región del Pacífico Nariñense”. Balance No.4. septiembre de 2014.

Dion, Michelle and Catherine Russler. 2008. "Eradication Efforts, the State, Displacement and Poverty: Explaining Coca Cultivation in Colombia during Plan Colombia". Journal of Latin American Studies. 40: 399-422.

Dirección de Antinarcóticos. Policía Nacional de Colombia (DIRAN). Accessed June 16, 2015. <http://www.policia.gov.co/portal/page/portal/UNIDADES_POLICIALES/ Direcciones tipo Operativas/Direccion_de_Antinarcoticos $>$.

Dirección de Programas Contra Cultivos Ilícitos (DPCI). 2012. "Nuevo Enfoque de los Programas Contra Cultivos Ilícitos”. Versión 1. Accessed 9 April 2015. $<$ http://www.consolidacion.gov.co/>.

Dodds, Klaus, Merje Kuus, and Joanne Sharp. 2013. The Ashgate research companion to critical geopolitics. Farnham, England: Ashgate.

Duffield, Mark. 1998. "Post-modern conflict: warlords, post-adjustment states and private protection”. Civil Wars.1(1): 66-102.

Ebus, Bram. "Illegal gold mining in Colombia is destroying the rainforest". Newsweek. November 21, 2016. Accessed March 10, 2017. http://www.newsweek.com/2016 /11/25/colombia-illegal-gold-mining-521717.html.

The Economist. "Gushers and guns". March 17, 2012. Accessed March 20, 2017. http://www.economist.com/node/21550304.

---."A New Plan for Colombia". January 21, 2016. Accessed January 21, 2016. http://www.economist.com/news/americas/21688936-juan-manuel -santos-seeks-support-peace-washington-new-plan-colombia.

---. "Why Is Less Cocaine Coming from Colombia?" April 2, 2013. Accessed April 14, 2016. http://www.economist.com/blogs/economistexplains/2013/04/economist-explains-why-colombia-produces-less-cocaine.

Elden, Stuart. 2013a. How Should We Do the History of Territory?" Territory, Politics, Governance. 1(1): 5-20.

---. 2010. “Land, terrain, territory”. Progress in Human Geography 34 (6): 799- 817.

---. 2013b. "The Significance of Territory." Geographica Helvetica 68(1): 65-68. 
---. 2009. Terror and territory: the spatial extent of sovereignty. Minneapolis: University of Minnesota Press.

Elhawary Samir. 2010. "Security for whom? Stabilisation and civilian protection in Colombia". Disasters. 34: 388-405.

Eltiempo.com. "El Dinero De La Guerilla." March 10, 1998. Accessed July 13, 2016. http://www.eltiempo.com/archivo/documento/MAM-760778.

---. "Más De 400 Bloqueos De Cocaleros Frenan Proceso De Erradicación-Justicia-El Tiempo". August 23, 2016. Accessed September 1, 2016. http://www. eltiempo.com/politica/justicia/erradicacion-manual-de-cultivo-ilicitos-en-colombiafrenada-por-bloqueos/16680444.

---. "Si erradican coca, los pequeños cultivadores no irían a la cárcel". September 7, 2015. Accessed January 15, 2016. http://www.eltiempo.com/archivo/documento/CMS16347535 .

Erazo, Juliet. 2013. Governing Indigenous Territories: Enacting Sovereignty in the Ecuadorian Amazon. Duke University Press.

Escobar, Arturo. 1999. "After Nature: Steps to an Antiessentialist Political Ecology". Current Anthropology. 40(1): 1-30.

---. 2004. "Beyond the Third World: Imperial Globality, Global Coloniality and AntiGlobalisation Social Movements". Third World Quarterly. 25(1): 207-230.

---. 1996. "Constructing nature: elements for a poststructural political ecology". In Peet, Richard, and Michael Watts (eds.). Liberation ecologies: environment, development, social movements. London: Routledge.

---. 2003. "Displacement, development, and modernity in the Colombian Pacific". International Social Science Journal. 55(1): 157-167.

---. 2006. "An ecology of difference: Equality and conflict in a glocalized world". Focaal-Utrecht. (47): 120-140.

---. 2008. Territories of difference: place, movements, life, redes. Durham: Duke University Press.

---. 1998. " ¿Whose knowledge, whose nature? Biodiversity conservation and the political ecology of social movements". Journal of political ecology. 5: 53-82.

FARC: Degrading Security, Impending Prosperity and Violating Human Rights Since 1964. 2012. Universal Strategy Group. 
Ferro, Juan Guillermo, and Graciela Uribe. 2002. Las marchas de los cocaleros del departamento de Caquetá, Colombia: contradicciones políticas y obstáculos a la emancipación social. Bogotá (Colombia): Facultad de Ciencias Económicas y Administrativas.

Flórez López, Jesús. 2012. "Territorialidad étnica, territorialidad colombiana y $\mathrm{t}$ territorialidad del capital". En Territorios étnicos y autonomía en América Latina. Bogotá: Pontificia Universidad Javeriana.

Foucault, Michel. 2003. Society Must Be Defended: Lectures at the Collège de France: 1975-76. New York: Picador.

Forsyth, Tim. 2008. "Political ecology and the epistemology of social justice". Geoforum. 39 (2): 756-764.

Fraser, Nancy. 2010. "Who Counts? Dilemmas of Justice in a Postwesphalian World." The point is to change it; Geographies of hope and survival in an age of crisis. In Castree, Noel, Paul Chatterton, Nik Heynen, Wendy Larner, and Melissa Wright (eds.). Chichester, U.K.: Wiley-Blackwell.

Friedemann, Nina de. 1998. "Gold Mining and Descent: Güelmambí, Nariño”. In Blackness in Latin America and the Caribbean: Social Dynamics and Cultural Transformations: Central America and Northern and Western South America. Ed. Norman E. Whitten and Arlene Torres, 2 vols. Bloomington: Indiana University Press. 1: 183-185.

---. 1985. "Troncos among black miners in Colombia.” In T. Greaves and W. Culver, eds. Miners and mining in the Americas. Manchester, UK: Manchester University Press: 204-25.

Gootenberg, Paul. 2003. "Between coca and cocaine: a century or more of U. S. Peruvian drug paradoxes, 1860-1980". The Hispanic American Historical Review (North Carolina). 83 (01): 119-150.

Gottmann, Jean. 1973. The Significance of Territory. Charlottesville VA: University of Virginia Press.

Graham-Harrison, Emma. "Colombia death toll rises as gangs fill vacuum left by Farc rebels". The Guardian. February 18, 2017. Accessed April 10, 2017. https://www.theguardian.com/world/2017/feb/19/colombia-farc-activist-killings.

Grajales, Jacobo. 2011. "The rifle and the title paramilitary violence, land grab and land control in Colombia". Journal of Peasant Studies. 38(4): 771-792. 
Gregory, Derek. 2004. The colonial present: Afghanistan, Palestine, and Iraq. Malden, MA: Blackwell Pub.

---. 2000. “Ontology”. In The dictionary of human geography. Ron Johnston, Derek Gregory, Geraldine Pratt, and Michael Watts. Malden, MA: Blackwell: 561-64.

Grueso Libia, Carlos Rosero and Arturo Escobar. 2003. "The process of black community organizing in the Southern Pacific Coast region of Colombia". In Gutmann, Matthew C. Perspectives on Las Américas: a reader in culture, history, and representation. Maden, MA: Blackwell Pub.

The Guardian. "Colombia's government formally ratifies revised Farc peace deal". December 01, 2016. Accessed March 13, 2017. https://www.theguardian.com /world/2016/dec/01/colombias-government-formally-ratifies-revised-farc-peacedeal.

Hale, Charles. 2011. "Resistencia para que? Territory, autonomy and neoliberal entanglements in the 'empty spaces' of Central America". Economy and Society 40(2): 184-210.

Hartman, Betsy. 2001. "Will the Circle Be Unbroken? A Critique of the Project on Environment, Population, and Security. In Peluso, Nancy Lee, and Michael Watts. 2001. Violent environments. Ithaca: Cornell University Press.

Haraway, Donna Jeanne. 1988. "Situated knowledges: the science question in feminism and the privilege of partial perspective". Feminist Studies. 575-599.

Haraway, Donna Jeanne, and Thyrza Nichols Goodeve. 2000. How like a leaf: an interview with Thyrza Nichols Goodeve. New York: Routledge.

Harvey, David. 1996. Justice, nature, and the geography of difference. Oxford: Blackwell.

---. The Limits to Capital. Oxford: Basil Blackwell, 1982.

Herb, Guntram, Jouni Hakli, Mark Corson, Nicole Mellow, Sebastian Cobarrubias, and Maribel Casas-Cortes. 2009. "Intervention: Mapping is critical!" Political Geography. 28(6): 332-342.

Hergenrather, Kenneth, Scott Rhodes, Chris Cowan, Gerta Bardhoshi, and Sara Pula. 2009. "Photovoice as community-based participatory research: a qualitative review". American Journal of Health Behavior. 33(6): 686-698. 
Hoffmann, Odile. 2002. “Afrodescendientes En Las Américas”. En Mosquera RoseroLabbé, Claudia, Mauricio Pardo, and Odile Hoffmann (eds.). Afrodescendientes en las Américas: trayectorias sociales e identitarias : 150 años de la abolición de la esclavitud en Colombia. Bogotá: Universidad Nacional de Colombia.

Human Rights Watch. "Paramilitaries' Heirs: The New Face of Violence in Colombia.". February 03, 2010. Accessed August 02, 2016. https://www.hrw.org/report/ 2010/02/03/paramilitaries-heirs/new-face-violence-colombia.

Impactos de las aspersiones aéreas con glifosato en los municipios de Guapi y Timbiquí, en el Departamento del Cauca. 2011. Volumen I. Popayán, Cauca.

Instituto Colombiano de Desarrollo Rural (INCODER). Programación Presupestal. Accessed March 23, 2016. http://www.incoder.gov.co/documentos/AÑO _2015/Gestion_Incoder/Programas y Proyectos/11. Implementación del Programa de Legalización de Tierras y Fomento al Desarrollo Rural para Comunidades Negras a Nivel Nacional.pdf.

International Court of Justice. 2012. Case concerning aerial herbicide spraying (Ecuador v. Colombia): Volume iv, Annexes 34 - 55. 1 February 2012. [The Hague]: International Court of Justice.

Internal Displacement Monitoring Centre (IDMC) - Norwegian Refugee Council. "Colombia ". Accessed July 11, 2017. http://www.internaldisplacement.org/countries/colombia.

International Labour Organization (ILO). 1989. "C169 - Indigenous and Tribal Peoples Convention. (No. 169)". http:/www.ilo.org/dyn/normlex/en/f?p= NORMLEXPUB:12100:0::NO::P12100_ILO_CODE:C169.

Isacson, Adam. "Confronting Colombia's Coca Boom Requires Patience and a Commitment to the Peace Accords". Washington Office on Latin America. March 13, 2017. Accessed April 5, 2017. https://www.wola.org/analysis/confrontingcolombias-coca-boom-requires-patience-commitment-peace-accords/.

Jelsma, Martin. 2001. Vicious circle: the chemical and biological "war on drugs". Amsterdam, Netherlands: Transnational Institute.

Jhally, Sut, and Stuart Hall. 1996. Race: the floating signifier. Northampton, MA: Media Education Foundation.

Jiménez, Germán. 2001. “Llorente, nuevo campo de batalla”. El Espectador. 31 de mayo.

Joxe, Alain. 2002. Empire of Disorder. New York: Semiotext(e). 
Koopman, Sara. 2011. "Alter-geopolitics: Other securities are happening". Geoforum. 42(3): 274-284.

Kosek, Jake. 2006. Understories: the political life of forests in northern New Mexico. Durham: Duke University Press.

Krauss, Clifford. "U.S. Will Assist Peru's Army in Fighting Cocaine and Rebels". The New York Times. January 24, 1992. Accessed July 09, 2016. http://www.nytimes.com/1992/01/25/world/us-will-assist-peru-s-army-infighting-cocaine-and-rebels.html.

Landel, Morgan. 2010. "Are Aerial Fumigations in the Context of the War in Colombia a Violation of the Rules of International Humanitarian Law?". Transnational Law \& Contemporary Problems. 19 (2): 491513.

LaRosa, Michael, and Germán Mejía P. 2012. Colombia: a concise contemporary history. Lanham: Rowman \& Littlefield Publishers.

Leal Buitrago, Francisco. 2002. La seguridad nacional a la deriva: del Frente Nacional a la posguerra fría. Santafé de Bogotá: Alfaomega.

Le Billon, Philippe. 2001. "The political ecology of war: natural resources and armed conflicts". Political Geography. 20(5): 561-584.

Li, Tania. 2007. The will to improve: governmentality, development, and the practice of politics. Durham: Duke University Press.

---. 1999. Transforming the Indonesian uplands: marginality, power and production. Amsterdam, The Netherlands: Harwood Academic Publishers.

Leszczynski, Agnieszka. 2009. "Quantitative Limits to Qualitative Engagements: GIS, Its Critics, and the Philosophical Divide*". The Professional Geographer. 61(3): 350-365.

"Ley 70 de 1993." La Alcaldía de Bogotá. Accessed March 30, 2017. http://www.alcaldiabogota.gov.co/sisjur/normas/Norma1.jsp?i=7388.

Londoño Zapata, Nery. 2006. "Lo ambiental y lo social de la aspersión en Colombia: ¿política ambiental o estrategia antinarcóticos?". Desafíos (Bogotá). (15): 178235.

Martínez-Alier, Juan. 2002. The environmentalism of the poor: a study of ecological conflicts and valuation. Northhampton, MA: Edward Elgar Pub. 
Martínez-Alier, Joan, Giorgos Kallis, Sandra Veuthey, Mariana Walter, and Leah Temper. 2010. "Social Metabolism, Ecological Distribution Conflicts, and Valuation Languages". Ecological Economics. 70(2): 153-158.

Martínez Hernández, Santiago, and Daniel Salgar Antolínez. "Fiscal General Pide Reactivar La Aspersión Aérea De Cultivos Ilícitos." El Espectador. September 03, 2016. Accessed November 10, 2016. http://colombia2020.elespectador. $\mathrm{com} /$ politica/fiscal-general-pide-reactivar-la-aspersion-aerea-de-cultivos-ilicitos.

Mason, Ann. 2005. "Constructing Authority Alternatives on the Periphery: Vignettes from Colombia". International Political Science Review. 26 (1): 37-54.

Mathews, Andrew. 2011. Instituting nature authority, expertise, and power in Mexican forests. Cambridge, Mass: MIT Press.

McDermott, Jeremy. "How President Alvaro Uribe changed Colombia". BBC News. August 04, 2010. Accessed March 20, 2017. http://www.bbc.com/news/worldlatin-america-10841425.

Meertens, Donny. 2001. 'The nostalgic future. Terror, displacement and gender in Colombia”. In Moser, Caroline and Fionna Clark (eds.). Victims, Perpetrators or Actors? Gender, Armed Conflict and Political Violence. London: Zed Books: 133148.

Mejía, Daniel. 2015. "Plan Colombia: An Analysis of Effectiveness and Costs". Washington, DC: Brookings Institution. http://www.brookings.edu/ /media/ Research/Files/Papers/2015/04/global-drug-policy/Mejia--Colombiafinal.pdf?la=en.

Meléndez, Ángela. "Ecuador-Colombia Settlement Won't End Spraying." Inter Press Service News Agency. October 28, 2013. Accessed May 14, 2015. $<$ http://www.ipsnews.net/2013/10/ecuador-colombia-settlement-wont-endspraying/>.

Mitchell, Katharyne. 2010. "Ungoverned space: Global security and the geopolitics of broken windows". Political Geography. 29 (5): 289-297.

Mitchell, Timothy. 2009. "The Limits of the State: beyond Statist Approaches and their Critics". Politics of the Modern Arab World: Critical Issues in Modern Politics. 1: 48-72.

Morales, Waltraud Queiser. 1992. "Militarising the drug war in Bolivia". Third World Quarterly. 13(2): 353-370. 
Moreno-Sánchez, Rocio, David S Kraybill, and Stanley R Thompson. 2003. "An Econometric Analysis of Coca Eradication Policy in Colombia". World Development. 31(2): 375-383.

Motta González, Nancy. 2005. Gramática Ritual: Territorio, poblamiento e identidad afropacífica. Cali, Colombia : Programa Editorial Universidad del Valle.

Musto, David F. 1999. The American disease: origins of narcotic control. New York: Oxford University Press.

Neumann, Roderick. 1998. Imposing wilderness: struggles over livelihood and nature preservation in Africa. Berkeley: University of California Press.

---. 2005. Making Political Ecology. New York: Oxford University Press.

---. 2004. "Moral and discursive geographies in the war for biodiversity in Africa". Political Geography. 23(7): 813-837.

Ng'weno, Bettina. 2007. Turf wars: territory and citizenship in the contemporary state. Stanford, Calif: Stanford University Press.

Noticias RCN . "CNE Aprobó Fumigación Manual Y Terrestre Con Glifosato Para Erradicar Cultivos Ilícitos." Noticias RCN. 4 de mayo de 2016. Accessed May 10, 2016. http://www.noticiasrcn.com/nacional-pais/cne-aprobo-fumigacion-manual-yterrestre-glifosato-erradicar-cultivos-ilicitos.

----. "Santos: No Habrá Más Aspersión Aérea De Cultivos Ilícitos En Colombia".14 de septiembre de 2016. Accessed September 20, 2016. http://www.noticiasrcn.com /nacional-pais/santos-no-habra-mas-aspersion-aerea-cultivos-ilicitos-colombia.

Observatorio de Territorios Étnicos. "Comunidades que acompañamos". Accessed March 19, 2017. http://www.etnoterritorios.org/Caribe.shtml?apc=g-xx$1-\& \mathrm{x}=18$.

Offen, Karl. 2011. "Making Black Territories”. In Dym, Jordana, and Karl Offen (eds.). Mapping Latin America: a cartographic reader. Chicago: The University of Chicago Press.

---. 2003. "The Territorial Turn: Making Black Territories in Pacific Colombia". Journal of Latin American Geography. 2(1): 43-73.

Ojeda Diana. 2012. "Green pretexts: Ecotourism, neoliberal conservation and land grabbing in Tayrona National Natural Park, Colombia". Journal of Peasant Studies. 39(2): 357-375. 
O'Shaughnessy, Hugh and Sue Bradford. 2005. Chemical Warfare in Colombia: the Costs of Fumigation. London: Latin America Bureau.

Oslender, Ulrich. 2008a. "Another History of Violence: The Production of 'Geographies of Terror' in Colombia's Pacific Coast Region". Latin American Perspectives. 35(5): 77-102.

---. 2016a. "The banality of displacement: Discourse and thoughtlessness in the internal refugee crisis in Colombia". Political Geography. 50: 10-19.

---. 2008b. Comunidades negras y espacio en el Pacífico colombiano: hacia un giro geográfico en el estudio de los movimientos sociales. Bogotá: Instituto Colombiano de Antropología e Historia.

---. 2016b. The geographies of social movements Afro-Colombian mobilization and the aquatic space. Durham: Duke University Press.

---. 2015. "Leaving the Field: How to Write About Disappointment and Frustration in Collaborative Research". In Reiter, Bernd, and Ulrich Oslender (eds.). 2015. Bridging scholarship and activism: reflections from the frontlines of collaborative research. East Lansing: Michigan State University Press.

---. 2002. "'The Logic of the River": A Spatial Approach to Ethnic-Territorial Mobilization in the Colombian Pacific Region". Journal of Latin American Anthropology. 7(2): 86-117.

---. 2007a. "Revisiting the Hidden Transcript: Oral Tradition and Black Cultural Politics in the Colombian Pacific Coast Region". Environment and Planning D: Society and Space. 25 (6): 1103-1129.

---. 2007b. "Violence in development: the logic of forced displacement on Colombia's Pacific coast". Development in Practice. 17(6): 752-764.

Ó Tuathail, Gearóid. 1996. Critical geopolitics: the politics of writing global space. London: Routledge.

---. 2010. "Localizing geopolitics: Disaggregating violence and return in conflict regions". Political Geography. 29(5): 256-265.

Paasi, Anssi. 2003. “Territory”. In Agnew, John A., Katharyne Mitchell, and Gerard Toal. A companion to political geography. Malden, MA: Blackwell Publishers.

Painter, Joe. 2010. "Rethinking Territory". Antipode. 42(5): 1090-1118. 
El País. February 6, 2011. "Región Pacífico, La Vía Económica a La Descentralización". Accessed July 13, 2015.

Palacios, Marco. 2003. Entre la legitimidad y la violencia: Colombia 1875-1994. Bogotá, Colombia: Grupo Editorial Norma.

Patel, Raj. 2009. "Food sovereignty". The Journal of Peasant Studies. 36 (3): 663-706.

Paulston, Rolland, and Martin Liebman. 1994. "An Invitation to Postmodern Social Cartography". Comparative Education Review. 38(2): 215-32.

Pécaut, Daniel. 2013. La experiencia de la violencia: los desafios del relato y la memoria.

---. 1999. "From the Banality of Violence to Real Terror: the Case of Colombia". In Koonings, Kees, and Dirk Kruijt.. Societies of fear: the legacy of civil war, violence and terror in Latin America. London: Zed Books.

Peet, Richard, and Michael Watts. 2004. "Liberating Political Ecology.” In Liberation ecologies: environment, development, social movements. London: Routledge.

Peluso, Nancy Lee. 1995. "Whose woods are these?: counter-mapping forest territories in Kalimantan, Indonesia". Antipode. 27(4): 383-406

Peluso, Nancy Lee, and Christian Lund. 2011. "New frontiers of land control introduction". Journal of Peasant Studies. 38(4): 667-681.

Pereira, Laura. 2010. "Becoming coca: A materiality approach to a commodity chain analysis of hoja de coca in Colombia". Singapore Journal of Tropical Geography. 31 (3): 384-400.

Pickles, John. 2004. A history of spaces: cartographic reason, mapping, and the geocoded world. London: Routledge.

Porto-Gonçalves, Carlos Walter and Enrique Leff. 2012. "Political ecology in Latin America: natures social reapropriation and the reinvention of territories". Revista InternacionalInterdisciplinarINTERthesis. 9(1): 16-50.

"Posture Statement of General John F. Kelly, United States Marine Corps Commander, United States Southern Command". Testimony before the 113th Congress Senate Armed Services Committee. February 24, 2014. Accessed 25 Aug 2015. $<$ http://www.southcom.mil/newsroom $>$. 
Presidencia De La República. "Gobierno lanza estrategia integral de sustitución de cultivos ilícitos". September 22, 2015. Accessed September 30, 2015. http://wp.presidencia.gov.co/Noticias/2015/Septiembre/Paginas/20150922_02Gobierno- lanza-Estrategia-Integral-de-Sustitucion-de-Cultivos-Ilicitos.aspx.

---. 1999. "El Plan Colombia: una gran alianza con el mundo contra el delito internacional, por losderechos humanos, los derechos sociales y por la ecología". In Hechos de Paz V-VI. Colombia: Presidencia de la República de Colombia, Oficina del Alto Comisionado para la Paz.

Programa Presidencial de Derechos Humanos y Derechos Internacional Humanitario. 2010. "Impacto de la Política de Seguridad Democrática sobre la violencia y los derechos humanos". Bogotá.

Ramírez, María Clemencia. 2011. Between the Guerrillas and the State: the Cocalero Movement, Citizenship, and Identity in the Colombian Amazon. Durham [N.C.]: Duke University Press.

---. 2010. "Maintaining democracy in Colombia through political exclusion, states of exception, counterinsurgency and dirty war". In: E. Desmond Arias and D. Goldstein, eds. Violent democracies in Latin America. Durham and London: Duke University P ress.

Renwick, Danielle. "FARC, ELN: Colombia's Left-Wing Guerrillas". Council on Foreign Relations. July 8, 2016. Accessed July 15, 2016.http://www.cfr.org/colombia /farc-eln-colombias-left-wing-guerrillas/p9272.

Restrepo, Eduardo. 2013. Etnización de la negridad: la invención de las "comunidades negras" como grupo étnico en Colombia. Popayán, Colombia: Editorial Universidad del Cauca.

Reyes Posada, Alejandro. 2009. Guerreros y campesinos: el despojo de la tierra en Colombia. Bogotá: Norma.

Rhoades, Robert, and Virginia Nazarea. 1999. "Local Management of Biodiversity in Traditional Agroecosystems”. In Collins, Wanda, and Calvin Qualset. Biodiversity in agroecosystems. Boca Raton: CRC Press.

Richani, Nazih. 2002. Systems of violence: the political economy of war and peace in Colombia. Albany, NY: State University of New York Press.

Rincón-Ruiz, Alexander and Giorgos Kallis. 2013. "Caught in the Middle, Colombia's War on Drugs and its Effects on Forest and People". Geoforum. 46: 60-78. 
Robbins, Paul. 2012. Political ecology: a critical introduction. Chichester, U.K.: Wiley Blackwell.

Rojas, Cristina. 2009. "Securing the State and Developing Social Insecurities: the securitisation of citizenship in contemporary Colombia". Third World Quarterly. 30 (1): 227-245.

Ruggie, John Gerard. 1993. "Territoriality and Beyond: Problematizing Modernity in International Relations". International Organization. 47(1): 139-174.

Sack, Robert. 1983. "Human Territoriality: A Theory". Annals of the Association of American Geographers. 73(1): 55-74.

--- 1986. Human territoriality: its theory and history. Cambridge: Cambridge University Press.

Said, Edward. 1978. Orientalism. New York: Pantheon Books.

Salazar, Alonso. 2012. Pablo Escobar: el patrón del mal. Doral, Fla: Aguilar.

Sánchez, Gonzalo, Donny Meertens, and Eric Hobsbawm. 2000. Bandoleros, gamonales y campesinos: el caso de la violencia en Colombia. Bogotá: El Áncora.

Sassen, Saskia. 2013. "When Territory Deborders Territoriality". Territory, Politics, Governance. 1(1): 21-45.

Sayer, Andrew. 1992. Method in social science: a realist approach. London: Routledge.

Schaffer, Adam, and Coletta A. Youngers. 2015. "Twilight Hour of Coca Fumigation in Colombia Shows Its Injustice, Ineffectiveness." Washington Office on Latin America. Accessed October 18, 2015. www.wola.org/commentary/good_riddance _to_a_bad_policy_twilight_hour_of_coca_fumigation_campaign_highlights.

Schuurman, Nadine.2006. Why formalization matters: Critical GIS and ontology research. Annals of the Association of American Geographers. 96 (4): 726-39.

Serje de la Ossa, Margarita Rosa, Ashley Caja, Rebecca Natolini, Laura Moll Rexach, and Christopher Britt-Arredondo. 2007. "Iron Maiden Landscapes: The Geopolitics of Colombia's Territorial Conquest". South Central Review. 24(1): $37-55$.

Sharp, Joanne. 2011a. "A subaltern critical geopolitics of the war on terror: Postcolonial security in Tanzania". Geoforum. 42(3): 297-305.

---. 2011b. "Subaltern Geopolitics: Introduction". Geoforum. 42(3): 271-273. 
Shifter, Michael. 2012. "Plan Colombia: A Retrospective." Americas Quarterly. Americas Society/Council of the Americas. Accessed 3 Aug 2015. $<$ http://www.americasquarterly.org/node/3787>.

The Integrated Illicit Crops Monitoring System (SIMCI) \& United Nations Office on Drugs and Crime (UNODC). 2011. Características agroculturales de los cultivos de coca en Colombia 2005-2010. Bogotá: Sistema Integrado de Monitoreo de Cultivos ilícitos.

Slater, David. 2004. Geopolitics and the Post-colonial: Rethinking North-South Relations. Malden, Mass: Blackwell Pub.

Sletto, Bjørn. 2002. "Producing space(s), representing landscapes: maps and resource conflicts in Trinidad". Cultural Geographies. 9(4): 389-420.

Smith, Neil. 2000. "Is a critical geopolitics possible? Foucault, class and the vision thing". Political Geography. 19(3): 365-371.

---. 1984. Uneven development: nature, capital, and the production of space. New York, NY: Blackwell.

Soja, Edward. 1971. The Political Organization of Space, Resource Paper No. 8. Association of American Geographers.

Stratfor. “Can Colombia Protect Its Oil Infrastructure?”. December 27, 2016. Accessed December 30, 2016. ttps://www.stratfor.com/image/can-colombia-protect-its-oilinfrastructure.

---. “Colombia Labors to Weed out Coca Crops". August 31, 2016. Accessed June 4, 2016.

https://www.stratfor.com/image/colombia-labors-weed-out-coca-crops.

---. "In Colombia, a Peace Deal May Not Improve Security". November 13, 2015. Accessed March 4, 2016. https://www.stratfor.com/sample/image/colombiapeace-deal-may-not-improve-security.

Stonich, Susan C. 1989. "The dynamics of social processes and environmental destruction: a Central American case study". Population and Development Review. 15(2): 269-296.

Tate, Winifred. 2015. Drugs, thugs, and diplomats: US policymaking in Colombia. Stanford, Calif: Stanford Univ. Press. 
Taylor, Peter. 1994. "The state as container: territoriality in the modern world-system". Progress in Human Geography. 18(2): 151-162.

Thoumi, Francisco E. 2003. Illegal drugs, economy and society in the Andes. Washington, D.C.: Woodrow Wilson Center Press.

Tickner, Arlene. 2007. "Intervención por Invitación: Claves de la política exterior colombiana y de sus debilidades principales". Colombia Internacional. (65): 90111.

Tickner, Arlene, Diego Garcia and Catalina Arreaza. 2011. "Actores violentos no estatales y narcotráfico en Colombia". In Gaviria, Alejandro, and Daniel Mejia (eds.). Políticas antidroga en Colombia: éxitos, fracasos y extravios. Bogotá, D.C., Colombia: Universidad de los Andes.

United Nations Development Programme, and UNDP Colombia. 2011. Informe nacional de desarrollo humano 2011. Bogotá, Colombia: PNUD.

United Nations Office on Drugs and Crime (UNODC). 2004. Colombia Coca Survey. New York.

---. 2006. Colombia Coca Survey. New York.

---. 2014. Colombia Coca Survey. New York.

United Nations Refugee Agency in Colombia (UNHCR)."2012 UNHCR Country Operations Profile - Colombia". Accessed April 18, 2012. http://www.unhcr.org/pages/49e492ad6.html.

---“UNHCR: The UN Refugee Agency". Accessed January 10, 2016. http://www.acnur.org/t3/donde-trabaja/america/colombia/.

United Nations Regional Information Centre for Western Europe (UNRIC). 2016. "The Guerrilla Groups in Colombia.". Accessed July 15, 2016. http://www.unric.org/en/colombia/27013-the-guerrilla-groups-in-colombia.

United States. 1972. Protocol amending the Single Convention on Narcotic Drugs: hearing before the Committee on Foreign Relations, United States Senate, Ninetysecond Congress, second session, on Executive J, 92d Congress, $2 d$ session, protocol amending the Single Convention on Narcotic Drugs, 1961. June 27, 1972. Washington, DC: United States Government Printing Office. https://www.unodc.org/pdf/convention_1961_en.pdf. 
---. 2000. Providing for the consideration of H.R. 3908, the "2000 Emergency

Supplemental Appropriations Act": report (to accompany H. Res. 450).

Washington, D.C.: U.S. G.P.O.

United State Drug Enforcement Agency (DEA). "Drug Scheduling". Accessed July 07, 2016. https://www.dea.gov/druginfo/ds.shtml.

United States Embassy in Bogotá. "Puntos claves sobre el programa de aspersión en Colombia". Accessed June 23, 2015. <http://spanish.bogota.usembassy.gov>.

UN Mine Action Gateway. "Colombia". Accessed May 13, 2016. http://www.mineaction.org/programmes/colombia.

Uprimny Yepes, Rodrigo. 2003. "Violence, Power, and Collective Action: A Comparison between Bolivia and Colombia". In Bergquist, Charles, Ricardo Peñaranda, and Gonzalo Sánchez.Violence in Colombia 1990-2000: waging war and negotiating peace. Wilmington, Del: SR Books.

Vandergeest, Peter, and Nancy Lee Peluso. 1995. "Territorialization and state power in Thailand". Theory and Society: Renewal and Critique in Social Theory. 24(3): 385-426.

Vargas, Ricardo. 1999a. Drogas, máscaras y juegos: narcotráfico y conflicto armado en Colombia. Santafé de Bogotá: TM Editores.

---. 1994. Drogas poder y región en Colombia. Santafé de Bogotá, Colombia: Cinep.

---. 1999b. Fumigación y conflicto: políticas antidrogas y deslegitimación del estado en Colombia. Santafé de Bogotá: Transnational Institute.

---. 2005. Narcotráfico, guerra y política antidrogas: una perspectiva sobre las drogas en el conflicto armado colombiano. Bogotá, Colombia: Acción Andina Colombia.

---."USAID's Alternative Development Policy in Colombia". Transnational Institute. October 24, 2011. Accessed August 12, 2014. http://www.tni.org/briefing/usaidsalternative-development-policy-colombia.

Veillette, Connie, and Jose E. Arvelo-Velez. 2003. "Colombia and Aerial Eradication of Drug Crops U.S. Policy and Issues". Washington, D.C.2: Congressional Research Service, Library of Congress.

Velasco, Marcela. 2016. "Injustice and organisation in Anchicayá, Colombia: an environmental legal case in a hydropower watershed". Local Environment. 21(6): 707-729. 
Verdad Abierta. "En Yurumanguí buscan apoyo para sobrevivir sin coca y minería ilegal". 8 de abril de 2017.Accessed April 12, 2017. http://www.verdadabierta.com/ victimas-seccion/los-resistentes/6604-en-yurumangui-buscan-apoyo-parasobrevivir-sin-coca-y-mineria-ilegal.

Wade, Peter. 1993. Blackness and race mixture: the dynamics of racial identity in Colombia. Baltimore: Johns Hopkins University Press.

Wainwright, Joel, and Joe Bryan. 2009. "Cartography, territory, property: postcolonial reflections on indigenous counter-mapping in Nicaragua and Belize". Cultural Geographies. 16(2): 153-178.

Walker, Peter, and Pauline Peters. 2001. "Maps, Metaphors, and Meanings: Boundary Struggles and Village Forest Use on Private and State Land in Malawi". Society and Natural Resources. 14(5): 411-424.

Walsh, John, Gimena Sánchez, and Yamile Salinas. Washington Office on Latin America (WOLA), "Chemical Reactions Fumigation: Spreading Coca and Threatening Colombia's Ecological and Cultural Diversity." Last modified 2008. Accessed December 4, 2012. http://www.wola.org/sites/default/files/ downloadable/Andes/Colombia/past/WOLA Chemical Reactions February 2008.pdf.

Wang Caroline, and Mary Ann Burris. 1997. "Photovoice: concept, methodology, and use for participatory needs assessment". Health Education \& Behavior: the Official Publication of the Society for Public Health Education. 24(3): 369-87.

Webster's New World Spanish Dictionary: Spanish-English. 1991. New York: Macmillan.

White, Meg. Transnational Institute, "When Cocaine and Monsanto's Roundup Collide, War on Drugs Becomes a Genetically-Modified War on Science." Last modified 2009. Accessed December 3, 2012. http://www.tni.org/archives/media _buzzflash310809.

Wolf, Eric. 1972. "Ownership and Political Ecology". Anthropological Quarterly. 45(3): 201-205.

Wood, Denis, John Fels, and John Krygier. 2010. Rethinking the power of maps. New York: Guilford Press.

Youngers, Coletta. 2000. "Cocaine Madness Counternarcotics and Militarization in the Andes". NACLA Report on the Americas. 34(3): 16-23. 
Youngers, Coletta, and Eileen Rosin. 2005. Drugs and democracy in Latin America: the impact of U.S. policy. Boulder, Colo: L. Rienner. 
Vita

\section{ALEXANDER DAVID HUEZO}

Born, Walnut Creek, California

1993-1997

B.A., Political Science

University of California, Los Angeles

Los Angeles, California

2007-2009

M.A., Latin American Studies

University of California, Los Angeles

Los Angeles, California

\section{PRESENTATIONS}

The Violence of Displacement: Rural Migrants and Elements of the Supernatural in Cali, Colombia presented at the conference "Overt and Discreet Violence: Ruptures and Continuities in Latin America and the Caribbean," Columbia University, March 6, 2010.

Consuming Cuba: Privileged Mobility, Imperial Fantasy, and the Tourist Gaze, copresented with Jacqueline Lyon at the Wolfsonian Student Conference, the Wolfsonian Museum, April 12, 2012.

Imperial Globality \& the Geopolitics of Knowledge: Some perspective on the letter from Guapi, presented at "Im/Mobilities \& Dis/Connections," Florida International University, April 4, 2013.

Aspersión Aérea: Territorialiades, Inseguridades y Biodiversidad, presented to the Political Science Department at La Universidad de los Andes, August 6, 2015.

Contested Natures \& Insecurities: Examining the Disconnect Between Aerial Eradication Guidelines \& Local Experiences in Colombia, presented at "Desafios para la paz," University of Toronto, October 3, 2015.

Territory is Life: The Aerial Eradication of Coca in Colombia, presented at the Annual Meeting of the American Association of Geographers, San Francisco, CA, April 30, 2016. 